\title{
Novel gas-separation membranes for \\ intensified catalytic reactors
}

\section{Thesis submitted by Sara Escorihuela Roca \\ To apply for the Degree of Doctor}

\section{Supervisors:}

Prof. José Manuel Serra Alfaro

Dr. Sonia Escolástico Rozalén

Valencia, April 2019 
A mis padres

A mi hermana

A Diego 

"The more I learn, the more I realize how much I don't know"

A. Einstein

"Luck is what happens when preparation meets opportunity" Seneca 



\section{Table of contents}

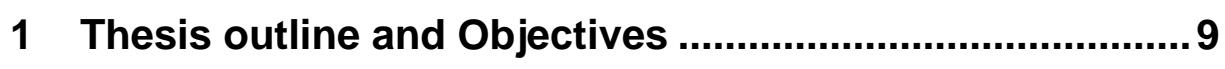

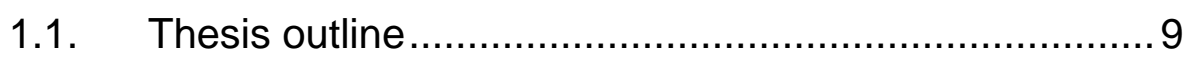

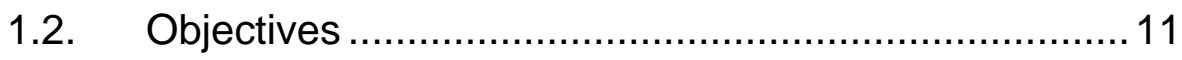

2 Summary/Resumen/Resum ..........................................15

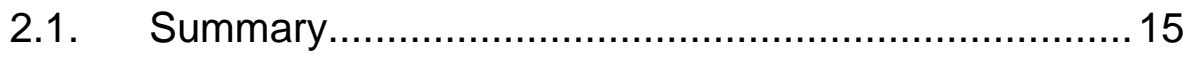

2.2. Resumen ........................................................ 16

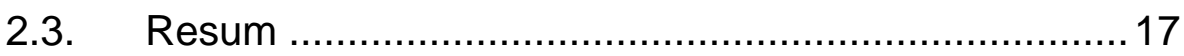

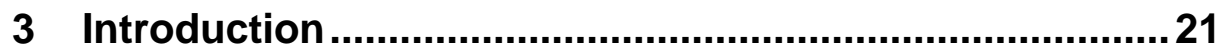

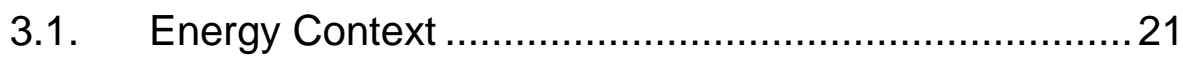

3.2. Sustainable Chemistry and Process Intensification ....23

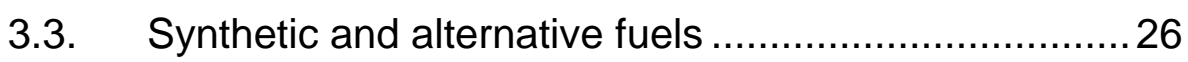

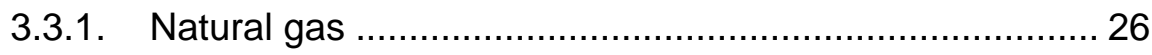

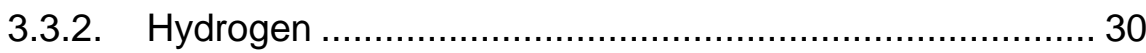

3.3.2.1. Hydrogen production ………………………………...... 30

3.3.2.2. Hydrogen uses ............................................................. 32

3.3.3. Synthetic fuels from Fischer-Tropsch synthesis .............. 33

3.4. Membrane Technology and Reactors ........................ 36

3.4.1. Catalytic membrane reactors .......................................... 38

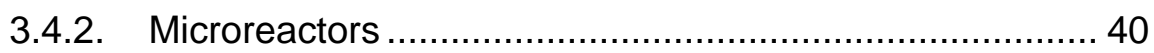

3.4.3. $\mathrm{H}_{2}$ separation membranes ............................................ 41

3.4.4. $\quad \mathrm{H}_{2} \mathrm{O}$ separation membranes ......................................... 43

3.5. Membrane transport mechanisms................................ 44

3.5.1. Pore-flow model........................................................... 45

3.5.2. Solution-Diffusion model............................................... 46

3.5.3. Inorganic membranes ……………………………...... 52

3.5.3.1. Zeolite membranes........................................................ 52

3.5.3.2. Ceramic membranes ………………………………..... 55

3.5.3.3. Metallic membranes ........................................................... 57 
3.5.4. Organic membranes: Polymer membranes ................... 64

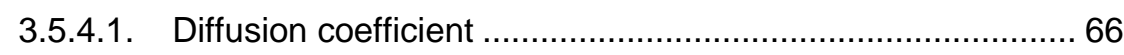

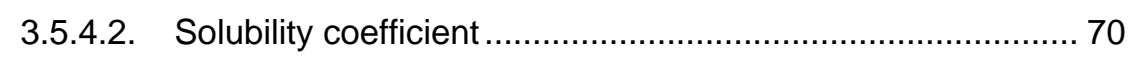

3.6. References...................................................... 73

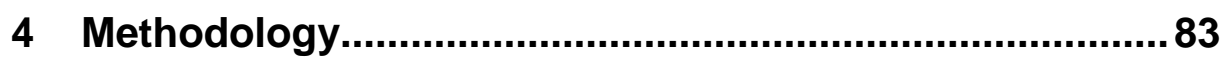

4.1. Material Synthesis........................................... 83

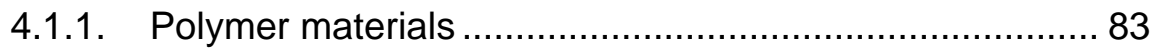

4.1.2. Co-precipitation...................................................... 85

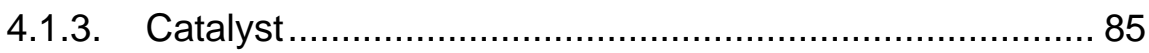

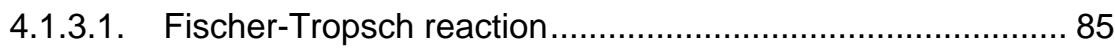

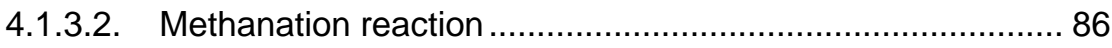

4.1.3.3. Catalyst manufacturing process ....................................... 87

4.2. Membrane manufacture .................................... 87

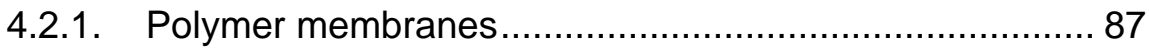

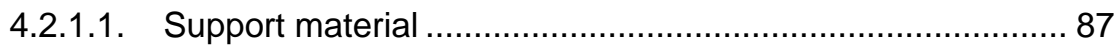

4.2.1.2. Coating process............................................................. 90

4.2.1.3. Inorganic fillers for Mixed Matrix Membranes (MMMs) ........ 92

4.2.2. Palladium membranes ................................................ 94

4.2.2.1. Sputtering coating........................................................... 95

4.3. Characterization techniques................................ 95

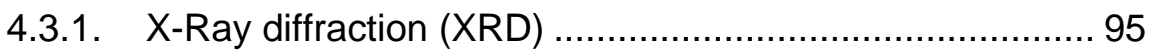

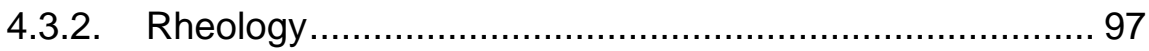

4.3.3. Scanning Electron Microscopy (SEM) ......................... 98

4.3.3.1. Field emission scanning electron microscopy (FESEM) ...... 99

4.3.3.2. Focused Ion Beam (FIB) ............................................... 100

4.3.4. Thermal analysis methods .......................................... 100

4.3.4.1. Temperature-programmed reduction (TPR) ..................... 100

4.3.4.2. Thermogravimetric analysis (TGA) ................................. 101

4.3.4.3. Differential Scanning Calorimetry (DSC) ......................... 101

4.3.5. Gel Permeation Chromatography (GPC) .................... 102

4.3.6. Gas chromatography (GC)................................... 102

4.4. Permeation Modules .......................................... 103

4.4.1. Single gas permeances test .................................... 103

4.4.1.1. Pressure Increase equipment ...................................... 103 
4.4.1.2. Time-lag equipment...................................................... 106

4.4.2. Polymeric membrane module .................................... 106

4.4.3. Palladium membrane module ..................................... 108

4.4.4. Fischer-Tropsch reaction module ............................... 110

4.4.5. Methanation reaction module .................................... 111

4.5. References............................................... 116

\section{Development of composite ceramic-polymer membranes} 121

5.1. Introduction ................................................ 121

5.2. Results and discussion ..................................... 122

5.2.1. Fundamental characterization .................................. 122

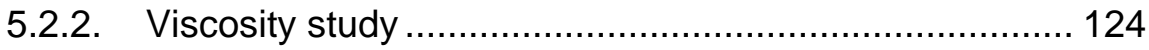

5.2.3. Membrane formation............................................... 129

5.2.4. Microscopy analysis............................................... 131

5.2.5. Permeation study ................................................... 134

5.2.6. High temperature permeation study .......................... 139

5.3. Conclusions ............................................... 143

5.4. References............................................. 144

\section{Polymer membranes for high temperature applications} 149

6.1. Introduction ................................................... 149

6.2. Results and discussion ..................................... 150

6.2.1. Composite Ceramic-Polymer Membranes .................... 150

6.2.1.1. Support material ........................................................... 150

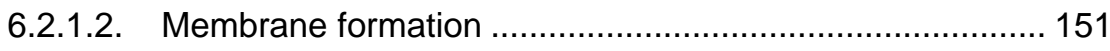

6.2.1.3. Gas transport properties.................................................. 155

6.2.2. Composite Polymer-Polymer Membranes/TFCMs ........ 159

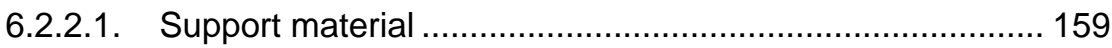

6.2.2.1. Membrane formation ...................................................... 160

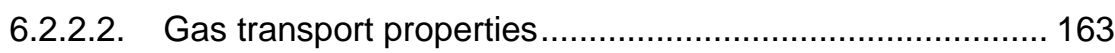

6.3. Conclusions .............................................. 167

6.4. References................................................ 169 


\section{Mixed Matrix Membranes for high temperature}

applications

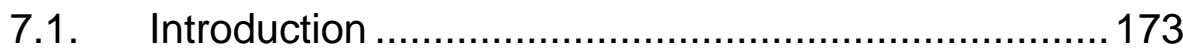

7.2. Results and discussion ........................................ 174

7.2.1. MMMs as Thick Films ................................................ 174

7.2.1.1. Membrane formation ........................................................ 174

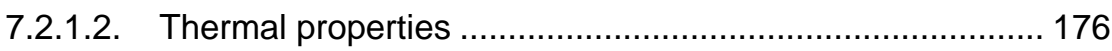

7.2.1.3. Microstructural characterization ......................................... 178

7.2.1.4. Gas transport properties............................................... 181

7.2.2. MMMs as TFCMs …………………………............. 191

7.2.2.1. Support material ........................................................... 191

7.2.2.1. Membrane formation ........................................................ 191

7.2.2.2. Microstructural characterization ....................................... 191

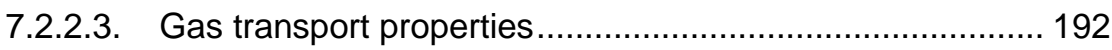

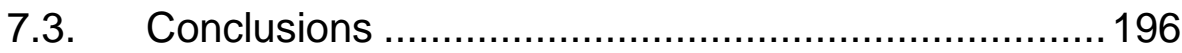

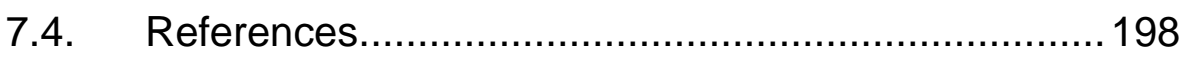

8 Catalytic Membrane Reactor for $\mathrm{CO}_{2}$ Methanation ....... 203

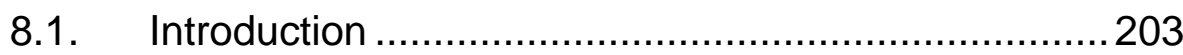

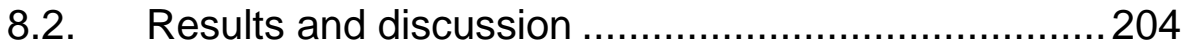

8.2.1. Methanation catalyst..................................................... 204

8.2.2. Membrane characterization .......................................... 207

8.2.3. Catalytic membrane reactor ............................................ 209

8.2.3.1. Reactor manufacture ....................................................... 209

8.2.3.2. Catalytic performance and water extraction ……………..... 212

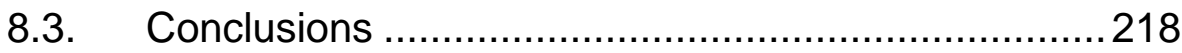

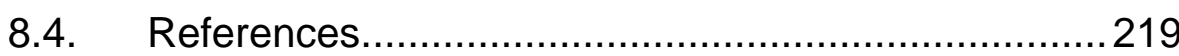

\section{Use of Pd-based membrane under Fischer-Tropsch} reaction conditions.

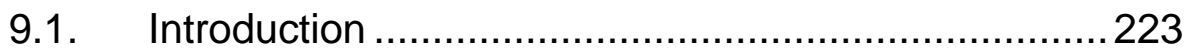

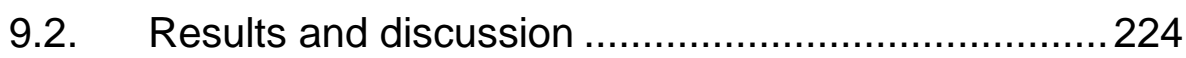

9.2.1. Gas transport properties ............................................... 224 
9.2.1.1. Pd-based membrane and $\mathrm{N}_{2}$ as sweep gas ...................... 224

9.2.1.2. Pd-based membrane and syngas as sweep gas .............. 226

9.2.1.3. Pd-based membrane with a Cu protective layer and syngas as sweep gas 229

9.2.2. Microstructural characterization ................................... 233

9.2.3. Fischer-Tropsch reaction ....................................... 235

9.3. Conclusions .............................................. 239

9.4. References...................................................... 241

10 General remarks and Conclusions ..............................245

11 Acronyms, abbreviations and symbols .....................251

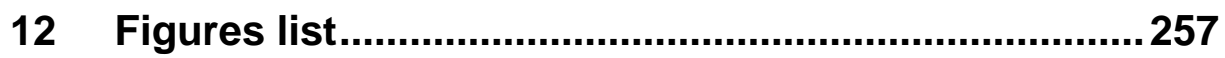

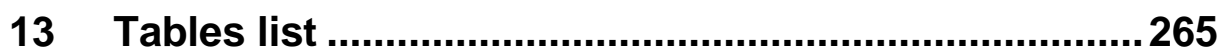

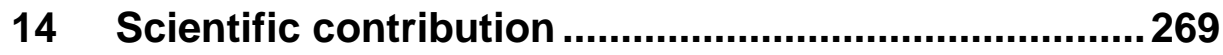



Chapter 1

Thesis outline and Objectives 



\section{Thesis outline and Objectives}

\subsection{Thesis outline}

The current thesis is focused on the development of novel gas-separation membranes and the subsequent in-situ integration on catalytic membrane reactors for process intensification. Firstly, the synthesis and elaboration of different polymeric membranes was assessed, and secondly the implementation of the developed gas-separation membranes was accomplished for $\mathrm{CO}_{2}$ methanation and Fischer-Tropsch synthesis reaction.

Chapter 3 aims to provide an overview of the current energy context and the role of sustainable chemistry and process intensification in our society, as well as how these concepts have grown continuously since the beginning of the 90s. In addition, alternative fuels such as natural gas, hydrogen and synthetic fuels from Fischer-Tropsch synthesis have been addressed. Moreover, several reactors, i.e. microreactors, together with membrane technology were described. In order to obtain a broad overview of the different existing membranes, membrane transport mechanisms and a detailed classification of inorganic and organic membranes was covered, giving more importance to the ones used in this thesis.

Chapter 4 is focused on the experimental work performed in this thesis, describing the different procedures employed, such as material synthesis (polymers and catalysts) and membrane manufacture (organic and inorganic). The characterization techniques and the different permeation modules used are exhaustively exposed.

Chapter 5 covers the development of novel selective ceramic-supported thin polyimide films, produced in a single dip coating step for membrane applications at elevated temperatures for hydrogen separation. Three different polyimides, which are used during this thesis, were selected due to its outstanding properties. To overcome the challenge of polymer/inorganic incompatibility, the deposition of the polymer layer was studied in dependence of the polymer solution viscosity. Finally, gas transport properties were studied with a variety of gases as a function of temperature. 
Chapter 6 focuses in polymer membranes for high temperature applications, and it is divided in composite ceramic-polymer membranes and composite polymerpolymer membranes. In the first part of this chapter, water separation is investigated. Hence, $\mathrm{H}_{2} \mathrm{O} / \mathrm{N}_{2}$ gas pair was selected as target for composite ceramic-polymer membranes. Regarding the second part, $\mathrm{H}_{2} / \mathrm{CO}_{2}$ separation is investigated at high temperatures up to $280 \stackrel{\circ}{\circ}$ by using polymer membrane deposited on polymer porous support.

In chapter 7 , in order to improve gas transport properties, six inorganic materials in a form of nanometer-sized particles were studied as membrane fillers. Mixed matrix membranes as thick films were first developed by using the already tested polyimides for single gas transport of $\mathrm{CO}_{2}, \mathrm{CH}_{4}$ and $\mathrm{H}_{2} \mathrm{O}$. Secondly, the fillers and the most permeable polyimide, 6FDA-6FpDA were used in thin-film composite membranes (TFCMs) for mix gas transport of $\mathrm{H}_{2}, \mathrm{CO}_{2}$ and $\mathrm{H}_{2} \mathrm{O}$.

The last two chapters of results are related to the implementation of the previous developed membranes in catalytic membrane reactors (CMR). In chapter 8, a novel micro reactor is used in order to merge the outstanding characteristics of the TFCMs, recently developed in the previous chapters, and $\mathrm{CO}_{2}$ methanation reaction. TFCMs were used to selective removal of water, which could deactivate or poison the catalyst.

Chapter 9 covers the use of Pd-based membrane under Fischer-Tropsch synthesis (FTS) reaction for the selective production of liquid hydrocarbons $\left(\mathrm{C}_{5}-\mathrm{C}_{20}\right)$ in a single stage using bi-functional catalysts. To assess the capability of the metallic membrane to be used in CMR for FTS for the selective addition of hydrogen, three different permeation tests under similar operation conditions were performed. Additionally, in order to avoid the membrane damage due to $\mathrm{CO}$ co-adsorption on the $\mathrm{Pd}$ active sites, a Cu protection layer was deposited on the Pd surface and this enabled to achieve a remarkable improvement of $\mathrm{H}_{2}$ permeation in presence of syngas. 


\subsection{Objectives}

The present thesis has two main objectives:

1. Research and development of novel materials for gas-separation membranes, such as hydrogen purification, carbon dioxide separation and water extraction, as well as selective addition of hydrogen.

2. Implementation of the already studied gas-separation membranes in catalytic reactors for process intensification, such as microreactors or packed bed reactors.

The sub-objectives of the thesis can be listed as below:

1. Study of polymer materials that may be feasible to work at temperature above $100 \stackrel{\circ}{ } \mathrm{C}$ and exhibit proper selectivity for gas pairs such as $\mathrm{H}_{2} / \mathrm{CO}_{2}, \mathrm{CO}_{2} / \mathrm{CH}_{4}$ and $\mathrm{H}_{2} \mathrm{O} / \mathrm{CO}_{2}$ separation applications.

2. Research of coating membrane conditions and compatibility issues regarding organic and inorganic materials. Study of the deposition of the polymer layer in dependence of the polymer solution concentration and, consequently, the polymer solution viscosity.

3. Development of thin film composite membranes with ceramic support and polymer supports for high temperature applications.

4. Investigation of inorganic fillers in form of nanometer-sized particles for their use in mixed matrix membranes.

5. Design and development of a microreactor for its use as catalytic membrane reactor for $\mathrm{CO}_{2}$ methanation, including a gasseparation membrane previously tested for in-situ water removal. Improve catalyst stability and $\mathrm{CO}_{2}$ conversion.

6. Functionalization of Pd-based membranes for reducing $\mathrm{Pd}-\mathrm{CO}$ bonding interactions and combination of a packed bed reactor with the membrane for selective and distributed addition of $\mathrm{H}_{2}$. Improve catalyst stability and enhance the selectivity to the target products. 

Chapter 2

Summary/Resumen/Resum 



\section{Summary/Resumen/Resum}

\subsection{Summary}

The present thesis is focused on the development of new gas-separation membranes, as well as their in-situ integration on catalytic membrane reactors for process intensification. For this purpose, several materials have been synthesized such as polymers for membrane manufacture, catalysts for $\mathrm{CO}_{2}$ methanation and Fischer-Tropsch synthesis reaction, and inorganic materials in form of nanometersized particles for their use in mixed matrix membranes. Regarding membranes manufacture, this thesis deals mainly with two types: organic and inorganic. With regards to the organic membranes, different polymeric materials have been considered as promising candidates, both for the selective layer of the membrane, as well as a support thereof. Polyimides have been selected since they are materials with very high glass transition temperatures, in order to be used in industrial reactions which take place at temperatures around $250-300 \stackrel{\circ}{ } \mathrm{C}$. To obtain highly permeable membranes, while maintaining a good selectivity, it is necessary to develop selective layers of less than one micron. Using another type of polymer as support material, it is not necessary to study the compatibility between membrane and support. On the other hand, if the support is inorganic, an exhaustive study of the relation between the concentration and the viscosity of the polymer solution is highly necessary. In addition, various inorganic particles were studied to favor the permeation of water through polymeric materials. Secondly, as regards to inorganic membranes, the functionalization of a palladium membrane to favor the permeation of hydrogen and avoid carbon monoxide contamination was carried out. The membrane selective layer was doped with another metal in order to be used in a Fischer-Tropsch reactor. Regarding the design and manufacture of the reactors used during this thesis, a prototype of a microreactor for $\mathrm{CO}_{2}$ methanation was carried out, where a thin-film polymer membrane selective to water was integrated to avoid the deactivation of the catalyst and to displace the equilibrium and increase the $\mathrm{CO}_{2}$ conversion. On the other hand, a Fischer-Tropsch reactor was redesigned to introduce a hydrogen-selective metal membrane and to be able to inject it in a controlled manner. In this way, and following previous studies, the aim is to enhance the selectivity to the target products by hydrocracking and hydroisomerization the olefins and paraffins assisted by the presence of an elevated partial pressure of hydrogen. 


\subsection{Resumen}

La presente tesis doctoral se centra en el desarrollo de nuevas membranas de separación de gases, así como su empleo in-situ en reactores catalíticos de membrana para la intensificación de procesos. Para este propósito, se han sintetizado varios materiales, como polímeros para la fabricación de membranas, catalizadores tanto para la metanación del $\mathrm{CO}_{2}$ como para la reacción de síntesis de Fischer-Tropsch, y diversas partículas inorgánicas nanométricas para su uso en membranas de matriz mixta. En lo referente a la fabricación de las membranas, la tesis aborda principalmente dos tipos: orgánicas e inorgánicas. Con respecto a las membranas orgánicas, se han considerado diferentes materiales poliméricos, tanto para la capa selectiva de la membrana, así como soporte de la misma. Se ha trabajado con poliimidas, puesto que son materiales con temperaturas de transición vítrea muy alta, para su posterior uso en reacciones industriales que tienen lugar

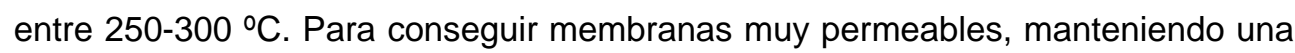
buena selectividad, es necesario obtener capas selectivas de menos de una micra. Usando como material de soporte otro tipo de polímero, no es necesario estudiar la compatibilidad entre ellos, siendo menos compleja la obtención de capas finas. En cambio, si el soporte es de tipo inorgánico, un exhaustivo estudio de la relación entre la concentración y la viscosidad de la solución polimérica es altamente necesario. Diversas partículas inorgánicas nanométricas se estudiaron para favorecer la permeación de agua a través de los materiales poliméricos. En segundo lugar, en cuanto a membranas inorgánicas, se realizó la funcionalización de una membrana de paladio para favorecer la permeación de hidrógeno y evitar así la contaminación por monóxido de carbono. El motivo por el cual se dopó con otro metal la capa selectiva de la membrana metálica fue para poder emplearla en un reactor de Fischer-Tropsch. Con relación al diseño y fabricación de los reactores, durante esta tesis, se desarrolló el prototipo de un microreactor para la metanación de $\mathrm{CO}_{2}$, donde una membrana polimérica de capa fina selectiva al agua se integró para evitar la desactivación del catalizador, y a su vez desplazar el equilibrio y aumentar la conversión de $\mathrm{CO}_{2}$. Por otro lado, se rediseñó un reactor de Fischer-Tropsch para poder introducir una membrana metálica selectiva a hidrogeno y poder inyectarlo de manera controlada. De esta manera, y siguiendo estudios previos, el objetivo fue mejorar la selectividad a los productos deseados mediante el hidrocraqueo y la hidroisomerización de olefinas y parafinas con la ayuda de la alta presión parcial de hidrógeno. 


\subsection{Resum}

La present tesi doctoral es centra en el desenvolupament de noves membranes de separació de gasos, així com el seu ús in-situ en reactors catalítics de membrana per a la intensificació de processos. Per a aquest propòsit, s'han sintetitzat diversos materials, com a polímers per a la fabricació de membranes, catalitzadors tant per a la metanació del $\mathrm{CO}_{2}$ com per a la reacció de síntesi de Fischer-Tropsch, i diverses partícules inorgàniques nanomètriques per al seu ús en membranes de matriu mixta. Referent a la fabricació de les membranes, la tesi aborda principalment dos tipus: orgàniques $i$ inorgàniques. Respecte a les membranes orgàniques, diferents materials polimèrics s'ha considerat com a candidats prometedors, tant per a la capa selectiva de la membrana, així com com a suport d'aquesta. S'ha treballat amb poliimides, ja que són materials amb temperatures de transició vítria molt alta, per al seu posterior ús en reaccions industrials que tenen lloc entre $250-300{ }^{\circ} \mathrm{C}$. Per a aconseguir membranes molt permeables, mantenint una bona selectivitat, és necessari obtindre capes selectives de menys d'una micra. Emprant com a material de suport altre tipus de polímer, no és necessari estudiar la compatibilitat entre ells, sent menys complexa l'obtenció de capes fines. En canvi, si el suport és de tipus inorgànic, un exhaustiu estudi de la relació entre la concentració i la viscositat de la solució polimèrica és altament necessari. Diverses partícules inorgàniques nanomètriques es van estudiar per a afavorir la permeació d'aigua a través dels materials polimèrics. En segon lloc, quant a membranes inorgàniques, es va realitzar la funcionalització d'una membrana de pal-ladi per a afavorir la permeació d'hidrogen i evitar la contaminació per monòxid de carboni. El motiu pel qual es va dopar amb un altre metall la capa selectiva de la membrana metàl-lica va ser per a poder emprar-la en un reactor de Fischer-Tropsch. En relació amb el disseny $\mathrm{i}$ fabricació dels reactors, durant aquesta tesi, es va desenvolupar el prototip d'un microreactor per a la metanació de $\mathrm{CO}_{2}$, on una membrana polimèrica de capa fina selectiva a l'aigua es va integrar per a així evitar la desactivació del catalitzador i al seu torn desplaçar l'equilibri i augmentar la conversió de $\mathrm{CO}_{2}$. D'altra banda, un reactor de Fischer-Tropsch va ser redissenyat per a poder introduir una membrana metàl-lica selectiva a l'hidrogen i poder injectar-lo de manera controlada. D'aquesta manera, i seguint estudis previs, el objectiu va ser millorar la selectivitat als productes desitjats mitjançant el hidrocraqueix i la hidroisomerització d'olefines i parafines amb l'ajuda de l'alta pressió parcial d'hidrogen. 

Chapter 3

Introduction 



\section{Introduction}

\subsection{Energy Context}

The existing socio-economic situation creates an increase of the energy requirements of industrialized nations. Sufficient and secure energy is the main enabler for welfare and economic development of a society. The world's total human population is over 7.5 billion currently, and recent studies estimate that it will surpass 10 billion in roughly 40 years [1].

Parallel, it is predicted a significant growth in worldwide energy demand from 2012 to 2040 [2]. Total world consumption of traded energy enlarges from 549 quadrillion Btu in 2012 to 815 quadrillion Btu in 2040 (Btu is equal to the quantity of heat required to raise one pound of water one degree Fahrenheit at or near its point of maximum density [3]), which means that almost a $50 \%$ increase in 28-year period. This astounding increase in energy demand has its origin in the development of nonOECD countries (Organization for Economic Cooperation and Development), due to an improvement on their economy, as well as the emergent rise population. Looking up the numbers, it is estimated that the energy demand from 2012 to 2040 will rise over $70 \%$ in the non-OECD nations, whereas not even a $20 \%$ of the total energy use will rise on the OECD economies.

Regarding world energy consumption by source, fossil fuels persist providing most of the energy demand worldwide, accounting for $78 \%$, which includes petroleum and other liquid fuels (with a $33 \%$ ), natural gas and coal, according to Figure 3.1. However, despite staying ahead, the use of liquid fuels is estimated would decreased in 3 points from 2012 to 2040, mainly due to a diminution in the residential and electric power sectors. This decline result from rising world oil prices, which lead to switching from liquids fuels to alternative fuels where possible, together with the unstoppable oilfields depletion. 


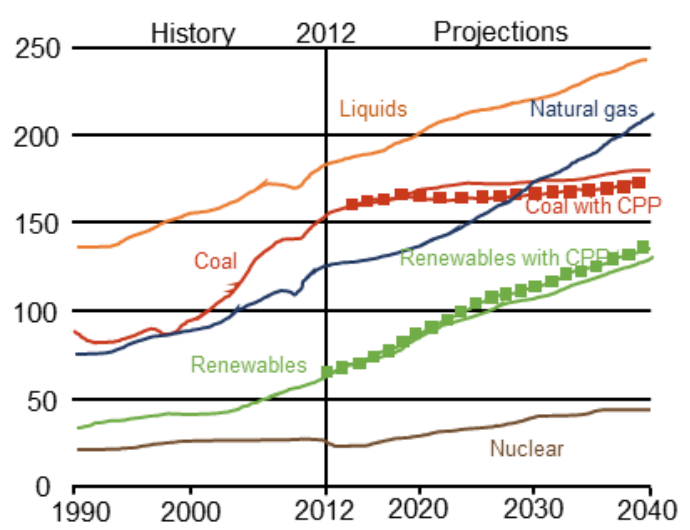

Figure 3.1. World energy consumption by energy source (quadrillion Btu). Note that dotted line for coal and renewables show projected effects of the U.S. Clean Power Plan [2]

As concerns to the different energy areas, chemical and refining industries are considered as energy-intensive sectors, together with food, paper and pulp, metals (ferrous and non-ferrous) and non-metallic minerals. This 7 energy-intensive industries constitute close to the half of all industrial sector delivered energy use. Hence, the future energy consumption delivered by the industrial sector will be defined by those sectors. In addition, this energy-intensive industries generate big amounts of $\mathrm{CO}_{2}$ emissions, not only as combustion emissions, but also as process emissions, among other industry waste [2]. Currently, as it can be seen in Figure 3.2, the largest industrial energy consumer is, by far, the basic chemical sector, and it is estimated to increase up to $20 \%$ by the year 2040 , in both OECD and non-OECD countries.
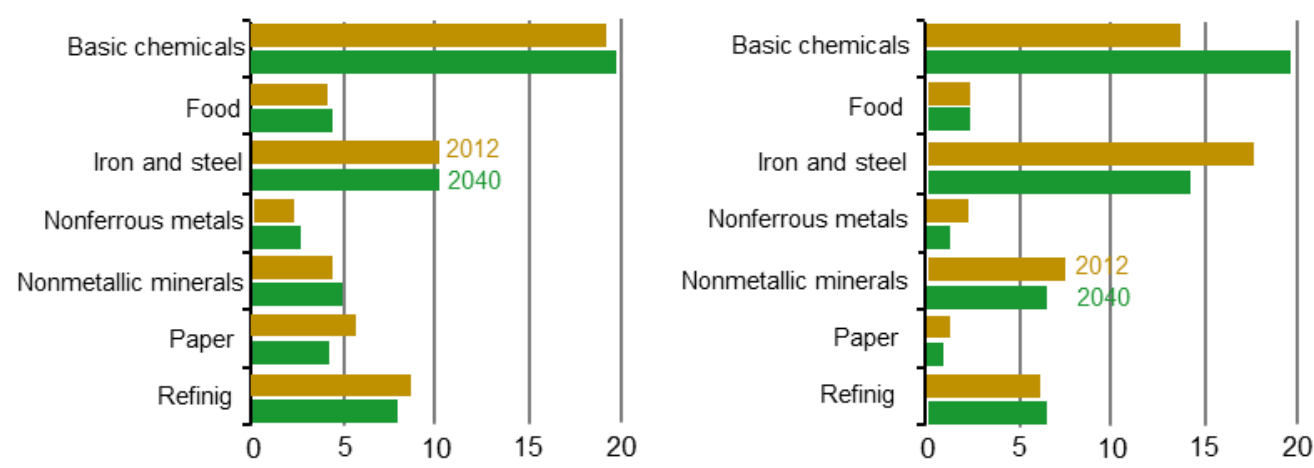

Figure 3.2. Energy-intensive industry shares of total OECD industrial sector energy consumption (left) and non-OECD industrial sector energy consumption (right), for 2012 and 2040 [2] 
Taking all of this into account, it can be assessed that the chemical industry plays a highly important role as contributor to the wealth of a country. It contributes over $1 \%$ to the Gross National Product (GNP) of European countries, which is over $6 \%$ of the total GNP produced by all manufacturing industries [4]. As it was advanced before, as global chemical production grows, so do the chemical waste generated by that industry. $\mathrm{CO}_{2}$ emissions related to energy industries will double by 2050 and the rising fossil energy demand will increase the concerns about the energy supplies. For all of this, it is a necessity to develop new energy efficient processes and to apply renewable energies [5]. In this sense, Sustainable Chemistry has growth in the last few decades as a plausible solution. In addition, Process Intensification contributes to expand new techniques, which are more environmental friendly. These two approaches complement each other intimately and are explained in the following section.

\subsection{Sustainable Chemistry and Process Intensification}

According to the Organization for Economic Cooperation and Development (OECD), Sustainable Chemistry is defined as "a scientific concept that seeks to improve the efficiency with which natural resources are used to meet human needs for chemical products and services. Sustainable Chemistry encompasses the design, manufacture and use of efficient, effective, safe and more environmentally benign chemical products and processes." [6].

This concept, also known as green chemistry, it is not a separate branch or a specialization inside chemistry. It is a new approach that has a set of principles to address sustainable development by preventing pollution and waste from the beginning. This term was firstly introduced by the Environmental Protection Agency (EPA) at the beginning of the 90s. The EPA generated 12 principles, which describe a philosophy that aims for a greener and safer chemistry [7]. The list belong tries to synthetize the idea of these principles.

1. Prevention: It is easier to prevent waste than to treat it later.

2. Atom economy: Design synthetic methods in order to maximize the incorporation of all materials used in the process into the final product. 
3. Less hazardous chemical synthesis: Synthetic methods should be designed in order to use and generate substances that exhibit little or no toxicity to people or to the environment, if it is possible.

4. Designing safer chemicals: Design chemical products in order to keep their effectiveness but minimizing their toxicity.

5. Safer solvents and reactor conditions: Try to avoid all kind of solvents or auxiliary substances as far as possible.

6. Design for energy efficiency: Whenever practicable, conduct chemical reactions at room temperature and pressure.

7. Use of renewable feedstocks: Encourage renewable starting materials instead of exhaustible materials.

8. Reduce derivatives: Avoid, whenever possible, unnecessary derivation (blocking or protection groups).

9. Catalysis: Promote, as possible, catalytic reagents instead of stoichiometric reagents.

10. Design for degradation: Chemical products should be designed thus they decompose into innocuous degradation products (biodegradable products) and do not persist in the environment.

11. Real-time analysis for pollution prevention: In order to prevent the formation of by-products, there is a need of in-process, real-time monitoring and control.

12. Inherently safer chemistry for accident prevention: Choose substances and their physical forms to minimize the potential for chemical accidents.

This list is just, as it was mentioned before, a roadmap, a verbalization of a philosophy that needs to be implemented. This implementation should be translated as important fields of research, which leads to achieve the Sustainable Chemistry basic principles [8]. Seven are the priority fields, and among all of them, Process Intensification outstands.

Process Intensification (PI) consists in a new approach that has emerged as a discipline of chemical engineering. Several engineers and researchers are working on innovative devices and techniques in order to optimize what it is understand as chemical plants, in terms of safety, efficiency and environmentally-friendly systems. This term was defined many times by notorious scientists and engineers. Colin Ramshaw defined $\mathrm{PI}$ as "a strategy for making dramatic reductions in the size of a chemical plant so as to reach a given production objective" and, together with his 
team at Imperial Chemical Industries, coined "HiGee", a synonym for high-gravity technology, which means a clear and trailblazing example for process intensification equipment [9]. However, this definition does not include any improvement on energy consumption or reduction on waste production. Another pioneer definition was given by Andrzej I. Stankiewicz and Jacob A. Moulijn: "Any chemical engineering development that leads to a substantially smaller, cleaner, and more energy efficient technology is process intensification", including those items that were missed in the preceding definition [10]. Unfortunately, another important point was left apart, safety, which nowadays also belongs to the list of benefits that Process Intensification gives, as long as energy reduction, equipment reduction and sustainability.

To sum up, Process Intensification refers not only to a minimization of process steps and the adoption of more eco-friendly and more efficient synthesis routes, but also to a reduction in hazardous substances and products, in order to increase the grade of safety. $\mathrm{PI}$ aims to obtain more with less, greater production with less energy consumption, it highlights also the use of small quantities of solvents, decrease environmental impact and obtain higher selectivity for higher conversions of reactants.

Understanding Process Intensification as field of study, it can be divided into two different sections: process-intensifying equipment (innovative reactors, novel heat and mass transfer devices...) and process intensifying methods (hybrid separations, integrated reactors-separations, multifunctional reactors, novel process-control methods...). Figure 3.3 gives an overview of Process Intensification and its components [10]. On one hand, regarding the process-intensifying equipment, in this thesis, microreactors will be addressed. This type of reactors have an extremely small dimensions in the shape of sandwich-like, which allow the integration of different functions, such as heat exchange or separation. On the other hand, concerning process-intensifying methods, membrane reactors outstand from all the possible options in this area. Membrane reactors can play several roles, from being used as selective in-situ separations to being applied for a controlled distributed feed. As well as microreactors, membrane reactors will be tackled over this thesis. 


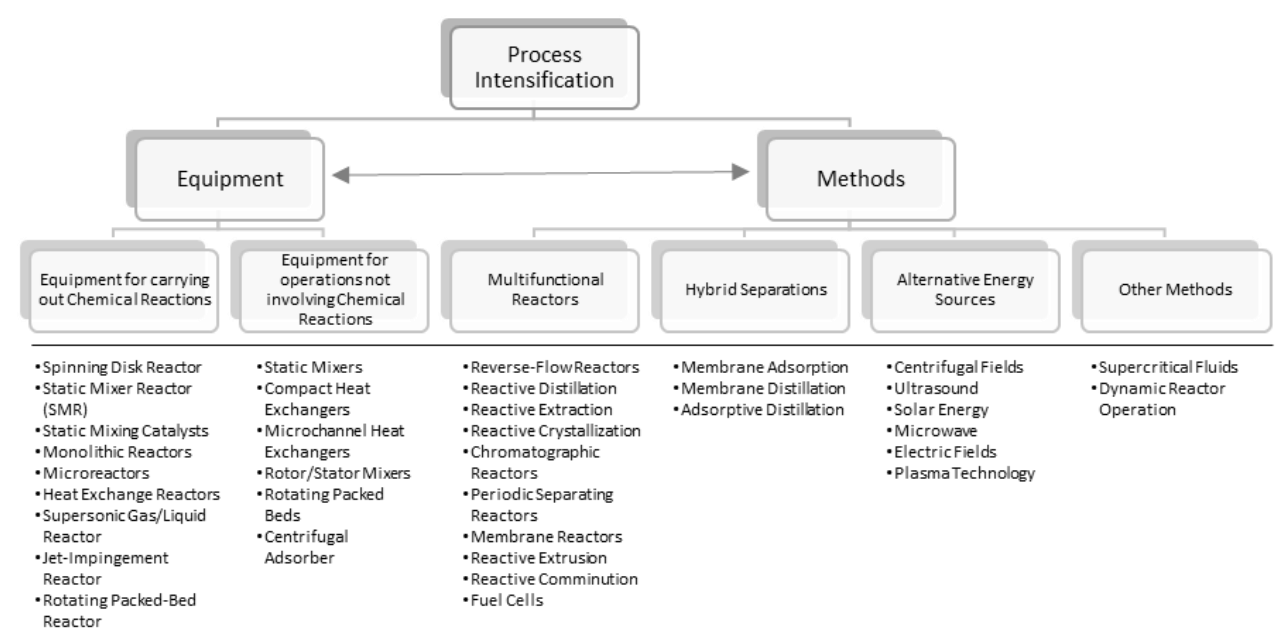

Figure 3.3. Process intensification and its components [10]

\subsection{Synthetic and alternative fuels}

The unstoppable oilfields depletion will lead to the requirement of using more and more alternative sources to petroleum, apart from the reasons mentioned in the section 1.1. Taking into account all the possible solutions, natural gas (with $>70 \%$ methane) is considered as one of the most promising alternative energy sources due to several reasons: (a) the numerous natural gas deposits that has been discovered in the past years, (b) the fact that it possesses the largest heat of combustion relative to the amount of $\mathrm{CO}_{2}$ formed (low carbon footprint) and, because of its $\mathrm{C} / \mathrm{H}$ low ratio, (c) its combustion leads to a reduction on pollutant gas emissions. These advantages help the cause of going slowly to a clean and green development, towards sustainable chemistry in all industries.

\subsubsection{Natural gas}

Natural gas is mainly formed by $\mathrm{CH}_{4}$ and a small amount of alkanes (paraffins) and alkenes (olefins) [3]. Natural gas can be used itself as a fuel or it can be converted in other types of synthetic fuels, in other words, natural gas must be valorized. The first and most obvious way to methane valorization, is to use it itself. Nevertheless, this first option is not as easy as it could appear, due to natural gas may be currently uneconomical to transport to a specific target markets. Transporting natural gas from the wellhead to consumers feels the necessity for several 
infrastructure assets and different process steps [3]. Subsequently, from the economical and also, from the thermodynamic point of view, the other reasonable option is to convert natural gas into a valuable product, i.e. valuable fuel. Moreover, $\mathrm{CH}_{4}$ has around 20 times higher global warming potential (GWP) than $\mathrm{CO}_{2}$ [11].

Methods for $\mathrm{CH}_{4}$ conversion may be divided in two groups: direct and indirect catalytic routes. Regarding direct processes, they have not progressed to a commercial stage mainly because they have thermodynamic limitations derived from the high stability of the $\mathrm{CH}_{4}$ molecule $\left(\Delta \mathrm{H}^{0}{ }_{f}=-75 \mathrm{~kJ} / \mathrm{mol}{ }^{\circ} \mathrm{C}\right)$, which requires severe operating conditions for its activation [12]. Without the use of strong oxidants, it is extremely difficult to convert methane into higher hydrocarbons at unexcessive temperatures using conventional catalytic strategies.

Concerning indirect methods, they require synthesis gas as intermediate product for the process. Synthesis gas, as abbreviate syngas, is a gas mixture consisting primarily of $\mathrm{H}_{2}$ and $\mathrm{CO}$ with a molar ratio of $\mathrm{H}_{2} / \mathrm{CO}=0.5-3$ (depending on the reforming processes) and very often less than $10 \%$ of $\mathrm{CO}_{2}$. In this way, methane is transforming into a more reactive structural unit (such as $\mathrm{CO}$ ) leading to a wide range of petrochemical reactions. Production of syngas can be achieved through 3 different processes $[13,14]$ (see Figure 3.4):

1. Methane dry reforming (MDR): A highly endothermic reaction route that may be beneficial to utilizing $\mathrm{CO}_{2}$ emissions [15].

$$
\mathrm{CH}_{4}+\mathrm{CO}_{2} \leftrightarrow 2 \mathrm{CO}+2 \mathrm{H}_{2} \quad\left(\Delta \mathrm{H}_{298 \mathrm{~K}}^{0}=247 \mathrm{~kJ} / \mathrm{mol}\right)
$$

2. Methane partial oxidation ( $\mathrm{POM})$ : A slightly exothermic reaction using oxygen or air to form $\mathrm{H}_{2}$ and $\mathrm{CO}$ at a ratio of 2 in a single-step reaction, which is ideal for most downstream reactions, for example the obtaining of methanol [16]. Additionally, $\mathrm{H}_{2} / \mathrm{CO}$ ratio of 2 is exemplary for the FischerTropsch (F-T) synthesis.

$$
\mathrm{CH}_{4}+1 / 2 \mathrm{O}_{2} \leftrightarrow \mathrm{CO}+2 \mathrm{H}_{2} \quad\left(\Delta \mathrm{H}_{298 \mathrm{~K}}^{0}=-35 \mathrm{~kJ} / \mathrm{mol}\right)
$$


3. Steam methane reforming (SMR): Being an endothermic reaction as MDR, the $\mathrm{H}_{2} / \mathrm{CO}$ ratio is 3 , resulting on a more appropriate reaction for $\mathrm{H}_{2}$ production more than for syngas production.

$$
\mathrm{CH}_{4}+\mathrm{H}_{2} \mathrm{O} \leftrightarrow \mathrm{CO}+3 \mathrm{H}_{2} \quad\left(\Delta \mathrm{H}_{298 \mathrm{~K}}^{0}=206 \mathrm{~kJ} / \mathrm{mol}\right)
$$

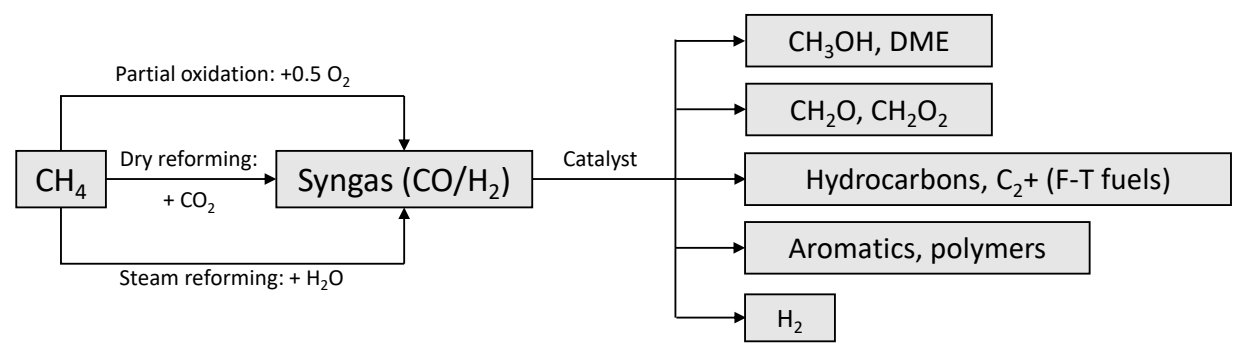

Figure 3.4. Indirect natural gas route conversions to produce fuels and value-added chemicals [14]

Additionally, another option is the combination of POM and SMR. Although SMR is the most widely used process for syngas production, it is extremely endothermic as it is mentioned before, so it requires a lot of energy during the process. In this sense, the combination of POM and SMR reduce substantially energy requirements. This process is called autothermal reforming:

$$
4 \mathrm{CH}_{4}+\mathrm{O}_{2}+2 \mathrm{H}_{2} \mathrm{O} \leftrightarrow 4 \mathrm{CO}+10 \mathrm{H}_{2} \quad\left(\Delta H_{298 K}^{0}=171 \mathrm{~kJ} / \mathrm{mol}\right)
$$

Apart from the Equations 1.1, 1.2, 1.3 and 1.4, there is another typical reaction that takes place as an important step in several industrial processes, known as Water-Gas shift reaction:

$$
\mathrm{CO}+\mathrm{H}_{2} \mathrm{O} \leftrightarrow \mathrm{CO}_{2}+\mathrm{H}_{2} \quad\left(\Delta \mathrm{H}_{298}=-41 \mathrm{KJ} / \mathrm{mol}\right)
$$

The Water-Gas shift is a reversible, exothermic chemical reaction, usually assisted by a catalyst [17]. The water-gas shift reaction (WGSR) was discovered in 
1780 by an Italian physicist named Felice Fontana. But it was not until 1888 when the reaction was firstly used for fuel cell application in coal gasification by the British scientists Ludwig Mond and Carl Langer. They were pioneered on implementing WGSR over nickel catalyst at $400{ }^{\circ} \mathrm{C}$, producing $\mathrm{CO}_{2}$ and $\mathrm{H}_{2}$, and, after the removal of carbon dioxide, $\mathrm{H}_{2}$-rich steam was fed into a fuel cell [18]. Among the possible synthetic fuels and different chemical products derived from syngas, in this thesis $\mathrm{H}_{2}$ production and F-T synthesis are covered.

Nevertheless, it is also feasible to produce methane as a synthetic fuel by the Sabatier process. Also known as methanation reaction, Sabatier process produces methane from carbon dioxide and hydrogen, favoring the reduction of $\mathrm{CO}_{2}$ emissions and using a renewable energy. Methanation reaction was first studied by Sabatier and Senderens in the 1910s [19], it is an exothermic reaction and its stoichiometry is shown in Equation (3.6), which is favored at low temperature, but due to kinetic limitations, catalyst must be used [20].

$$
\mathrm{CO}_{2}+4 \mathrm{H}_{2} \rightarrow \mathrm{CH}_{4}+2 \mathrm{H}_{2} \mathrm{O} \quad\left(\Delta \mathrm{H}_{298}=-165 \mathrm{KJ} / \mathrm{mol}\right)
$$

The mechanism of this reaction is the combination of an endothermic reversed water-gas shift (RWGS) reaction and an exothermic CO methanation, shown in Equation (3.7) and (3.8):

$$
\begin{array}{cc}
\mathrm{CO}_{2}+\mathrm{H}_{2} \rightarrow \mathrm{CO}+\mathrm{H}_{2} \mathrm{O} & \left(\Delta \mathrm{H}_{298}=41 \mathrm{KJ} / \mathrm{mol}\right) \\
3 \mathrm{H}_{2}+\mathrm{CO} \rightarrow \mathrm{CH}_{4}+\mathrm{H}_{2} \mathrm{O} & \left(\Delta \mathrm{H}_{298}=-206 \mathrm{KJ} / \mathrm{mol}\right)
\end{array}
$$

In the past decade, $\mathrm{CO}_{2}$ methanation has achieved a renewed interest resulting from its application in the so-called power-to-gas (P2G) technology. P2G technology uses $\mathrm{H}_{2}$ from excess renewable energy and $\mathrm{CO}_{2}$ from power plants, reacting to chemically obtaining methane, which can be stored and transported through the welldeveloped natural gas infrastructure already in place [21]. In the subsequent section, P2G technology will be explained with more detail. 


\subsubsection{Hydrogen}

Hydrogen is considered as a secondary source of energy, together with electricity. In fact, hydrogen is considered the greatest alternative to fossil energies [22]. $\mathrm{H}_{2}$ is mostly known as energy carrier, which is implemented to move, store and deliver energy in a way that can be efficiently used. Despite of being one of the most plentiful elements on Earth, it cannot be found as gas state, due to the fact that $\mathrm{H}_{2}$ gas is lighter than air and ascent to the atmosphere. Thus, there is a need of acquiring and manufacturing $\mathrm{H}_{2}$ gas by other synthetic routes. On one hand, hydrogen has the highest energy content by weight of any common fuel. On the other hand, hydrogen has the lowest energy content by volume. This is related to one of its main advantages as energy carrier, a large volume of hydrogen can be easily stored in a number of different techniques. Hydrogen is recognized as a high efficient and low polluting alternative fuel, so it may be used for transportation, heating, and power generation in places where it is not easy to have access to a general energy supplier. In some cases, it is even cheaper to ship hydrogen by pipeline than sending electricity over long distances by wire [23].

\subsubsection{Hydrogen production}

In view of the fact that it is impossible to find hydrogen as a gas, different methods for obtaining $\mathrm{H}_{2}$ as product or by-product has been studied [24]. Hydrogen can be produced from biomass, natural gas, coal gasification and/or water. A general classification may be attending to the production method: (a) hydrogen production from fuel processing and (b) hydrogen production from non-reforming sources. Table 3.1 summarized the different techniques, which belong to those two broad groups. 
Table 3.1. Classification of Hydrogen production [25]

\begin{tabular}{|c|c|c|c|c|c|c|c|}
\hline \multicolumn{7}{|c|}{ Fuel processing } \\
\begin{tabular}{|c|c|c|c|c|}
\hline \multicolumn{1}{|c|}{ Hydrocarbon } \\
reforming
\end{tabular} & Desulfurization & Pyrolysis & $\begin{array}{c}\text { Plasma } \\
\text { reforming }\end{array}$ & $\begin{array}{c}\text { Aqueous } \\
\text { phase } \\
\text { reforming }\end{array}$ & $\begin{array}{c}\text { Ammonia } \\
\text { reforming }\end{array}$ & Biomass & Water \\
\hline
\end{tabular}

Fuel processing means that a product with some $\mathrm{H}_{2}$ in its composition, such as methanol or gasoline, is converted into a $\mathrm{H}_{2}$-rich stream. Due to the before mentioned advantages of natural gas, methane fuel processing is the most common method used. Among different techniques, three procedures outstands: (a) steam methane reforming, (b) partial oxidation of methane and (c) autothermal reaction. These techniques were already explained in section 1.3.1.

The most widely and exploited reaction system for hydrogen production is steam methane reforming (SMR) [26], see equation 1.3. Despite of its beneficial $\mathrm{H}_{2} / \mathrm{CO}$ ratio equal to 3 , which favored a greater hydrogen production, this process discharges more emissions than partial oxidation or autothermal reactions. In addition, together with SMR, since a large amount of carbon monoxide is produced, WGS reaction usually takes place at the same time. The reforming reaction is favored at high temperatures $\left(\approx 850^{\circ} \mathrm{C}\right)$ [27], whereas the water gas shift reaction takes place at lower temperatures $\left(\approx 200{ }^{\circ} \mathrm{C}\right)$ [28]. In order to use the hydrogen obtained by this method, an extra purification step is necessary. The impurity generated during the process is mainly carbon dioxide (15-20\%) among other gases as methane $(5-8 \%)$, and carbon monoxide $(0.1-1.5 \%)$ among others $\left(\mathrm{N}_{2}\right.$, $\mathrm{NH}_{3}, \mathrm{O}_{2}, \mathrm{H}_{2} \mathrm{~S}, \mathrm{SO}_{x}$, and $\mathrm{H}_{2} \mathrm{O}$ ) [29]. Currently, in most industrial reformers, pressure swing adsorption (PSA) is used as a purification method for the hydrogen [30]. Due to the fact that hydrogen can be used as a high-quality and clean energy source, its demand has grown continuously in the past years, which has motivated research into improving methods of hydrogen production, separation and purification [31]. PSA together with cryogenic distillation are widely commercially available but highly energy-intensive processes [31, 32]. In this sense, gas separation using membranes has been extensively investigated as one of the most energy efficient separation processes, and as a strong alternative to conventional purification systems. In the subsequent sections, this topic is addressed. 


\subsubsection{Hydrogen uses}

In terms of hydrogen uses, the applications can be divided in two big groups: (a) production of fertilizer (ammonia production) and (b) production of synthetic fuel, such as refinery processes and methanol production. According to Evers Hydrogen Association [33] approximately 50 million tons of hydrogen are produced each year. From this hydrogen production, nearly the half is used to produce ammonia, around a quarter is used for hydrocracking in petroleum refining, with the balance used to produce methanol and other industrial applications including coal-to-liquids, as it can be seen in Figure 3.5 [25].
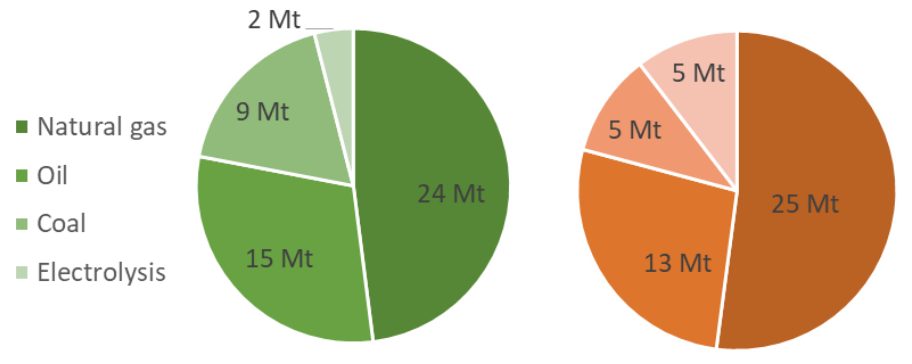

- Ammonia production

- Refining

घethanol production

- Other uses

Figure 3.5. World hydrogen production (left graph) and use (right graph) [25]

Regarding the used as synthetic fuel, nowadays, hydrogen is mainly employed as fuel in the NASA Space Program. Liquid hydrogen is used to propel space shuttle and other rockets, while hydrogen fuel cells power the electrical systems of the shuttle and produce pure water for the shuttle crew [23]. However, one of the most attempted application for hydrogen as an alternative fuel is in the automobile industry. $\mathrm{H}_{2}$ burns with a higher efficiency than gasoline and is by far the cleanest burning fuel, thus, there is a tremendous interest to apply it as fuel in automobiles [34].

Fuel cells are electrochemical devices that convert chemical energy into electrical energy directly, leading to higher efficiency (between two to three-fold) than the obtained by conventional combustion systems. Usually, the reactants are hydrogen and oxygen, generating a flux of electrons and, as the only by-products, heat and steam, having a low environmental impact [35]. Fuel cells can replace any battery used in a portable device and also power any mean of transport. In the near future, hydrogen may replace petroleum used in our vehicles. 
3.3.3. Synthetic fuels from Fischer-Tropsch synthesis

Syngas can be converted into valuable synthetic fuels and chemicals via Fischer-Tropsch (F-T) synthesis. F-T synthesis was firstly developed after the First World War by Franz Fischer and Hans Tropsch in 1922. It was emerged due to the demand for fuel with the abundant coal supply. Nowadays, F-T synthesis has continued developing in order to produce alternative fuels, along with more efficient catalysts. F-T synthesis occurs at temperatures between 200 to $300 \stackrel{\circ}{C}$ and at pressures around 1 to $6 \mathrm{MPa}$. Nevertheless, there are many other factors that may vary the high liquid product selectivity, including catalytic material (usually based on $\mathrm{Fe}$ and $\mathrm{Co}$ ), process conditions, synthesis catalytic procedure and reactor type. Among all the reactions that take place during F-T synthesis, they can be divided into desired and undesired reactions [36]:

\section{Desired reactions:}

i. Alkanes or paraffins.

$$
n C O+(2 n+1) H_{2} \rightarrow C_{n} H_{2 n+2}+n H_{2} \mathrm{O}
$$

ii. Alkenes or olefins.

$$
n \mathrm{CO}+2 n \mathrm{H}_{2} \rightarrow \mathrm{C}_{n} \mathrm{H}_{2 n}+n \mathrm{H}_{2} \mathrm{O}
$$

iii. Alcohols.

$$
n \mathrm{CO}+2 n \mathrm{H}_{2} \rightarrow \mathrm{C}_{n} \mathrm{H}_{2 n+1} \mathrm{OH}+(n-1) \mathrm{H}_{2} \mathrm{O}
$$

Undesired reactions:

i. Water-gas shift reaction

$$
\mathrm{CO}+\mathrm{H}_{2} \mathrm{O} \leftrightarrow \mathrm{CO}_{2}+\mathrm{H}_{2}
$$


ii. Carbonaceous materials

$$
\left(x+\left(\frac{y}{2}\right)\right) H_{2}+x C O \rightarrow C_{x} H_{y}+x H_{2} \mathrm{O}
$$

iii. Boudouard reaction

$$
\mathrm{C}+\mathrm{CO}_{2} \leftrightarrow 2 \mathrm{CO}
$$

iv. Bulk carbide formation

$$
\begin{gathered}
y C O+x M \rightarrow M_{x} O_{y}+y C \\
y C O_{2}+x M \rightarrow M_{x} O_{y}+y C O
\end{gathered}
$$

Fischer-Tropsch (F-T) synthesis is evolving into a key industrial process in order to assuring an unlimited and independent supply of high quality liquid fuels. This necessity responds to an environmental requirement, as it was explained at the beginning of the introduction, the use and exploiting plentiful renewable sources, e.g. natural gas [37]. Apart from high quality liquid fuels, F-T synthesis by-products may be generated, such as $\mathrm{H}_{2} \mathrm{O}$ and $\mathrm{CO}_{2}$, being the first the main undesired one. Removing of water from F-T reactors can lead to several advantages for the reaction that can be divided into three different approaches [38].

\section{Protect the catalyst material.}

A large amount of $\mathrm{H}_{2} \mathrm{O}$ partial pressure may guide into a deactivation of the catalyst material, both $\mathrm{Fe}$ and Co-based catalysts. A critical value for $\mathrm{H}_{2} \mathrm{O}$ accelerated catalyst deactivation was found at $\mathrm{pH}_{2} \mathrm{O}>0.6 \mathrm{MPa}$, which is quite feasible when the conversion of $\mathrm{CO}$ is greater than $60 \%$ and at elevated working pressures [39]. One possible solution towards this problem may be the study of catalyst lifetime improvement. But, removal of water by different reactors in series or in-situ $\mathrm{H}_{2} \mathrm{O}$ removal by integrated reactors will allow to maintain the $\mathrm{H}_{2} \mathrm{O}$ partial pressure below its critical value. 
2. Enhance F-T synthesis conversion.

At higher conversion levels, water may control the gas phase and, as a consequence, the partial pressure of the reactants may decrease, as well as their residence time [40]. $\mathrm{H}_{2} \mathrm{O}$ removal will benefit $\mathrm{F}-\mathrm{T}$ synthesis reaction, leading to a higher reaction rate, thus to a conversion enhancement.

3. Displace WGS equilibrium reaction.

Removing $\mathrm{H}_{2} \mathrm{O}$ from the WGS reaction means that more $\mathrm{CO}$ is produced from $\mathrm{CO}_{2}$, which reacts in a subsequent step towards long-chain hydrocarbons.

Membranes for water removal will be addressed in the following sections. Furthermore, another beneficial approach to enhance F-T synthesis selectivity to the products is the controlled feeding of $\mathrm{H}_{2}$ into the catalytic bed. Increasing $\mathrm{H}_{2} / \mathrm{CO}$ ratio will lead to a favored conversion of high valuable liquid fuels. This approach is not as widely studied as water removal from F-T synthesis. Thus, not many paper has been published in this topic.

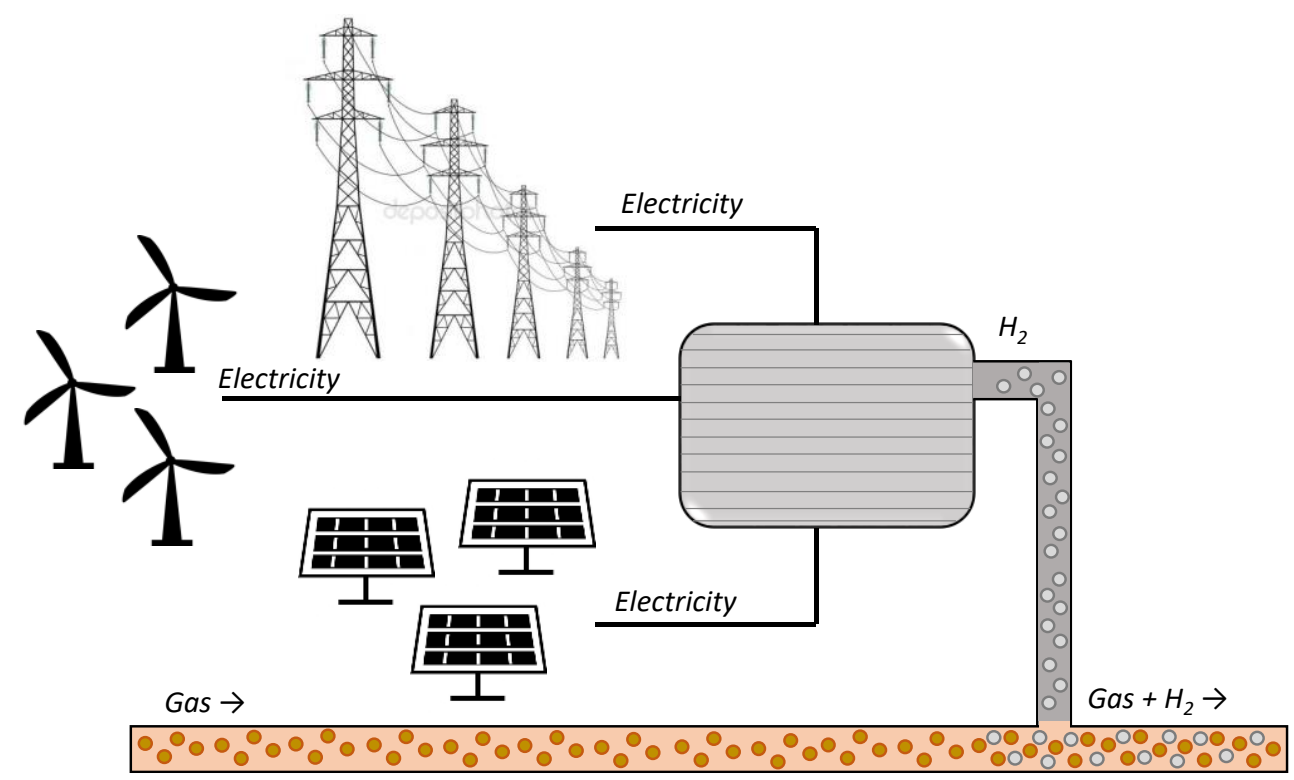

Figure 3.6. Scheme of Power-to-gas technology

Additionally, as it was previously mentioned, "power-to-gas (P2G) is the functional description of the conversion of electrical power into a gaseous energy 
carrier like e.g. hydrogen or methane" [41]. P2G technology (Figure 3.6) converts electrical power into gas fuel. It uses hydrogen and carbon dioxide in order to obtain synthetic fuels, such as methane. As a result, $\mathrm{CO}_{2}$ would be storage and recycled, using a renewable energy, hydrogen. In this sense, the energy system is $100 \%$ sustainable.

\subsection{Membrane Technology and Reactors}

Membrane separation processes are assumed to be more energy efficient and outstand as an alternative way to replace the well-established and energy intensive methods such as cryogenic distillation and adsorptive process, following the path of Process Intensification statements [42]. They cover from more traditional applications such as industrial gas separation and purification, catalysis reaction, carbon capture and storage, and removal of volatile organic liquid from air exhaust stream, to a large quantity of new applications, for instance, fuel cell, drug delivery, desalination and clean energy. Among these, a large amount of work has been done on membrane-based devices in the last two decades.

Membrane industry has a relevant position within the chemistry industry due to its extensive number of possible applications, such as electrodialysis (ED), dialysis (D), reverse osmosis (RO), nanofiltration (NF), ultrafiltration (UF), microfiltration (MF), gas separation (GS) and pervaporation (PV) [43, 44].

Regarding membranes categorization, the first classification refers to biological and synthetic membranes. Before going deeper on the topic, it is important to mention that in this thesis, only synthetic membranes are addressed. Synthetic membranes can be defined as "an interphase that separates two phases and restricts the transport of various chemical species in a rather specific manner" [45]. Synthetic membranes can be subdivided into organic and inorganic membranes. This terms includes a broad number of different materials and structures. There are several aspects that can change in a membrane: symmetric or asymmetric, homogenous or heterogeneous, neutral or positive/negative charged, thin $(\approx 100$ $\mathrm{nm}$ ) or thick $(\approx 2 \mathrm{~cm})$, etc. However, a membrane is better defined not for what it is, but for what it does.

As it was mentioned before, another means of classifying is by the morphology. There are 2 main types of membranes: isotropic or symmetrical membranes and 
anisotropic or asymmetrical membranes [43]. Isotropic membranes are characterized by having a completely uniform composition, they can be porous or dense. Total membrane thickness determine the mass transfer resistance in these membranes, so as the thickness decrease, the permeation rate increase. Membrane thickness is usually between 30 and $500 \mu \mathrm{m}$. On the other hand, anisotropic membranes have an asymmetric structure and they exhibit different layers with different pore size, and the top layer could be either dense or porous.

Depending on the trans-membrane gradient, they can be divided with relation to concentration, pressure or electrical field. At the same time, these three categories could be divided into microporous, mesoporous, macroporous and dense membranes, as Table 3.2 shows.

Table 3.2. Classification of membranes for their trans-membrane gradient [46]

\begin{tabular}{|c|c|c|c|}
\hline Membrane barrier structure & Trans-memb & e gradient & \\
\hline & Concentration & Pressure & Electrical field \\
\hline Dense & $\begin{array}{l}\text { Pervaporation } \\
\text { (PV) }\end{array}$ & $\begin{array}{l}\text { Gas separation } \\
\text { (GS) } \\
\text { Reverse osmosis } \\
\text { (RO) }\end{array}$ & $\begin{array}{l}\text { Electrodialysis } \\
\text { (ED) }\end{array}$ \\
\hline $\begin{array}{l}\text { Porous with } d_{p}<=2 \mathrm{~nm} \\
\text { (Micropores) }\end{array}$ & Dialysis (DI) & Nanofiltration (NF) & \\
\hline $\begin{array}{l}\text { Porous with } d_{p}=2-50 \mathrm{~nm} \\
\text { (Mesopores) }\end{array}$ & Dialysis (DI) & Ultrafiltration (UF) & $\begin{array}{l}\text { Electrodialysis } \\
\text { (ED) }\end{array}$ \\
\hline $\begin{array}{l}\text { Porous with } d_{p}>=50 \mathrm{~nm} \\
\text { (Macropores) }\end{array}$ & & $\begin{array}{l}\text { Microfiltration } \\
\text { (MF) }\end{array}$ & \\
\hline
\end{tabular}


In the last decades, the interest for gas-phase catalytic processes have gained a noteworthy interest. Numerous authors have demonstrated the used of membrane reactors (MR) and its applications [47-50]. The reason for place a membrane in a catalytic reactor is to supply a separation effect at the same time the reaction is occurring. Thus, the selectively separation of certain products or by-products will improve the reaction conversion, being this application beneficial for the overall process [51]. As it was advanced in the previous section, regarding processintensifying methods, MR can be categorized in two different groups, inert membrane reactors (IMR) and catalytic membrane reactors (CMR). In this thesis, only CMR will be assessed. With regards to process-intensifying methods, microreactors will be explained.

In terms of the target compound to be separated, in this thesis, hydrogen and water will be addressed. As it was advanced, the use of $\mathrm{H}_{2}$ as alternative to fossil fuels is difficult to deny in several ways, such as transportation, versatility, efficiency, etc. [52]. Regarding water, it is usually an undesired by-product in different reactions such as esters formations or alternative fuels (paraffins, methanol, dimethyl ether...) [53]. Hence, the application for selective gas separations might be different, but membrane technology can be applied for both scenarios.

\subsubsection{Catalytic membrane reactors}

In a catalytic reactor, a permeable membrane is placed between two chambers in order to allow the transport of specific substances through itself, separating selectively two or more species. Basically, a separation membrane and a chemical reaction are merged in one single unit. In the reaction region, reactants produce different products, which are transported selectively through the membrane and join the sweep gas in the permeation chamber, favoring the reaction conversion by shifting the thermodynamic equilibrium, among other reasons such as improve yields and purifying a by-product that can be used for other purposes, reducing downstream separation cost, e.g. hydrogen. Figure 3.7 is a scheme of a tubular catalytic membrane reactor. 


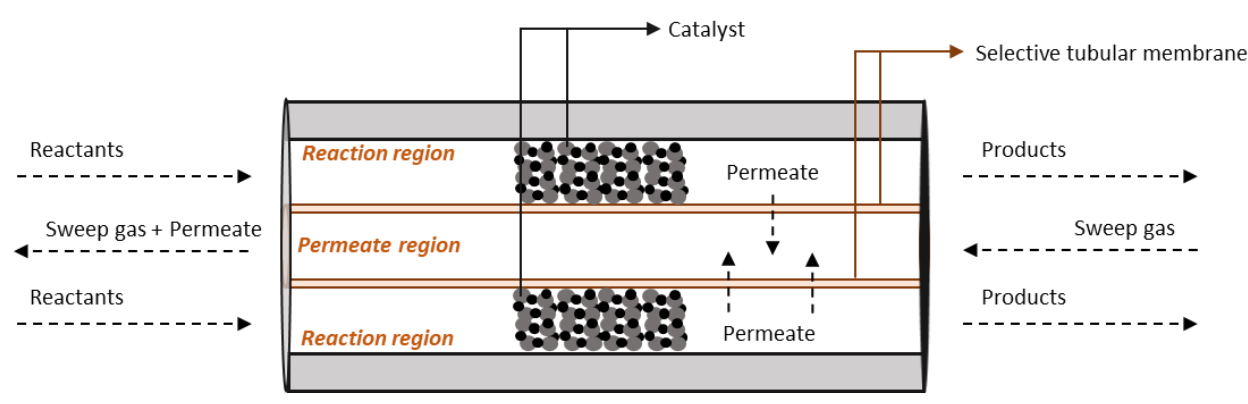

Figure 3.7. Tubular catalytic membrane scheme

CMR are recognized to exhibit a huge potential as new technology approach in different industrial fields, to give some examples, pharmaceutical sector, petrochemical, biotechnology, chemical plants, energy and environmental applications, etc. CMR follows the process intensification strategy, merging different process units. Reducing the industrial equipment will lead, not only to a rise of industrial process efficiency or to an improvement of industrial automation, but also to a decrease of environmental impact and to a reduction in capital cost. Depending on the process parameters, such as reaction duration (membrane lifetime), separation selectivity required or economic investment, among others, CMR can be separated, regarding their based material, into organic (polymer) or inorganic (metallic and ceramic) catalytic membranes, see Table 3.3. This membranes can be applied to different processes, regarding membrane function [54]:

i. Contactor catalytic membrane: the aim is to provide a close contact between reactants and catalyst. Usually, reactants are forced to penetrate together through the catalytic pores of the membrane.

ii. Extractor catalytic membrane: its goal is to extract or remove one or more of the products from the reaction zone, in order to improve the reaction yield.

iii. Distributor catalytic membrane: in this case, the intention is to dispense one or more of the reactants to the reaction zone, in a specific dose that can generate successive reactions and improve the overall process. 
Table 3.3. Advantages and disadvantages of organic and inorganic catalytic membranes [54]

\begin{tabular}{|c|c|c|c|c|}
\hline & \multicolumn{2}{|r|}{ Advantages } & \multicolumn{2}{|r|}{ Disadvantages } \\
\hline $\begin{array}{l}\text { Organic } \\
\text { Catalytic } \\
\text { Membrane }\end{array}$ & $\begin{array}{l}\circ \\
0 \\
\circ \\
0\end{array}$ & $\begin{array}{l}\text { High develop technique } \\
\text { Cost } \\
\text { Low temperature } \\
\text { Less stringent demands for } \\
\text { module construction materials }\end{array}$ & $\begin{array}{l}0 \\
0\end{array}$ & $\begin{array}{l}\text { Life time } \\
\text { Stability to: } \\
\quad \text { High pressure } \\
\quad \text { Aggressive environments } \\
\text { Difficulty in modeling }\end{array}$ \\
\hline $\begin{array}{l}\text { Inorganic } \\
\text { Catalytic } \\
\text { Membrane }\end{array}$ & & $\begin{array}{l}\text { High thermal stability } \\
\text { Stability to: } \\
\text { High pressure } \\
\text { Aggressive environments }\end{array}$ & $\begin{array}{l}\circ \\
\circ \\
\circ\end{array}$ & $\begin{array}{l}\text { High capital cost } \\
\text { Brittleness } \\
\text { Difficulty in sealing at high } \\
\text { temperatures }\end{array}$ \\
\hline
\end{tabular}

\subsubsection{Microreactors}

Microreactors stands as one of the possible options regarding processintensifying equipment. Microreactors possess excellent mass and heat transfer performance for extraction and multi-phase reactions, being an effective tool for PI and micro scale processing. Despite an excellent control of mass and heat transfer rates, microreactors offer other properties, which contribute to consider them as an efficient possibility for membrane reactors. They are suitable for exothermic, explosive and fast reactions. In addition, due to their small volume capacity, great efficient development of more sophisticated continuous flow reactions has been emerged, since they greatly reduce the quantities of materials required to optimize reaction conditions [55].

Reactions that can take place in a microreactor can be divided attending to the reaction rate [56]:

A. Very fast reactions ( $<1$ second). They are controlled by the mixing process. If they are perform in a microreactor, the mixing process becomes faster, leading to an increase in the reaction yield and an enhancement of heat exchange performance. 
B. Fast reactions ( 1 seconds to 20 minutes). They are controlled by the kinetics. Owing to microreactors, there is a more accurate control of temperature and residence time, leading again to an increase in the reaction yield.

C. Slow reactions ( $>20$ minutes). In this third and final case, they are controlled by the kinetics but a continuous process will contribute to safeness and high quality. As concerns equipment, large residence time modules will be better and more advantageous than microreactors. Only when an unexpected and abrupt heat generation may happen, microreactors will be a possible solution.

\subsection{3. $\mathrm{H}_{2}$ separation membranes}

It was already mentioned the two main processes to purify $\mathrm{H}_{2}$ are PSA and cryogenic distillation. As a third possible option, $\mathrm{H}_{2}$ membrane separation are winning an exceptional place in the current industry. Despite of being commercial available systems, PSA and cryogenic distillation are not cost effective and they are extremely demanding in terms of the energy required for the separation and $\mathrm{H}_{2}$ purification. Moreover, they do not produce enough final product for the targeted application in the hydrogen industry. Due to all this drawback, membrane technology is considered as the most promising technique for hydrogen separation, not only because its low investing cost and low energy consumption, but also due to the possibility for continuous operation and performance facility [29].

Membrane transport mechanism and different types of membranes will be explained in the following section. Previously, the purpose of this section is to classify, accordingly with the membrane types, the different properties and characteristics of $\mathrm{H}_{2}$ separation membranes, in order to give a general overview before a more detailed explanation. A general classification can be found in Table 3.4. One of the main difference of $\mathrm{H}_{2}$ separation membranes is the material difference between organic and inorganic membranes. Table 3.5 shows the advantages and disadvantages of both materials. 
Table 3.4. Characteristic classification of $\mathrm{H}_{2}$ separation membranes [29]

\begin{tabular}{|c|c|c|c|c|c|}
\hline & Metallic & \multicolumn{2}{|c|}{ Ceramic and Zeolites } & Polymer & Carbon \\
\hline & Dense & Dense & Porous & Dense & Porous \\
\hline T range $\left({ }^{\circ} \mathrm{C}\right)$ & $300-600$ & $600-900$ & $200-600$ & $\begin{array}{c}200-300 \\
\text { (depending } \\
\text { on their } T_{g} \text { ) }\end{array}$ & $500-900$ \\
\hline Selectivity & $>1000$ & $>1000$ & $5-139$ & $10-20$ & $4-20$ \\
\hline $\begin{array}{c}\text { Flux } \\
\left(\mathrm{mol} / \mathrm{cm}^{2} \cdot \mathrm{s}\right)\end{array}$ & $60-300$ & $6-80$ & $60-300$ & $1-20$ & $10-200$ \\
\hline $\begin{array}{l}\text { Mechanical } \\
\text { issues }\end{array}$ & $\begin{array}{l}\text { Phase } \\
\text { transitions }\end{array}$ & \multicolumn{2}{|c|}{ Brittle } & $\begin{array}{l}\text { Thermal } \\
\text { stability and } \\
\text { compaction }\end{array}$ & Very brittle \\
\hline $\begin{array}{l}\text { Chemical } \\
\text { stability }\end{array}$ & $\begin{array}{l}\text { Poisoned by } \\
\mathrm{H}_{2} \mathrm{~S}, \mathrm{HCl} \\
\mathrm{CO}_{2}, \mathrm{SO}_{x} \\
\mathrm{CO}\end{array}$ & \multicolumn{2}{|c|}{$\begin{array}{l}\text { Degradation with } \mathrm{H}_{2} \mathrm{O} \text {, } \\
\qquad \mathrm{H}_{2} \mathrm{~S}, \mathrm{CO}_{2}\end{array}$} & $\begin{array}{l}\text { Degraded } \\
\mathrm{H}_{2} \mathrm{~S}, \mathrm{HCl} \\
\mathrm{CO}_{2}, \mathrm{SO}_{x}\end{array}$ & $\begin{array}{c}\text { Oxidizing and } \\
\text { susceptible } \\
\text { to organic } \\
\text { vapors }\end{array}$ \\
\hline $\begin{array}{l}\text { Transport } \\
\text { mechanism }\end{array}$ & $\begin{array}{l}\text { Solution- } \\
\text { diffusion }\end{array}$ & $\begin{array}{l}\text { Solution- } \\
\text { diffusion }\end{array}$ & $\begin{array}{l}\text { Knudsen } \\
\text { diffusion }\end{array}$ & $\begin{array}{l}\text { Solution- } \\
\text { diffusion }\end{array}$ & $\begin{array}{l}\text { Molecular } \\
\text { sieve }\end{array}$ \\
\hline
\end{tabular}

Table 3.5. Advantages and disadvantages between organic and inorganic membranes for $\mathrm{H}_{2}$ separation [42]

\begin{tabular}{|c|l|l|}
\multicolumn{2}{|c|}{ Advantages } \\
Membrane & Mechanical stability & Brittle \\
Inorganic & $\begin{array}{l}\text { Thermal stability } \\
\text { Durability }\end{array}$ & $\begin{array}{l}\text { Expensive } \\
\text { Hydrothermal stability } \\
\text { Chemical stability }\end{array}$ \\
\hline \multirow{2}{*}{ Organic } & $\begin{array}{l}\text { Ease to manufacture } \\
\text { Cheap }\end{array}$ & $\begin{array}{l}\text { Mechanical stability } \\
\text { Thermal stability } \\
\end{array}$ \\
& Good quality control & Short term durability \\
\hline
\end{tabular}




\subsection{4. $\mathrm{H}_{2} \mathrm{O}$ separation membranes}

In terms of chemical industrial reactors, as it was already advanced, by applying in-situ water removal, two main approaches can be outline: (a) improving thermodynamic limitation, e.g. F-T conversion and WGS reaction, and (b) protecting catalyst material from deactivation. Membranes that are able to separate water at temperature and pressure conditions have been studied in the last years, and still further investigations are required to accomplish this task. In order to remove water, different techniques have been advised, being one of the most well-accepted membrane reactors (MR). As it was previously advanced, membrane reactors can be divided as (a) inert membrane reactors (IMR), adjacent to the catalytic reaction zone, and (b) catalytic membrane reactors (CMR), where the catalyst is inserted on the membrane or the membrane has catalytic properties itself [53]. Membranes that possess the capability to separate water selectively are polymeric membranes, zeolite membranes and porous ceramic membranes.

Regarding porous ceramic membranes, the ability of the membrane resides in the pore size of the material. For example, silica membranes are a good example of water separation membranes, with a pore size of approximately $4 \AA$. So water, with a kinetic diameter of $2.65 \AA$ can preferentially pass through the membrane, whereas other gases with higher kinetic diameter may stay on the other side of the membrane (see Table 3.6).

Zeolite membranes behave in a similar way to the porous ceramic membranes, where the transport mechanism is pore-flow model. Zeolites membranes are used to separate water vapour from other gases and they have been extensively studied due to their strong hydrophilicity and suitable pore size. LTA zeolite membranes were the first commercialized in the dehydration of alcohol/water mixtures by steam permeation [57]. In addition, other zeolite types are used for selective water separation, such as SOD membrane, which is also hydrophilic but with a higher framework density, providing higher thermal stability than LTA. In addition, SOD exhibit a smaller pore size than LTA, with $2.7 \AA$, which allows only water to go through [57].

Finally, polymer membranes also allows water to go through and separate selectively from other gases. Water vapor exposes solubility coefficients which differ widely from the solubility coefficient of other gases, due to its strong hydrogen 
bonding and polar interactions with the polymer chains [58]. Permeability and solubility coefficient at a given temperature depend on several aspects of the polymers: (a) molecular weight, (b) degree of crystallinity, which means, the morphology, (c) concentration or pressure and (d) the permeant itself. Generally, the polymer polarity the gas solubility and, thus, the permeability [59]. In section 1.5, an exhaustive explanation of different membranes is given.

\subsection{Membrane transport mechanisms}

As rule of thumb, two main assumption governing transport mechanisms in membranes should be made to describe any permeation model [43]:

i. Fluid or gases on either sides of the membrane are in equilibrium with the membrane material at the interface. In other words, the gradient in chemical potential from one side of the membrane to the other, is continuous. In addition, the rate of absorption and the rate of desorption are higher than the rate of diffusion through the membrane, almost in all the cases. However, this may not be true when the transport processes involve chemical reactions, e.g. metal membranes, where interfacial absorption may be slower than the diffusion through the membrane bulk.

ii. Expression of the chemical potential across the membrane may vary according to the structure

a. Solution-diffusion model postulates that the pressure within a membrane is uniform and that the chemical potential gradient of a permeant across the membrane is represented only as a concentration gradient.

b. Pore-flow model postulates that the permeant concentration within a membrane is uniform and that the chemical potential gradient across the membrane is represented only as a pressure gradient.

Figure 3.8 describes the effects of these assumptions. It compares the pressuredriven permeation of a one-component solution by these two models: solutiondiffusion and pore-flow. In both models, the difference in pressure though the membrane produces a gradient in the chemical potential. In the pore flow model (leftside), the pressure difference produces a slight pressure gradient across the 
membrane, whereas the concentration gradient remains constant. In contrast, in the solution-diffusion model (right-side), the pressure within the membrane is constant, while the concentration varies across the membrane. As a consequence, the chemical potential difference is represented as a concentration gradient within the membranes. In the following sections, equations providing a mathematical link between pressure and concentration are explained.
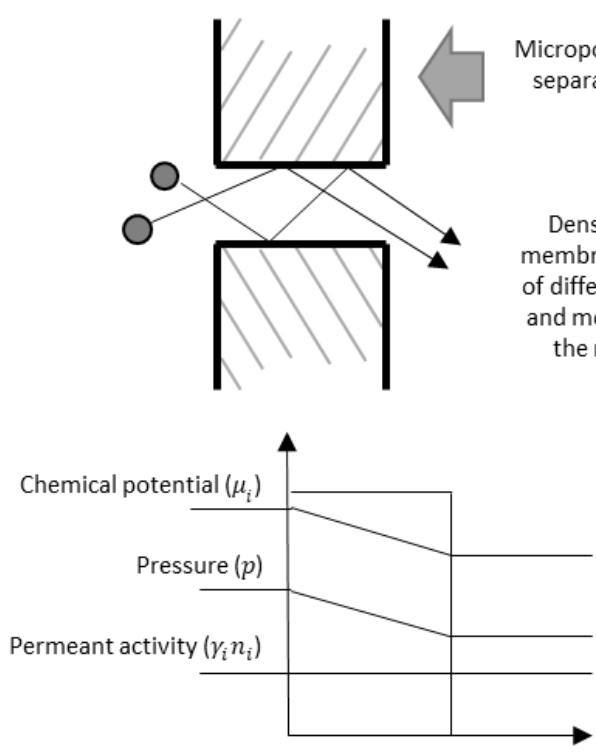

(a)
Microporous membranes separate by molecular filtration

Dense solution-diffusion membranes separate because of differences in the solubility and mobility of permeants in the membrane material
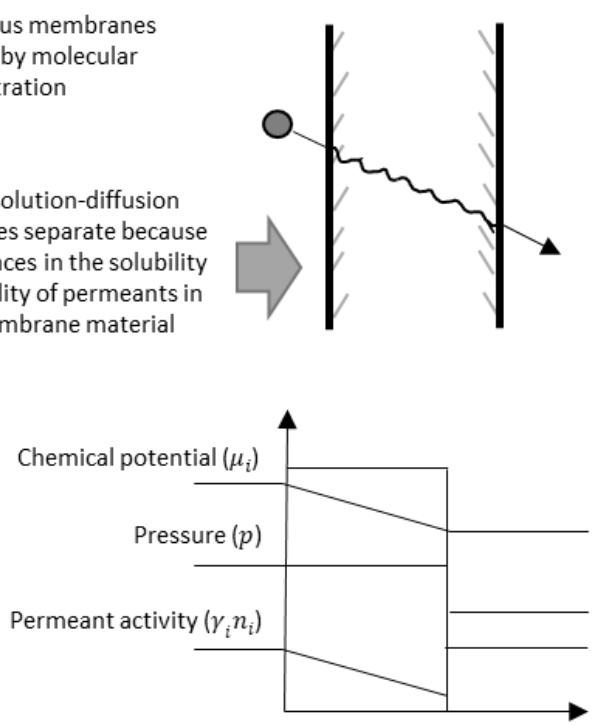

(b)

Figure 3.8. Driving force gradients acting on a single component solution permeating (a) pore flow and (b) solution-diffusion membrane [43]

\subsubsection{Pore-flow model}

Microporous membranes possess a rigid, open and random structure with interconnected pores. They may seem similar to a standard filter albeit the main difference is the pore size. While conventional filter presents large pore diameters up to millimeters range, microporous membranes pore size are extremely small. According to the International Union of Pure and Applied Chemistry (IUPAC) definition, microporous inorganic membranes are referred to those porous membranes with a pore diameter smaller than $2 \mathrm{~nm}$ (see Table 3.2) [60].

Transport mechanism of porous membranes is called pore-flow model, in which permeants are transported by pressure-driven convective flow through the pores. 
Transport of these membranes works as function of the molecules diameter, particles larger than the largest pores are completely denied whereas particles smaller than the smallest pores go through the membrane. In between, molecules smaller than the largest pores but, at the same time, larger than the smallest pores will be partially denied. Basically, those that differ substantially in size will be effectively separate. The equation that comprises this transport is Darcy's law, which states that fluid flow is directly proportional to the hydraulic gradient [61], which can be written as:

$$
J_{i}=K^{\prime} c_{i} \frac{d p}{d x}
$$

where $J_{i}$ is the flux of component $i, d p / d x$ is the pressure gradient, $c_{i}$ is the concentration component $i$ and $K^{\prime}$ is a coefficient reflecting the nature of the medium.

\subsubsection{Solution-Diffusion model}

Solution-diffusion model is implemented to pervaporation (PV), gas separation (GS), reverse osmosis (RO) and electrodialysis (ED), see Table 3.2. All these four applications seems to be very different between each other, but the principle is the same, diffusion of molecules is involved. Firstly, parameters such as temperature, pressure and composition of the fluid or stream on either sides of the membrane define the diffusing concentration of the species at the membrane surface in equilibrium state. Secondly, after species are dissolved in the membrane, molecules will individually permeate by the same process of arbitrary molecular diffusion, regardless the type of membrane that it is being applied. In this case, transport mechanism is conducted by diffusion under partial pressure (GS and RO), concentration (PV) or electrical gradient (ED) as driving force. Permeants penetrate in the membrane and then diffuse through due to the gradient generated. The parameters that determine the relative transport rate through the membrane are the diffusion $(D)$ and the solubility $(S)$ coefficient, and the transport model that follow is called solution-diffusion [62]. In this thesis, only gas permeation (conducted by diffusion under partial pressure) will be addressed, so the solution-diffusion model is explained for this type of dense separation membranes.

In order to characterize mathematically any transport model in membranes, the first premise is based in thermodynamics, any driving force such as pressure, 
concentration or electrical potential, apart from temperature, are interrelated and subsequently, the entire driving force that produces movement is a gradient in its chemical potential.

$$
J_{i}=-L_{i} \frac{d \mu_{i}}{d x}
$$

Flux in the membrane is described as $J_{i}$ of component $i\left(\mathrm{~g} / \mathrm{cm}^{2} \cdot \mathrm{s}\right), d \mu_{i} / d x$ is the chemical potential gradient of component $i$ and $L_{i}$ is a proportional coefficient for linking flux and chemical potential. All the driving forces mentioned before can be described as chemical potential gradients, being able to used Equation (3.17) for all the cases. Furthermore, when concentration and pressure are limiting as the only gradients, chemical potential is described as

$$
d \mu_{i}=R T d \ln \left(\gamma_{i} n_{i}\right)+v_{i} d p
$$

where $p$ is the pressure, $\gamma_{i}$ is the activity coefficient, $n_{i}$ is the mol fraction and $v_{i}$ is the molar volume, all last three of component $i$. For liquids or solids (incompressible phases) volume does not change with pressure, so Equation (3.18) can be written as:

$$
\mu_{i}=\mu_{i}^{0}+R T \ln \left(\gamma_{i} n_{i}\right)+v_{i}\left(p-p_{i_{s a t}}\right)
$$

where $\mu_{i}^{0}$ is the chemical potential of pure $i$ at a reference pressure $p_{i_{s a t}}$ that is defined as the saturation vapor pressure of that component. In the case of gases (compressible phases) where the molar volume changes with pressure, Equation (3.18) is written as following, applying the ideal gas law [43]:

$$
\mu_{i}=\mu_{i}^{0}+R T \ln \left(\gamma_{i} n_{i}\right)+R T \ln \left(\frac{p}{p_{i_{s a t}}}\right)
$$

Focusing on gas separation, Figure 3.9 depicts how pressure and concentration behave. At the feed side, pressure within the membrane is constant, and the chemical gradient is described as a concentration gradient across the membrane. 
This gradient may change if the feed pressure $\left(p_{i_{o}}\right)$ or permeate pressure $\left(p_{i_{l}}\right)$ change. For example, if the feed pressure increases, the concentration at the feed interface $\left(c_{i_{o(m)}}\right)$ increases, leading to a maximum value when the vapor pressure is equal to the saturation vapor pressure $\left(p_{i_{s a t}}\right)$. If the permeate pressure decreases, the concentration at the permeate interface decreases, even reaching zero when vacuum is applied. As conclusion, pressures on gas separation membrane follow this rule:

$$
p_{i_{s a t}} \geq p_{i_{o}} \geq p_{i_{l}}
$$

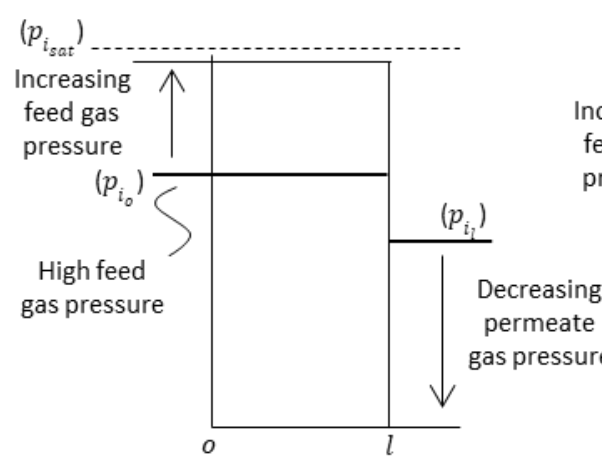

a) Membrane pressure profiles

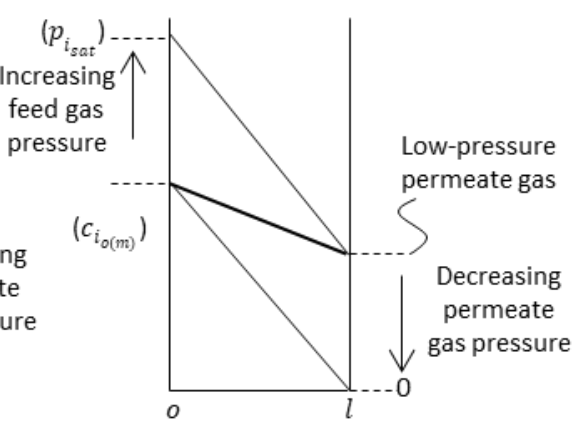

b) Membrane concentration profiles

Figure 3.9. Pressure (a) and concentration (b) gradients through a dense gas permeation membrane, in agreement with solution-diffusion model [43]

The first premise is to equalize the chemical potential on the feed side and the chemical potential on the permeate side, using Equation (3.20) for compressible gases and using Equation (3.19) for an incompressible phase:

$$
\begin{aligned}
\mu_{i_{o}} & =\mu_{i_{o(m)}} \\
\rightarrow \mu_{i}^{0}+R T \ln \left(\gamma_{i_{o}} n_{i_{o}}\right)+R T \ln \left(\frac{p_{o}}{p_{i_{s a t}}}\right) & =\mu_{i}^{0}+R T \ln \left(\gamma_{i_{o(m)}} n_{i_{o(m)}}\right)+v_{i}\left(p_{o}-p_{i_{s a t}}\right)
\end{aligned}
$$

Equation (3.22) may be reorganized to Equation (3.23), and replacing concentration for mole fraction $\left(c_{i}=M_{w_{i}} \partial n_{i}\right)$ and $p_{o} \cdot n_{i_{o}}$ as the partial pressure of component $i\left(p_{i_{o}}\right)$, Equation (3.23) is converted into Equation (3.24). 


$$
\begin{aligned}
n_{i_{o(m)}} & =\frac{\gamma_{i_{o}}}{\gamma_{i_{o(m)}}} \cdot \frac{p_{o}}{p_{i_{s a t}}} \cdot n_{i_{o}} \exp \left[\frac{-v_{i}\left(p_{o}-p_{i_{s a t}}\right)}{R T}\right] \\
c_{i_{o(m)}} & =\frac{M_{w_{i}} \partial \gamma_{i_{o}}}{\gamma_{i_{o(m)}} p_{i_{s a t}}} \cdot p_{i_{o}} \exp \left[\frac{-v_{i}\left(p_{o}-p_{i_{s a t}}\right)}{R T}\right]
\end{aligned}
$$

Once it is explained up to know, it is time to summarize and reach a final equation. It was explained that the parameters that determine the relative transport rate through the membrane are the diffusion $(D)$ and the solubility $(S)$ coefficient. From Equation (3.24), it can be defined the solubility coefficient as it is written in Equation (3.25):

$$
S_{i}=\frac{M_{w_{i}} \partial \gamma_{i_{o}}}{\gamma_{i_{o(m)}} p_{i_{s a t}}}
$$

where $M_{w_{i}}$ is the molecular weight $(\mathrm{g} / \mathrm{mol})$ of the component $i, \partial$ is the density $\left(\mathrm{mol} / \mathrm{cm}^{3}\right),, \gamma_{i}$ is the activity coefficient and $p_{i_{s a t}}$ is the saturation vapor pressure of the component $i$. In this way, Equation (3.24) can be translated, for the process at the feed side interphase and the process at the permeate side interphase, into Equation (3.26) and Equation (3.27), respectively [43].

$$
\begin{gathered}
c_{i_{o(m)}}=S_{i} \cdot p_{i_{o}} \exp \left[\frac{-v_{i}\left(p_{o}-p_{i_{s a t}}\right)}{R T}\right] \\
c_{i_{o(l)}}=S_{i} \cdot p_{i_{l}} \exp \left[\frac{-v_{i}\left(p_{o}-p_{i_{s a t}}\right)}{R T}\right]
\end{gathered}
$$

Once solubility coefficient is explained, it is time for diffusion coefficient, which reflects the mobility of the individual molecules in the membrane material and depends on the molecular size. Permeants are transported from one side of the membrane to another by a concentration gradient. This process is explained by Fick's law of diffusion (1855), which states that in a steady state, flux moves from 
regions of high concentration to regions of low concentration proportionally to a concentration gradient [63].

$$
J_{i}=-D_{i} \frac{d c_{i}}{d x}
$$

In Equation (3.28), $J_{i}$ is the mass flux of component $i\left(\mathrm{~g} / \mathrm{cm}^{2} \cdot \mathrm{s}\right)$ and $d c_{i} / d x$ is the concentration gradient of component $i\left(\mathrm{~g} / \mathrm{cm}^{3} \cdot \mathrm{cm}\right)$. As it was previously mentioned, the term $D_{i}$ refers to the diffusion coefficient $\left(\mathrm{cm}^{2} \cdot \mathrm{s}\right)$ and it reflects the mobility of the individual molecules in the membrane material. If the Equation (3.26) and Equation (3.27) are merged with Equation (3.28), they become Equation (3.29).

$$
J_{i}=\frac{D_{i} \cdot S_{i}\left(p_{i_{o}}-p_{i_{l}}\right)}{l} \cdot \exp \left[\frac{-v_{i}\left(p_{o}-p_{i_{s a t}}\right)}{R T}\right]
$$

The first term of Equation (3.29) makes reference to the partial pressure difference of component $i$ across the membrane, whereas the second term refers to the total pressure of the gas on the feed side of the membrane. Additionally, the term $v_{i}$ is related to the partial molar volume of the component $i$ dissolved in the membrane material, not to the molar volume of the component $i$ in the gas phase. Thus, this second exponentially term, is habitually equivalent to the unity, and only differs to 1 and becomes significant for vapors at high pressures with larger molar volumes. Consequently, Equation (3.29) can be modified into Equation (3.30).

$$
J_{i}=\frac{D_{i} \cdot S_{i}\left(p_{i_{o}}-p_{i_{l}}\right)}{l}
$$

Product of $D_{i}$ and $S_{i}$ is equal to the permeability coefficient $\rho_{i}$. Finally, a term that needs to be explained is the capability of a membrane to separate two components, called the selectivity coefficient $\alpha_{i j}$.

$$
\alpha_{i j}=\frac{\rho_{i}}{\rho_{j}}=\left\lfloor\frac{D_{i}}{D_{j}}\right\rfloor \cdot\left[\frac{S_{i}}{S_{j}}\right]
$$


Difference between the two models, pore-flow an solution-diffusion model, relies completely in the size and permeance of the membrane pores. For membranes that are controlled by the pore-flow model, pores are moderately large and rigid, whereas membranes dominated by solution-diffusion model possess extremely small pores that seem to appear and disappear at the same time molecules are been transported. It can be stated that the transition value between both models is a diameter in the range of 5-10 $\AA$ [43], according to the Figure 3.10.

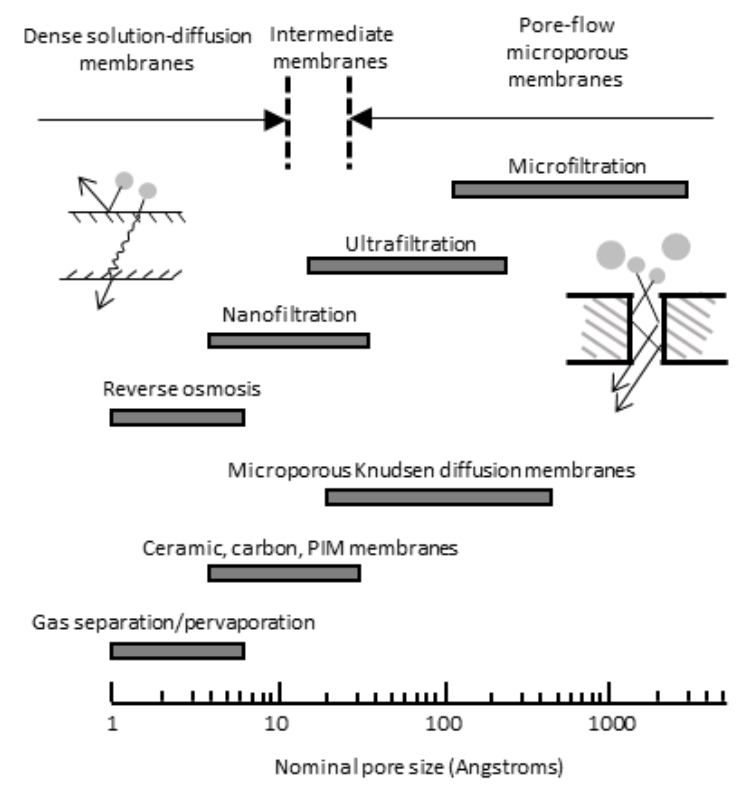

Figure 3.10. Theoretical relation between pore size and membrane type [43]

The rationalization into a manageable equation of the transport model in microporous membranes is not that trivial. As it was already explained, pore-flow transport occur by convective flow with some form of sieving mechanism, generating that a large number of factors affects the permeation calculation. Nevertheless, predictions of solution-diffusion model are in good agreement with experimental data, which allow to use simple equation in order to rationalize the properties of these membranes. This will be explained more in detail in the subsequent sections of this chapter, where the types of membranes are widely described.

With regard to this first sub-division, organic membranes are mainly based on modified polymers, whereas inorganic membranes comprehend ceramics and 
metals among others. According to Peyravi, a greater number of membranes in research and commercial use are organic polymers, on the strength of their simple processing into viable membrane forms and the variety of polymers available, as well as the ability to synthesize novel polymer structures [64]. Nevertheless, inorganic membranes, as well as composite membranes, have gained a massive attention due to their major potential in terms of, as example, performance, stability and long lifetime $[65,66]$.

In the subsequent sections, the properties of the different types of membranes are described, emphasizing on the ones that have been used in this thesis.

\subsubsection{Inorganic membranes}

Inorganic membranes are broadly divided into 5 different groups: ceramic membranes, zeolite membranes, metallic membranes, and carbon membranes [67].

\subsubsection{Zeolite membranes}

Concerning zeolite membrane, they consist on crystalline $\mathrm{SiO}_{4}$ and $\mathrm{AlO}_{4}$ tetrahedra with defined nanopores, which can be deposited as a thin layers on top of porous substrates. Adjacent tetrahedral are linked at their corners via a common oxygen atom, forming cages. These cages combine in different geometrical forms resulting in an inorganic macrostructure with three-dimensional framework [68]. Zeolite membranes possess not only excellent thermal and chemical stability, but also a uniform and very narrow molecular-size pores, named as channels. Dimensions of these channels are between $0.3-1.3 \mathrm{~nm}$ approximately [69], which allow to a more selective separation between molecules with similar pore diameters. Taking into consideration the IUPAC classification mentioned before in Table 3.2, zeolites are typically considered as microporous membranes. The chemical composition of a zeolite is represented as follow:

$$
A_{y / m}^{m+}\left[\left(\mathrm{SiO}_{2}\right)_{x} \cdot\left(\mathrm{AlO}_{2}^{-}\right)_{y}\right] \cdot z \mathrm{H}_{2} \mathrm{O}
$$

where $A$ is a cation with the charge $m,(x+y)$ is the number of tetrahedral per crystallographic unit cell and $x / y$ is the so-called framework silicon/aluminum ratio $n_{S i} / n_{A l}(\mathrm{Si} / \mathrm{Al})$. 
Table 3.6. Kinetic diameter and other properties for different gas molecules

\begin{tabular}{l|cccc} 
Molecule & $\begin{array}{c}\text { Kinetic } \\
\text { diameter }(\AA)\end{array}$ & $\begin{array}{c}\text { Polarizability } \\
\left(\AA^{3}\right)\end{array}$ & $\begin{array}{c}\text { Dipole } \\
\text { moment }(D)\end{array}$ & $\begin{array}{c}\text { Quadrupole } \\
\text { moment }(D \AA)\end{array}$ \\
\hline $\mathrm{H}_{2} \mathrm{O}$ & 2.65 & 1.45 & 1.870 & 2.30 \\
$\mathrm{H}_{2}$ & 2.89 & 0.80 & 0.000 & 0.66 \\
$\mathrm{CO}_{2}$ & 3.30 & 2.65 & 0.000 & 4.30 \\
$\mathrm{O}_{2}$ & 3.47 & 1.60 & 0.000 & 0.39 \\
$\mathrm{~N}_{2}$ & 3.64 & 1.76 & 0.000 & 1.52 \\
$\mathrm{CO}$ & 3.76 & 1.95 & 0.112 & 2.50 \\
$\mathrm{CH}_{4}$ & 3.80 & 2.60 & 0.000 & 0.02 \\
$\mathrm{C}_{2} \mathrm{H}_{4}$ & 4.16 & 4.26 & 0.000 & 1.50 \\
$\mathrm{C}_{2} \mathrm{H}_{6}$ & 4.44 & 4.47 & 0.000 & 0.65 \\
$n-\mathrm{C}_{4} \mathrm{H}_{10}$ & 4.69 & 8.20 & 0.050 & - \\
$i-\mathrm{C}_{4} \mathrm{H}_{10}$ & 5.28 & 8.29 & 0.132 & - \\
$\mathrm{SF}_{6}$ & 5.50 & 6.54 & 0.000 & 0.00
\end{tabular}

As microporous membranes, zeolites are controlled by the pore-flow transport model, which is not as simple to describe in one single equation. Separation through zeolite membranes proceeds by three mechanisms: (a) adsorption-controlled permeation, (b) diffusion-controlled permeation and (c) molecular sieving [70].

The first separation mechanism that is revealed in a zeolite membrane is the adsorption of the molecules from the gas phase onto the zeolite pore surface. Zeolite membranes commonly exhibit adsorption selectivity, which means that the components that are absorbed, stop or block somehow the permeation of other gases, leading to a driving force boost. The most significant parameters to evaluate the adsorption capability of the gas molecules are the polarizability and the dipole and quadrupole moments (see Table 3.6). These parameters are in charge of the correlation between the adsorbing molecule and the zeolite surface. Regarding the zeolite adsorbent, one of the leading parameters is the polarity, strongly dependent on the zeolite chemical composition. When increasing the Al content, i.e. low Si/Al ratio, zeolite structures become more polar, which leads to a more adsorption capacity improving the permeability. Adsorption selectivity is generally the governing separation mechanism at low temperatures $\left(100-200^{\circ} \mathrm{C}\right)$. 
Secondly, diffusion selectivity occurs at moderate temperatures, and it can be described as the ability of the molecules to leap from one adsorption site to another inside the zeolite framework. This mechanism will take place when the molecules in a gas flow meet two requirements: they are small compared to other molecules in the component, and their diffusivity in zeolites pores is faster than the rest. Finally, molecular sieving is the main gas transport mechanism (which is an extreme case of diffusion selectivity) and it occurs when one molecule can barely permeate through the zeolite framework.

In Table 3.6 is represented different properties for different gas molecules. One of the most important principle for choosing a zeolite for separation is the pore size, which is related to the kinetic diameter $(1 \AA=0.1 \mathrm{~nm})$. Figure 3.11 shows a comparison of the most common zeolite pore diameter and the kinetic diameter of some gases.

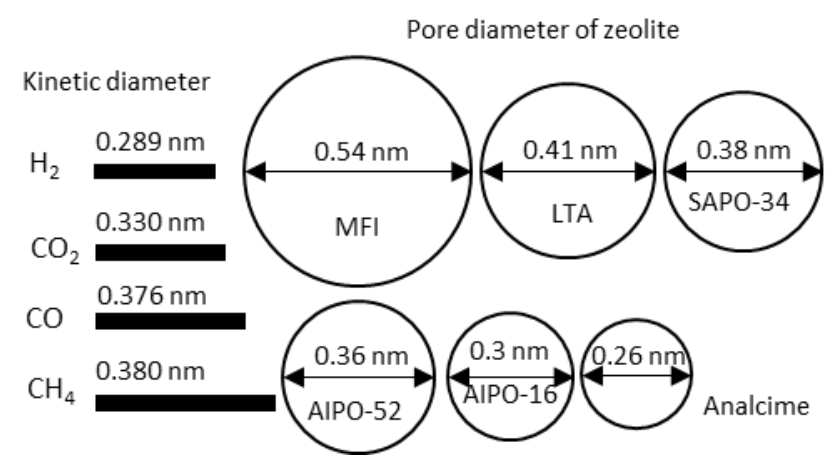

Figure 3.11. Pore diameter of zeolite and some kinetic diameter for small gases [69]

Permeance of zeolites $\rho_{i}^{0}\left(\mathrm{~mol} \cdot \mathrm{m}^{-2} \cdot \mathrm{s}^{-1} \cdot \mathrm{Pa}^{-1}\right)$ can be calculated as the ratio of the molar flux $F_{i}\left(\mathrm{~mol} \cdot \mathrm{m}^{-2} \cdot \mathrm{s}^{-1}\right)$ and the partial pressure difference of component $i$.

$$
\rho_{i}^{0}=\frac{F_{i}}{\left(p_{i, \text { feed }}-p_{i, \text { sweep }}\right)}
$$

The separation factor $\alpha_{i j}$ of a binary mixture permeation is defined as the quotient of the molar ratios in the permeate side, divided by the quotient of the molar ratio in the retentate side. 


$$
\alpha_{i j}=\frac{n_{i, \text { perm }} / n_{j, \text { perm }}}{n_{i, \text { ret }} / n_{j, \text { ret }}}
$$

\subsubsection{2. $\quad$ Ceramic membranes}

Ceramic membranes can be either dense or porous. Regarding microporous membranes, they are usually applied in microfiltration (MF), ultrafiltration (UF) and nanofiltration (NF) for the food and pharmaceutical industry (among others), due to their good chemical, thermal and mechanical stability. Ceramic membranes usually possess an asymmetric structure, consisting on a rough support, generally with a pore size of several microns, followed by other layers that exhibit smaller pore size. They are generally named as ceramic composite membranes (Figure 3.12) [71].

Preparation of ceramic membranes consists on the combination of a metal with a non-metal in the form of oxide, nitride or carbide. Most commonly microporous ceramic membranes are made from different oxides, such as silica $\left(\mathrm{SiO}_{2}\right)$, alumina $\left(\mathrm{Al}_{2} \mathrm{O}_{3}\right)$, zirconia $\left(\mathrm{ZrO}_{2}\right)$ or titania $\left(\mathrm{TiO}_{2}\right)$.

Regarding ceramic dense membranes, they are usually a combination of transition metals with good mixed-conducting properties, such as perovskite structures $\left(\mathrm{ABO}_{3}\right)$ [72]. All these membranes can also be used as ceramic support for other types of membranes such as polymer composites membranes [73-75]. Some of the main advantages of inorganic dense ceramic membranes are high selectivity and competently thermal stability. In contrast, their main drawback is their low permeability and sensitivity to poisoning.

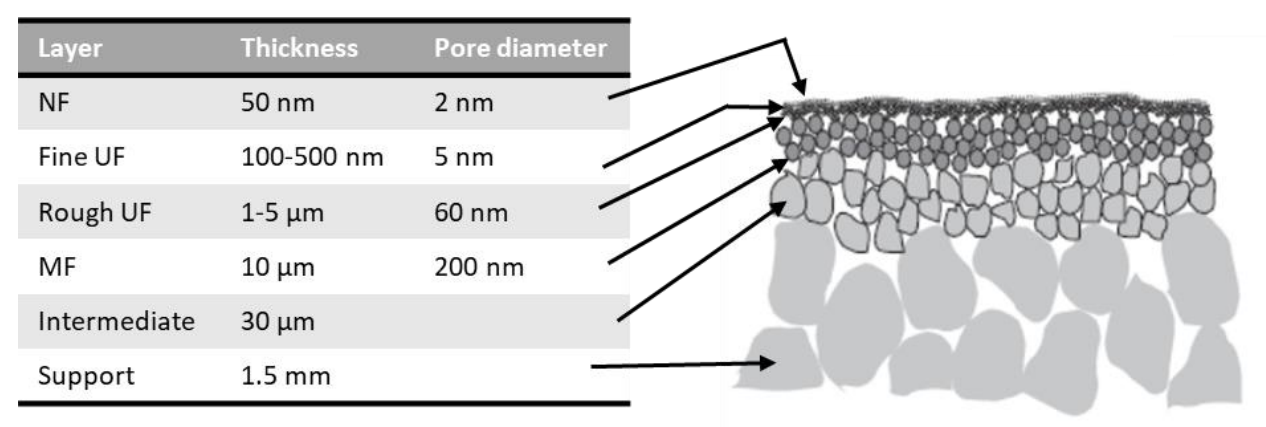

Figure 3.12. Ceramic composite membranes structure 
Depending on the size of the membrane pore diameter $\left(d_{p}\right)$, different diffusion mechanism may exist: viscous flow mechanism, gas diffusion mechanism (Knudsen diffusion) and surface affinity mechanism [76].

1. Viscous flow mechanism $\left(d_{p}>50 \mathrm{~nm} \rightarrow\right.$ macropores $)$. Permeability can be expressed as:

$$
\rho_{V}=\frac{\varepsilon R^{2}}{8 \tau \vartheta}
$$

where $\rho_{V}$ is the permeability for a viscous flow, $\varepsilon$ is the membrane porosity, $R$ is the internal pore radius, $\tau$ is the membrane tortuosity (the ratio of the length of the pore to the thickness of the membrane) and $\vartheta$ is the gas viscosity.

2. Knudsen diffusion ( $2 \mathrm{~nm}<d_{p}<50 \mathrm{~nm} \rightarrow$ mesopores $)$. In this configuration, the mean free path of molecules is smaller than the membrane pore. Thus, the collision between the molecules and the pore wall becomes more frequent. In this situation, Knudsen diffusion $\left(D_{k}\right)$ is equal to :

$$
D_{k}=\frac{2 r_{p}}{3} \sqrt{\frac{8 R T}{\pi M_{w}}}
$$

where $r_{p}$ is the pore radius, $R$ is the gas constant, $T$ is the temperature and $M_{w}$ is the molecular weight.

3. Surface affinity mechanism ( $d_{p}<2 \mathrm{~nm} \rightarrow$ micropores).

Particularly, when the pore size is no less than $40 \AA$ ( $4 \mathrm{~nm})$, they are modelled by the Knudsen diffusion [77]. Knudsen flux happens when the mean pore diameter of the porous medium is smaller than the mean free path of the gas particles (see Figure 3.13). As a matter of course, Knudsen diffusion occurs in low permeability porous media (small pore radii), and at low gas pressures (the mean free path becomes large) [78]. 


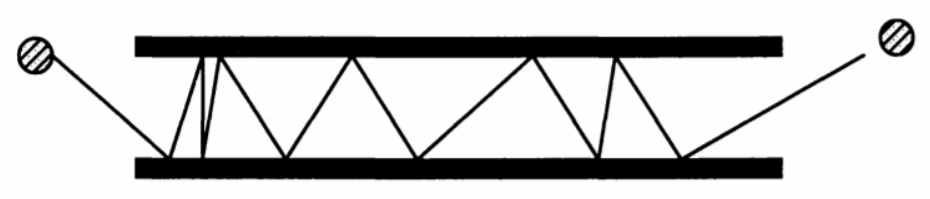

Figure 3.13. Knudsen diffusion mechanism

When Knudsen diffusion regime is applied, molecules move in all different directions between the walls of the porous medium without colliding with each other. As for the driving force, the partial pressure gradient stands for the Knudsen diffusion, which is equivalent to the total pressure gradient in a single gas system. Generally, Knudsen flux follows the equation [79]:

$$
J_{K}=w\left(y_{1}-y_{2}\right) v_{T}
$$

where $w$ is the probability of a molecule that goes in and goes out in a pore, and it depends on the geometry of the system, $y_{1}$ and $Y_{2}$ is the mol concentration $\left(\mathrm{mol} / \mathrm{m}^{3}\right)$ of a molecule in both sides of the pore and $v_{T}$ is the mean thermal molecular speed $(\mathrm{m} / \mathrm{sec})$.

Among all the possible candidates, silica and silica functionalized ceramic membranes outstand with a great potential for gas separation processes. Silica membranes are governed by the pore-flow transport model. In principle, microporous membranes indicates that the pore diameter must be less than $2 \mathrm{~nm}(20 \AA)$. Nevertheless, in order to obtain defect-free microporous silica membranes, pore size should be similar to the size of the penetrant molecules [80].

\subsubsection{Metallic membranes}

Metallic membranes are usually dense films, which separates $\mathrm{H}_{2}$ from other molecules. Oxygen-permeable metal based membranes exist, but their permeabilities are low in comparison with hydrogen-permeable metal based membranes [81, 82]. Transport mechanism for hydrogen separation through metallic membranes entails the conduction of free electrons. Metallic membranes have typically dense structure with no pore framework, so the transport is not controlled 
by the pore-flow model if not by solution-diffusion mechanism. In addition, hydrogen selectivity is most often extremely high, close to infinity in the majority of the cases, resulting from their dense structure, which block large molecules to go through, such as $\mathrm{N}_{2}, \mathrm{CO}, \mathrm{CO}_{2}$, etc.

Metallic membranes for hydrogen separation are made from a wide variety of compounds, for instance, pure metals ( $\mathrm{Pd}, \mathrm{V}, \mathrm{Ta}, \mathrm{Nb}$ and $\mathrm{Ti}$ ), $\mathrm{Pd}$ alloys (with $\mathrm{Cu}, \mathrm{Ag}$, $\mathrm{Y}, \mathrm{Ni}, \mathrm{Au}, \mathrm{Ce}$ and $\mathrm{Fe}$ ), complex alloys (Pd with 3 or more metals), amorphous alloys (group IV and V metals) and coated metals (Pd over others). In order to classify and check the best option for hydrogen permeation, there are some parameters that can be studied.

Firstly, hydrogen permeability as a function of temperature is key to determine the suitability of the selected metals [31]. Secondly, solubility coefficient also plays an important role due to the fact that it is the responsible for the hydrogen dissociation on the metal surface. Palladium has shown an excellent stability over temperature, as well as the greater solubility among other metals [83]. These two properties are depicted in Figure 3.14.
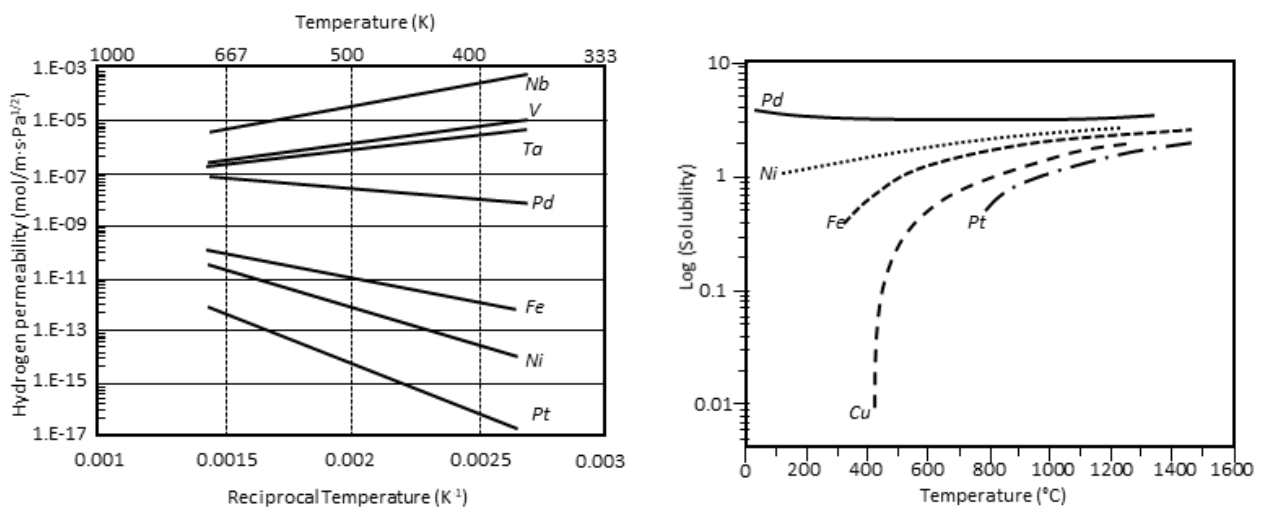

Figure 3.14. Hydrogen permeability (left graph) and hydrogen solubility at 1 atm pressure (right graph) as a function of temperature for different metals [43]

At first glance, it seems like $\mathrm{Nb}, \mathrm{V}$ and Ta have greater hydrogen permeability, which should indicate their convenience for hydrogen separation membranes. The main explanation for this is that body centered cubic metals (BCC) such as this three possess greater $\mathrm{H}_{2}$ permeability than those with face centered cubic (FCC), e.g. $\mathrm{Pd}$ 
or Ni. BCC systems possess one lattice point in the center of the unit cell plus to eight corner points, whereas FCC owns lattice points on the faces of the cube. It is evident that hydrogen permeability decrease with temperature in the case of BCC metals, attributable to the decrease of hydrogen solubility more rapidly than the increase of the diffusion coefficient. In addition, these metals form oxide layers, which lead to an outstanding problem for using them as hydrogen separation materials [84, 85].

Despite Pd seems to be the most appropriate option up to now, it is affected by diverse limitations. As first constrain, hydrogen absorption produces two different phases $\left(\alpha\right.$ and $\beta$ ) under the critical point of $298^{\circ} \mathrm{C}$ and $2 \mathrm{MPa}$. The $\alpha$-phase is acquired at low $\mathrm{H} / \mathrm{Pd}$ atomic ratios and emerge as the dominant phase at high temperature, whereas the $\beta$-phase is produced at high $\mathrm{H} / \mathrm{Pd}$ atomic ratios. Both phases occur simultaneously at low temperature, while the hydrogen vapor pressure is kept constant. When both phases coexist, a change in volume can lead to a recrystallization that rise to bulk and grain boundary defects. In order to avoid this problem, operational temperature, as it can be seen in Figure 3.15, must be above $300{ }^{\circ} \mathrm{C}$ approximately [86].

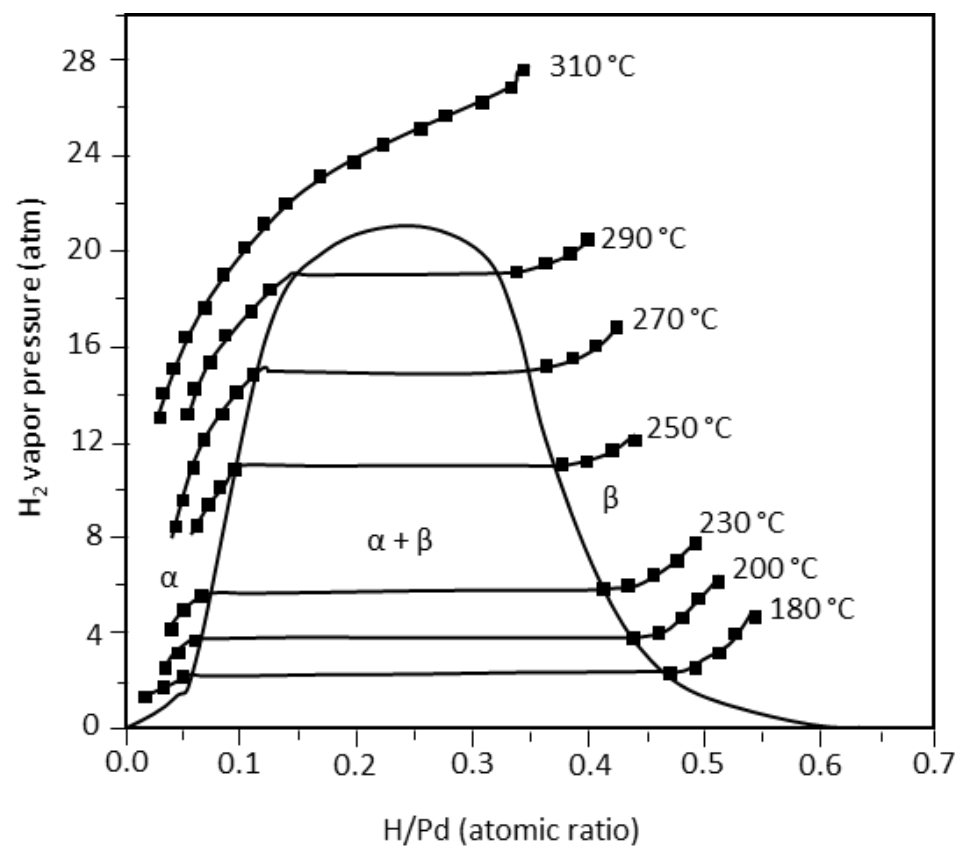

Figure 3.15. Palladium-hydrogen phase diagram 
As second constrain, which is closely linked to the first constrain, the process named as hydrogen embrittlement cause cracking on the material, deactivating the metal surface. This process occurs due to the fact that metals can lose ductility from exposure to hydrogen. In addition, palladium may interact with carbon containing species such as unsaturated hydrocarbons, sulfur and $\mathrm{CO}$, leading to an increase in the deactivation of the membrane [87]. This embrittlement is fundamentally resulting from changes in chemical structure and unit cell dimensions which introduce stress through sharp changes in lattice constants [29].

So as to preventing both issues, alloying Pd with other metallic compounds have been verified as a positive solution. Hydrogen embrittlement is solved and the critical temperature to overpass the $\alpha / \beta$ phase has been reported to be lowered from 298 ${ }^{\circ} \mathrm{C}$ to room temperature [88-92]. Moreover, in case of binary alloys, a relation between $\mathrm{H}_{2}$ permeance and the average bond distance of the alloys was observed (see Table 3.7). This is a plausible finding because hydrogen permeation is controlled by diffusion of atomic hydrogen through the metal lattice. The greater the average bond distance, the higher is the permeation of $\mathrm{H}_{2}$. 
Table 3.7. Properties of metals, binary alloys and ternary alloys [83, 93]

\begin{tabular}{|c|c|c|c|}
\hline Metal & Alloy metal wt\% & $\begin{array}{l}\text { Average bond } \\
\text { distance }(\mathrm{nm})\end{array}$ & $\begin{array}{c}\text { Permeance ratio } \mathrm{Pd} \text { - } \\
\text { alloy/Pd }\end{array}$ \\
\hline$P d$ & 0 & 0.275 & 1 \\
\hline$Y$ & 0 & 0.355 & - \\
\hline$A g$ & 0 & 0.289 & - \\
\hline $\mathrm{Ce}$ & 0 & 0.365 & - \\
\hline $\mathrm{Cu}$ & 0 & 0.256 & - \\
\hline$A u$ & 0 & 0.288 & - \\
\hline$R u$ & 0 & 0.265 & - \\
\hline In & 0 & 0.325 & - \\
\hline$P d-Y$ & 6.6 & 0.281 & 3.50 \\
\hline$P d-A g$ & 23 & 0.278 & 1.70 \\
\hline$P d-C e$ & 7.7 & 0.280 & 1.60 \\
\hline$P d-C u$ & 10 & 0.272 & 0.48 \\
\hline$P d-A u$ & 5 & 0.275 & 1.10 \\
\hline$P d-R u-I n$ & $0.5-6$ & 0.278 & 2.80 \\
\hline$P d-A g-R u$ & $30-2$ & 0.279 & 2.00 \\
\hline
\end{tabular}


Transport mechanism on metallic membranes consists on seven steps, and it is explained according to Figure 3.16 [29]:

1) Mixture of $\mathrm{H}_{2}$ and undesired gases are moved as feed stream to the surface of the membrane

2) Dissociation of chemisorbed $\mathrm{H}_{2}$ into hydrogen ions or protons $\left(\mathrm{H}^{+}\right)$and electrons $\left(e^{-}\right)$

3) Adsorption of $\mathrm{H}^{+}$and $\mathrm{e}^{-}$into the membrane bulk

4) Diffusion of $\mathrm{H}^{+}$and $\mathrm{e}^{-}$through the membrane

5) Desorption of $\mathrm{H}^{+}$and $\mathrm{e}^{-}$into the membrane bulk

6) Reassociation of $\mathrm{H}^{+}$and $\mathrm{e}^{-}$into $\mathrm{H}_{2}$ molecule at the opposite side of the membrane

7) Movement of $\mathrm{H}_{2}$ gas to the sweep stream
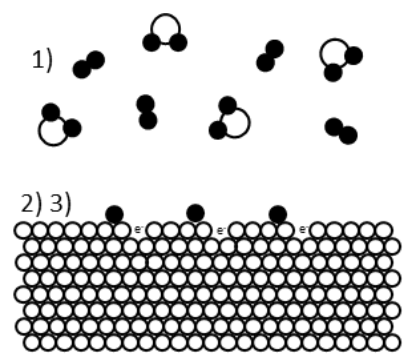
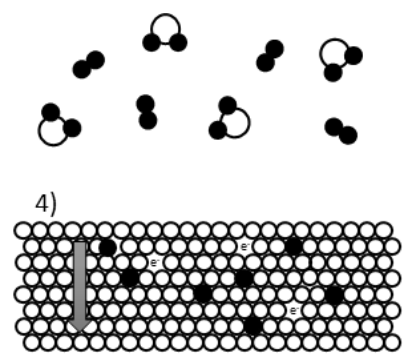
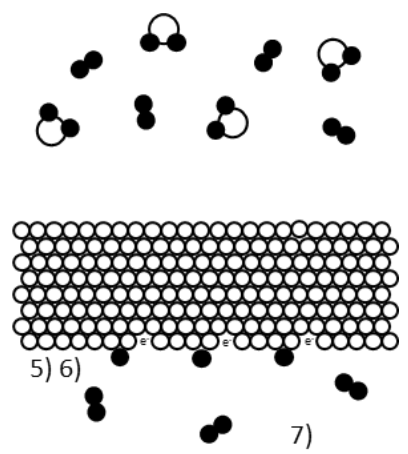

Figure 3.16. Transport mechanism in metallic membranes

The equation that describes this seven-step model results from a combination of Fick's first law, Equation (3.28), and Sievert's law, Equation (3.39). This combination is made due to the necessity of modelling the prior dissociation of the $\mathrm{H}_{2}$ molecule. Usually, permeability is a factor that becomes important when concentration of gases are not known on the feed stream. For these cases, Henry's law is used:

$$
S=c_{i} / p_{i}
$$

where $S$ is the constant relating the vapor pressure of a nondissociative gas to its dilute concentration in a liquid or solid (solubility coefficient), $c_{i}$ is the 
concentration of gas and $p_{i}$ is the pressure of gas [29]. Henry's law is modified for the case of diatomic $\mathrm{H}_{2}$ molecule into Sievert's law, which strictly belong to metallic membranes:

$$
S=c_{\text {gas }} / p_{\text {gas }}^{1 / 2}
$$

Implementing Equation (3.28) and Equation (3.39), a definitive formula for modelling metallic membranes transport for $\mathrm{H}_{2}$ permeation is described as:

$$
F_{H_{2}}=\frac{\rho_{H_{2}}\left(p_{H, \text { feed }}^{n}-p_{H, \text { sweep }}^{n}\right)}{l}
$$

where $F_{\mathrm{H}_{2}}$ is the hydrogen permeation flux $\left(\mathrm{mol} \cdot \mathrm{m}^{-2} \cdot \mathrm{s}^{-1}\right), \rho_{\mathrm{H}_{2}}$ is the hydrogen permeability $\left(\mathrm{mol} \cdot \mathrm{m}^{-1} \cdot \mathrm{s}^{-1} \cdot \mathrm{Pa}^{-n}\right), l$ is the membrane thickness $(\mathrm{m})$ and $P_{H, f e e d}^{n}$ and $P_{H, \text { sweep }}^{n}$ are the hydrogen partial pressures in the retentate and permeate sides of the membrane, respectively $(\mathrm{Pa})$. Finally, $n$ is the exponential pressure value, which may range from 0.5 (ideal value) to 1 . The variation of this value depends on the rate-determining step. On one hand, when the rate controlling step is the diffusion of $\mathrm{H}^{+}$and $\mathrm{e}^{-}$into the membrane bulk, $\mathrm{n}$ is equal to 0.5 , because the diffusion rate is proportional to the concentration of $\mathrm{H}_{2}$ atoms on opposite sides of the metal surface and this $\mathrm{H}_{2}$ concentration is proportional to the square root of the $\mathrm{H}_{2}$ pressure. On the other hand, when one of the other processes is the rate controlling step, the foreseen value of $n$ is close to 1 , due to the fact that these steps depend linearly on the concentration of molecular $\mathrm{H}_{2}$. This deviation from Sievert's law predictions happens, usually, at low temperatures [83].

According to Equation (3.40), flux is inversely proportional to the thickness, albeit the lower the thickness is, the less mechanical stability the membrane structure has. It is important to find a compromise between permeation properties and the mechanical properties. Generally, thinner membranes are preferable since the material cost is reduced sorely, apart from increasing the flux. In contrast, extremely thin films will lead to non-continuous layer with defects, among other possible drawbacks. 
Permeability is a parameter that do not depend on the thickness of the membranes, being a primary property of the material. Permeability can be expressed as the product of diffusion and solubility coefficient and, in addition, it can be represented by Arrhenius equation:

$$
\rho_{H_{2}}=\rho^{0} \exp \left(\frac{-E_{A}}{R T}\right)
$$

where $\rho^{0}$ is the pre-exponential factor, also called permeance, $\left(\mathrm{mol} \cdot \mathrm{m}^{-1} \cdot \mathrm{s}^{-1}\right.$. $\left.\mathrm{Pa}^{-n}\right), E_{A}$ is the activation energy $\left(\mathrm{J} \cdot \mathrm{mol}^{-1}\right), R$ is the gas constant $\left(8.314 \mathrm{~J} \cdot \mathrm{mol}^{-1}\right.$. $K^{-1}$ ) and $T$ is the absolute temperature $(K)$. Finally, the membrane capacity to separate gases is represented by the selectivity. Selectivity $(\alpha)$ or separation factor is defined as the ratio of the penetrants permeability.

$$
\alpha_{i j}=\frac{\rho_{i}}{\rho_{j}}=\frac{D_{i} S_{i}}{D_{j} S_{j}}
$$

\subsubsection{Organic membranes: Polymer membranes}

Polymeric membranes, as dense membranes, follow a solution-diffusion model, the same general principal of metallic membranes. Again, permeability can be expressed as the product of diffusion coefficient and solubility coefficient.

$$
\rho=D \cdot S
$$

Diffusion coefficient is related with the kinetic terms and it reflects the mobility of the individual molecules in the membrane material. More simply, it depends on the molecular size. In contrast, solubility coefficient links the concentration of a component in the fluid phase with its concentration in the membrane polymer phase, and reflects the number of molecules dissolved in the membrane material. It depends on molecular interaction, hence it is an equilibrium term. 


$$
\alpha_{i j}=\alpha_{D} \cdot \alpha_{S}=\left\lfloor\frac{D_{i}}{D_{j}}\right\rfloor \cdot\left[\frac{S_{i}}{S_{j}}\right]
$$

According to Equation (3.44), which describes the separation factor or selectivity, $D_{i} / D_{j}$ is the fraction of the diffusion coefficients of the two gases, named as mobility selectivity, it indicates the different size of the two molecules. The second term, $S_{i} / S_{j}$, is the ratio of the solubility coefficients of the two gases.

Based on these previous definitions, membrane material is more related to diffusion coefficient, being more affected by the membrane changes than to solubility coefficient. Taking as an example, in Figure 3.17, diffusion and solubility coefficients of four gases in a group of several related polyimides are plotted against each other. Both coefficients are reasonably well grouped for each gas. Thus, for any gas, the difference in diffusion coefficient from the highest value is 100 times bigger than to the lowest value, while the deviation in solubility coefficients is only 2 to 4 times. Changes in polymer chemistry affect both, diffusion and solubility coefficients, but the effect on the diffusion coefficient is more meaningful [43]. In the following subsections, diffusion and solubility coefficient are explained for polymer membranes. 


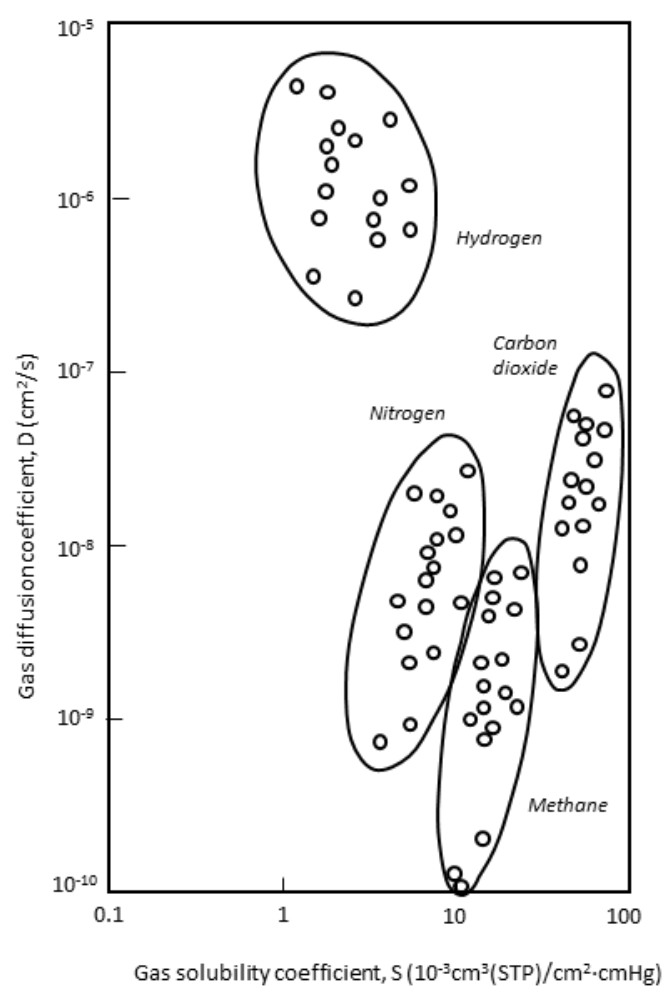

Figure 3.17. Diffusion and solubility coefficient for different polyimides [43, 94]

\subsubsection{Diffusion coefficient}

Regarding diffusion coefficient, it is a measure of the frequency with which the molecule moves and the extent of each movement. Consequently, diffusion coefficient is controlled by the restrictive forces of the medium on the diffusing gases. Diffusion coefficient range is quite broad, in the sense that, depending on which medium is the analyzed specie, the movement may be very small (around $1 \AA$ ) or extremely high, in constant movement (up to $1000 \AA$ ). Values may vary from $10^{-1}$ to $10^{-30} \mathrm{~cm}^{2} / \mathrm{s}$, specifically, in polymers, it covers from $10^{-5}$ to $10^{-10} \mathrm{~cm}^{2} / \mathrm{s}$. In polymers, diffusion coefficient decreases with increasing permeants molecular size, as a result of the greater interaction of large molecules with more segments of the polymer chain than the small molecules. Consequently, mobility coefficient always benefits movement of small molecules.

Nonetheless, diffusion coefficient is greatly influenced by the polymeric material and the temperature. Polymers can be divided into two broad groups: rubber 
polymers and glassy polymers. In a rubbery polymer, portions of the polymer chains can move without any restrain because of thermal motion, and segments of the polymer backbone can also rotate around their axis, which makes the polymer soft and elastic. This freely thermal motion gives rise to an increase in diffusion coefficients. In contrast, in a glassy polymer, steric hindrance along the polymer backbone prevents rotation and free motion of segments of the polymer. The result is a rigid and tough polymer. Thermal motion in this type of material is limited, therefore diffusion coefficients are low. There is a possibility to change from glass to rubber, when glassy polymers temperature increases, at some point, the thermal energy becomes sufficient to surpass the steric hindrance restricting motion of the polymer backbone segments. This temperature is called glass transition temperature ( $\mathrm{T}_{\mathrm{g}}$ [43].

Depending if the polymer is rubber or glass, diffusion coefficient will vary accordingly. There is a considerable difference between the motion of polymer segments in a malleable rubbery polymer, which are substantially more flexible and rotate effortlessly, and in a stiff glassy polymer. As a consequence, diffusion coefficients of glassy polymer are usually lower and decrease faster with increasing permeate molecular size than the diffusion coefficients of rubbery polymers. In other words, mobility selectivity term for rubbery membranes is smaller than the mobility coefficient of glassy membranes. In order to correlate permeation properties, such as diffusion coefficient, with the structure and the chemical of the polymers, fractional free volume (FFV) parameter is used. Permeability factor of gases in glassy polymers are highly dependent on the FFV, which can be defined as the free space that is not occupied by the polymer molecules [95]. The equation that defined FFV is the followed:

$$
v_{f}=\frac{v-v_{0}}{v}
$$

where $v$ is the specific volume of the polymer $\left(\mathrm{cm}^{3} / g\right)$, i.e., the correlative of the polymer density, and $v_{0}$ is the volume occupied by the polymer molecules $\left(\mathrm{cm}^{3} / \mathrm{g}\right)$. In principle, FFV is the sum of all the spaces between the polymer chains. There are some studies that expose how to calculated FFV. Firstly, by measuring the specific volume of the polymer (correlated to the polymer density). Secondly, the occupied volume can be calculated summing the molar volume of all the different 
chemical groups in the polymer basic unit. It exists different books that publish tables with molar volumes of a diverse range of chemical groups [96, 97].

Diffusivity coefficient can be related to FFV by the following equation:

$$
D=A \cdot \exp \left(\frac{B}{v_{f}}\right)
$$

where $D$ is the diffusivity coefficient, $v_{f}$ is the fractional free volume and $A$ and $B$ are variable parameters. Usually, Equation (3.46) is well-correlated when it is applied to single material category [98, 99]. In contrast, scattering occurs when there are different materials in the polymer structure.

FFV depends on the specific volume of the polymer, and this in turn depends on the temperature. It has been already explained that, at high temperatures, polymers behave as rubbers. At this rubber state, polymer chains cannot pack entirely and some space between those chains remains unoccupied. Figure 3.18 shows the specific volume of a general polymer as a function of temperature. As it can be seen, when the temperature decreases, so does the FFV. Once the polymer reaches a glassy state, the motion of the polymer chains is reduced abruptly and two possibilities can be faced. On one hand, if the specific volume stays on the equilibrium performance $(t=\infty)$, FFV would decrease speedily, and as a consequence, diffusion coefficient would be very low.

On the other hand, and most likely to happen, below $T_{g}$ temperatures, an extra free volume elements between the polymer chains are frozen due to a high restriction motion of the polymer matrix, which can be observed in Figure 3.18. As a consequence, glassy polymers contain, not only the free volume caused by the incomplete packing of the groups which forms the polymer chains, but also an excess of free volume as a result of the non-equilibrium glassy state. These free volume elements are only very slowly eliminated by movement of the glassy polymer chains. Due to this combination of free volume, the value remains basically constant. In addition, the reason for a high permeability and selectivity of glassy polymers is the existence of these very small excess free volume elements. 


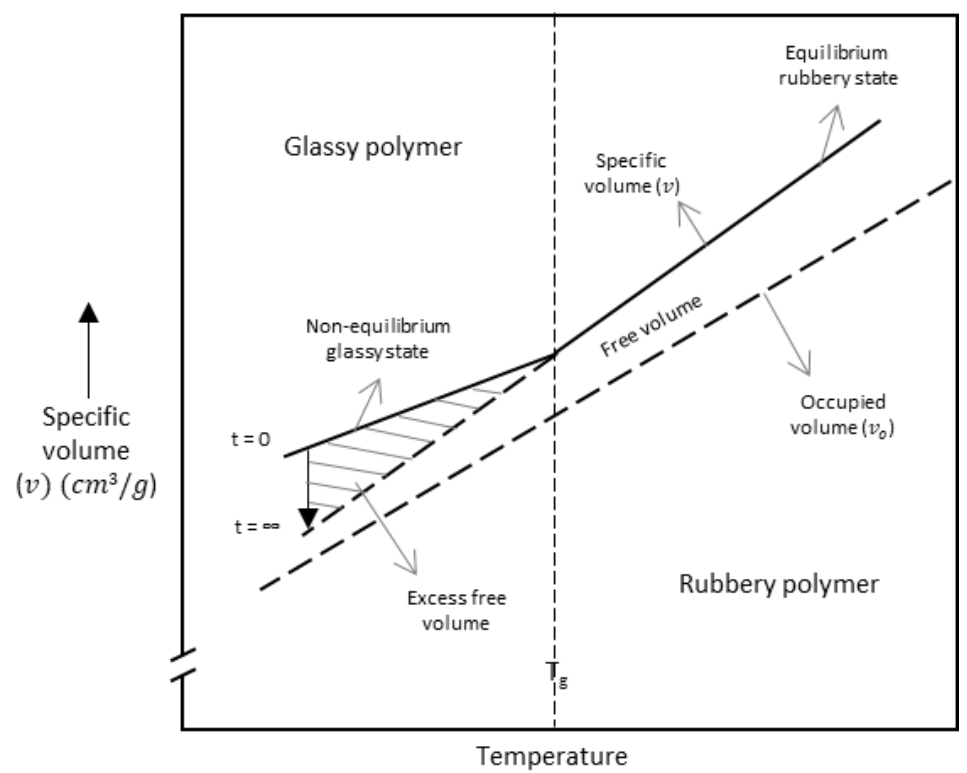

Figure 3.18. Behavior of a general specific volume polymer as a function of temperature

Nevertheless, these extra free volumes gradually decrease from its first value $(t=0)$ to its last value $(t=\infty)$, which severely hampers the effect of the FFV on the diffusion coefficient. Additionally, the effect of this loss varies between thick films and thin films. In a thick film, the extra free volume element must move to the surface of the polymer (similar to a bubble leaving a liquid), in order to eliminate its space, which is a significant distance to escape, and so densification of the polymer is very slow. In the case of thin membranes, the distance the free volume element must go through to escape is much less. In these thin membrane films, polymers can lose a large fraction of their excess free volume over a period of a few months to a few years, leading to a significant effect on the permeation properties of these membranes, knowing as aging effect. Hence, permeability of polymers decreases with time, whereas selectivity increases. As example, Figure 3.19 shows $\mathrm{O}_{2}$ permeability and $\mathrm{O}_{2} / \mathrm{N}_{2}$ selectivity as a function of time for a polyphenylene oxide (PPO) thin film, where it can be observed the effect of long-term aging. [43]. As a consequence, polymer membranes are usually treat at temperature close to the $T_{g}$, in order to increase their stabilization in terms of both permeability and selectivity. 

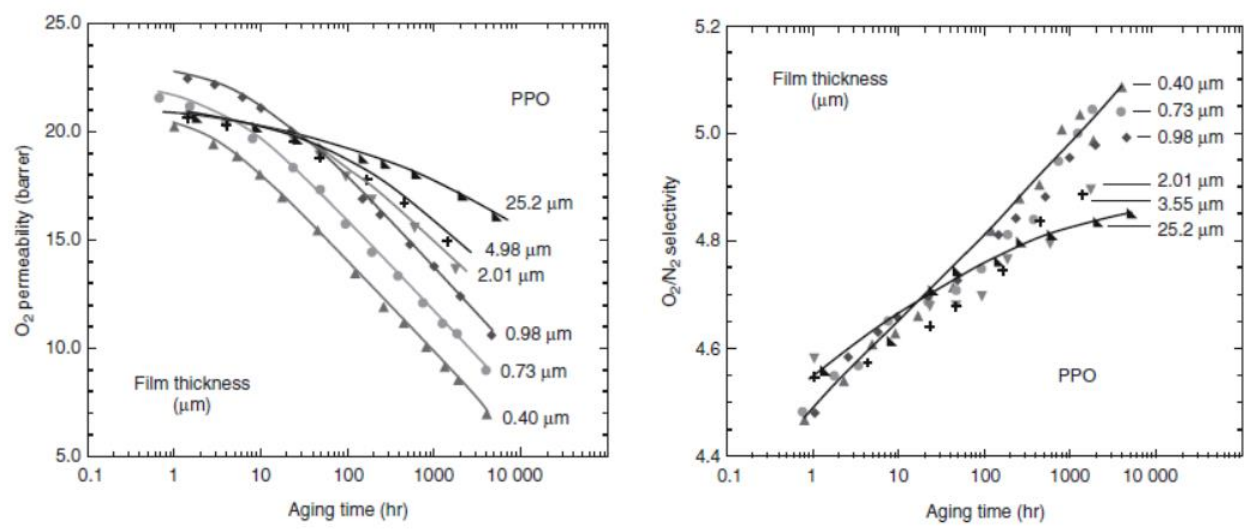

Figure 3.19. Effect of long-term aging on PPO thin film membrane

\subsubsection{Solubility coefficient}

In general, solubility coefficient increases with increasing condensability of the permeants. This means that it also increases with the molecular size, due to the fact that large molecules are more condensable than small molecules. However, when it comes to rubber or glass polymers, the difference of solubility coefficient is less evident than the difference in diffusion coefficient. Solubility coefficient in rubbery polymers is usually higher than in glassy polymers.

As it was already explained in Figure 3.17, membrane material is more related to diffusion coefficient, being more affected by the membrane changes, than to solubility coefficient. Actually, solubility coefficients of gases in polymers are approximately stable for a broad range of chemically different polymers. This results in a stable solubility selectivity $\left(S_{i} / S_{j}\right)$, in contrast with the less constant value of mobility selectivity $\left(D_{i} / D_{j}\right)$. Nevertheless, continuing the discussion above, in glassy polymers, mobility coefficient dominates the transport, so permeability decreases with increasing permeant molecular size and small molecules permeate preferentially. On the other hand, in rubbery polymers, solubility selectivity controls the transport, so permeability increases with increasing permeant molecular size and large molecules permeate preferentially.

In order to study the properties of different membrane materials, Robeson published charts, for the first time in 1991, of membrane permeability as a function of selectivity called Upper Bound correlation [100]. This experimental data is 
obtained from single gas tests, meaning that permeabilities were measured with pure gas tests and selectivities were obtained from the ratio of the pure gas permeabilities, giving ideal selectivities, despite the fact that industrial processes of gas separation membranes are performed with gas mixtures. In principle, if gases do not interact with the membrane material, difference between single gas selectivity and gas mixture selectivity will be small. Consequently, in gas mixtures, molecules that possess high solubility coefficient will be enough sorbed by the membrane material to affect the other gas permeability.
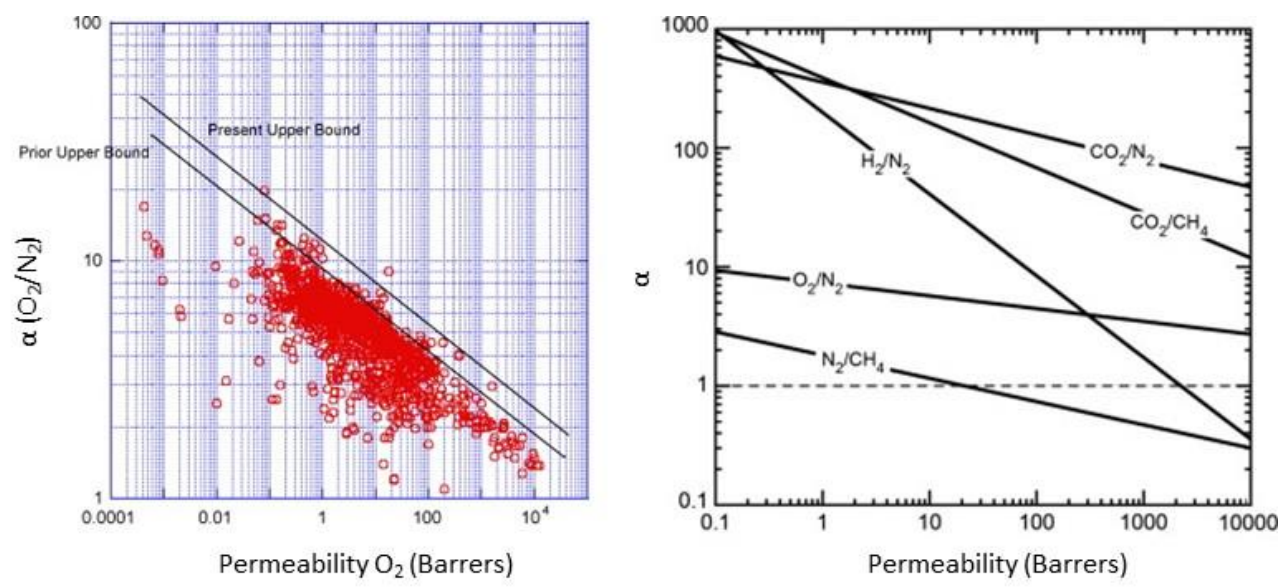

Figure 3.20. a) Robeson prior Upper Bound for $\mathrm{O}_{2} / \mathrm{N}_{2}$ (1991) and present Upper Bound for $\mathrm{O}_{2} / \mathrm{N}_{2}(2008)$

[101] and b) Robeson's upper bound selectivity/permeability lines for a number of commercially important gas separations [102]

In Figure 3.20a, it can be seen the Upper Bound correlation for $\mathrm{O}_{2} / \mathrm{N}_{2}$. Each dot on the graph represents a polymer material, giving a wide range of possible combination. Polymers with a high selectivity, usually show low permeability, and the other way around, polymers with high permeabilities exhibit not that high selectivity values. The line that links the materials with the greatest values of permeability and selectivity is called Upper Bound, beyond which no better material is currently known. The goal for the scientific community is to move that Upper Bound and get polymers of interest with greater permeability and selectivity.

Not only $\mathrm{O}_{2} / \mathrm{N}_{2}$ pair of gases was studied, multiple combination are made in order to estimate the quality of the future membrane material. This can be seen in Figure 3.20b, where other important pair of gases are analyzed. Initially, Robeson Upper Bound was an empirical result out of all the individual values of permeability 
and selectivity. However, these lines can be represented by the following expressions:

$$
\begin{gathered}
\ln \alpha_{i j}=\ln \beta_{i j}-\varphi_{i j} \ln \rho_{i} \\
\alpha_{i j}=\frac{\beta_{i j}}{\rho_{i}{ }^{\varphi_{i j}}}
\end{gathered}
$$

where, $\alpha_{i j}$ is the selectivity of the two gases, $\varphi_{i j}$ is the slope of the lines in Figure $3.20 \mathrm{a}$ and $\ln \beta_{i j}$ is the interception at $\ln \rho_{i}=0$ [103]. In this thesis, only glassy polymers are studied. 


\subsection{References}

1. Worldometers. Current world population. Available from: www.worldometers.info.

2. $\quad$ Administration, U.S.E.I., International Energy Outlook. 2016.

3. Administration, U.S.E.I. Energy Explained. 2017; Available from: https://www.eia.gov/energyexplained/index.cfm.

4. Collaboration, U.o.Y.C.f.I.E. The chemical industry. 2016; Available from: http://www.essentialchemicalindustry.org/the-chemical-industry/thechemical-industry.html.

5. Agency, I.E., Technology Roadmap. Energy and GHG Reductions in the Chemical Industry via Catalytic Processes. 2013.

6. (OECD), O.f.E.C.a.D. Sustainable Chemistry. 2017; Available from: http://www.oecd.org/env/ehs/risk-management/.

7. Agency, U.S.E.P. Basics of Green Chemistry. 2017; Available from: https://www.epa.gov/greenchemistry/basics-green-chemistry.

8. CHEMISTRY, E.T.P.f.S., Reaction and Process Design. Towards a Strategic Research Agenda. 2005.

9. Wang, G.Q., Z.C. Xu, and J.B. Ji, Progress on Higee distillationIntroduction to a new device and its industrial applications. Chemical Engineering Research and Design, 2011. 89(8): p. 1434-1442.

10. Stankiewicz, A. and J.A. Moulijn, Process Intensification: Transforming Chemical Engineering. Vol. 96. 2000. 22-33.

11. Agency, U.S.E.P., Global Anthropogenic Non-CO2 Greenhouse Gas Emissions: 1990 - 2030. 2012.

12. Alvarez-Galvan, M.C., et al., Direct methane conversion routes to chemicals and fuels. Catalysis Today, 2011. 171(1): p. 15-23.

13. Lunsford, J.H., Catalytic conversion of methane to more useful chemicals and fuels: a challenge for the 21st century. Catalysis Today, 2000. 63(2): $\mathrm{p}$. 165-174.

14. Ojala, S., et al., Utilization of Volatile Organic Compounds as an Alternative for Destructive Abatement. Vol. 5. 2015. 1092-1151.

15. LERCHER, J.A., et al., METHANE UTILISATION VIA SYNTHESIS GAS GENERATION - CATALYTIC CHEMISTRY AND TECHNOLOGY, in Environmental Catalysis. p. 103-126.

16. A. Al-Sayari, S., Recent Developments in the Partial Oxidation of Methane to Syngas. Vol. 6. 2013. 17-28.

17. Newsome, D.S., The Water-Gas Shift Reaction. Catalysis Reviews, 1980. 21(2): p. 275-318. 
18. Reddy, G.K. and P.G. Smirniotis, Chapter 1 - Introduction About WGS Reaction, in Water Gas Shift Reaction. 2015, Elsevier: Amsterdam. p. 1-20.

19. Stangeland, K., et al., CO2 Methanation: The Effect of Catalysts and Reaction Conditions. Energy Procedia, 2017. 105: p. 2022-2027.

20. Brooks, K.P., et al., Methanation of carbon dioxide by hydrogen reduction using the Sabatier process in microchannel reactors. Chemical Engineering Science, 2007. 62(4): p. 1161-1170.

21. Götz M, K.A., Graf F., State of the Art and Perspectives of CO2 Methanation Process Concepts for Power-to-Gas Applications., in International Gas Union Research Conference. 2014: Copenhagen.

22. Jain, I.P., Hydrogen the fuel for 21st century. International Journal of Hydrogen Energy, 2009. 34(17): p. 7368-7378.

23. AZoCleantech. Hydrogen Energy - The Perfect Energy Source for the Future? 2008.

24. Turner, J.A., Sustainable Hydrogen Production. Science, 2004. 305(5686): p. $972-974$.

25. Cook, P.Z.G., CCS Roadmap for Industry: High-purity CO2 sources. 2010, Global CCS Institute.

26. Holladay, J.D., et al., An overview of hydrogen production technologies. Catalysis Today, 2009. 139(4): p. 244-260.

27. Gallucci, F., et al., Steam Reforming of Methane in a Membrane Reactor: An Industrial Case Study. Industrial \& Engineering Chemistry Research, 2006. 45(9): p. 2994-3000.

28. Reddy, G.K. and P.G. Smirniotis, Chapter 3 - Low-Temperature WGS Reaction, in Water Gas Shift Reaction. 2015, Elsevier: Amsterdam. p. 47100.

29. Ockwig, N.W. and T.M. Nenoff, Membranes for Hydrogen Separation. Chemical Reviews, 2007. 107(10): p. 4078-4110.

30. L. Spath, P. and D. C. Dayton, Preliminary Screening - Technical and Economic Assessment of Synthesis Gas to Fuels and Chemicals With Emphasis on the Potential for Biomass-Derived Syngas. 2003. 160.

31. Adhikari, S. and S. Fernando, Hydrogen Membrane Separation Techniques. Industrial \& Engineering Chemistry Research, 2006. 45(3): p. 875-881.

32. Sircar, S. and T.C. Golden, Purification of Hydrogen by Pressure Swing Adsorption. Separation Science and Technology, 2000. 35(5): p. 667-687.

33. Evers, A.A. Evers Hydrogen Association. 2018; Available from: http://www.hydrogenambassadors.com/. 
34. Ramachandran, R. and R.K. Menon, An overview of industrial uses of hydrogen. International Journal of Hydrogen Energy, 1998. 23(7): p. 593598.

35. Carrette, L., Friedrich, K. A. and Stimming, U., Fuel Cells - Fundamentals and Applications. Fuel Cells, 2001. 1: p. 5-39.

36. Dalai, A.K. and B.H. Davis, Fischer-Tropsch synthesis: A review of water effects on the performances of unsupported and supported Co catalysts. Applied Catalysis A: General, 2008. 348(1): p. 1-15.

37. Prieto, G., et al., Cobalt supported on morphologically tailored SBA-15 mesostructures: The impact of pore length on metal dispersion and catalytic activity in the Fischer-Tropsch synthesis. Applied Catalysis A: General, 2009. 367(1): p. 146-156.

38. Rohde, M.P., et al., Fischer-Tropsch synthesis with in situ H2O removal Directions of membrane development. Microporous and Mesoporous Materials, 2008. 115(1): p. 123-136.

39. C.H. Bartholomew, R.J.F., Fundamentals of Industrial Catalytic Processes. 2005, New York: John Wiley \& Sons.

40. Unruh, D., M. Rohde, and G. Schaub, Improving carbon utilization in biomass conversion to synthetic hydrocarbons via Fischer-Tropsch Synthesis, in Studies in Surface Science and Catalysis, S.-E. Park, J.-S. Chang, and K.-W. Lee, Editors. 2004, Elsevier. p. 91-96.

41. Platform, M.o.E.P.t.G. European Power to Gas Platform. 2018; Available from: http://www.europeanpowertogas.com.

42. Lu, G.Q., et al., Inorganic membranes for hydrogen production and purification: A critical review and perspective. Journal of Colloid and Interface Science, 2007. 314(2): p. 589-603.

43. Baker, R.W., Membrane Technology and Applications. 3rd ed. 2012: Wiley.

44. Fried, J.R., Basic Principles of Membrane Technology By Marcel Mulder (University of Twente, The Netherlands). Kluwer Academic: Dordrecht. 1996. 564 pp. \$255.00. ISBN 0-7823-4247-X. Journal of the American Chemical Society, 1997. 119(36): p. 8582-8582.

45. Synthetic Membranes: Science, Engineering and Applications. 1 ed. 1986: Springer Netherlands. 734.

46. Ulbricht, M., Advanced functional polymer membranes. Polymer, 2006. 47(7): p. 2217-2262.

47. Osamu, S., M. Makoto, and Y. Yukio, The Dehydrogenation of Cyclohexane by the Use of a Porous-glass Reactor. Bulletin of the Chemical Society of Japan, 1982. 55(9): p. 2760-2764.

48. Kameyama, T., et al., Possibility for effective production of hydrogen from hydrogen sulfide by means of a porous Vycor glass membrane. Industrial \& Engineering Chemistry Fundamentals, 1981. 20(1): p. 97-99. 
49. Itoh, N., A membrane reactor using palladium. AIChE Journal, 1987. 33(9): p. $1576-1578$.

50. Sun, Y.M. and S.J. Khang, Catalytic membrane for simultaneous chemical reaction and separation applied to a dehydrogenation reaction. Industrial \& Engineering Chemistry Research, 1988. 27(7): p. 1136-1142.

51. Sun, Y.-M. and S. Jai Khang, A Catalytic Membrane Reactor: Its Performance in Comparison with Other Types of Reactors. Vol. 29. 1990.

52. Veziro $>$ lu, T.N. and F. Barbir, Hydrogen: the wonder fuel. International Journal of Hydrogen Energy, 1992. 17(6): p. 391-404.

53. Diban, N., et al., Membrane Reactors for in Situ Water Removal: A Review of Applications. Industrial \& Engineering Chemistry Research, 2013. 52(31): p. $10342-10354$.

54. Abdallah, H., A Review on Catalytic Membranes Production and Applications. 2017, 2017: p. 21.

55. Yao, X., et al., Review of the applications of microreactors. Renewable and Sustainable Energy Reviews, 2015. 47: p. 519-539.

56. Roberge, D.M., et al., Microreactor Technology: A Revolution for the Fine Chemical and Pharmaceutical Industries? Chemical Engineering \& Technology, 2005. 28(3): p. 318-323.

57. Wang, N., et al., Hydrophilic SOD and LTA membranes for membranesupported methanol, dimethylether and dimethylcarbonate synthesis. Microporous and Mesoporous Materials, 2015. 207: p. 33-38.

58. Chen, G.Q., et al., The thickness dependence of Matrimid films in water vapor permeation. Chemical Engineering Journal, 2012. 209: p. 301-312.

59. Physics, P., Barrier Properties of Polymers. 2015.

60. Wilkinson, A.D.M.a.A., IUPAC. Compendium of Chemical Terminology, 2nd ed. (the "Gold Book"). 2014: Blackwell Scientific Publications, Oxford (1997).

61. Gray, W.G. and C.T. Miller, Examination of Darcy's Law for Flow in Porous Media with Variable Porosity. Environmental Science \& Technology, 2004. 38(22): p. 5895-5901.

62. Wijmans, J.G. and R.W. Baker, The solution-diffusion model: a review. Journal of Membrane Science, 1995. 107(1): p. 1-21.

63. Fick, A., Ueber Diffusion. Vol. 170. 1855, Annalen der Physik, vol. 170, Issue 1, pp.59-86: Wiley.

64. Peyravi, M., A. Rahimpour, and M. Jahanshahi, Thin film composite membranes with modified polysulfone supports for organic solvent nanofiltration. Journal of Membrane Science, 2012. 423-424(Supplement C): p. 225-237. 
65. Escolastico, S., et al., Outstanding hydrogen permeation through CO2stable dual phase ceramic membranes. Vol. 2. 2014. 3736.

66. Escolastico, S., et al., Enhanced H-2 Separation through Mixed ProtonElectron Conducting Membranes Based on La5.5W0.8M0.2011.25. Vol. 6. 2013.

67. Ladewig, B. and M.N.Z. Al-Shaeli, Fundamentals of Membrane Processes, in Fundamentals of Membrane Bioreactors: Materials, Systems and Membrane Fouling. 2017, Springer Singapore: Singapore. p. 13-37.

68. Weitkamp, J., Zeolites and catalysis. Solid State Ionics, 2000. 131(1): p. 175-188.

69. Michalkiewicz, B. and Z.C. Koren, Zeolite membranes for hydrogen production from natural gas: state of the art. Journal of Porous Materials, 2015. 22(3): p. 635-646.

70. Kosinov, N., et al., Recent developments in zeolite membranes for gas separation. Journal of Membrane Science, 2016. 499(Supplement C): p. 6579.

71. Benfer, S., P. Árki, and G. Tomandl, Ceramic Membranes for Filtration Applications - Preparation and Characterization. Advanced Engineering Materials, 2004. 6(7): p. 495-500.

72. Athayde, D.D., et al., Review of perovskite ceramic synthesis and membrane preparation methods. Ceramics International, 2016. 42(6): $p$. 6555-6571.

73. Moghimifar, V., A. Raisi, and A. Aroujalian, Surface modification of polyethersulfone ultrafiltration membranes by corona plasma-assisted coating TiO2 nanoparticles. Journal of Membrane Science, 2014. 461(Supplement C): p. 69-80.

74. Liang, S., et al., A novel ZnO nanoparticle blended polyvinylidene fluoride membrane for anti-irreversible fouling. Journal of Membrane Science, 2012. 394-395(Supplement C): p. 184-192.

75. Lin, Y.S., Microporous and dense inorganic membranes: current status and prospective. Separation and Purification Technology, 2001. 25(1): p. 39-55.

76. Wiheeb, A.D., et al., Identification of Molecular Transport Mechanisms in Micro-Porous Hydrotalcite-Silica Membrane. Transport in Porous Media, 2014. 104(1): p. 133-144.

77. Levy, R.A., et al., Microporous SiO2/Vycor membranes for gas separation. Journal of Materials Research, 1996. 11(12): p. 3164-3173.

78. Reinecke, S.A. and B.E. Sleep, Knudsen diffusion, gas permeability, and water content in an unconsolidated porous medium. Water Resources Research, 2002. 38(12): p. 16-1-16-15.

79. Do, D.D., Adsorption Analysis: Equilibria and Kinetics. 1998: Imperial College Press. 
80. Deyhim, S., Deriving Gas Transport Properties of Microporous Silica Membranes from First Principles and Simulating Separation of MultiComponent Systems in Different Flow Configurations, in Chemical \& Biological Engineering. 2014, University of Ottawa.

81. Phair, J.W. and S.P.S. Badwal, Materials for separation membranes in hydrogen and oxygen production and future power generation. Science and Technology of Advanced Materials, 2006. 7(8): p. 792-805.

82. Imbault, A., et al., Ultrathin Gas Permeable Oxide Membranes for Chemical Sensing: Nanoporous Ta(2)O(5) Test Study. Materials, 2015. 8(10): p. 66776684.

83. Yun, S. and S. Ted Oyama, Correlations in palladium membranes for hydrogen separation: A review. Journal of Membrane Science, 2011. 375(1): p. 28-45.

84. Steward, S.A., Review of Hydrogen Isotope Permeability Through Materials. 1983, ; Lawrence Livermore National Lab. (LLNL), Livermore, CA (United States). p. Medium: ED; Size: 28 p.

85. Uemiya, S., Brief Review of Steam Reforming Using a Metal Membrane Reactor. Topics in Catalysis, 2004. 29(1): p. 79-84.

86. Brodowsky, H., The Palladium Hydrogen System. Von F. A. Lewis, Academic Press, London-New York 1967. 1. Aufl., XII, 178 S., zahlr. Abb., geb. 45 s. Angewandte Chemie, 1968. 80(12): p. 498-498.

87. Rogers, H.C., Hydrogen Embrittlement of Metals. Science, 1968. 159(3819): p. 1057-1064.

88. Tovbin, Y. and E. Votyakov, Evaluation of the influence of dissolved hydrogen on mechanical properties of palladium. Vol. 42. 2000. 1192-1195.

89. Yoshida, H., et al., Metallurgical Considerations on Pd, Pd-Alloy and Their Metal-Hydrogen Systems. Fusion Technology, 1985. 8(2P2): p. 2388-2394.

90. Cabrera, A., E. Morales, and J. N. Armor, Kinetics of hydrogen desorption from palladium and ruthenium-palladium foils. Vol. 10. 1995. 779-785.

91. Sakamoto, Y., et al., Absorption of hydrogen by palladium-nickel-rhodium ternary alloys. Journal of Alloys and Compounds, 1995. 217(2): p. 226-234.

92. Sakamoto, Y., et al., The $(\alpha+\beta)$ hydrogen miscibility gaps in hydrogenated palladium-rich $P d-Y(G d)-A g$ ternary alloys. Journal of the Less Common Metals, 1990. 166(1): p. 45-56.

93. Gryaznov, V., Metal containing membranes for the production of ultrapure hydrogen and the recovery of hydrogen isotopes. Separation and Purification Methods, 2000. 29(2): p. 171-187.

94. Tanaka, K., et al., Permeability and permselectivity of gases in fluorinated and non-fluorinated polyimides. Polymer, 1992. 33(3): p. 585-592. 
95. White, R.P. and J.E.G. Lipson, Polymer Free Volume and Its Connection to the Glass Transition. Macromolecules, 2016. 49(11): p. 3987-4007.

96. Van Krevelen, D.W.T.N., K. , Properties of Polymers (Fourth Edition). Elsevier B.V. 2009.

97. Boyer, R.F., Physical properties of molecular crystals, liquids and glasses. Arnold, Bondi, Wiley, New York, 1968, 502 pp. \$18.50. Journal of Polymer Science Part A-1: Polymer Chemistry, 1969. 7(8): p. 2466-2466.

98. Aitken, C.L., W.J. Koros, and D.R. Paul, Effect of structural symmetry on gas transport properties of polysulfones. Macromolecules, 1992. 25(13): $p$. 3424-3434.

99. McHattie, J.S.K., W. J.; Paul, D. R., Polymer, 1991. 32: p. 840.

100. Robeson, L.M., Correlation of separation factor versus permeability for polymeric membranes. Journal of Membrane Science, 1991. 62(2): p. 165185.

101. Robeson, L.M., The upper bound revisited. Journal of Membrane Science, 2008. 320(1): p. 390-400.

102. Baker, R.W. and B.T. Low, Gas Separation Membrane Materials: A Perspective. Macromolecules, 2014. 47(20): p. 6999-7013.

103. Freeman, B.D., Basis of Permeability/Selectivity Tradeoff Relations in Polymeric Gas Separation Membranes. Macromolecules, 1999. 32(2): p. 375-380. 

Chapter 4

Methodology 



\section{Methodology}

\subsection{Material Synthesis}

In this thesis, different membranes for different gas separation processes were selected. In some cases, the permeation tests were carried out in collaboration with an international company. Thus, membranes were provided by the company. On the other hand, some others were manufactured, either by the ITQ or in collaboration with other group.

\subsubsection{Polymer materials}

Regarding polymeric membranes, three different polyimides were used for their production. But, only one of them was manufactured (6FDA-6FpDA), the other two were commercially available (Matrimid ${ }^{\circledR}$ and $\mathrm{P} 84^{\circledR}$ ). All these polymers possess high thermal stability, chemical resistance and mechanical properties suitable for gas separation processes. Figure 4.1 shows the glass transition temperatures $\left(T_{g}\right)$ and the molecular weight $\left(\mathrm{M}_{\mathrm{w}}\right)$ of the three polyimides, as well as their chemical structures.

Monomers for polyimide synthesis are 4,4'-(hexafluoroisopropylidene) diphthalic anhydride (6FDA) and 2,2-bis(4-aminophenyl) hexafluoropropane (6FpDA) which were purchased from Sigma-Aldrich. Polyimides $\mathrm{P} 84^{\circledR}$ and Matrimid ${ }^{\circledR}$ 5218 were purchased from HP Polymer GmbH (Austria) and Huntsman (USA), respectively. Reactants and solvents, such as chlorotrimethylsilane (CTMS), pyridine (Py), acetic anhydride $\left(\mathrm{Ac}_{2} \mathrm{O}\right), \mathrm{N}, \mathrm{N}$-dimethylaminopyridine (DMAP), oxylene, anhydrous N-methyl-2-pyrrolidone (NMP), tetrahydrofuran (THF), dimethyl sulfoxide (DMSO), dimethylformamide (DMF) and dimethyl acetamide (DMAc) of reagent grade quality were all purchased from Sigma-Aldrich and were used without further purification.

The 6FDA-6FpDA polyimide was synthesized following the classical in-situ silylation two steps method [1, 2]. A three-necked flask, equipped with a mechanical stirrer and gas inlet and outlet, was charged with $5.0 \mathrm{mmol}$ of the diamine 6FpDA and $5.0 \mathrm{~mL}$ of solvent (NMP). The solution was stirred at room temperature under argon atmosphere until the solid was completely dissolved. Then, the solution was cooled, by the use of an ice bath, to $0^{\circ} \mathrm{C}$, and the required amount of CTMS and Py 
( $1 \mathrm{~mol} / \mathrm{mol}$ reactive group) and small amounts of DMAP $(0.1 \mathrm{~mol} / \mathrm{mol} \mathrm{Py})$ were added to the mixture. At that moment, the temperature was raised up to room temperature to ensure the formation of the silylated diamine. After this, the corresponding dianhydride 6 FDA $(5.0 \mathrm{mmol})$ and additional solvent were added. The reaction mixture was left overnight to ensure the formation of the corresponding poly(amic acid) in the solution. The viscosity of the solution significantly increased during this period. Afterwards, the reaction was completed by chemical imidization. For this purpose, an excess of acetic anhydride $(20.0 \mathrm{mmol})$ and Py $(10.0 \mathrm{mmol})$ was added to the poly (amic acid) solutions; the obtained mixture was heated to $60^{\circ} \mathrm{C}$ and stirred vigorously for $8 \mathrm{~h}$. Afterwards, the mixture was precipitated in distilled water and repeatedly washed in a water/ethanol mixture. The polymer was dried under vacuum at $120^{\circ} \mathrm{C}$ for $24 \mathrm{~h}$.

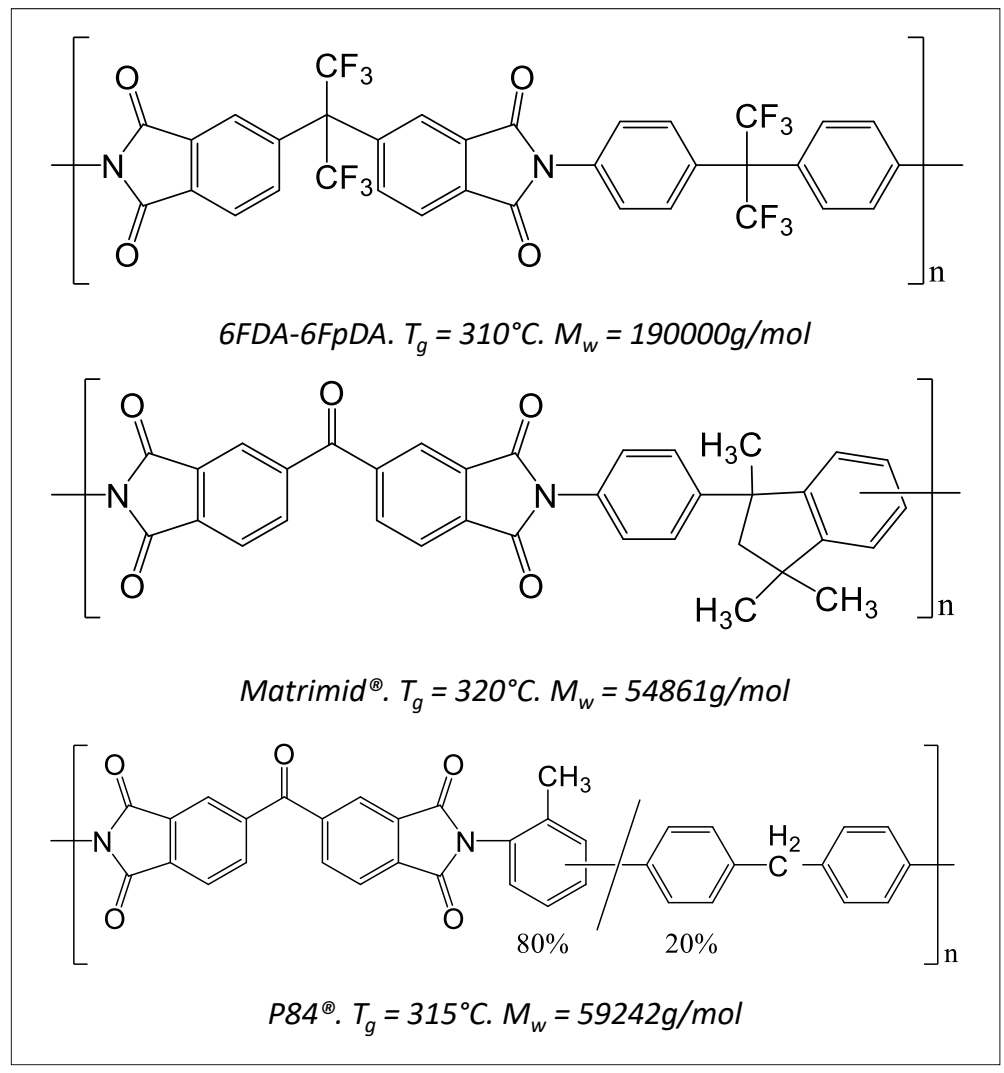

Figure 4.1. Structures and properties of the polyimides used in this thesis 


\subsubsection{Co-precipitation}

Co-precipitation method offers as a main advantage the possibility to synthesis nanometric size powders. In this thesis, this method has been used to synthesis $\mathrm{La}_{2} \mathrm{O}_{3}$ for the MMMs. In the co-precipitation route, stoichiometric amount of soluble salts of the metals ions is dissolved and then is precipitated as hydroxide, citrates, oxalates or formates [3]. A solution of lanthanum nitrate (Sigma Aldrich) was prepared in deionized water at $60{ }^{\circ} \mathrm{C}$. Once is dissolved, a $\left(\mathrm{NH}_{4}\right)_{2} \mathrm{CO}_{3}$ solution was added to the nitrate solution to get total precipitation and the final $\mathrm{NO}_{3}{ }^{-1} / \mathrm{CO}_{3}{ }^{-2}$ molar ratio is 0.75 . Then, the resultant precursor powder is dried at $100-150{ }^{\circ} \mathrm{C}$ after filtration and rinsing with water (Figure 4.2).

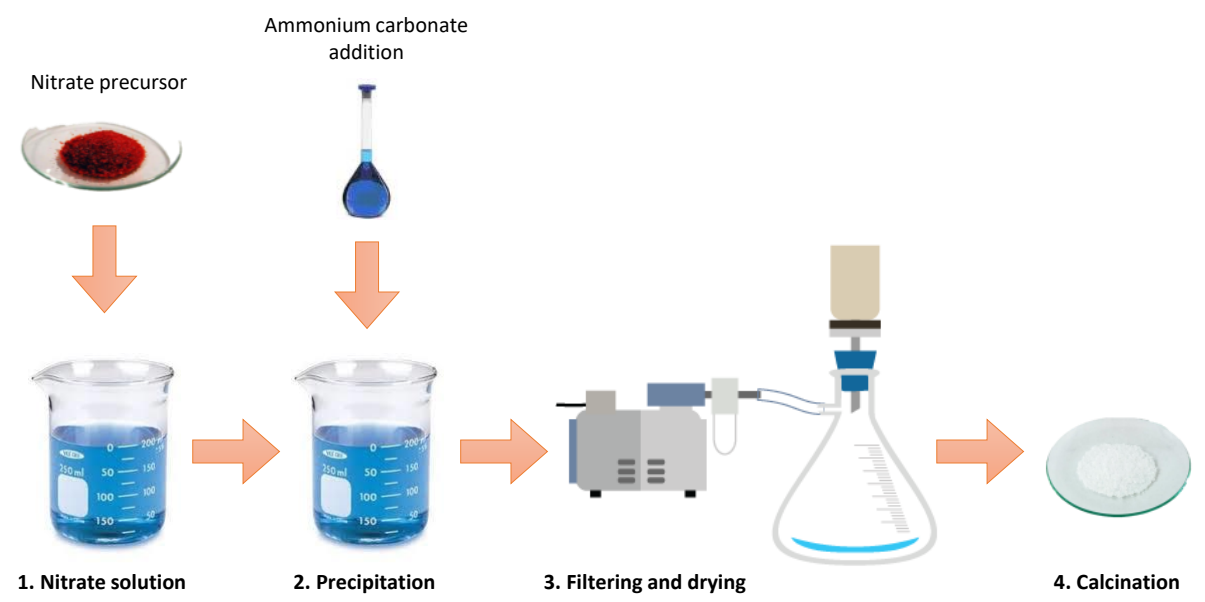

Figure 4.2. Co-precipitation route for pure solid oxide phase formation

\subsubsection{Catalyst}

\subsubsection{Fischer-Tropsch reaction}

A hybrid catalyst was used for Fischer-Tropsch reaction. It consists of two components: (i) one of the components corresponds to a catalyst for the FischerTropsch synthesis and (ii) the second component is a commercial zeolite.

Firstly, Fischer-Tropsch synthesis catalyst was prepared. A commercial $\gamma-\mathrm{Al}_{2} \mathrm{O}_{3}$ from Puralox TH 100/150 (Sasol) was used as support. For the incorporation of the metallic phases of $\mathrm{Co}$ and $\mathrm{Ru}$, the method of preparation used was incipient wetness 
impregnation with an aqueous solution containing the required precursors $\mathrm{Co}\left(\mathrm{NO}_{3}\right)_{2} \cdot 6 \mathrm{H} 2 \mathrm{O}$ and $\mathrm{HN}_{4} \mathrm{O}_{10} \mathrm{Ru}$ (Aldrich, $1.5 \% \mathrm{Ru}$ solution), with the adequate quantities so that in the calcined catalyst, the percentages and weight of $\mathrm{Co}$ and $\mathrm{Ru}$ were $20 \%$ and $0.5 \%$, respectively. The impregnations were performed in two stages, with an intermediate drying stage at $60{ }^{\circ} \mathrm{C}$ in an oven. After the second impregnation, the solids were dried in an oven at $100 \stackrel{\circ}{\circ}$ for $12 \mathrm{~h}$, and finally calcined in air flow at $300{ }^{\circ} \mathrm{C}$ for $3 \mathrm{~h}$ in a muffle, using a heating ramp of $1 \stackrel{\circ}{\circ} \mathrm{C} / \mathrm{min}$. This catalyst is named as CoBase in this thesis.

Secondly, the zeolite used in this thesis corresponds to a commercial Beta Zeolite (Zeolyst, CP814E) with a Si/Al molar ratio of 12.5 , which were originally in ammonium form. In order to obtain the protonic form, it was submitted to a calcination in air flow $(G S H V=150 \mathrm{ml} / \mathrm{g} \cdot \mathrm{min})$ at $500 \stackrel{\circ}{\circ}$ for $3 \mathrm{~h}$ in a muffle. This catalyst is named as Beta in this thesis.

The hybrid catalyst was obtained by physically mixing $0.35 \mathrm{~g}$ of each component, both previously pressed, crushed, and sieved to a particle size of 0.25 $0.42 \mathrm{~mm}[4]$.

\subsubsection{Methanation reaction}

$\mathrm{Ni}$-Todorokite catalyst was synthesized according to the procedure described by Onda et al. [5]. Synthesis of Ni-todorokite is composed by two solutions: (A) consisted of $\mathrm{Ni}\left(\mathrm{NO}_{3}\right)_{2} \cdot 6 \mathrm{H}_{2} \mathrm{O}(1.87 \mathrm{~g}, 6.43 \mathrm{mmol})$ and $\mathrm{MnCl}_{2} \cdot 4 \mathrm{H}_{2} \mathrm{O}(6.37 \mathrm{~g}, 32.2$ $\mathrm{mmol}$ ) in $100 \mathrm{ml}$ of distilled deionized water and (B) consisted of $\mathrm{KMnO}_{4}(2.02 \mathrm{~g}$, $12.8 \mathrm{mmol}$ ) and $\mathrm{NaOH}$ ( $36 \mathrm{~g}, 0.90 \mathrm{~mol}$ ) in $100 \mathrm{ml}$ of distilled deionized water. Solution A was added dropwise over a period of $10 \mathrm{~min}$ (rate $10 \mathrm{ml} / \mathrm{min}$ ) with vigorous stirring at room temperature into solution B. After the solutions were perfectly mixed, they were stirred for a total of $30 \mathrm{~min}$, and the final suspension was left aging at room temperature for $24 \mathrm{~h}$. Afterwards, it was filtered and washed with distilled deionized water until the $\mathrm{pH}$ was 7 . As a results, a shiny sample was obtained, which was a layered birnessite material, referred to as $\mathrm{Na}$-(Ni)-birnessite. Most cations at the cation sites in interlayers are sodium ions.

Furthermore, the $\mathrm{Na}$-(Ni)-birnessite was ion-exchanged with $200 \mathrm{ml}$ of a 0.1 $\mathrm{mol} \cdot \mathrm{l}^{-1} \mathrm{Ni}\left(\mathrm{NO}_{3}\right)_{2}$ aqueous solution at room temperature for another $24 \mathrm{~h}$ more. The reason is because the ion-exchange expanded the interlayer distance. Once more, the emergent layered sample was washed and filtered ten times with $200 \mathrm{ml}$ of 
distilled deionized water and is referred to as $\mathrm{Ni}$-buserite. Finally, it was treated under hydrothermal conditions ( $433 \mathrm{~K}$ for $48 \mathrm{~h}$ in an autoclave lined with Teflon) and the resultant solid was washed and filtered with distilled deionized water, and dried at $333 \mathrm{~K}$ to yield Ni-todorokite.

\subsubsection{3. $\quad$ Catalyst manufacturing process}

Both, F-T catalyst and Methanation catalyst, were obtained like fine powder after the calcination step. Hence, it was necessary to shape it in granules between 0.25 to $0.42 \mathrm{~mm}$ for catalytic evaluation. The procedure used in the shaped of the catalyst particles consisted of the formation of a disk in a die applying a pressure of $30 \mathrm{kN}$ for 1 minute with a hydraulic press. Then, the disk was crushed in a mortar and the granules obtained were sieved, repeating this step as many times as it was needed.

\subsection{Membrane manufacture}

\subsubsection{Polymer membranes}

\subsubsection{Support material}

Regarding membrane manufacture, for polymer membrane, three different supports were selected in order to obtain appropriate membranes for gas separation techniques, all of them shown in Figure 4.3. Whatman ${ }^{\circledR}$ Anodisc inorganic filter, a) and b), was purchased from Sigma-Aldrich, with a diameter of $25 \mathrm{~mm}$ and pore size of $0.02 \mu \mathrm{m}$ [6]. Anodisc was used as support material because of its high purity alumina matrix that combines good thermal stability, solvent compatibility and very regular porous structure. It is bonded to a polypropylene ring at the outer circumference for ease of handling and coating. 


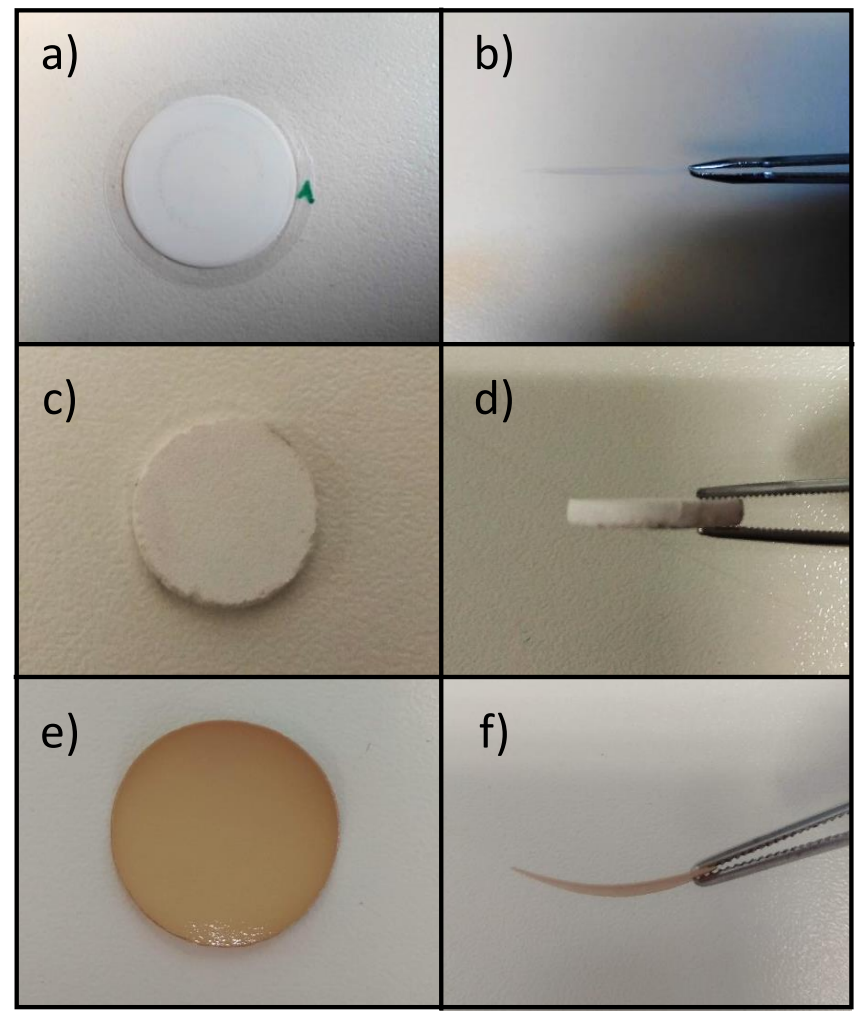

Figure 4.3. Whatman ${ }^{\circledR}$ Anodisc inorganic filter, a) front face and b) side face, Atech ceramic membranes, c) front face and d) side face and polymer support, e) front face and f) side face

In addition, ceramic discs from the company Atech, c) and d), were used in order to ensure a better mechanical stability. Both, Anodisc inorganic filter and ceramic disc from Atech, are ceramic based support. Nevertheless, the main difference between them is the thickness and their structure. While Anodisc are symmetric alumina filters. Atech ceramic disc are asymmetric membranes consist on a pure support of $\mathrm{Al}_{2} \mathrm{O}_{3}$, a microfiltration membrane of $\mathrm{Al}_{2} \mathrm{O}_{3}$ and a final ultrafiltration membrane of $\mathrm{ZrO}_{2}$. The diameter of the Atech ceramic disc is around $15 \mathrm{~mm}$ and the pore size of the UF $\mathrm{ZrO}_{2}$ layer is approximately $0.03 \mu \mathrm{m}$ [7].

Polymer were also used as supports, polymer membranes were processed as thin film composite membranes (TFCMs), where the supporting structures of the selective layer should exhibit high thermal and chemical stability, while possessing high permeable values at the same time. It was used an asymmetric support of nonwoven polyphenylene sulfide (PPS) and polybenzimidazole (PBI), which is used for the thin film composite membrane production. 
The non-woven PPS was purchased from Hirose Paper Mfg Co, Ltd. (Hei, Japan) [8]. It has an excellent thermal and chemical resistance and is characterized by high porosity. The PPS support has a thickness of $60 \mu \mathrm{m}$. The casting solution is deposited to the flattened (calendered) side of the PPS support. The PBI, a Poly[2,2'(m-phenylene)-5,5'-bibenimidazole], was purchased from $\mathrm{PBI}^{\circledR}$ Performance Products, Inc. (Charlotte, USA) in solution [9]. The solution (S26) has a content of 26 wt. \% PBI, 1.5 wt. \% $\mathrm{LiCl}$ and Dimethyl acetamide as a solvent. This support possesses good chemical and mechanical stability properties, as well as high thermal resistance up to $300{ }^{\circ} \mathrm{C}$. Structure of both polymers can be seen in Figure 4.4. Additionally, a porosity modifier was used: polyethylene glycol (PEG) was obtained from Sigma-Aldrich with an average molecular weight with 2000. Furthermore, Teflon AF 2400, an amorphous PDD-PTFE copolymer containing 87 mol\% 2,2-bistrifuoromethyl-4,5-difluoro-1,3-dioxole and 13 mol\% tetrafluarethylene, was used as protective layer. Teflon AF 2400 was purchased by Dupont (Wilmington, USA), and it has a density of $1.744 \mathrm{~g} / \mathrm{cm} 3$ at $25^{\circ} \mathrm{C}$ and a glass transition temperature of $240^{\circ} \mathrm{C}$. Teflon AF 2400 begins to decompose above $360^{\circ} \mathrm{C}$.

The porous support for the TFCMs was prepared on the non-woven PPS support on a lab scale membrane casting machine. First, the S26 PBI solution was diluted with dimethyl acetamide until it was obtained a PBI concentration of 18 wt. $\%$. Afterwards, 6 wt. \% PEG 2000 was added to the solution as porosity modifier. On the lab scale casting machine, PBI solution was casted on the calendered side of the non-woven PPS, in order to achieve a porous PBI support. As a non-solvent, water was used. Characteristics of the lab scale casting machine were the following: doctor blade had a gap of $200 \mu \mathrm{m}$, water bath temperature was $20^{\circ} \mathrm{C}$, speed of the membrane casting was $10 \mathrm{~mm} / \mathrm{sec}$ and the air gap between casting knife and immersing in water was set to $12.5 \mathrm{~mm}$. After casting, the porous support was washed in boiling water for $24 \mathrm{~h}$ to remove the PEG and $\mathrm{LiCl}$. Then, it was dried at $60^{\circ} \mathrm{C}$ and samples for the preparation of the different TFCM were cutted out. 


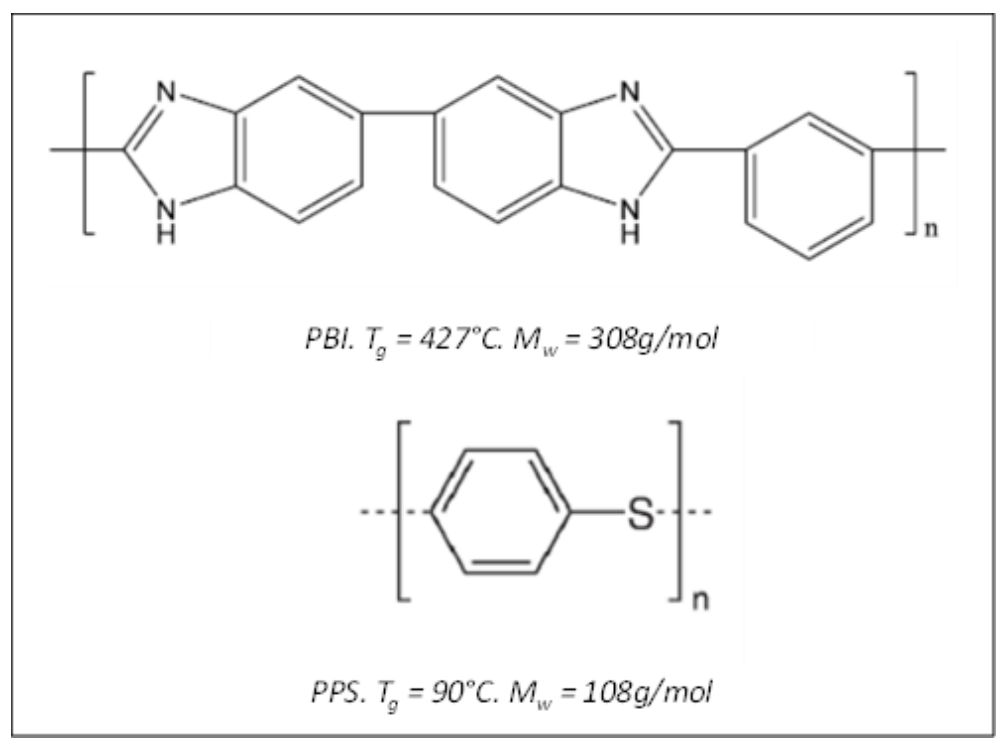

Figure 4.4. Polymers support structure

\subsubsection{2. $\quad$ Coating process}

In order to dip-coating the different polymers on top of the ceramic support, various polymer solutions were prepared using THF as a solvent for Matrimid ${ }^{\circledR}$ and 6FDA-6FpDA polymers, and NMP in the case of $\mathrm{P} 84^{\circledR}$. Several concentrations were prepared (0.5 - 1 - 2.5 - 3 - 4 - 5 - 7.5 - 8 and $10 \mathrm{wt}$ \%) in order to detect the optimal concentration for each polymer.

1. Anodisc and ceramics supports were placed on top of a glass plate and fixed with Kapton adhesive tape. In this way, only one side of the supports were in direct contact with the polymer solution. Afterwards, the supports were dipcoated in the polymer solution at $250 \mathrm{~mm} / \mathrm{min}$ speed, perpendicular orientation to the solution (Figure 4.5) and with no down time waiting. With regard to TFCMs, membranes were not placed on top of a glass plate with Kapton adhesive tape, neither with a fixed speed. This kind of membranes were coated manually and with no protection on the bottom part of the membranes. Temperature and relative humidity were controlled and kept constant in order to avoid defects during the coating, such as pin-holes or non-continuous layer formation. 


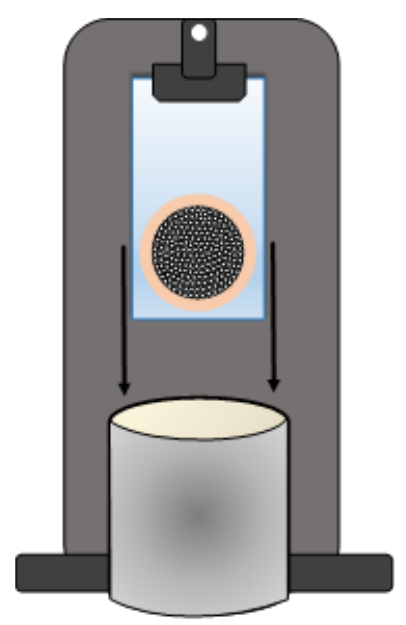

Figure 4.5. Schematics of the dip coating configuration and process for composite ceramicpolymer membranes

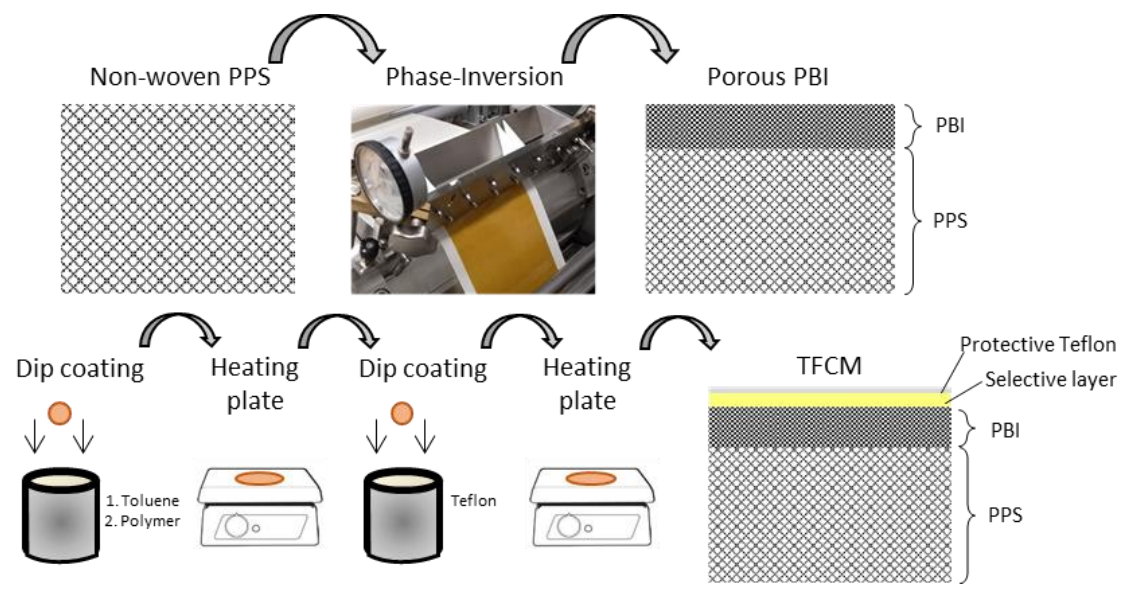

Figure 4.6. Schematics of the dip coating configuration and process for composite polymer-polymer membranes 
2. Regarding TFCMs, samples of the porous support (PPS, PBI) were dip coating in toluene to fill the pores of the PBI support. Polymer solutions were prepared using THF as a solvent for Matrimid ${ }^{\circledR}$ and 6FDA-6FpDA polymers, and DMF in the case of $P 84^{\circledR}$. The solvent selection depend on the compatibility with PPS and PBI. In the case of ceramic support, NMP was used as solvent for P84 ${ }^{\circledR}$, but this solvent was not able to be used in the case of polymer support since it is not compatible with PPS and PBI. After drying the samples for 20 seconds at room temperature, they were dip coating in solutions of $3.5 \mathrm{wt}$. \% or the three polymers. Afterwards the samples were dried on a heating plate for $5 \mathrm{~min}$ at 50 ${ }^{\circ} \mathrm{C}$, in the case of $6 \mathrm{FDA}-6 \mathrm{FpDA}$ and Matrimid ${ }^{\circledR}$, and $90{ }^{\circ} \mathrm{C}$ in the case of $\mathrm{P} 84^{\circledR}$. The reason to maintain this low temperature is to prevent the formation of defects, such as pin-holes, while the solvent is being evaporated. Then, membranes were dip coating in a solution of 1 wt. \% Teflon AF 2400 in FC770 to get a protective layer out of Teflon AF 2400, see Figure 4.6.

Finally, all the different membranes were treated under vacuum at high temperature (between $200{ }^{\circ} \mathrm{C}$ and $300 \stackrel{\circ}{\circ}$ ) for 2 hours. The high temperature was selected in order to ensure that all the solvent used during the dip-coating process is completely evaporated and as well to accelerate the initial aging process in the polymer, which leads to experimental results reproducible both in time (samples can be measured at different times after membrane preparation) and for different samples.

\subsubsection{Inorganic fillers for Mixed Matrix Membranes (MMMs)}

Six inorganic fillers were employed: 8mol\% Yttria Stabilized Zirconia (8YSZ), $\mathrm{La}_{2} \mathrm{O}_{3}, \mathrm{La}_{5.4} \mathrm{WO}_{12}$ (LaWO), $\mathrm{BaCe}_{0.2} \mathrm{Zr}_{0.7} \mathrm{Y}_{0.1} \mathrm{O}_{3}$ (BCZY) and two zeolites (ITQ-2 and Beta). 8YSZ powder was provided by Tosoh Corporation (Japan). $\mathrm{La}_{2} \mathrm{O}_{3}$ was synthesized by co-precipitation from lanthanum nitrate $\left(\mathrm{La}\left(\mathrm{NO}_{3}\right)_{3}\right)$ and subsequent calcination at $800{ }^{\circ} \mathrm{C}$ for $5 \mathrm{~h}$. LaWO, provided by CerPoTech (Norway) in powder form was calcined at $800^{\circ} \mathrm{C}$ for $6 \mathrm{~h}$. BCZY powder, also provided by CerPoTech, was calcined at $950^{\circ} \mathrm{C}$ for $6 \mathrm{~h}$. Nanocrystalline Beta zeolite (BEA material) and ITQ2 (delaminated MCM-22 zeolite material) [10] were synthesized by the ITQ and are here used after calcination (organics removal) in its acidic form. All the fillers were ball-milled previously for 24 hours. Table 4.1 shows a summary of the fillers properties. 
Table 4.1. Properties of the used particles. 8YSZ [11], $\mathrm{La}_{2} \mathrm{O}_{3}$ [12], LaWO [13], BCZY [14, 15], ITQ-2 [10] and Beta [16]

\begin{tabular}{|c|c|c|c|c|c|c|}
\hline PARTICLES & 8YSZ & $\mathrm{La2O} 3$ & Lawo & $B C Z Y$ & ITQ-2 & Beta \\
\hline Description & $\begin{array}{l}8 \% \text { mol of } \mathrm{Y}_{2} \mathrm{O}_{3} \\
\text { stabilized } \mathrm{rrO}_{2} \\
\text { (Tosoh) }\end{array}$ & $\begin{array}{l}\text { Co-precipitation from } \\
\text { La( }\left(\mathrm{NO}_{3}\right)_{3} \text {. } \\
\text { Calcined } \\
800^{\circ} \mathrm{C} / 5 \mathrm{~h}\end{array}$ & $\begin{array}{c}\mathrm{La}_{5,4} \mathrm{WO}_{12} \\
\text { (CerPoTech). } \\
\text { Calcined } 950^{\circ} \mathrm{C} / 6 \mathrm{~h}\end{array}$ & $\begin{array}{c}\mathrm{BaCe}_{0.2} \mathrm{Zr}_{0.7} \mathrm{Y}_{0.1} \mathrm{O}_{3} \\
\text { (CerPoTech). } \\
\text { Calcined } \\
950^{\circ} \mathrm{C} / 6 \mathrm{~h}\end{array}$ & $\begin{array}{l}\text { ITQ-2 zeolite. } \\
\qquad \mathrm{Si} / \mathrm{Al}=50\end{array}$ & $\begin{array}{c}\text { Zeolite } \\
\text { nanocrystalline. } \\
\text { Si/Al }=12.5\end{array}$ \\
\hline \multicolumn{7}{|l|}{ Structure } \\
\hline Density $\left(\mathrm{g} / \mathrm{cm}^{3}\right)$ & 5.95 & 6.56 & 6.58 & 6.14 & - & - \\
\hline BET area $\left(\mathrm{m}^{2} / \mathrm{g}\right)$ & 6.0 & 2.9 & 9.4 & 31.4 & $>700$ & $>700$ \\
\hline Size $(\mathrm{nm})$ & $20-80$ & $60-100$ & $30-120$ & $30-100$ & $\begin{array}{l}\text { Thin sheets (2.5 } \\
\text { thick) }\end{array}$ & $10-30$ \\
\hline Uses & $\begin{array}{l}\text { Solid electrolyte } \\
\text { in solid oxide fuel } \\
\text { cells (SOFC) }\end{array}$ & $\begin{array}{l}\text { Ferroelectric materials } \\
\text { and as feedstock for } \\
\text { catalysts }\end{array}$ & $\begin{array}{c}\text { Asymmetric } \\
\text { membranes for } \\
\text { hydrogen separation }\end{array}$ & $\begin{array}{l}\text { Electrolyte } \\
\text { material for } \\
\text { proton-conducting } \\
\text { fuel cells (PCFC) }\end{array}$ & Catalysis & Catalysis \\
\hline
\end{tabular}

In terms of inorganic fillers dispersion, different solvents such as THF, NMP, DMF, DMAc, toluene, chloroform, and isopropanol were tested. The ultrasonic devices used to disperse the fillers were the digital Sonifier ${ }^{\circledR}$, models $250 \& 450$ (BRANSON Ultrasonics Corporation). The dispersion was carried out with the pulse/pause mode, in particular, pulse off for one second and pulse on for one second for a total duration of 30 minutes. In addition, the dissolution container was inside an ice bath to avoid the sample heating during the dispersion process. In all the cases, the best dispersions and the most visually stable over time (smallest degree of sedimentation) were obtained by using NMP. The zeolites were fully suspended whereas in the dispersions obtained with $8 \mathrm{YSZ}, \mathrm{La}_{2} \mathrm{O}_{3}, \mathrm{LaWO}$ and $\mathrm{BCZY}$ some sedimentation with time was observed.

As conclusion, different types of polymeric membranes will appear in this thesis, see Figure 4.7. 


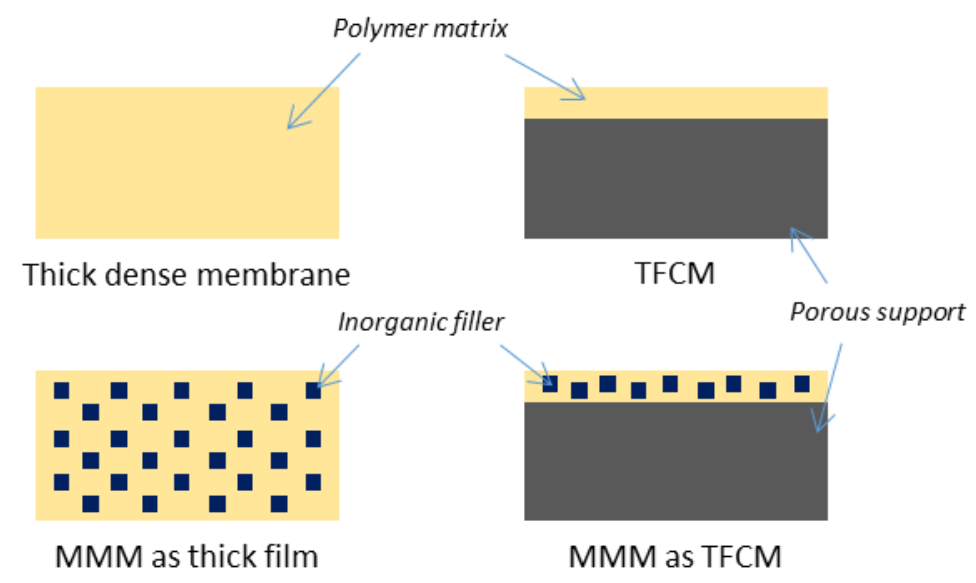

Figure 4.7. Schematic representation of the different polymeric membrane structures

\subsubsection{Palladium membranes}

Palladium membranes used during this thesis were commercially available by the company SAES [17]. SAES Company have patented a "Micro-Channel Palladium Hydrogen Gas Purification Systems", offering 2-3 times higher flow capacity compared to competitors models. In this thesis, it was not used the purifiers system, but the palladium membrane itself.

$\mathrm{Pd}$ membrane is $153 \mathrm{~mm}$ length, including the extremes which are made of steel, so the effective length is $137 \mathrm{~mm}$. External diameter is $2 \mathrm{~mm}$ and the internal diameter $1,9 \mathrm{~mm}$ (self-supported membrane). The membrane has only one of the two sides open, and it can be connected by $1 / 4$ VCR nuts type (see Figure 4.8 ).

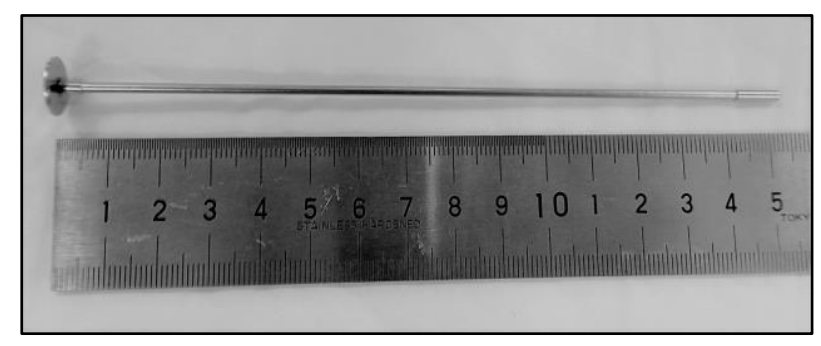

Figure 4.8. SAES Pd membrane 
In order to adapt the membranes to the reactor module, they were cut to a certain length and welded to a $1 / 8$ stainless steel tube. In this way, membranes are versatile to any required length of the catalytic bed.

\subsubsection{Sputtering coating}

The physical sputtering process involves the physical (not thermal) vaporization of atoms from a surface (target) by momentum transfer from bombarding energetic atomic sized particles. Normally, the energetic particles are ions of a gaseous material accelerated in an electric field [18]. Presently, the most extensively used sputtering configuration is the planar magnetron sputtering, which uses a magnetic field to constrain the motion of secondary electrons to near the target surface. Sputtering equipment used in this thesis was Pfeiffer Vacuum GmbH Sputtering CLASSIC 250. In Figure 4.9, it can be seen a scheme of sputtering deposition used during this thesis.

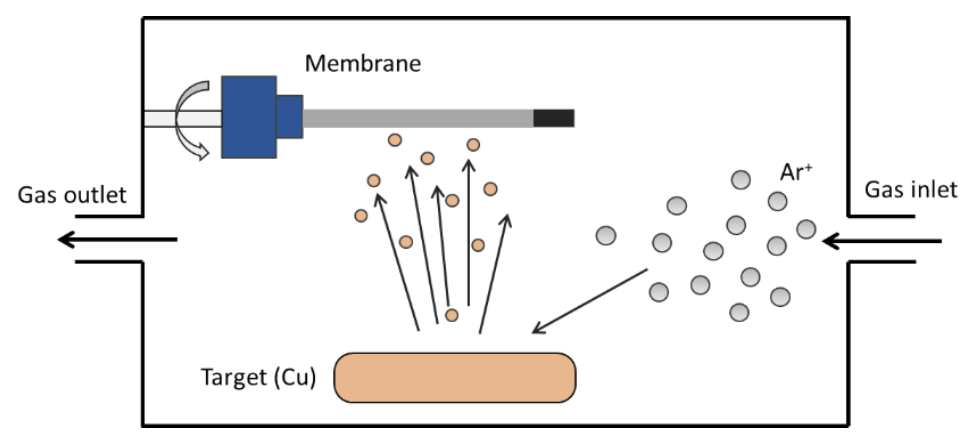

Figure 4.9. Scheme of sputtering deposition

\subsection{Characterization techniques}

\subsubsection{X-Ray diffraction (XRD)}

X-Ray diffraction (XRD) is a non-destructive technique which is used to provide information about crystallographic structure and orientation of crystalline materials, chemical composition and crystallite size. X-rays are transverse electromagnetic radiations, with shorter wavelength than visible light. They are produced via interactions of the high energy accelerated electrons with a heavy metal target (the anode) [19]. 
In order to obtain the information about the sample, several steps are resulted. Firstly, X-ray are generated when the electrons hit the anode, and subsequently they are radiated in all the possible directions. Secondly, as soon as a monochromatic Xray beam collide the sample material, it interacts with the material atoms, producing the diffraction of the X-rays to specific angles. Due to the fact that each crystalline material possess a special atomic structure, the diffraction of the $X$-rays are unique and acts as a fingerprint of the sample. Bragg equation relates the wavelength $(\lambda)$, the angle resulting from the electron beam and the sample material $(\theta)$ and the spacing between atoms, or intersegmental distance $(d)$ [20].

$$
\lambda=2 d \cdot \sin \theta
$$

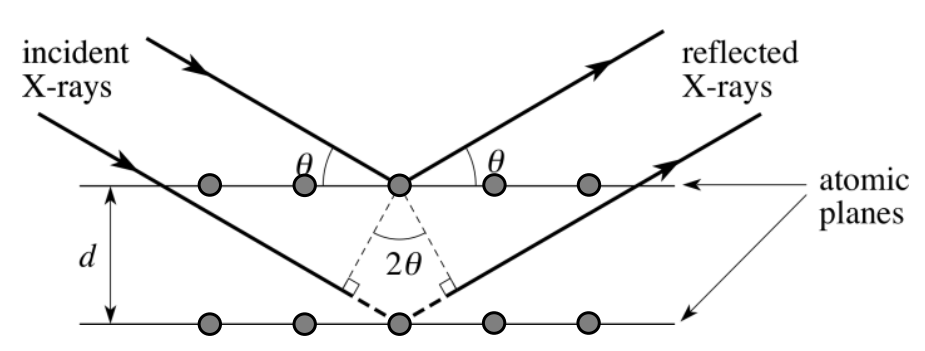

Figure 4.10. Schematic figure of Bragg's law, diffraction of X-rays on a crystalline material [21]

Once the X-rays are diffracted by the sample, the detector reports the intensity of them, giving a diffractogram. The diffractogram peaks are represented by the angles $(\theta)$, whereas the height is function of two parameters: (a) the X-ray interaction with the crystal and (b) the intensity of the source. Chemical composition can be determined by the angles and the intensities of the diffractogram, owing to every material has its unique diffraction pattern. In addition, information about unit cell size and lattice parameters can be obtained thanks to the position of the peaks, which are related to the atoms arrangement in the crystalline compound. Gathering all the information, X-ray diffraction data can be analyzed to acquire crystal structures.

Crystal structures are regular and repetitive, and its smallest volume element is the unit cell. Three axes describe the dimensions of the unit cell: $a, b, c$ and so the angles between them $\alpha, \beta, \gamma$. Different combinations of these parameters release fourteen kinds of cells covering all possible point lattices or all crystals, which were 
classified by August Bravais [22]. The fourteen kinds of lattice systems are summarized in Figure 4.11. XRD measurements in the present thesis were carried out in a PANalytical Cubix fast diffractometer by using CuKa1,2 radiation. XRD patterns were recorded in the $2 \theta$ range from 20 to $90^{\circ}$ and analyzed using the X'Pert HighScore Plus software.

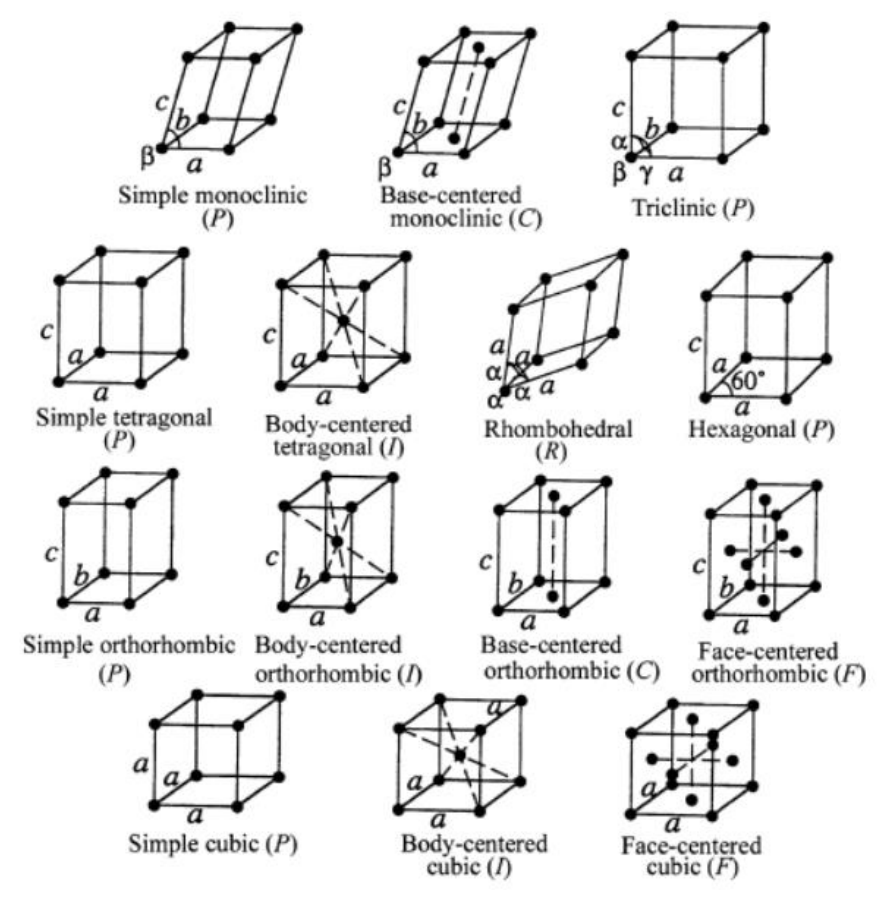

Figure 4.11. The fourteen Bravais lattices [22]

\subsubsection{Rheology}

Rheology describes the study of the matter flow and material deformation. When a force is applied to a volume of material, deformation occurs. If two plates with a specific area, separated by a fluid with a determined separation, are moved with a particular speed by a concrete force, relative to each other, Newton's law states that the shear stress (force divided by area parallel to the force) is proportional to the shear rate (speed of the plates divided by the fluid distance). The proportionality constant is known as the (dynamic) viscosity (n) [23]. 
Rheology applies to more complex substances such as polymers. Regarding polymer properties, rheology can relate those characteristics with the performance of the material. Viscosity is a rheological property that indicates the resistance to flow in fluids. The effective viscosity for the different polymer solutions was measured by using a Lovis $2000 \mathrm{M} / \mathrm{ME}$ Microviscometer (Anton Paar GmbH). This equipment measures the rolling time of a ball through transparent fluids according to Hoeppler's falling ball principle [24]. Measurement requires only $400 \mu \mathrm{L}$ sample volume and the

$$
\eta=\frac{\text { shear } \text { stress }}{\text { strain stress }}=\frac{\text { Force } / \text { Area }}{\text { Speed } / \text { distance }}(P a \cdot s)
$$

results are given as relative, kinematic or dynamic viscosity [25]. Different solution concentrations of the three different polymers were investigated in order to obtain a relation between solution concentration and solution viscosity. Accuracy of the equipment is $0.5 \%$ and $0.05^{\circ} \mathrm{C}$ for the temperature.

Once dynamic viscosity was obtained, different parameters can be deduced, such as: relative viscosity $\left(\eta_{\text {rel }}\right)$, specific viscosity $\left(\eta_{s p}\right)$, reduced viscosity $\left(\eta_{\text {red }}\right)$, inherent viscosity $\left(\eta_{i n h}\right)$, intrinsic viscosity $([\eta])$ and entanglement concentration, also called overlap concentration $\left(C^{*}\right)$. Acquisition of these properties is explained in Chapter 5 , as well as the information that can be extracted from them.

\subsubsection{Scanning Electron Microscopy (SEM)}

Scanning Electron Microscopy (SEM) is a type of electron microscope which generates high-resolution images of a sample by scanning the surface with a focused beam of high-energy electrons $(1.5-20 \mathrm{keV})$ generated by a heated tungsten filament. Figure 4.12 describes a schematic SEM column description. The electrons interact with the sample, producing several signals that can be collected by the detector obtaining different information about the sample. The primary beam penetrates the sample surface, and consequently, it scatters as a variety of signals. On one hand, if the scattered electrons come from the atoms at the top surface of the sample, they are known as secondary electrons (SE) and they are used to provide images which highlight topography and morphology of the sample. On the other hand, the electrons that are scattered from the deeper levels of the sample are named as back scattered electrons (BSE) and they are most commonly used for drawing contrasts in composition in multiphase samples [26]. 


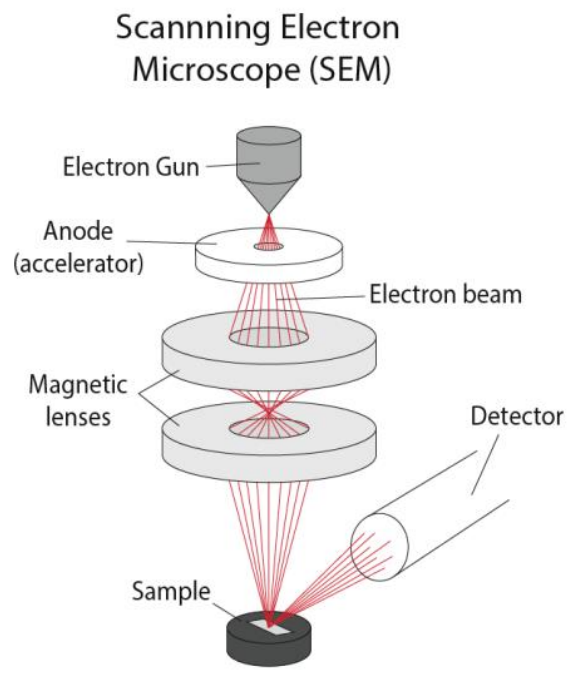

Figure 4.12. Schematic SEM column description [27]

In addition, energy dispersive $x$-ray spectroscopy (EDS) is a qualitative and quantitative chemical microanalysis technique to characterize the elemental composition of the sample. EDS is performed in conjunction with a SEM, but uses the X-rays that are emitted from the sample due to the electron beam. The combination of SEM with EDS allows the analysis of the sample composition. In order to allow the transport of the incident beam electrons and getting high quality images, samples need to be good conducting materials. Poor conductors or insulator materials require a conducting layer that do not modify the topography. This coating is made in vacuum with Au or graphite, using a sputter coater.

\subsubsection{Field emission scanning electron microscopy (FESEM)}

Field emission scanning electron microscopy (FESEM) is another electron microscopy, based on the same basics of SEM, but with a relevant difference: the emission source. As a consequence, FESEM produces clearer and less electrostatically distorted images with higher spatial resolution. SEM equipment used in this thesis was a JEOL JSM6300 electron microscope, and FESEM equipment was a ZEISS Ultra55. 


\subsubsection{2. $\quad$ Focused lon Beam (FIB)}

Focused lo Beam is another scientific instrument setup, based on the same basics of SEM, but again, with a significant difference: FIB setup uses a focused beam of ions to image the sample rather than a focused beam of electrons. FIB can directly modify or "mill" the sample surface, via the sputtering process, and this milling can be controlled with nanometer precision. As a result, it is possible to accomplish an extremely precise nano-machining in order to remove unwanted material or to obtain detailed components, by carefully controlling the energy and intensity of the ion beam. FIB can also be incorporated in a system with an electron beam column, favoring the use of both beams for the same sample [28].

\subsubsection{Thermal analysis methods}

Thermal analysis techniques are tools that allow the detection of any transformations occurring in a sample under a temperature variation in a controlled atmosphere. Among all the possible methods, only the ones that are employed in this thesis will be explained.

\subsubsection{Temperature-programmed reduction (TPR)}

Temperature programmed reduction (TPR) is a widely used technique for the characterization of solid materials. It is applied to find the most efficient reduction situation, and frequently is used in the field of heterogeneous catalysis. TPR technique works as follow: a reducible catalyst (or catalyst precursor) is exposed to a reducing gas mixture stream, typically a mixture of hydrogen (3\%-17\%) and an inert gas (argon or nitrogen), while the temperature is linearly increased. The rate of reduction is continuously acquired by measuring the composition of $\mathrm{H}_{2}$ content at the outlet of the reaction. Accordingly, once the experiment is done, it is possible to define the total amount of $\mathrm{H}_{2}$ consumed, and also to calculate the degree of reduction, the temperature at which the material is completely reduced and the oxidation state of the solid after reduction [29].

In this thesis, a 2910 Micromeritics system was used to perform the measurements. $100 \mathrm{mg}$ of sample was degassed under Ar flow for $1 \mathrm{~h}$ and then, it was subjected to reduction under $10 \%$ of $\mathrm{H}_{2}$ in Ar flow and heating rate of $10 \% \mathrm{C} / \mathrm{min}$ till $1000 \stackrel{\circ}{ } \mathrm{C}$. The $\mathrm{H}_{2}$ consumption was measured by a thermal conductivity detector (TCD). TCD measures the changes in the thermal conductivity of the gas stream. 
Afterwards, TCD signal is converted to concentration of active gas using a level calibration. In order to obtain the total $\mathrm{H}_{2}$ consumed, the area integration under the concentration vs. temperature is done.

\subsubsection{Thermogravimetric analysis (TGA)}

Thermogravimetric analysis (TGA) is an experimental technique which measures the mass change of a sample as function of increasing temperature, or as function of time and at constant temperature. Studying the mass variation, other parameters can be investigated, as decomposition, dehydration, oxidation/reduction reactions, reaction pathways, kinetics of reaction, among others. TGA device registers the mass changes experienced by the sample as a function of temperature/time. Together with TGA, another tool named differential thermal analysis (DTA) is combined. DTA identify exothermic or endothermic processes (comparing with inert reference material), giving extra information about the sample [30].

TGA measurements were carried out at Helmholtz Zentrum Geesthacht (HZG) during a research stage. Thermogravimetric analysis (TGA) was used to evaluate the thermal stability of the polymers. Disc-shaped samples, cut from cast films, with weights between 5 and $15 \mathrm{mg}$ were tested. TGA experiments were performed on a Thermal Analysis NETZSCH TG209 F1 Iris instrument. The experiments were accomplished (i) under a flow of $20 \mathrm{~mL} / \mathrm{min}$ of Argon in the temperature range from 25 to $800{ }^{\circ} \mathrm{C}$ with a heating rate of $5 \mathrm{~K} / \mathrm{min}$ (dynamic scan) and, once $800{ }^{\circ} \mathrm{C}$ were reached (ii) the temperature was maintained for 30 minutes under synthetic air (static scan). TGA analysis were also used to quantify the percentage of fillers in the mixed matrix membranes.

\subsubsection{Differential Scanning Calorimetry (DSC)}

Differential Scanning Calorimetry (DSC) is a thermal analysis technique which measure the heat flow rate difference into a sample and a reference sample as a function of temperature, while they are subjected to a temperature alteration. The major applications of the DSC technique are in the polymer fields [31].

In this thesis, DSC analysis was used to determine the $T_{g}$ of polymers. DSC experiments were carried out with a calorimeter DSC 1 (Mettler Toledo), within the temperature range from $50{ }^{\circ} \mathrm{C}$ to $450{ }^{\circ} \mathrm{C}$ and a heating rate of $10 \mathrm{~K} / \mathrm{min}$. 
Measurements were accomplished in nitrogen atmosphere to prevent oxidation. Usually, the glass transition is determined in the second heating cycle to avoid the effect of sample preparation history rising, for example, from the remaining solvent traces. DSC measurements were carried out at Helmholtz Zentrum Geesthacht (HZG) during a research stage. See Figure 4.1 for the $T_{g}$ information of the 3 different polymers used in this thesis.

\subsubsection{Gel Permeation Chromatography (GPC)}

Gel permeation Chromatography (GPC) allows the determination of the polymer molecular weight distribution in a short period of time (from two to three hours). GPC is a type of size exclusion chromatography (SEC), which separates molecules in solution by their size [32]. GPC measurements were carried out at Helmholtz Zentrum Geesthacht (HZG) during a research stage. The apparent molecular weight of the polymers was determined by GPC after calibration with polystyrene standards. GPC measurements were performed at $40^{\circ} \mathrm{C}$ having DMAc as eluent on a Waters instrument (Waters $\mathrm{GmbH}$, Eschborn, Germany) equipped with polystyrene gel columns of different pore sizes, using a refractive index (RI) detector. In Figure 4.1, the apparent molecular weight of the three different polymers used in this thesis can be checked.

\subsubsection{Gas chromatography (GC)}

Gas chromatography (GC) is a powerful analytical separation technique for gas and vapor mixture. An accurate quantitative analysis of complex mixtures is possible due to the combination of separation and on-line detection, including traces of compounds. The sample solution is injected into a column and swept to the detector by a carrier gas. Figure 4.13 depicts a schematic representation of the GC equipment. GC separates substances on the strength of their differential migration velocities in a biphasic system [33]. Principally, separation in a GC will depend on the solubility of the components in the gas phase, as well as the affinity of each solute with the stationary phase and the column temperature. In addition, the differences in the retention time will influence the partition of the components, and thus, depending on their chemical and physical properties, components will separate accordingly, reaching the detector at different times. 


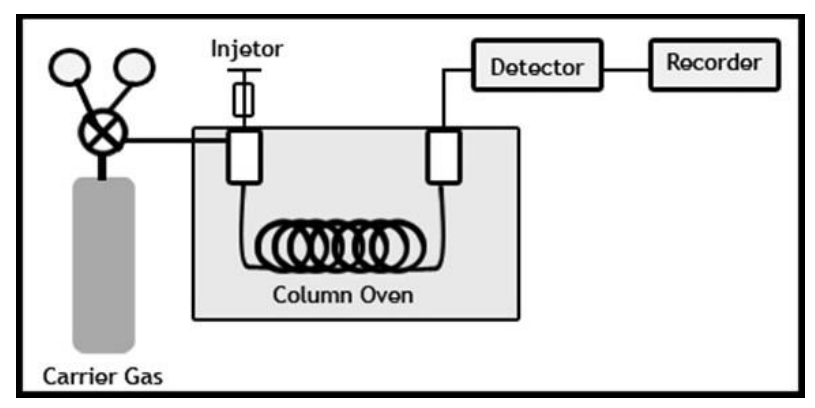

Figure 4.13. Schematic representation of the GC equipment

In order to analyze a sample with an unknown gas content and gas concentration, a known-standard sample is injected into the GC. Consequently, the instrument is calibrated and the peak area and retention time of the standard sample is used to compare with the test sample and to determine the real content and concentration of the sample. The gas chromatographs used in this thesis was (i) a Micro-GC CP-4900 with two columns, a Molsieve 5A and Pora PLOT Q columns, (ii) Varian 450-GC and Varian 3800-GC.

\subsection{Permeation Modules}

\subsubsection{Single gas permeances test}

\subsubsection{Pressure Increase equipment}

The single gas permeances of prepared thin film composite membranes (TFCMs) were determined by using the "pressure increase" facility at Helmholtz Zentrum Geesthacht ( $\mathrm{HZG}$ ), utilizing the "constant volume, variable pressure" method [34]. Single-gas permeation data were determined at 1000 mbar feed pressure and in the temperature range from $30^{\circ} \mathrm{C}$ to $90^{\circ} \mathrm{C}$. The pressure increase facility was described elsewhere [35]. Briefly, the facility determines the rate of a pressure increase in the calibrated permeate volume when certain feed pressure is applied to the membrane of a certain area. The facility is connected to 15 gas lines, and each gas can be taken into the feed volume of the facility. In this thesis, only 6 gas lines were used, as it can be seen in Figure 4.14, as well as a liquid sample deposit for water gas vapor. 


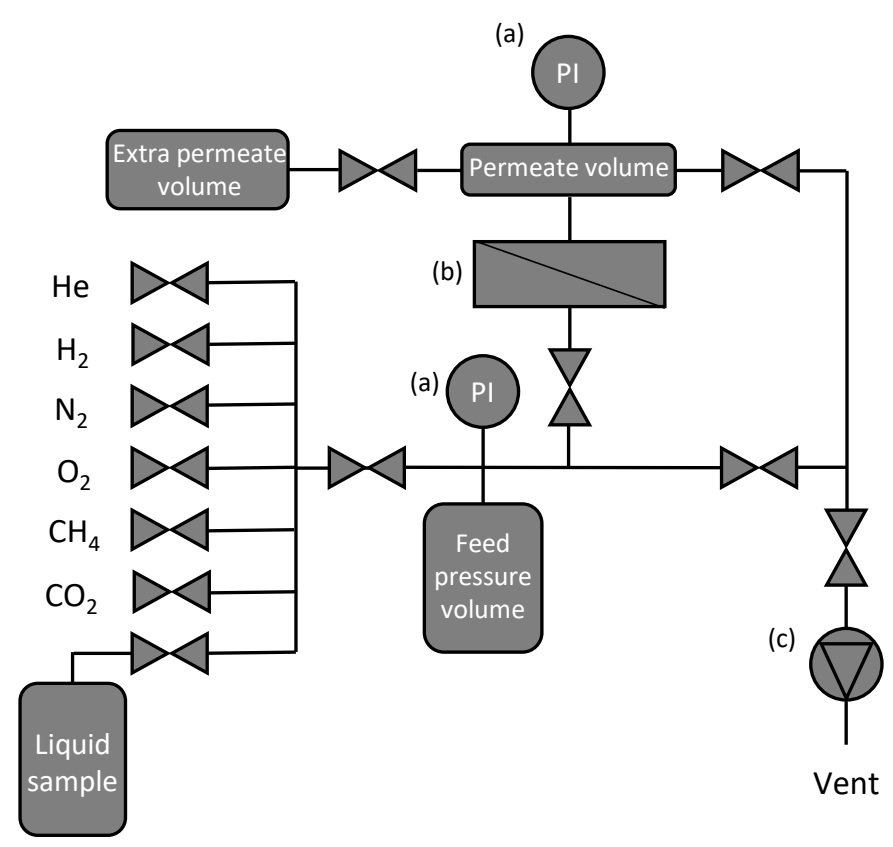

Figure 4.14. Pressure Increase equipment scheme

By changing the head parts of the membrane test cell (b), area can be varied from $2 \mathrm{~cm}^{2}$ to $40 \mathrm{~cm}^{2}$. The measurement part of the facility is thermostated with 0.1 ${ }^{\circ} \mathrm{C}$ precision, and all valves and pressure indicators (a) have no heating elements. The facility can be programmed to carry out gas transport experiments with any gas connected to it, at any feed pressure in the range 100-1200 mbar, and permeate pressure 0-13 mbar with a temperature step $1^{\circ} \mathrm{C}$ and higher [36].

The permeability coefficient $\rho\left[\mathrm{cm}^{3}(\mathrm{STP}) \mathrm{cm} \mathrm{cm}^{-2} \mathrm{~s}^{-1} \mathrm{cmHg}^{-1}\right.$ ] of single gas was determined as Equation (4.3).

$$
\rho=\frac{V_{p} l 22.4}{R T A t} \ln \left(\frac{p_{l}-p_{0}}{p_{l}-p_{0(t)}}\right)
$$

where $V_{p}$ is the constant permeate volume $\left(\mathrm{cm}^{3}\right), l$ is the film thickness $(\mathrm{cm}), A$ is the effective area of membrane $\left(\mathrm{cm}^{2}\right), \mathrm{R}$ is the gas constant $\left(8.314 \mathrm{~J} \mathrm{~mol}^{-1} \mathrm{~K}^{-1}\right), t$ is the time (s) for the measurement and $p_{l}, p_{0}$, and $p_{0(t)}(\mathrm{cmHg})$ are pressures at the feed, permeate side at the beginning, and permeate side at the end of the 
measurement, respectively. The factor of 22.4 is used to transfer from molar to volumetric units (assuming ideal gas behavior). The diffusion coefficient $D\left(\mathrm{~cm}^{2} \mathrm{~s}^{-1}\right)$ was calculated from membrane thickness $l(\mathrm{~cm})$ and time-lag $T(\mathrm{~s})$ determined graphically as intersection of the line drawn through the linear region of the pressure increase curve to intersection with the time axis, as it can be seen in Equation (4.4)

$$
D=\frac{l^{2}}{6 T}
$$

The solubility coefficient $S\left(\mathrm{~cm}^{3}(\mathrm{STP}) \mathrm{cm}^{-} \mathrm{cmHg}^{-1}\right)$ was calculated according to the following equation:

$$
S=\frac{\rho}{D}
$$

The ideal selectivity $\left(\alpha_{A / B}\right)$ of the material can be expressed as the ratio of perme5ability coefficients of two penetrants and, according to Equation (4.5), it is a function of diffusion and solubility selectivity, leading to the equation:

$$
\alpha_{A / B}=\frac{\rho_{A}}{\rho_{B}}=\frac{D_{A} S_{A}}{D_{B} S_{B}}
$$

The single gas permeance $\rho^{0}\left(\mathrm{~m}^{3}\right.$ (STP) $\left.\mathrm{m}^{-2} \mathrm{~h}^{-1} \mathrm{bar}\right)$ of the membrane can be calculated using the Equation (4.7)

$$
\rho^{0}=\frac{V_{p} 22.4}{R T A t} \ln \left(\frac{p_{l}-p_{0}}{p_{l}-p_{0(t)}}\right)
$$

where $V_{P}$ is the constant permeate volume $\left(\mathrm{m}^{3}\right), R$ is the gas constant $(8.314 \mathrm{~J}$ $\left.\mathrm{mol}^{-1} \mathrm{~K}^{-1}\right), A$ is the effective area of membrane $\left(\mathrm{m}^{2}\right), t(\mathrm{~h})$ is the time of measurement and $p_{l}, p_{0}$, and $p_{o(t)}($ bar) are pressures at the feed, permeate side at the beginning, and permeate side at the end of the measurement, respectively. The factor of 22.4 is used to transfer from molar to volumetric units (assuming ideal gas behavior). 


\subsubsection{Time-lag equipment}

The single gas permeances of prepared thick film membranes were determined by using the "time-lag" facility at Helmholtz Zentrum Geesthacht (HZG) [37]. Concisely, this equipment used the same principle as the "pressure increase" facility, but with a constant volume and pressure. Additionally, while the data provided by the "pressure increase" facility is permeance, "time-lag" equipment give permeability, selectivity and coefficients of diffusivity and solubility.

\subsubsection{Polymeric membrane module}

Polymeric membranes were measured in a module designed for the purpose. The set-up of the equipment was prepared for the thesis. The set-up (Figure 4.15) consists of: (a) 4 mass flow controllers (MF_1 - MF_4), in order to have the possibility to use different gases, (b) a gas bubbler connected in series with MF_2 to MF_4, allowing the possibility to inject water vapor as feed gas, (c) two manometers to control the internal pressure in both chambers of the reactor (feed side and permeate side), (d) two BPR valves to increase the pressure if it was needed, (e) one hygrometer to control the relative humidity, which can be translated into partial pressure of water vapor at the permeate side, (f) a micro GC to measure the outlet gases at the permeate side and finally, $(\mathrm{g})$ a reactor with two chambers that allow to place the membrane and seal the sample by rubber rings in the center. 
Due to the high water partial pressure that could be generated during the experiment, the gas lines were heating up to $110 \stackrel{\circ}{ } \mathrm{C}$ to avoid the condensation of water. Furthermore, all the parts in the system, including the gas bubbler, were made of steel, giving the possibility to work at high pressure.

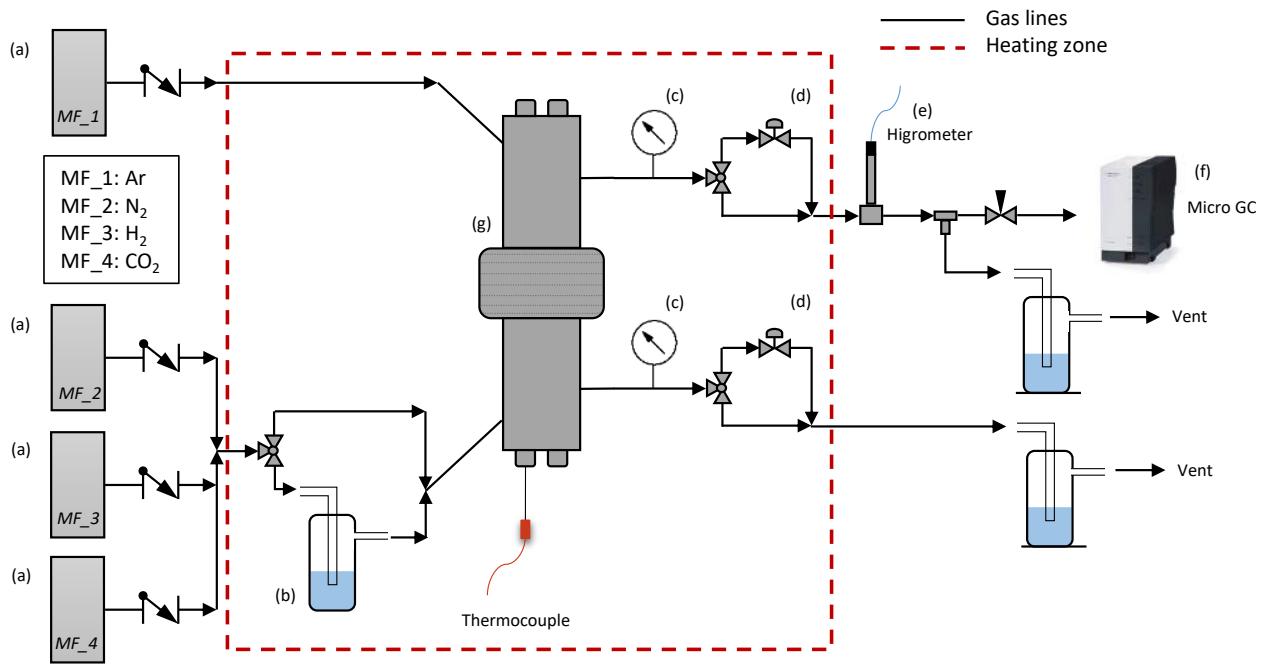

Figure 4.15. Set-up for polymeric membranes

Hygrometer was purchased to Fisher Scientific and it provides three different parameters: relative humidity, dew point and temperature. The equipment is able to save up to each second each parameter. During the experiments, relative humidity and temperature were saved each 60 seconds. As it was mentioned, it is possible to obtain the water flow from the relative humidity. Firstly, with the Antoine equation, the saturation partial pressure is calculated, taking into consideration the temperature of the probe, collected from the hygrometer. Secondly, the water partial pressure at the sweep stream can be calculated, following the equation:

$$
p_{H_{2} O_{-} \text {sweep }}=\frac{H R(\%)}{100} \cdot p_{H_{2} O_{-} \text {sweep }}^{*}
$$

where $p_{\mathrm{H}_{2} \mathrm{O}_{-} \text {sweep }}(\mathrm{atm})$ stands for partial pressure of water at the sweep side, $p^{*}{ }_{H_{2} O_{-} \text {sweep }}(\mathrm{atm})$ is the saturation pressure of water at the sweep side and $H R(\%)$ is the relative humidity. From the water partial pressure, and calculating the total flow 
at the permeate side, it can be substrated the water flow, as it is shown in Equation 2.9 and 2.10 .

$$
\begin{gathered}
Q_{\text {outlet_sweep }}=\frac{Q_{\text {inlet_sweep }}}{\left(1-p_{\mathrm{H}_{2} \mathrm{O}_{\_} \text {sweep }}-p_{\mathrm{H}_{2} \text { sweep }}\right)} \\
Q_{\mathrm{H}_{2} \mathrm{O}_{\text {outlet_sweep }}}=Q_{\text {outlet_sweep }} \cdot p_{\mathrm{H}_{2} \mathrm{O}_{\text {s }} \text { sweep }}
\end{gathered}
$$

where $Q_{\text {inlet_sweep }}(\mathrm{mL} / \mathrm{min})$ is the inlet total flow at the sweep side, $Q_{\text {outlet_sweep }}$ $(\mathrm{mL} / \mathrm{min})$ is the outlet total flow at the sweep side, $p_{H_{2}-\text { sweep }}(\mathrm{atm})$ is the partial pressure of hydrogen and at the sweep side and $Q_{\mathrm{H}_{2} \mathrm{O}_{-} \text {outlet_sweep }}(\mathrm{mL} / \mathrm{min})$ is the outlet water flow at the sweep side. Finally, molar flux and permeance can be calculated following the equations:

$$
\begin{gathered}
F_{\mathrm{H}_{2} \mathrm{O}}=\frac{Q_{\mathrm{H}_{2} \mathrm{O} \_ \text {outlet_sweep }}}{22400 \cdot 60 \cdot A} \\
\rho_{\mathrm{H}_{2} \mathrm{O}}^{0}=\frac{F_{\mathrm{H}_{2} \mathrm{O}}}{p_{l_{-} \mathrm{H}_{2} \mathrm{O}}-p_{0_{-} \mathrm{H}_{2} \mathrm{O}}}
\end{gathered}
$$

where $F_{\mathrm{H}_{2} \mathrm{O}}$ is the molar flux $\left(\mathrm{mol} / \mathrm{m}^{2} \mathrm{~s}\right), A$ is the area $\left(\mathrm{m}^{2}\right), p_{l_{-} \mathrm{H}_{2} \mathrm{O}}$ and $p_{0_{-} \mathrm{H}_{2} \mathrm{O}}$ are partial pressure of water $(\mathrm{Pa})$ in the permeate side and feed side, respectively, and $\rho_{\mathrm{H}_{2} \mathrm{O}}^{0}$ is the permeance of water $\left(\mathrm{mol} / \mathrm{m}^{2} \mathrm{sPa}\right)$.

\subsubsection{Palladium membrane module}

Palladium membranes were tested in a multifunctional module designed during this thesis, where samples with different outer diameters are able to be measured. In Figure 4.16, a scheme of the palladium membrane set-up is described. The module consists of: (a) 5 mass flow controllers (MF_1 - MF_5), in order to have the possibility to use different gases, (b) two manometers to control the internal pressure in both chambers of the reactor (feed side and permeate side), (c) two BPR valves to increase the pressure if it was needed, (d) one temperature controller that commands a jacketed heating, which in turn is composed of two resistors in parallel, 
(e) a micro GC to measure the outlet gases at the permeate side and finally, (g) a reactor with two concentric chambers.

Hydrogen and nitrogen are introduced as feed gas from the bottom part of the reactor, through a capillary pipe. They reach the top part of the membrane and then, both gases flow in contact with the sample and the retentate is discharge again from the down part of the reactor. In contrast, argon is used as sweep gas and it goes from the bottom to the top part of the reactor, reaching in a micro GC where the permeate stream is measured.

(a)

(a)

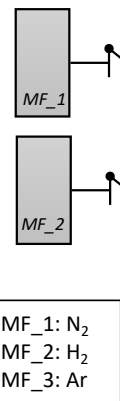

(a)

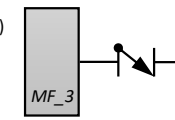

(a)

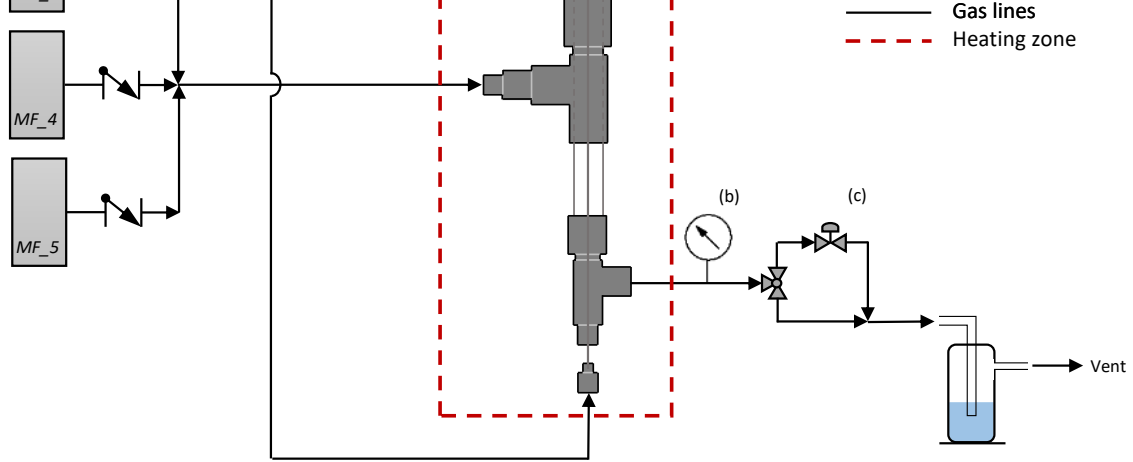

Figure 4.16. Set-up for palladium membranes 


\subsubsection{Fischer-Tropsch reaction module}

Fischer-Tropsch reaction module was adjusted for this thesis. The set-up, as it can be seen in Figure 4.17, consists of: a) 2 mass flow controllers (MF_1 - MF_2), (b) a mass flow sensor (MFS) which allows to measure the mass flow of hydrogen that permeates through the palladium membrane, (c) one manometer to control the internal pressure of the outer chamber, (d) a BPR valve to increase the pressure in the outer chamber, (e) two temperature controllers that command two jacketed heating, which in turn are composed of one resistor each, (f) a GC to measure the outlet gases at the reaction side and finally, (g) a reactor with two concentric chambers.

This equipment works at high pressure, up to $20 \mathrm{bar}$, and at $250^{\circ} \mathrm{C}$. It consists of two concentric chambers. The inner chamber is the membrane itself, where a stream of $\mathrm{H}_{2}$ will be pressurized and, once the temperature is reached, hydrogen will permeate through the membrane and it will be added controllably to the catalytic bed. The palladium membrane is welded to a stain steel tube of $1 / 8$ ". The outer chamber is a stainless steel reactor where the catalytic bed is placed and the reactants for FTS will be fed. The catalytic bed will be in direct contact with the palladium membrane.

Fischer-Tropsch process are characterized by high exothermicity, and for this reason, an efficient control of the heat and temperature are a basic need of FischerTropsch reactors. As a consequence, two fixed thermocouple are placed inside the membrane, in both ends of it, coinciding with the both sides of the catalyst bed. Thus, it is possible, when it is needed, to move the jacketed heating and avoid sudden rises in temperature during the reaction. In addition, one mobile thermocouple is placed also inside the membrane, so the whole catalyst bed can be controlled just moving this thermocouple and checking the temperature during the reaction. 


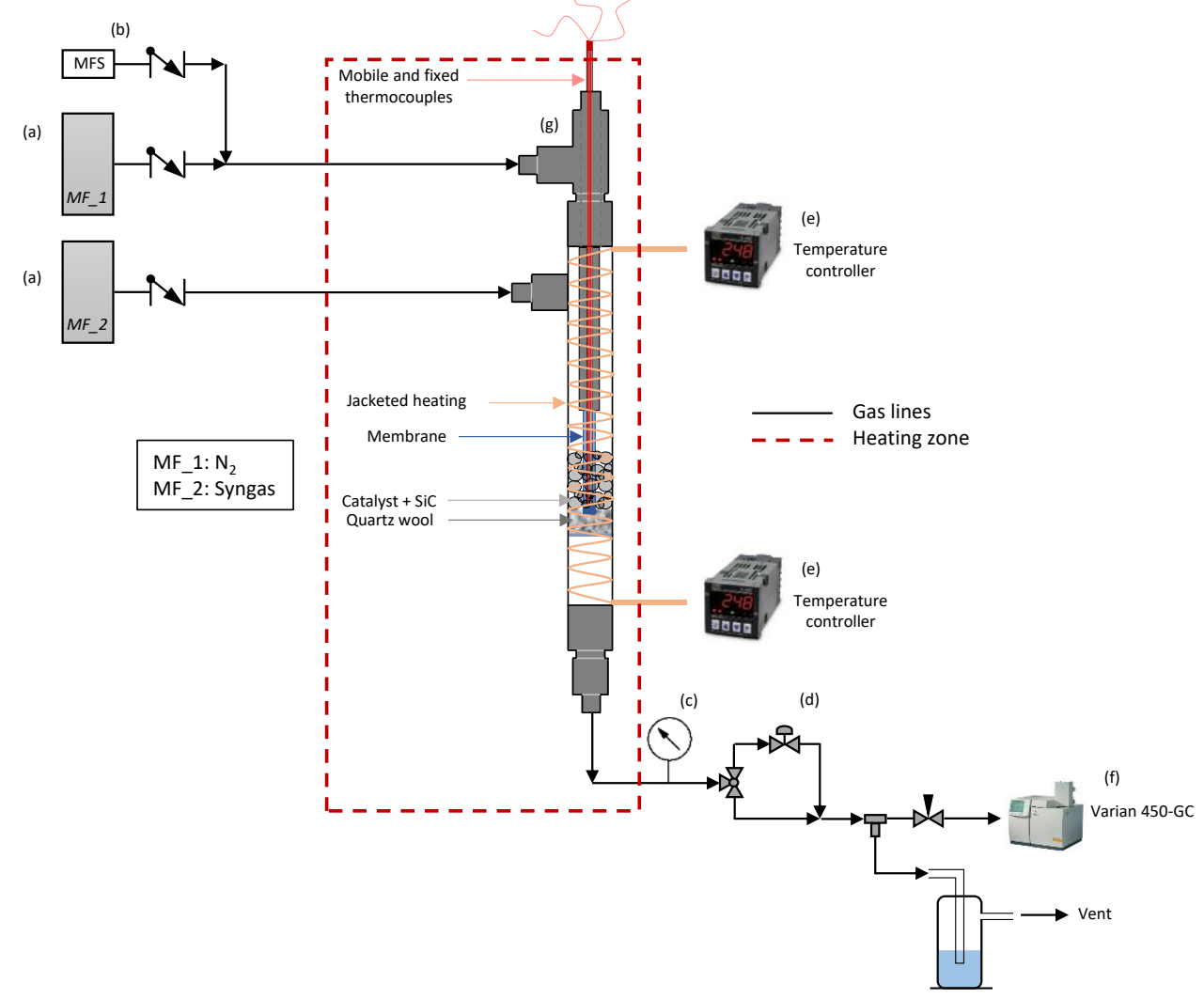

Figure 4.17. Set-up for Fischer-Tropsch reaction module

\subsubsection{Methanation reaction module}

For the methanation reaction, a microchannel reactor was designed specifically for the purpose of the thesis. In principle, the system is pretty similar to the set-up for polymeric membranes permeation. The main difference is the chamber for the microchannels. The set-up (Figure 4.18) consists of: (a) 4 mass flow controllers (MF_1 - MF_4), in order to have the possibility to use different gases, (b) one manometer to control the internal pressure in the feed chamber (microchannel), for controlling any possible over pressure, (c) one hygrometer to control the relative humidity, which can be translated into partial pressure of water vapor at the permeate side, (d) a Varian 3800-GC to measure the outlet gases at the reaction and permeate 
side and finally (e) a reactor with two chambers that allow to place the membrane and seal the sample by rubber rings in the center.

The outer body remained as stainless steel, whereas the microchannels were made first, out of silicone, and finally, another prototype was made of aluminium. Silicone used was SILRED H RED 5\% (red color) and its corresponding catalyst (blue color, in order to visually check a homogeneous mixing) from Resineco. Aluminium microchannel piece was modeled and manufactured during this thesis.

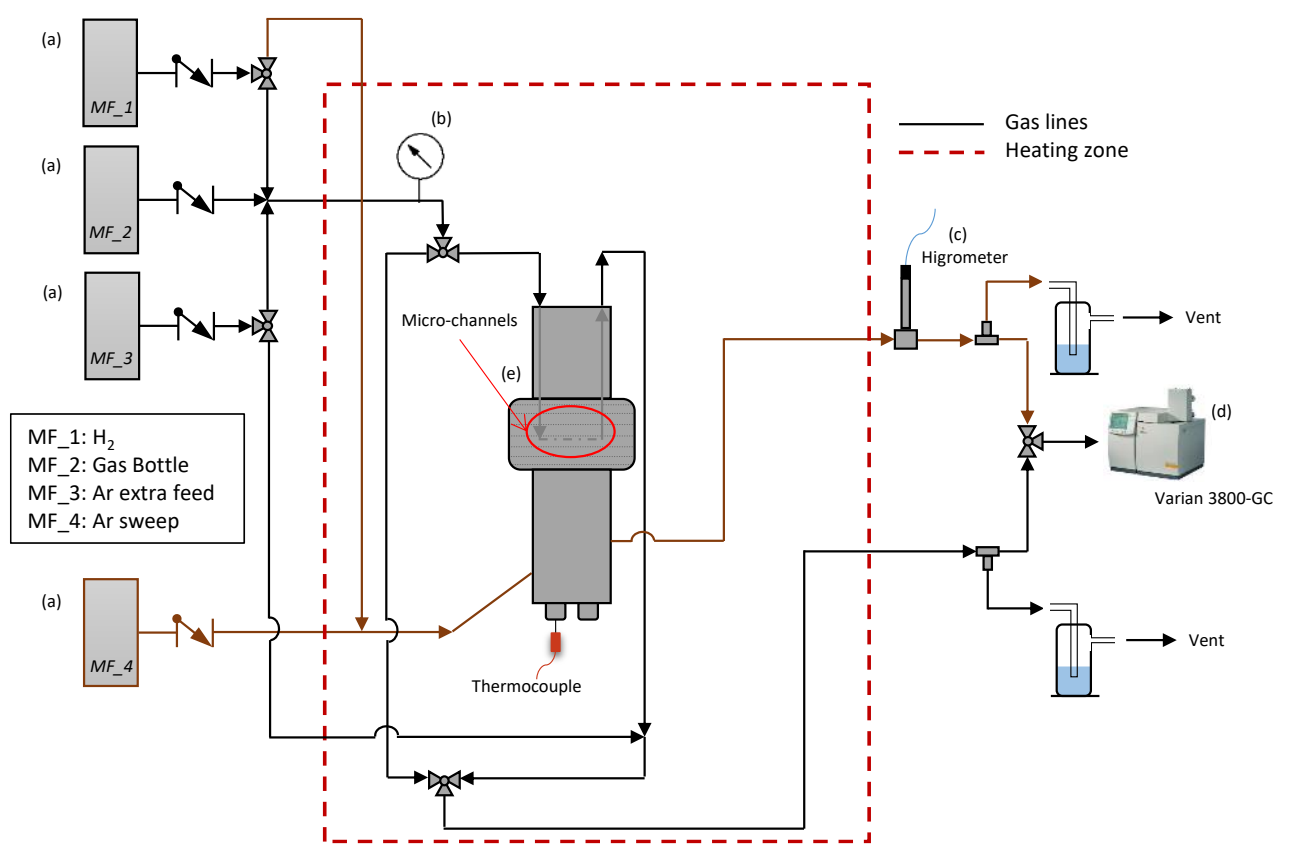

Figure 4.18. Set-up for methanation reaction

Permeate water during the reaction is measured with the hygrometer, following the same development as in section 2.5.2. Polymeric membranes. Additionally, it is also possible to measure with the GC the permeate side. Regarding reaction chamber, reaction parameters are measured in the GC, where the selectivity of methane and the conversion of carbon dioxide are calculated:

$$
S_{\mathrm{CH}_{4}}=\frac{\chi_{\mathrm{CH}_{4}}}{\chi_{\mathrm{CH}_{4}}+\chi_{\mathrm{CO}}+2 \chi_{\mathrm{C}_{2} \mathrm{H}_{6}}} \cdot 100
$$




$$
X_{\mathrm{CO}_{2}}=\frac{\chi_{\mathrm{CO}_{2 \_} \mathrm{O}}-\chi_{\mathrm{CO}_{2}}}{\chi_{\mathrm{CO}_{2 \_} \mathrm{O}}} \cdot 100
$$

where $X_{C_{2}}$ is the conversion of $\mathrm{CO}_{2}(\%), S_{\mathrm{CH}_{4}}$ is the selectivity of $\mathrm{CH}_{4}(\%)$ and $\chi_{\mathrm{CO}_{2} \mathrm{O}}$ is initial molar fraction of $\mathrm{CO}_{2}$, and $\chi_{i}$ are the molar fractions of the other gases.

For the design of the silicone microchannels piece, different options were scheme by SolidWorks. Firstly, four different resin molds were design and print with a 3D printer. ProJet ${ }^{\circledR} 3510$ HDPlus from 3DSYSTEMS was the printer used for obtain the different resin molds [38]. The printing mode used was Xtreme High Definition $(\mathrm{XHD})$ in order to acquire a fine resolution. The difference between them was the total volume of the microchannels and the shape of the channels. As it can be seen in Figure 4.19, channel volume goes from roughly $40 \mathrm{~mm}^{3}$ to almost $75 \mathrm{~mm}^{3}$.

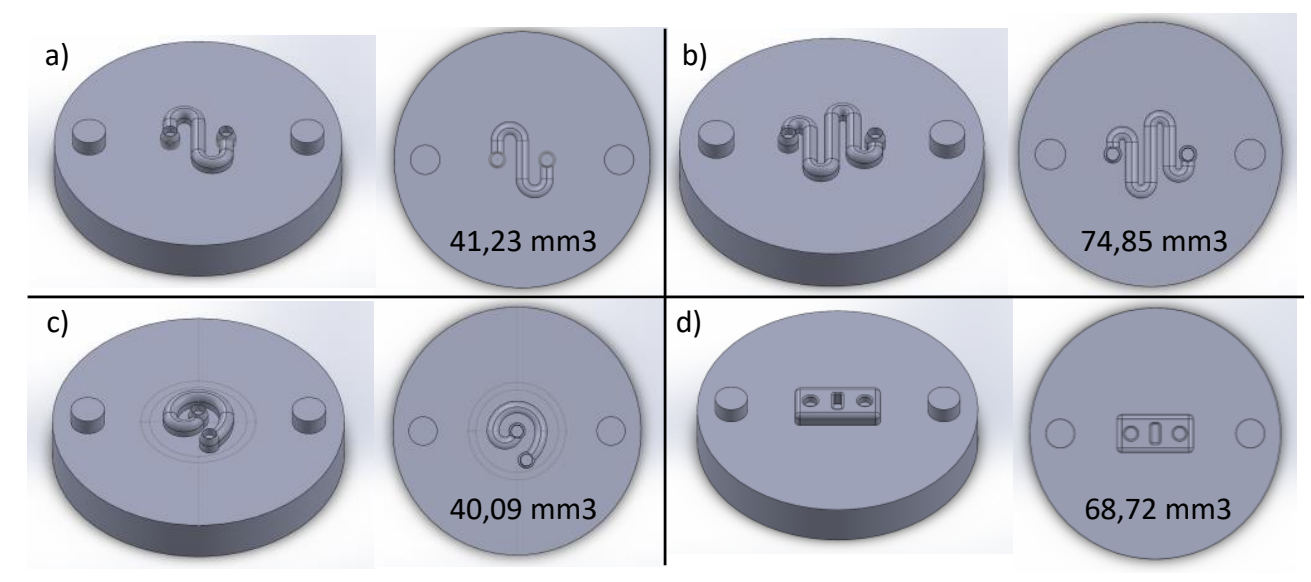

Figure 4.19. Different types for resin molds (bottom parts)

Apart from the diverse bottom parts, the walls of the different module options do not differ from each other, allowing to an interchangeability between the different parts of the microchannels. Figure 4.20 shows a complete microchannel mold, which correspond to option b) in Figure 4.19. Before introducing silicone in the mold, two stainless steel conductions of $1 / 16$ " outer diameter and $8 \mathrm{~cm}$ length are placed in the holes of the channels, in order to place the inlet and the outlet of the microchannels. For acquiring a defectless microreactor, the silicone was introduced 
slowly to the cavity and applying a small vibration to the whole piece, in order to help the correct filled.
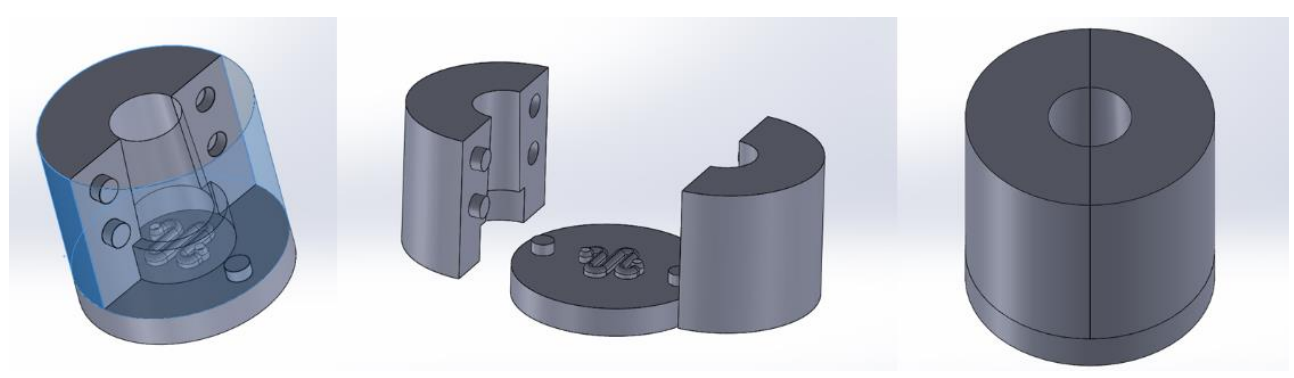

Figure 4.20. 3D drawings of the resin mold

In addition, it was left over night to cure (at least 20 hours) and afterwards, the resin mold was removed carefully. After the drying process, the microchannel silicone mold is prepared to be used up to temperatures of $350{ }^{\circ} \mathrm{C}$, according to specifications. Figure 4.21 shows the final silicone microchannels. From left to right, it can be seen how the silicone has been cured, firstly the bottom part is removed and secondly walls are separated one by one. Once the microchannel reactor is remove from the mold, it is place inside the stainless steel reactor in order to proceed with the reaction.

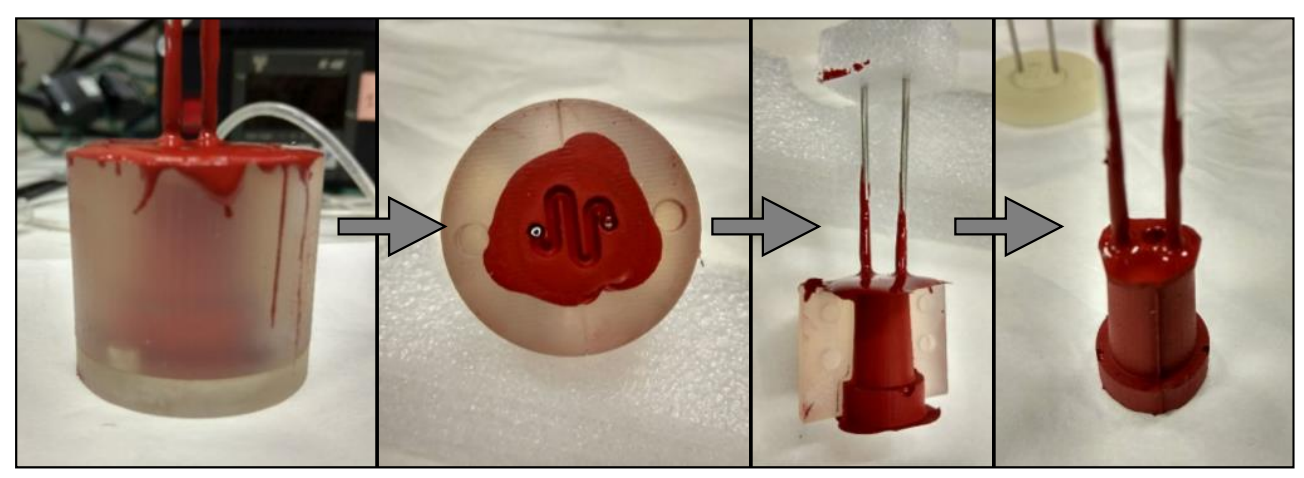

Figure 4.21. Final silicone mold after curing process

On the other hand, the aluminium mold was designed and manufacture. The two tubes of $1 / 16$ " were completely integrated, so the uncertainty of possible leaks is eliminated. The channel has a volume of $100 \mathrm{~mm}^{3}$, and a longitudinal shape, similar to the option d) in Figure 4.19. 
The reaction body can be closed directly to the body, because it already has the metal ferrules incorporated. The correct order to place the catalyst in the microchannel, independently the body that is being used is as follow: (i) microchannel reactor is placed upside down, (ii) catalyst is place inside the chamber, (iii) polymeric membrane is located with the selective layer in contact with the catalyst, (iv) porous stainless steel disc is disposed in order to support the membrane and protect the GC in case the membrane is broken, avoiding catalyst to go through the pipes, $(v)$ a silicone ring is placed to seal the permeate side of the reactor and finally, (vi) an alumina ring is located to close and seal completely the permeate side. This process can be seen in Figure 4.22. Once this is done and the reactor is closed, it is place in the set-up, but with the 1/16" pipes in the upper side.

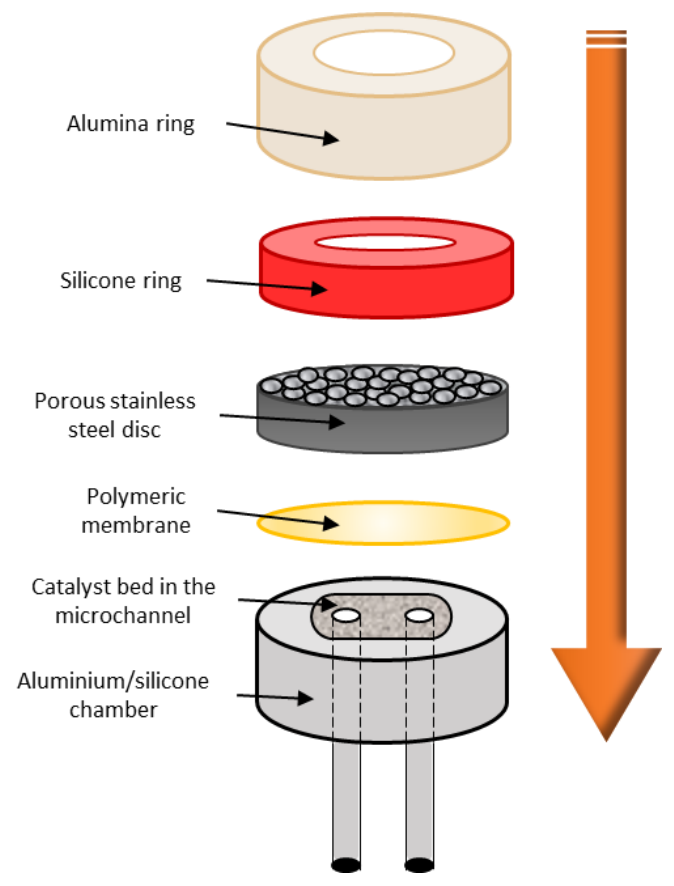

Figure 4.22. Visual description of the microchannel reactor parts 


\subsection{References}

1. Tena, A., et al., Influence of the Composition and Imidization Route on the Chain Packing and Gas Separation Properties of Fluorinated Copolyimides. Macromolecules, 2017. 50(15): p. 5839-5849.

2. Muñoz, D.M., et al., An Improved Method for Preparing Very High Molecular Weight Polyimides. Macromolecules, 2009. 42(15): p. 5892-5894.

3. Lesley E. Smart, E.A.M., Solid State Chemistry: An Introduction, Fourth Edition. 2012.

4. Martínez, A., et al., A detailed study of the activity and deactivation of zeolites in hybrid Co/SiO2-zeolite Fischer-Tropsch catalysts. Journal of Catalysis, 2007. 249(2): p. 162-173.

5. Onda, A., et al., Synthesis of manganese oxide octahedral molecular sieves containing cobalt, nickel, or magnesium, and the catalytic properties for hydration of acrylonitrile. Applied Catalysis A: General, 2007. 321(1): p. 7178.

6. Philpott, D.R., Whatman-Anotec update. Membrane Technology, 1992. 1992(21): p. 6-7.

7. gmbh, A.-i. 2018; Available from: http://www.atechinnovations.com/home.html.

8. HIROSE PAPER MFG CO., L. Hirose Paper Mfg Co., Ltd. 2018; Available from: http://www.hirose-paper-mfg.co.jp/english/index.html.

9. $\quad$ PBI Performance Products, I., PBI Performance Products, Inc. 2018.

10. Corma, A., et al., Preparation, characterisation and catalytic activity of ITQ2, a delaminated zeolite. Microporous and Mesoporous Materials, 2000. 38(2): p. 301-309.

11. Itoh, T., et al., Effect of Annealing on Crystal and Local Structures of Doped Zirconia Using Experimental and Computational Methods. The Journal of Physical Chemistry C, 2015. 119(16): p. 8447-8458.

12. Vigneron, F., et al., Etude par diffraction de neutrons des structures magnétiques de $\mathrm{TbBe} 13$ à basse température. Journal de Physique, 1980. 41(2): p. 123-133.

13. Scherb, T., et al., Nanoscale order in the frustrated mixed conductor La5.6WO12-[delta]. Journal of Applied Crystallography, 2016. 49(3): p. 9971008.

14. Han, D., et al., A Comprehensive Understanding of Structure and Site Occupancy of Y in Y-Doped BaZrO3. Journal of Materials Chemistry A 2013. 1: p. 3027-3033. 
15. H. Morejudo, S., et al., Direct conversion of methane to aromatics in a catalytic co-ionic membrane reactor. Vol. 353. 2016. 563-566.

16. IZA Structure Comission. 2018; Available from: http://www.izastructure.org/.

17. Entegris, S.P.G. SAES Pure Gas, Inc. 2017; Available from: http://www.saespuregas.com.

18. M. Mattox, D., Chapter 7. Physical Sputtering and Sputter Deposition (Sputtering). 1998. 343-405.

19. Katz, L., X-ray diffraction in crystals, imperfect crystals, and amorphous bodies (Guinier, A.). Journal of Chemical Education, 1964. 41(5): p. 292.

20. Epp, J., 4 - X-ray diffraction (XRD) techniques for materials characterization, in Materials Characterization Using Nondestructive Evaluation (NDE) Methods. 2016, Woodhead Publishing. p. 81-124.

21. University, O. PHYS 7.1: The atomic basis of matter. 1996; Available from: http://www.met.reading.ac.uk/pplato2/h-flap/phys7_1.html.

22. Waseda, Y., E. Matsubara, and K. Shinoda, X-Ray Diffraction Crystallography. 2011. 21-66.

23. Björn, A., Segura de La Monja, P., Karlsson, A., Ejlertsson, J. and Svensson, B. H., Rheological Characterization, in Biogas, D.S. Kumar, Editor. 2012: InTech.

24. Online, P. The Falling Ball Viscometer: Measurement Of Transparent Newtonian Fluids. 2018; Available from: https://www.pharmaceuticalonline.com/doc/the-falling-ball-viscometerdynamic-viscosity-measurement-0001.

25. GmbH, A.P. Rolling-ball viscometer Lovis 2000 M/ME. 2018; Available from: https://www.anton-paar.com/corp-en/products/details/rolling-ballviscometer-lovis-2000-mme/.

26. Khursheed, A., Scanning electron microscope optics and spectrometers. 2010. 1-403.

27. Cambridge, U.o. The Scanning Electron Microscope. 2017; Available from: https://www.eng-atoms.msm.cam.ac.uk/RoyalSocDemos/SEM.

28. Solutions, T.S.E.M. An Introduction to Electron Microscopy. 2018; Available from: https://www.fei.com/introduction-to-electron-microscopy/fib/.

29. Reiche, M.A., M. Maciejewski, and A. Baiker, Characterization by temperature programmed reduction. Catalysis Today, 2000. 56(4): p. 347355.

30. Handbook of Thermal Analysis and Calorimetry, in Handbook of Thermal Analysis and Calorimetry, E.B. Michael and K.G. Patrick, Editors. 2008, Elsevier Science B.V. p. ii. 
31. Menczel, J.D., et al., Differential Scanning Calorimetry (DSC), in Thermal Analysis of Polymers. 2008, John Wiley \& Sons, Inc. p. 7-239.

32. Sandler, S.R., et al., Polymer Synthesis and Characterization. 1998.

33. Guiochon, G. and C.L. Guillemin, Gas chromatography. Review of Scientific Instruments, 1990. 61(11): p. 3317-3339.

34. G. Pye, D., H. H. Hoehn, and M. Panar, Measurement of gas permeability of polymers. I. Permeabilities in constant volume/variable pressure apparatus. Vol. 20. 1976. 1921-1931.

35. Lilleparg, J., et al., Effect of the reactive amino and glycidyl ether terminated polyethylene oxide additives on the gas transport properties of Pebax[registered sign] bulk and thin film composite membranes. RSC Advances, 2016. 6(14): p. 11763-11772.

36. Nistor, C., et al., CO2 selective membranes based on epoxy silane. Vol. 54. 2009. 603-610.

37. Shishatskii, A.M., Y.P. Yampol'skii, and K.V. Peinemann, Effects of film thickness on density and gas permeation parameters of glassy polymers. Journal of Membrane Science, 1996. 112(2): p. 275-285.

38. 3D Systems, I. ProJet MJP 3600 Series. 2018; Available from: https://es.3dsystems.com/3d-printers/projet-mjp-3600-series. 
Chapter 5

Development of composite ceramicpolymer membranes 



\section{Development of composite ceramic-polymer membranes}

\subsection{Introduction}

In this chapter, novel selective ceramic-supported thin polyimide films, produced in a single dip coating step, were developed for membrane applications at elevated temperatures for hydrogen separation. Hydrogen production is the largest use of syngas, with steam methane reforming (SMR) being the predominant technology, which is a well-established process with two main reactions, reforming and water gas shift reaction [1, 2]. In order to use the hydrogen obtained by this method, an extra purification step is necessary. Apart from hydrogen, carbon dioxide is mainly generated during the process (15-20\%) among other gases [3]. In this sense, gas separation using membranes has been extensively investigated as one of the most energy efficient separation processes, and as a strong alternative to conventional purification systems.

Three different polyimides were selected due to its outstanding and convenient properties. As high-performance materials, polyimides present high chemical and thermal stability and high glass-transition temperature (above $300^{\circ} \mathrm{C}$ ) [4]. Therefore, these materials can be employed in high temperature applications, such as the water-gas shift process. For practical applications, the polymer membranes have to be processed as thin film composite membranes (TFCMs), where the supporting structures of the selective layer should possess high thermal and chemical stability whilst being highly permeable at the same time. Consequently, a high thermally resistant ceramic porous support and a dense layer of a highly stable polymer were combined.

However, it is hard to achieve good compatibility between polymers and ceramic materials. One typical mismatch of properties of these materials origins from the method of polymer layer deposition on the porous ceramic by application of a polymer solution. The inorganic surface is not changing its properties upon the contact to organic solvent, while polymer undergo a drastic change of its state from diluted solution via mechanically weak gel to solid state. This change of the polymer state is accompanied by significant stress within the formed polymer layer, and on the polymer/ceramic interface. In order to obtain defect free polymer layer, it is 
obligatory to have ceramic support surface of a very high quality, without any defects with sharp edges, which can cause defect formation during polymer film drying [5].

The study of the coating conditions is crucial in order to get a good, defect free selective layer on top of the inorganic porous support, which will ensure reproducible experimental results. The effect of the concentration of the polymer solution for three different polyimides on the properties of deposited thin polymeric layers on top of an alumina support is studied. To overcome the challenge of polymer/inorganic incompatibility, the deposition of the polymer layer was studied in dependence of the polymer solution concentration and, consequently, the polymer solution viscosity. A number of commercial and in-house synthesized polymers with outstanding gas transport properties for several gas pairs, such as $\mathrm{CO}_{2} / \mathrm{CH}_{4}$ or $\mathrm{O}_{2} / \mathrm{N}_{2}$, were chosen for coating experiments, in order to study the effect of polymer composition on the properties of TFCMs.

The gas transport properties of the obtained membranes were studied with a variety of gases as a function of temperature. The effect of the temperature on the permeance of prepared membranes was studied for $\mathrm{H}_{2}, \mathrm{CH}_{4}, \mathrm{~N}_{2}, \mathrm{O}_{2}$ and $\mathrm{CO}_{2}$. As expected, activation energy of permeance for $\mathrm{H}_{2}$ was higher than for $\mathrm{CO}_{2}$ resulting in $\mathrm{H}_{2} / \mathrm{CO}_{2}$ selectivity increase with temperature. More densely packed polymers lead to materials that are more selective at elevated temperatures.

\subsection{Results and discussion}

\subsubsection{Fundamental characterization}

Thermogravimetric analysis TGA is depicted in Figure 5.1, showing the thermal stability of the polymers studied in this chapter. For all the three polymers, a single weight loss step was observed at temperatures higher than $450^{\circ} \mathrm{C}$. Nevertheless, for Matrimid ${ }^{\circledR}$ and $\mathrm{P} 84^{\circledR}$, a previous and smother step was observed, which may be related to solvent evaporation or water desorption. This is an indication of the high thermal stability of these polymers, and provides an idea about the possible working temperature range.

Regarding glass transition temperature $\left(T_{g}\right)$ of these three polymers, it was determined by Differential Scanning Calorimetry (DSC), and it was found that all 
three polymers have $\mathrm{Tg}$ very close to each other, with $\mathrm{P} 84^{\circledR}$ having the highest: $\mathrm{P} 84^{\circledR}$ $\left(322^{\circ} \mathrm{C}\right)>$ Matrimid $^{\circledR}\left(320^{\circ} \mathrm{C}\right)>6$ FDA-6FpDA $\left(311^{\circ} \mathrm{C}\right)$, see Figure 5.2.

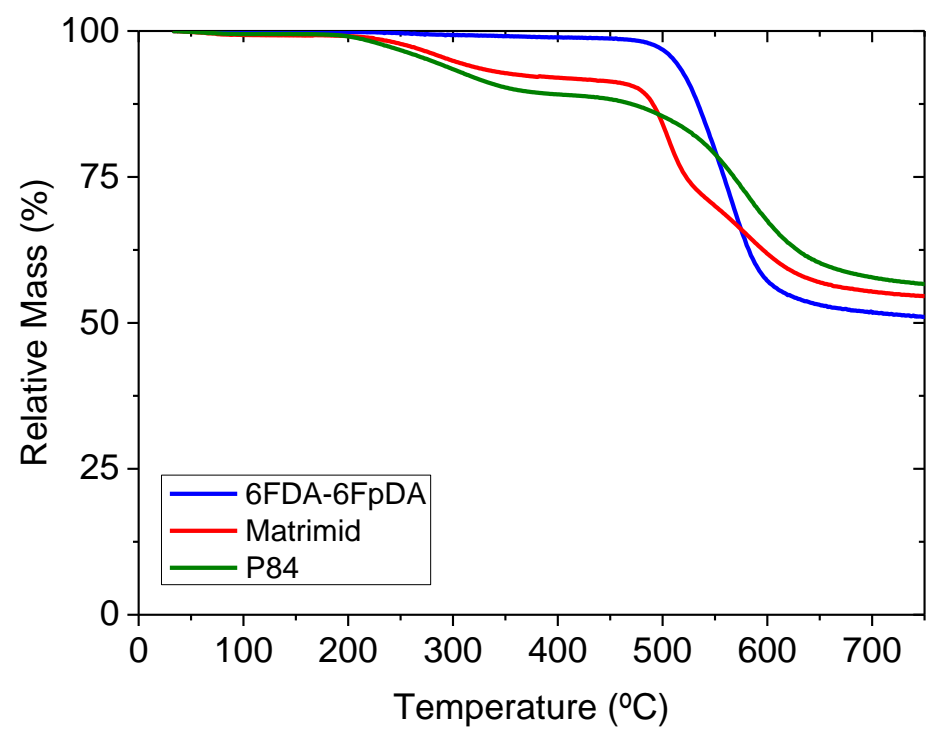

Figure 5.1. TGA of the three polyimide: $6 F D A-6 F p D A$, Matrimid $^{\circledR}$ and $P 84^{\circledR}$

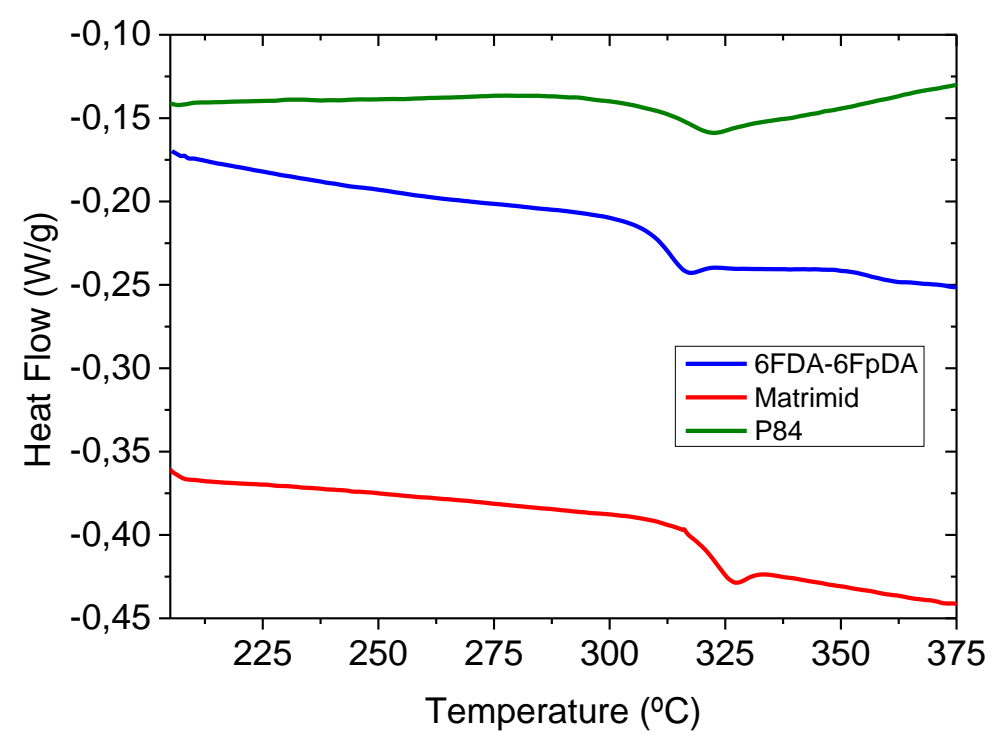

Figure 5.2. DSC of the three polyimides: $6 F D A-6 F p D A$, Matrimid $^{\circledR}$ and $P 84^{\circledR}$ 
Separation properties of the three different polymers are strongly influenced by the fractional free volume (FFV) [6]. As it was advanced in the Introduction, FFV is defined as the free space that is not occupied by the polymer molecules. Table 5.1 shows the permeability coefficients and ideal selectivity of the three polymers studied as a thick film for different gases. 6FDA-6FpDA presents the highest permeability, followed by Matrimid ${ }^{\circledR}$, and $P 84^{\circledR}$. This ideal permeabilities are well correlated with the values for FFV: 0.19 for $6 F D A$ [7], 0.17 for Matrimid ${ }^{\circledR}$ [8], and 0.14 for P84 ${ }^{\circledR}$ [9]. In the case of 6FDA-6FpDA, the values were experimentally obtained, whereas from the other two polymers, values were found in literature $[9,10]$.

Table 5.1. Ideal permeability and selectivity for the polymers studied as thick films at room temperature

\begin{tabular}{lccc|ccc}
\cline { 2 - 7 } & \multicolumn{3}{c|}{ Permeability (Barrer) } & \multicolumn{4}{|c}{ Selectivity (-) } \\
\cline { 2 - 7 } & $\boldsymbol{H}_{2}$ & $\mathbf{O}_{2}$ & $\mathbf{C O}_{2}$ & $\mathbf{H}_{2} / \mathbf{C O}_{2}$ & $\mathbf{O}_{2} / \mathbf{N}_{2}$ & $\mathbf{C O}_{2} / \mathbf{C H}_{4}$ \\
\hline $\mathbf{P 8 4}^{\circledR}[\mathbf{9}]$ & 7.2 & 0.24 & 1.2 & 6.0 & 10.0 & 50.0 \\
Matrimid $^{\circledR}[\mathbf{1 0}]$ & 17.5 & 1.5 & 7.3 & 2.4 & 6.6 & 34.7 \\
\hline 6FDA-6FpDA & 93.3 & 12.9 & 63.8 & 1.5 & 4.8 & 45.6 \\
\hline
\end{tabular}

As it can be seen from Table 5.1, the most permeable polymer 6FDA-6FpDA exhibits lower selectivies, whereas the less permeable polymer P84, due to its permemability values, it performs the higher selectivity values.

\subsubsection{Viscosity study}

All the membranes were fabricated by a single coating step. The possibility to dip-coat more than once (multiple steps) in order to avoid the possible pin-holes, as in previous studies [11], was considered. However, this technique was dismissed due to the better reproducibility and homogeneity of one-step dip-coating, and also to prevent the chance of massive polymer penetration into pores of the porous support. 
The relation between the polymer concentration and the viscosity $(\eta)$ was studied. This relation allows to establish the minimum viscosity needed to form a continuous defect-free-layer on top of the ceramic support. The evolution of the viscosity as a function of the polymer concentration for 6FDA-6FpDA, Matrimid ${ }^{\circledR}$ and $P 84^{\circledR}$ is depicted in Figure 5.3. The polymers showed an exponential increase of the viscosity with the polymer concentration, as it was described for other polymeric systems [12-14].

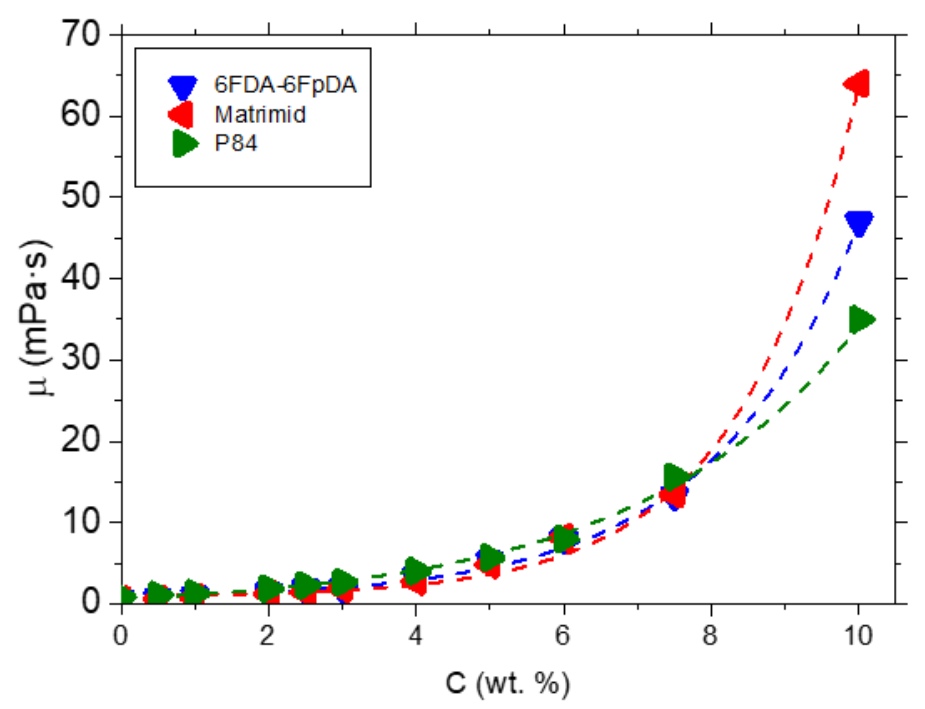

Figure 5.3. Evolution of the viscosity as a function of the polymer concentration (dotted lines are eye guides only)

The viscosity of a solution directly depends on its concentration, which is intimately related with the polymer coils. In a dilute solution, the polymer coils have enough space to avoid any interaction. Hence, the viscoelasticity in a dilute solution is attributable to the properties of individual polymer coils. The overall viscoelasticity exhibited by a dilute solution is the viscoelasticity associated with each coil, multiplied by the number of coils present. This behavior is represented by the RouseZimm model: if the concentration of polymer coils is increased beyond certain limit, the coils can no longer remain discrete and become prone to entanglement [15].

For the following calculations, a numbered of terminologies were used. Table 5.2 describes the employed nomenclature of the functional forms of viscosities. 
Table 5.2. Viscosity nomenclature

\begin{tabular}{l|c}
$\begin{array}{l}\text { Dynamic viscosity (solution viscosity) } \\
\text { Solvent viscosity }\end{array}$ & $\boldsymbol{\eta}$ \\
$\begin{array}{l}\text { Concentration of the solution } \\
\text { Relative viscosity }\end{array}$ & $\eta_{s}$ \\
Specific viscosity & $\eta_{\text {rel }}=\frac{\eta}{\eta_{s}}$ \\
& $\eta_{s p}=\frac{\eta-\eta_{s}}{\eta_{s}}=\eta_{\text {rel }}-1$ \\
Reduced viscosity & $\eta_{\text {red }}=\frac{\eta_{s p}}{C}$ \\
Inherent viscosity & $\eta_{\text {inh }}=\frac{\ln \eta_{r e l}}{C}$ \\
Intrinsic viscosity & {$[\eta]=\lim _{C \rightarrow 0}\left(\eta_{\text {red }}\right)=\lim _{C \rightarrow 0}\left(\eta_{\text {inh }}\right)$}
\end{tabular}

The solutions viscosities of various concentrations can be modelled by Huggins and Kraemer equations [16-18]. Huggins equation can be defined as:

$$
\frac{\eta_{s p}}{C}=\eta+k_{H}[\eta]^{2} C
$$

where $\mathrm{k}_{\mathrm{H}}$ is denominated Huggins constant and has values ranging from 0.3 in good solvents to 0.5 in poor solvents. This constant contains information about hydrodynamic and thermodynamic interactions between coils in solution. A plot of the reduced viscosity, extrapolated to zero concentration yields the intrinsic viscosity. Using the expression for the specific viscosity in the Huggins equation above, Equation (5.1), provides Equation (5.2), the Kraemer equation.

$$
\eta_{\text {red }}=1+[\eta] C+k_{H}[\eta]^{2} C^{2}
$$


For a range of moderate concentrations, Huggins equation exhibits a linear dependence, while Kramer plot is linear only at sufficiently low concentrations. In the present thesis, the solution concentrations were considered as moderate concentrations. Thus, Huggins equation was used, and its plot can be seen in Figure 5.4 , where the intercept of the line at the ordinate corresponds to the intrinsic viscosity $([\eta])$.

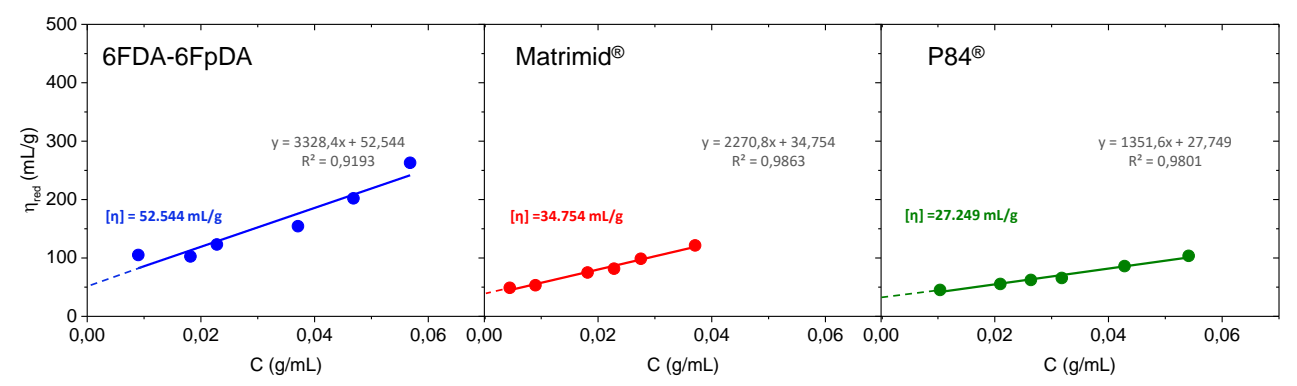

Figure 5.4. Huggins representation for intrinsic viscosity determination

Intrinsic viscosity values in $\mathrm{mL} \cdot \mathrm{g}^{-1}$ for the three different polyimides were: 6FDA6 FpDA $([\eta]=52.544)>$ Matrimid $^{\circledR}([\eta]=34.754)>P 84^{\circledR}([\eta]=27.249)$. Once $[\eta]$ is obtained, the entanglement concentration $\mathrm{C}^{*}$ (also called overlap concentration) can be obtained. Plotting the logarithm of the specific viscosity against the logarithm of the coil overlap parameter, which is equal to the product of the concentration $\left(\mathrm{g} \cdot \mathrm{mL}^{-}\right.$ $\left.{ }^{1}\right)$ and the intrinsic viscosity $\left(\mathrm{mL} \cdot \mathrm{g}^{-1}\right)$, two linear dependencies are obtained. The intersection between these two lines is the so-called overlap concentration [19-21]. This representation is plotted in Figure 5.5, in the left part.

Additionally, the overlap concentration can be also calculated by the intersection of the two linear dependencies obtained by the representation of the logarithm of the specific viscosity against the logarithm of the concentration $\left(\mathrm{g} \cdot \mathrm{mL}^{-1}\right)$ [22-24]. This second representation can be seen in Figure 5.5, but in the right part. As it can be ascertained, values determined by using the two preceding methods are identical. 


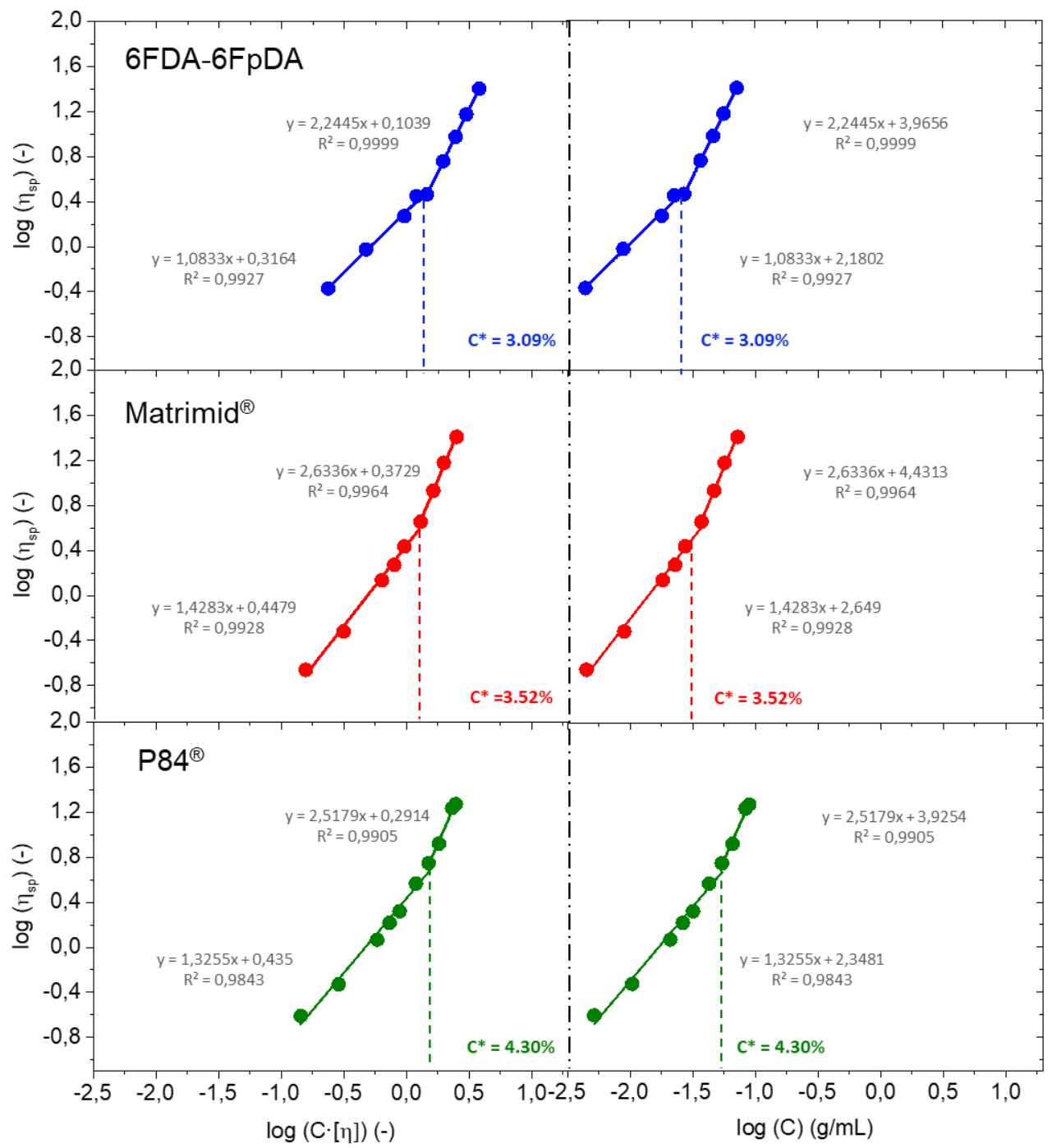

Figure 5.5. Overlap concentration $\left(C^{*}\right)$ for the polymers solutions studied obtained from the representation of $\log \eta_{s p}$ as a function of $\log (C[\eta])$ (left side) and as function of $\log (C)$ (right side) 
The entanglement concentration or overlap concentration, $C^{*}$, defines the border between the dilute and semi-dilute regions, and is representative of the concentration at which polymer chain entanglement is first observed. In other words, for concentration values above $\mathrm{C}^{*}, \mathrm{C}>\mathrm{C}^{*}$, the rheological behavior of the system is governed by interactions between multiple coils rather than by the properties of individual polymer molecules (semi-dilute regions). This results in an increase in polymer interaction and hence viscous drag. On the other hand, solutions where $\mathrm{C}$ $<\mathrm{C}^{*}$, polymer solution will be in a dilute state. In terms of film formation, polymer solutions where $\mathrm{C}>\mathrm{C}^{*}$, will be theoretically more prone to get continuous polymer layers.

\subsubsection{Membrane formation}

Once it was understood how the viscosity influences film formation, membranes for each concentration of polymer solution were obtained, in order to study coating quality, reproducibility, and to carry out the characterization of the separation properties. Selected concentrations were: $0.5-1$ - $2.5-3-4-5-7.5-8$ and 10 wt. $\%$.

Regarding the ceramic supports, Whatman ${ }^{\circledR}$ Anodisc inorganic filter was purchased from Sigma-Aldrich, with a diameter of $25 \mathrm{~mm}$ and pore size of $0.02 \mu \mathrm{m}$ [25]. Anodisc was used as support material because of its high purity alumina matrix that combines good thermal stability, solvent compatibility and very regular porous structure. More information about the support material used in this part of the thesis was already explained in the Chapter 4 - Methodology. After the coating process (described also in Chapter 4 - Methodology), membranes were treated at low temperature in a heating plate, in order to allow solvent evaporation at ambient conditions. In case of THF (6FDA-6FpDA and Matrimid $\left.{ }^{\circledR}\right)$, membranes were left at $40^{\circ} \mathrm{C}$, whereas for NMP $\left(\mathrm{P} 84^{\circledR}\right)$ membranes were treated at a maximum temperature of $90 \stackrel{\circ}{\circ}$ (increasing $20 \stackrel{\circ}{ } \mathrm{C}$ each two hours). The reason to maintain the temperature low is to prevent the formation of defects, such as pin-holes, while the solvent is being evaporated. Secondly, membranes were treated under vacuum at $200{ }^{\circ} \mathrm{C}$ for 12 hours. The temperature of $200^{\circ} \mathrm{C}$ was selected in order to ensure that all the solvent used during the dip-coating process is evaporated, as well to accelerate the initial aging process in the polymer, which leads to experimental results reproducible both in time (samples can be measured at different times after membrane preparation) and for different samples [26]. 
This aging effect is more notable in polymers with high fractional free volume, such as 6FDA-6FpDA, i.e. the most permeable polymers. The origin of the aging effect is related to the relaxation processes that occur in the polymeric film. Since the membrane is casted, the solvent is constantly evaporating and this evaporation changes and relax the polymer film formation. Due to this relaxation, the polymer chains are "arriving" to the low energy level and the fractional free volume is reduced, leading to a less permeable material, but with the advantage that the polymer membrane will maintain its properties over time and temperature [27]. The way to promote this situation is by thermal treatment at elevated temperatures, leading to polymers with more stable separation properties.

In Figure 5.6, the normalize $\mathrm{H}_{2}$ permeance over the time for 6FDA-6FpDA membranes not treated and thermally treated $\left(200^{\circ} \mathrm{C}\right)$ in a vacuum oven are shown. It can be seen that, in case of the untreated membrane, a decrease of the $\mathrm{H}_{2}$ permeance over the time is depicted, while the thermally treated sample presented a constant permeance value. This indicates that, after thermal treatment at $200^{\circ} \mathrm{C}$, the permeation properties are much more stable with the time. Therefore, all the films were thermally treated at $200{ }^{\circ} \mathrm{C}$ under vacuum for 12 hours before further characterization.

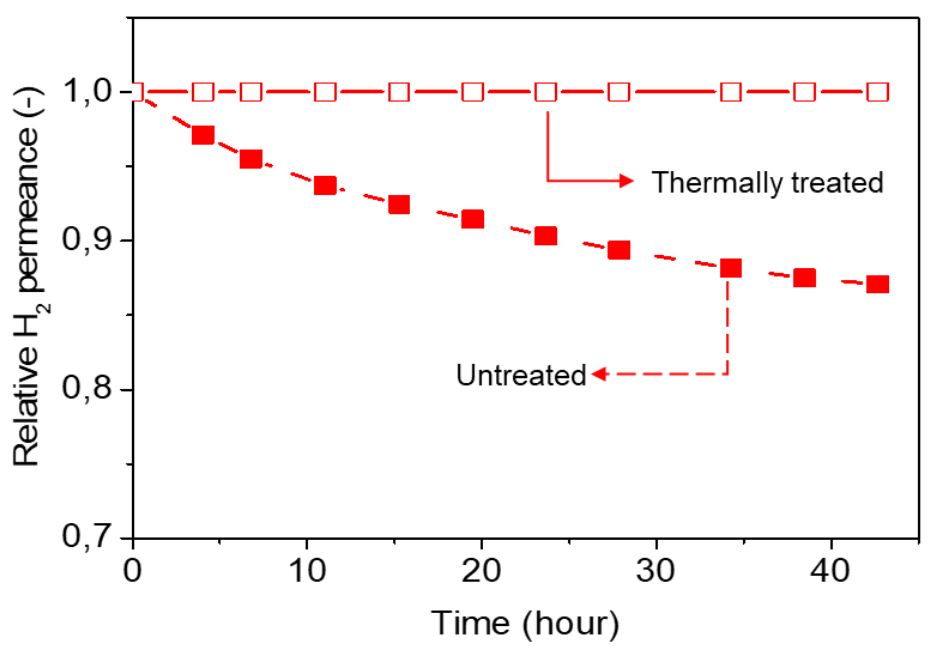

Figure 5.6. Relative $\mathrm{H}_{2}$ permeance at room temperature stabilization test. For untreated and thermally treated 6FDA-6FpDA membrane (5 wt. \% polymer solution) supported on alumina Anodisc 


\subsubsection{Microscopy analysis}

Microscopy analysis of the samples produced with different concentration and polymer solutions was performed. Figure 5.7 shows the effect of the polymer concentration in the solution on the polymer film formation. Insufficient chain overlap at solution concentrations below or similar to $C^{*}$ headed to the formation of discontinuous, if any, polymer layers. In case of low concentrations, $\mathrm{C}<\mathrm{C}^{*}$, high penetration of the solvent-polymer system into the pores was observed (position a). For concentrations close to $C^{*}, C \sim C^{*}$, the polymer formed a film on top of the ceramic support, but still the concentration was not high enough to ensure a continuous layer formation, but viscous enough to not penetrating into the porous structure (position b).

Note that the pores observed in position (a) are smaller than the ones observed in position (b). This fact is due to the polymer penetration into the pores of the substrate that causes the filling of the ceramic pores without producing a dense layer, just minimizing the porosity. This can be checked in the inset of (a), where pores formed by the polymer are distinguished from the substrate pores. For concentrations above $\mathrm{C}^{*}, \mathrm{C}>\mathrm{C}^{*}$, defect-free polymer layer was repeatedly formed (position c and d). 


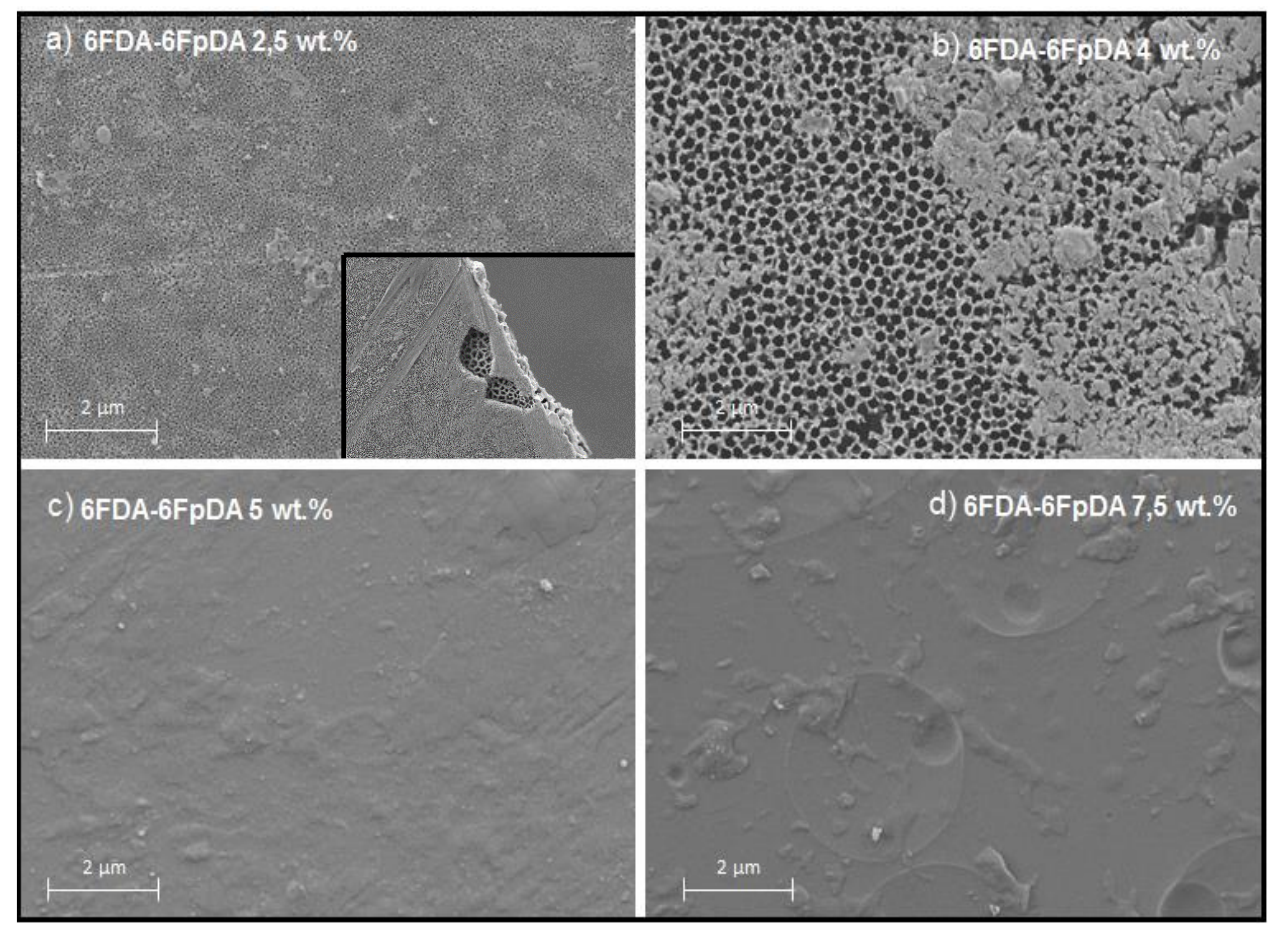

Figure 5.7. SEM micrographs of 6FDA-6FpDA dip-coated in alumina support with different solution concentrations: $C<C^{*}(\mathbf{a}), C \sim C^{*}(\mathbf{b})$, and $C>C^{*}(\boldsymbol{c}, \boldsymbol{d})$. Inset image in (a) corresponds to a magnification where the porous support is observed to be below the polymer layer

Regarding the cross-section of the membranes, SEM micrographs are able to give information on the penetration capability of the polymer solutions, thickness of the polymer layers as a function of the polymer concentration, and last but not least, the quality of the polymer coating on top of the ceramic support. Figure 5.8 depicts two different situations for the three different membranes. For samples deposited from polymer solution concentrations in the dilute region, $\mathrm{C}<\mathrm{C}^{*}(2.5 \mathrm{wt}$ \% in the left column), it can be seen how the polymer is penetrated into the pores of the support due to the lower interaction between the polymer chains. For samples deposited from polymer solution concentrations in the semi-dilute region, $\mathrm{C}>\mathrm{C}^{*}$ ( 5 and $7.5 \mathrm{wt}$. $\%$ in the right column), the penetration of the solution into the porous structure is 
much lower and a continuous and defect-free polymeric layer was formed on top of the ceramic support.

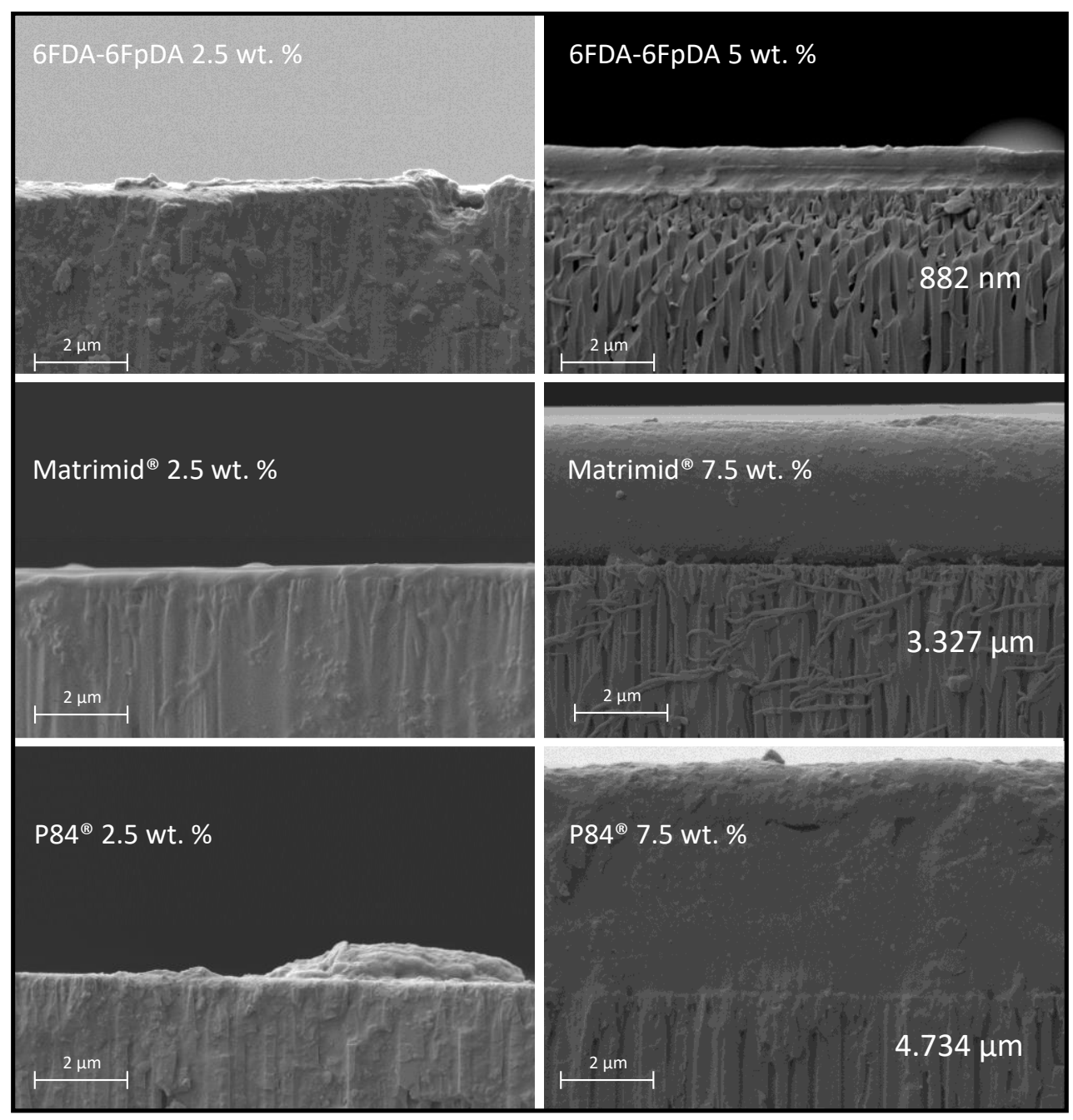

Figure 5.8. Cross-sections SEM micrographs for the polymers deposited with two different solution concentrations: $C<C^{*}\left(2.5\right.$ wt. \%) and $C>C^{*}\left(5\right.$ wt. \% for the $6 F D A-6 F p D A$ and 7.5 wt. \% for $P 84^{\circledast}$ and Matrimid $^{\circledR}$ )

Additionally, it was performed an EDX analysis (elemental maps for aluminium and carbon) of the cross-sections of samples coated with $2.5 \mathrm{wt} . \%$ and $5 \mathrm{wt}$. \% of 6FDA-6FpDA. The upper part of Figure 5.9 is related to $2.5 \mathrm{wt}$. \%, where aluminium from the ceramic support exhibits some blanks that perfectly correlate with some penetrated carbon from the polymer solution. Moreover, it can be seen that the 
concentration of the penetrated carbon is clearly higher than the deposited carbon on top of the ceramic support. The lower part of Figure 5.9 is related to 5 wt. \%, where aluminum is distributed homogenously and carbon is well distributed on top of the ceramic support.

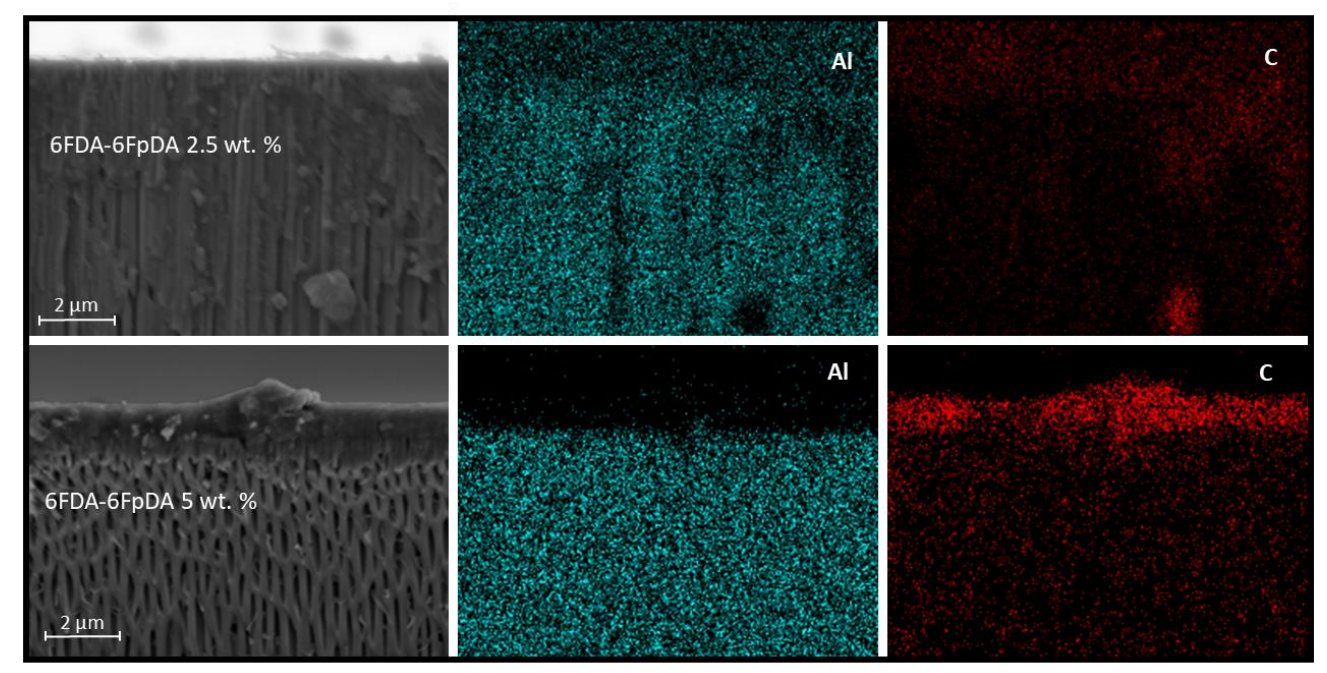

Figure 5.9. Cross-section micrograph and EDX analysis of 6FDA-6FpDA 2.5 wt. \% (upper part) and 6FDA-6FpDA 5 wt. \% (lower part)

\subsubsection{Permeation study}

Besides performing microscopy analysis, permeance values and ideal selectivities for the thin film polymer layers were measured by using the pressure increase facility described on the Chapter 4 - Methodology. $\mathrm{CO}_{2}$ and $\mathrm{O}_{2}$ permeance, as well as $\mathrm{CO}_{2} / \mathrm{CH}_{4}$ and $\mathrm{O}_{2} / \mathrm{N}_{2}$ selectivities were studied in order to assess the quality of the polymer layer. Furthermore, $\mathrm{H}_{2}$ permeance and $\mathrm{H}_{2} / \mathrm{CO}_{2}$ selectivities were also analyzed for the future applications mentioned before. Permeances and selectivities obtained as a function of the different polymer concentrations for $\mathrm{P} 84^{\circledR}$, Matrimid ${ }^{\circledR}$ and 6FDA-6FpDA are shown in Figure 5.10. It is also plotted the ideal selectivity for each polymer and gas pair was plotted in dashed lines, due to the fact that experimental selectivity values closer to the ideal selectivities (thick polymer membranes) mean lower defect concentration in the thin polymeric membranes. As it can be seen, for all the polymers, permeance values decrease as the polymer concentration in the solution increases. 


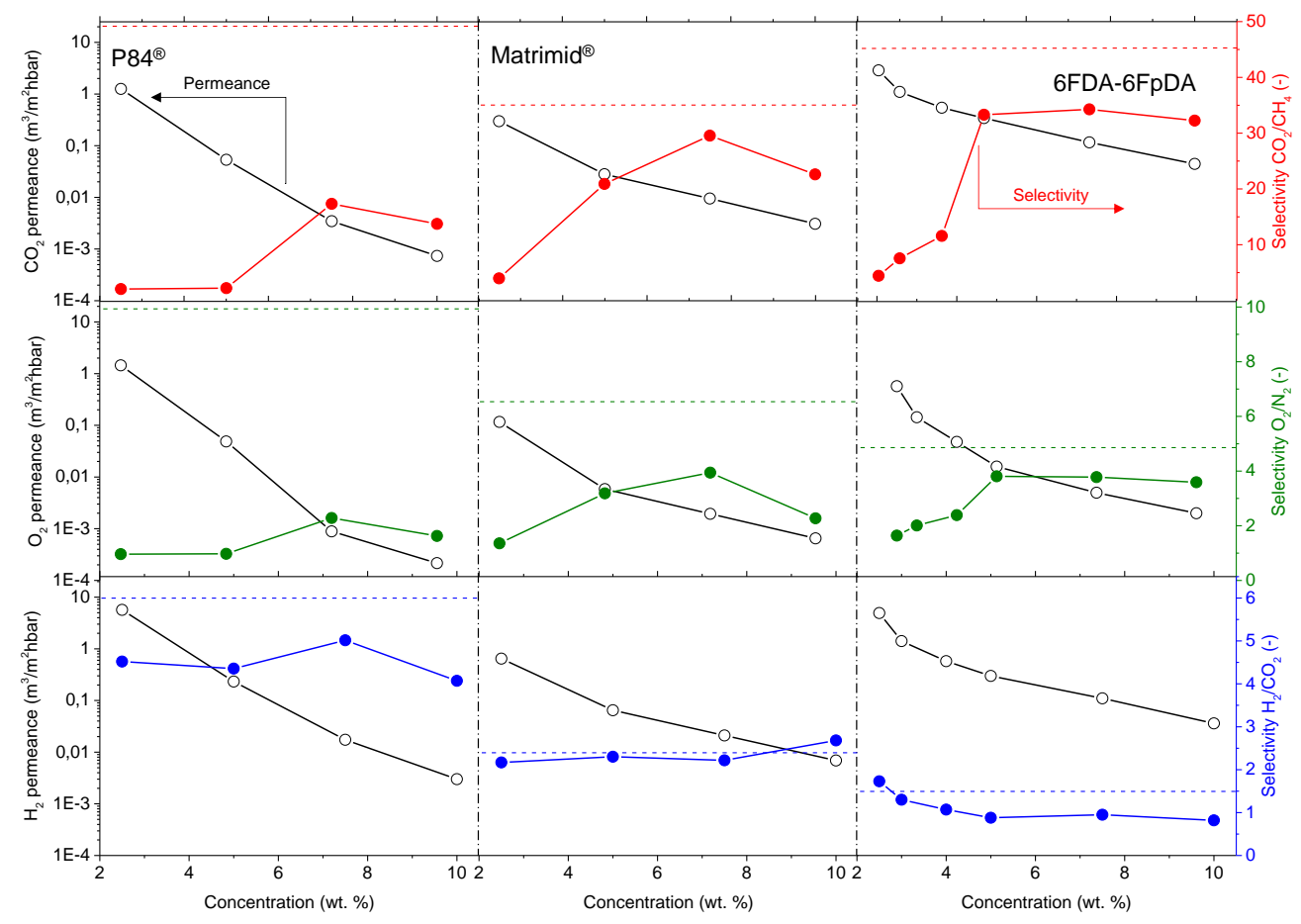

Figure 5.10. Separation properties of the polymers as a function of the solution concentration at $30^{\circ} \mathrm{C}$. Dashed lines refer to the ideal selectivity for each polymer and gas pair. Permeance values (left-y axis) are plotted in logarithmic scale

As it was previously advanced, the permeability of the polymer and the permeance of membranes with the same selective layer thickness is related with the polymer FFV: 0.19 for 6FDA-6FpDA [7], 0.17 for Matrimid ${ }^{\circledR}$ [8] and 0.14 for $\mathrm{P} 84^{\circledR}$ [9]. According to this statement, $\mathrm{P} 84^{\circledR}$ was less permeable than Matrimid ${ }^{\circledR}$ and both membranes were less permeable than 6FDA-6FpDA. With regard to selectivity values, it rises with increasing polymer concentration, generally at the cost of permeance, as it was shown in Table 5.1. Solutions with higher polymer concentrations result in thicker layers and lower defect concentration in the thin films. 
Concerning the gas pair $\mathrm{CO}_{2} / \mathrm{CH}_{4}$, polymers present an ideal selectivity between 35 and 50 for thick films. In terms of TFCMs supported by porous alumina for all three polymers, it is possible to see an evolution of the selectivity and the permeance. The most permeable polymer, 6FDA-6FpDA, showed $\mathrm{CO}_{2} / \mathrm{CH}_{4}$ selectivity values close to the ideal value obtained for thick films; whereas the less permeable polymer, $\mathrm{P} 84^{\circledR}$, showed bigger differences between both selectivities. As for the permeance, the differences between ideal selectivity for these ceramicsupported polymer membranes and the free-standing thick films were related to the FFV. Certainly, $P 84^{\circledR}$ showed bigger differences than Matrimid ${ }^{\circledR}$, and both more differences than 6FDA-6FpDA.

Regarding the comparison between other TFCMs, remarkable findings for the three studied polymers can be explained. The highest $\mathrm{CO}_{2} / \mathrm{CH}_{4}$ selectivity value for the ceramic-supported thin film Matrimid ${ }^{\circledR}$ was around 30 , which is close to the reported ideal selectivity for integral asymmetric hollow fiber membrane, $\alpha\left(\mathrm{CO}_{2} / \mathrm{CH}_{4}\right)=33$ [28], and similar to the selectivity for the same gas pair in flat sheet integral asymmetric membranes, 30 [29]. In case of $P 84^{\circledR}$, the reported ideal $\mathrm{CO}_{2} / \mathrm{CH}_{4}$ selectivity value for thin film hollow fiber is $12[28,30]$, which is lower than 16 , the ideal $\mathrm{CO}_{2} / \mathrm{CH}_{4}$ selectivity obtained in this thesis. Finally, for 6FDA-6FpDA, the ideal $\mathrm{CO}_{2} / \mathrm{CH}_{4}$ selectivity is 35 , lower than the ideal selectivity in thick films, 45 . In order to explain the reason for this difference of 10 points, one plausible interpretation regarding the possible sharp edges of the ceramic support was found: During the dip-coating process, the polymer is changing its state from vey diluted (even at $10 \%$ concentration solution) to the solid state, and evolves to gel state when polymer molecules are already entangled on top of the support. It has been previously reported that in thin films, the FFV is smaller than in thick films, which leads to restrictions in penetrant molecule transport [31]. Moreover, despite the outstanding separation properties of the 6FDA-6FpDA polymer, according to our knowledge, thin films out of this polymer in any configuration, i.e. supported by porous ceramics or polymers were not studied so far. Generally, the selectivity values obtained for the ceramic-supported thin films and the reported values for the same materials as a thin film are very similar, which confirms that the casting method was successfully done.

Secondly, similar behavior in terms of permeance and selectivity was found for the gas pair $\mathrm{O}_{2} / \mathrm{N}_{2}$. For the three polymers, thin films present lower selectivity values than thick films, especially in the case of low permeable but highly selective 
materials. Two main reasons can clarify this effect. In first place, the presence of defects is more likely in thin films, which, eventually, can reduce the selectivity. As for the second reason, it is related to their low fluxes through the membrane. When the flux or permeability is very low, the inherent error to the measurement is high, meaning that small differences in permeability could give rise to significant differences in selectivity. The selectivity values for the thin films closest to the ideal selectivity values in thick films were found for a polymer concentration of $5 \mathrm{wt}$. \% to $7.5 \mathrm{wt} . \%$ in all the cases. Hence, membranes obtained from polymer concentration solutions above the entanglement concentration $\left(C>C^{*}\right)$ are defect-free.

Finally, in case of $\mathrm{H}_{2}$ permeance, 6FDA-6FpDA shows the highest values, followed by Matrimid ${ }^{\circledR}$ and finally $P 84^{\circledR}$. For the $\mathrm{H}_{2} / \mathrm{CO}_{2}$ selectivity values, all the polymers present values close to the ideal selectivity for thick films. Concluding, and taking into account Figure 5.10, it can be ascertained a minimum concentration required to obtain a continuous and defect-less layer.

On one hand, for $\mathrm{P} 84^{\circledR}$ and Matrimid ${ }^{\circledR}$, selectivity values for $\mathrm{CO}_{2} / \mathrm{CH}_{4}$ and $\mathrm{O}_{2} / \mathrm{N}_{2}$ start to be acceptable for the $7.5 \mathrm{wt}$ \% concentration solutions (with a corresponding viscosity of $15 \mathrm{mPa} \cdot \mathrm{s}$ ). On the other hand, in the case of 6FDA-6FpDA, for the same pair of gases, selectivity value becomes approximately constant for solutions with a $5 \mathrm{wt}$. \% concentration (viscosity of $5 \mathrm{mPa} \cdot \mathrm{s}$ ).

Based on the SEM micrographs and gas transport data, one can conclude that it exists a minimum polymer solution concentration, $\mathrm{C}>\mathrm{C}^{*}$, which is needed in order to form a continuous and selective membrane. This minimum concentration is correlated with the viscosity, which changes depending on the polymer properties. In case of 6FDA-6FpDA, due to its high intrinsic viscosity, it formed a defect free continuous layer at a solution concentration, 5 wt. \%, lower than $\mathrm{P} 84^{\circledR}$ and Matrimid ${ }^{\circledR}$, $7.5 \mathrm{wt}$ \%, as it can be seen in Figure 5.11, where the evolution of permeance and selectivity for $5-7.5$ and $10 \mathrm{wt}$. \%. is depicted. 


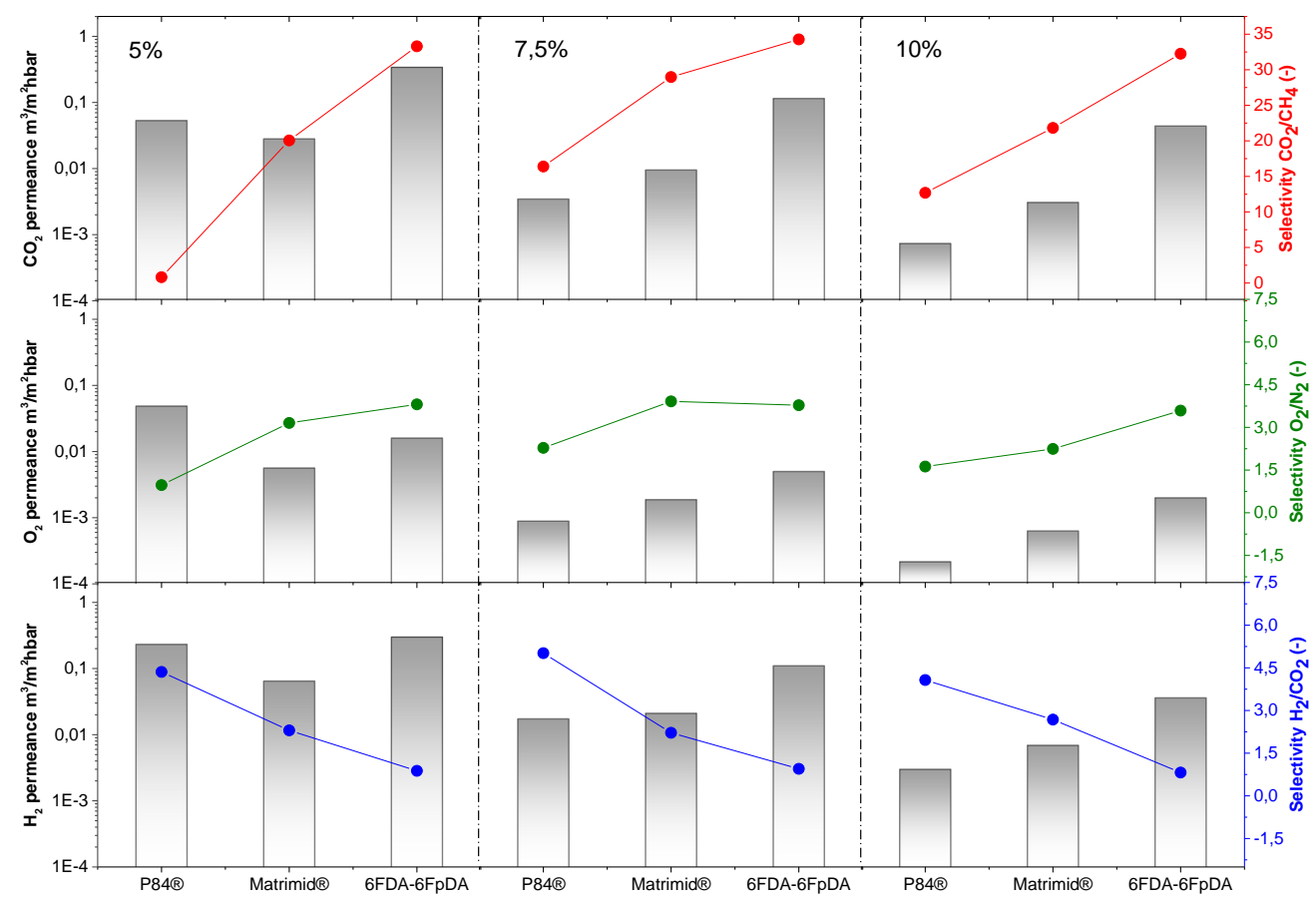

Figure 5.11. Evolution of the separation properties for the ceramic-supported thin film polymers obtained from 5, 7.5 and 10 wt. \% solution for the gas pairs $\mathrm{CO}_{2} / \mathrm{CH}_{4}, \mathrm{O}_{2} / \mathrm{N}_{2}$ and $\mathrm{H}_{2} / \mathrm{CO}_{2}$. Permeances (left-y axis) are plotted in logarithmic scale at room temperature

It can be appreciated how the membrane selectivity remains almost constant for each polymer, independent of the concentration. In contrast, the permeance decreases with the concentration increase, as it was discussed above. The differences between the polymers are directly related to their FFV. Consequently, $\mathrm{P} 84^{\circledR}$ is expected to have the lowest permeances. However, it can be seen that, at the concentration of 5 wt. \%, $P 84^{\circledR}$ is faster than Matrimid ${ }^{\circledR}$, and in the case of $\mathrm{O}_{2}$, even faster than the 6FDA-6FpDA polymer.

At the same time, it also can be appreciated that, the selectivity for $\mathrm{P} 84^{\circledR}$ at 5 wt. \% was lower than the selectivities for the films obtained from solutions that were more concentrated, especially in the case of $\mathrm{CO}_{2}$. This could be caused by a bad formation of the continuous layer on top of the membrane. In Chapter 4 Methodology, it was mentioned the molecular weight of the three polymers: P84 ${ }^{\circledR}$

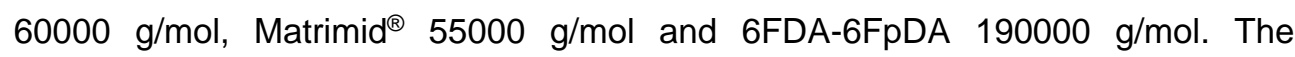
molecular weight of 6FDA-6FpDA is 3.2 times larger than that of $P 84^{\circledR}$ and 3.5 larger 
than that of Matrimid ${ }^{\circledR}$. A higher molecular weight will increment the viscosity of the polymer solution for the same polymer concentration; hence the formation of a continuous film will be favored. For the rest of the materials and concentrations, the results were as expected, what again confirms the successful deposition of the thin film polymer layer on top of the ceramic support.

\subsubsection{High temperature permeation study}

The use of ceramic supports and high thermally resistance polymers opens the possibility of the application of polymer TFCMs in processes that occur at elevated temperatures e.g. water gas shift reactors in coal gasification process. As it was advanced in the introduction, this kind of processes require a final $\mathrm{H}_{2}$ purification step, because hydrogen production increases with $\mathrm{CO}_{2}$ co-production [32]. Process temperature can vary depending on the plant and other process conditions but generally the range is between 200 and $500{ }^{\circ} \mathrm{C}[33,34]$. Hence, the separation properties as a function of temperature were studied to assess the suitability of these materials for operation at higher temperatures.

Figure 5.12 shows $\mathrm{H}_{2}$ permeance and $\mathrm{H}_{2} / \mathrm{CO}_{2}$ selectivity, measured at a wide range of temperatures, from 30 to $90^{\circ} \mathrm{C}$, and both increase as a function of temperature. Once again, permeance and selectivity are highly dependent on the FFV. It can be observed that the higher the FFV, the higher the permeability coefficient and, therefore, $\mathrm{H}_{2}$ permeability values follow the order $\mathrm{P} 84^{\circledR}<$ Matrimid $^{\circledR}$ $<6$ FDA-6FpDA. Additionally, the thickness of the polymer films also affects the permeance values: the higher the polymer solution concentration is, the thicker the membrane layer and consequently, lower permeance. Accordingly, a thinner polymer layer is always preferred since permeance values will be higher than for thicker polymer layers, if one does not take into consideration the concentration polarization effect, which becomes more important as permeance values increase. On the other hand, the thickness does not affect the selectivity .In the case of the $\mathrm{H}_{2} / \mathrm{CO}_{2}$ selectivity, as it can be seen in Figure 5.12, the most permeable polymer 6FDA-6FpDA presented the lowest selectivity, whereas the low permeable P84 ${ }^{\circledR}$ showed the highest selectivity. Moreover, selectivity for thick films, i.e. self-supported 
polymer membranes, can be seen in Figure 5.12 as cross symbols. As it was said previously, selectivity should not be affected by the thickness, it is an intrinsic property of the polymer. Hence, it should be similar to the TFCM studied. For 6FDA6FpDA, selectivity do not change depending on the structure of the polymer membrane. Matrimid exhibit slightly higher selectivity for thick films, but still acceptable. And finally, it is observed that the selectivity in thick film for $\mathrm{P} 84^{\circledR}$ is lower than selectivity in TFCM.

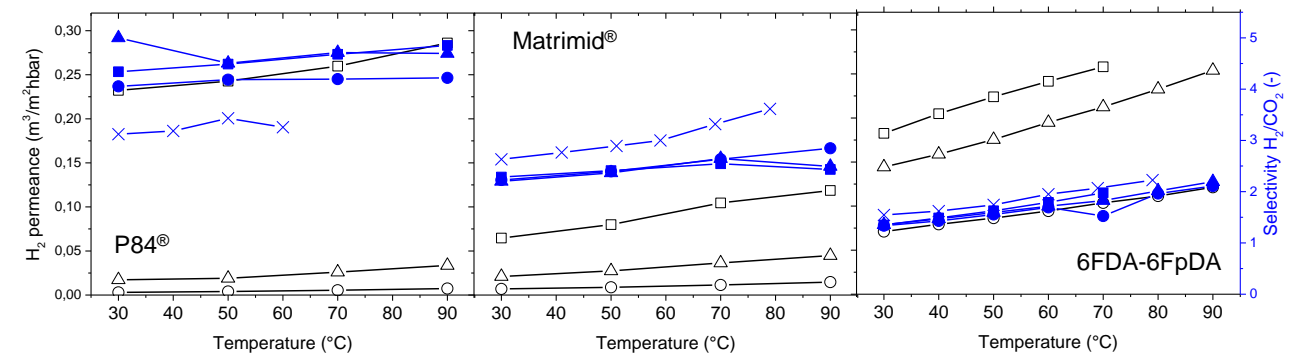

Figure 5.12. Separation properties of the ceramic-supported thin film polymers for the $\mathrm{H}_{2} / \mathrm{CO}_{2}$ separation as a function of the temperature and concentration of the polymer solution. Unfilled symbols represent the permeance (in the left-y axis) and filled symbols represent selectivity (in the right-y-axis). Squares represent $5 \%$ solution, triangles $7.5 \%$, circles $10 \%$ and crosses thick films

The dependence of gas permeance on temperature can be expressed in terms of an Arrhenius-type relationship. Arrhenius considers the transport of the gas molecules through a membrane as a thermally activated process [35]. Consequently, the activation energies $\left(E_{A}\right)$ for each gas and for the three different polymers were calculated from the "pressure increase" experimental results obtained in the range 30 to $90^{\circ} \mathrm{C}$, see Table 5.3. $\mathrm{E}_{\mathrm{A}}$ values depend on the polymer nature, and they are smaller for the polymers with higher FFV [36].

The differences between the $E_{A}$ values for different gases indicate how the selectivity will improve as a function of temperature. $\mathrm{CO}_{2}$ transport through polymers is strongly dependent on the solubility coefficient, which decreases with increasing temperature. For the current studied polymers, in theory, the diffusion coefficient change more significantly with temperature than the solubility coefficient, including in the case of $\mathrm{CO}_{2}$. This results in positive $\mathrm{E}_{\mathrm{A}}$ values. However, since the $\mathrm{E}_{\mathrm{A}}$ value for $\mathrm{CO}_{2}$ is significantly lower than that of $\mathrm{H}_{2}$, the selectivity $\mathrm{H}_{2} / \mathrm{CO}_{2}$ increases with temperature rise, opposite to e.g. $\mathrm{O}_{2} / \mathrm{N}_{2}$ selectivity. 
Table 5.3. Activation energies of permeance for the different gases for TFCMs prepared using 10 wt. $\%$ polymer solutions

\begin{tabular}{c|c|c|c|c|c}
\cline { 2 - 6 } & \multicolumn{5}{c}{ Activation energy $\left(\mathrm{E}_{\mathbf{A}}\right)\left(\mathbf{k J} \cdot \mathbf{m o l}^{-1}\right)$} \\
\cline { 2 - 6 } & $\mathrm{CO}_{2}$ & $\mathrm{O}_{2}$ & $\mathrm{H}_{2}$ & $\mathrm{CH}_{4}$ & $\mathrm{~N}_{2}$ \\
\hline P84 $^{\circledR}$ & 13.9 & 20.74 & 13.66 & 32.29 & 21.53 \\
Matrimid $^{\Theta}$ & 7.82 & 19.80 & 11.58 & 33.42 & 28.60 \\
6FDA-6FpDA & 1.63 & 7.83 & 8.07 & 21.60 & 19.75 \\
\hline
\end{tabular}

Finally, the measured $\mathrm{H}_{2}$ permeances and $\mathrm{H}_{2} / \mathrm{CO}_{2}$ selectivities for temperatures from $30{ }^{\circ} \mathrm{C}$ to $90{ }^{\circ} \mathrm{C}$, and the predicted (up to $300^{\circ} \mathrm{C}$ ) are shown in Figure 5.13. In case of reaching temperature above $300{ }^{\circ} \mathrm{C}$, membranes will require a crosslinking treatment in order to increase their $\mathrm{T}_{\mathrm{g}}$ and favor their mechanical and chemical properties. $\mathrm{H}_{2} / \mathrm{CO}_{2}$ selectivity of the studied membranes does only slightly exceed the Knudsen selectivity of 4.69 . However, ideal Knudsen flow would require a situation where no convective, non-selective contribution to the flow through a porous membrane would contribute to permeation. This situation is difficult to achieve. The dense, polymeric membrane layer prevents any possibility of convective flow. Furthermore dense polymer layers may allow (i) the controlled transport of other gaseous components and water through the membrane and (ii) an additional degree of freedom in process design, i.e. the selection of feed and permeate pressure without considering any selective transport in a pore system. As conclusion, thin film ceramic-supported membranes are capable for $\mathrm{H}_{2}$ separation at high temperatures up to $300{ }^{\circ} \mathrm{C}$ due to their relevant chemical, mechanical and transport properties. 


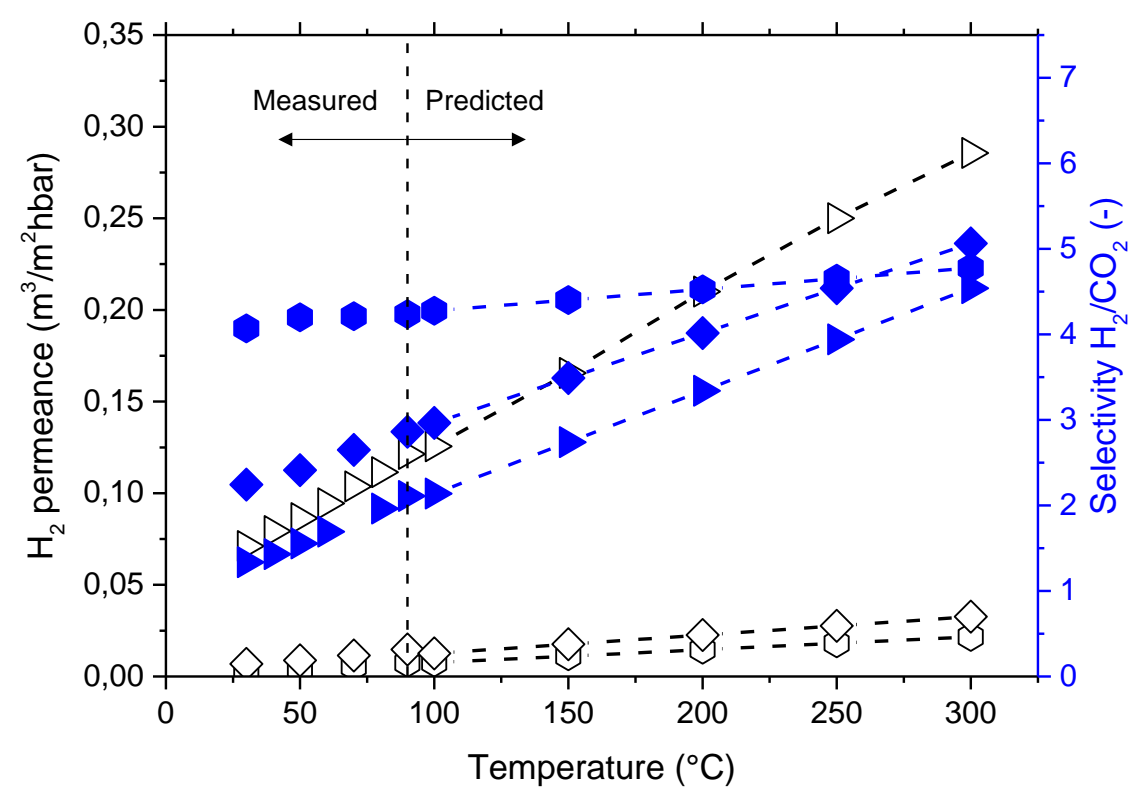

Figure 5.13. Evolution and prediction of the permeance and selectivity as a function of the process temperature conditions for $10 \%$ concentration of polymer. Open symbols represent the permeance (on the left-y axis) and filled symbols represent selectivity (on the right-y-axis). Hexagon represent $P 84^{\circledR}$, diamond Matrimid $^{\circledR}$ and triangle 6FDA-6FpDA 


\subsection{Conclusions}

The influence of the polymer solution used in the dip-coating process and its effect in the separation properties was studied for a selective ceramic-supported thin polymer. This approach was tested for three different polyimides, $\mathrm{P} 84^{\circledR}$, Matrimid ${ }^{\circledR}$, and 6FDA-6FpDA. Different polymer solutions were prepared with different concentrations for all the polymers: $0.5-1-2.5-3-4-5-7.5-8$ and $10 \mathrm{wt}$. \%. The deposited thickness was affected by the polymer concentration in the solution. By adjustment of the conditions, defect-free thin films of less than $1 \mu \mathrm{m}$ thickness were successfully deposited on porous alumina supports for all the studied polymers.

How the polymer concentration was influencing on the separation properties of the materials was carefully characterized. By increasing the concentration, thicker polymer layers were achieved and, as a consequence, lower permeances for all tested gases were measured. In order to test the quality of the polymer deposition, a comparison between the selectivity factors of thick and thin films was carried out. The value for the entanglement concentration $\left(C^{*}\right)$ for the three polymers were obtained from the solution viscosity study. The order for intrinsic viscosity values in $\mathrm{mL} \cdot \mathrm{g}^{-1}$ were 6FDA-6FpDA $(52.544)>$ Matrimid $^{\circledR}(34.754)>\mathrm{P} 84^{\circledR}(27.249)$. For the low molecular weight polymers, $\mathrm{P} 84^{\circledR}$ and Matrimid ${ }^{\circledR}$, highly viscous solutions were needed, while for the high molecular weight 6FDA-6FpDA polymer, lower viscous solution was sufficient to get a continuous defect free polymer layer.

The polymers were selected for their differences in permeability, according to the evolution of the FFV is $P 84^{\circledR}<$ Matrimid $^{\circledR}<6$ FDA-6FpDA. The same tendency was found for the ceramic-supported thin film polymers. The effect of the temperature on the separation properties was studied. As it can be expected, the permeance for all the gases tested increased with the temperature, but the increase of the $\mathrm{H}_{2}$ permeance was higher than for the rest of the gases, included $\mathrm{CO}_{2}$. Therefore, an increase of the $\mathrm{H}_{2} / \mathrm{CO}_{2}$ selectivity with temperature was observed for all the polymers and compositions. The prediction of the properties at elevated temperatures showed that the selectivity raises with decreasing FFV: $\mathrm{P} 84^{\circledast}>$ Matrimid $^{\circledR}>6$ FDA-6FpDA. This study shows the potential of this approach in order to apply polymeric membranes for processes at elevated temperatures. 


\subsection{References}

1. Gallucci, F., et al., Steam Reforming of Methane in a Membrane Reactor: An Industrial Case Study. Industrial \& Engineering Chemistry Research, 2006. 45(9): p. 2994-3000.

2. Reddy, G.K. and P.G. Smirniotis, Chapter 3 - Low-Temperature WGS Reaction, in Water Gas Shift Reaction. 2015, Elsevier: Amsterdam. p. 47100.

3. Ockwig, N.W. and T.M. Nenoff, Membranes for Hydrogen Separation. Chemical Reviews, 2007. 107(10): p. 4078-4110.

4. Liaw, D.-J., et al., Advanced polyimide materials: Syntheses, physical properties and applications. Progress in Polymer Science, 2012. 37(7): p. 907-974.

5. Wei, W., et al., Interfacial adhesion between polymer separation layer and ceramic support for composite membrane. AIChE Journal, 2010. 56(6): p. 1584-1592.

6. Park, J.Y. and D.R. Paul, Correlation and prediction of gas permeability in glassy polymer membrane materials via a modified free volume based group contribution method. Journal of Membrane Science, 1997. 125(1): p. 23-39.

7. Wang, X.-Y., et al., A molecular simulation study of cavity size distributions and diffusion in para and meta isomers. Polymer, 2005. 46(21): p. 91559161.

8. Wiegand, J.R., et al., Synthesis and characterization of triptycene-based polyimides with tunable high fractional free volume for gas separation membranes. Journal of Materials Chemistry A, 2014. 2(33): p. 13309-13320.

9. Tin, P.S., et al., Separation of $\mathrm{CO} 2 / \mathrm{CH} 4$ through carbon molecular sieve membranes derived from P84 polyimide. Carbon, 2004. 42(15): p. 31233131.

10. Zhang, Y., et al., Gas permeability properties of Matrimid® membranes containing the metal-organic framework $C u-B P Y-H F S$. Journal of Membrane Science, 2008. 313(1): p. 170-181.

11. Yoon, T.S., et al., Single and Multiple-Step Dip-Coating of Colloidal Maghemite ( $\gamma$-Fe2O3) Nanoparticles onto Si, Si3N4, and SiO2 Substrates. Advanced Functional Materials, 2004. 14(11): p. 1062-1068.

12. $\mathrm{Yu}, \mathrm{H}$., et al., Numerical Well Testing Interpretation Model and Applications in Crossflow Double-Layer Reservoirs by Polymer Flooding. The Scientific World Journal, 2014. 2014: p. 11.

13. Haider, A., K.C. Gupta, and I.-K. Kang, Morphological Effects of HA on the Cell Compatibility of Electrospun HA/PLGA Composite Nanofiber Scaffolds. BioMed Research International, 2014. 2014: p. 11. 
14. Tassieri, M., et al., Microrheology with Optical Tweezers: Measuring the relative viscosity of solutions 'at a glance'. Scientific Reports, 2015. 5: p. 8831.

15. Larson, R.G., The structure and rheology of complex fluids. 1999, New York: Oxford University Press.

16. Pamies, R., et al., Determination of intrinsic viscosities of macromolecules and nanoparticles. Comparison of single-point and dilution procedures. Colloid and Polymer Science, 2008. 286(11): p. 1223-1231.

17. D. Sudduth, R., Development of Huggins' and Kraemer's equations for polymer solution evaluations from the generalized viscosity model for suspensions. Vol. 66. 1997. 2319-2332.

18. Maron, S.H. and R.B. Reznik, $A$ new method for determination of intrinsic viscosity. Journal of Polymer Science Part A-2: Polymer Physics, 1969. 7(2): p. 309-324.

19. Bercea, M., S. Morariu, and D. Rusu, In situ gelation of aqueous solutions of entangled poly(vinyl alcohol). Soft Matter, 2013. 9(4): p. 1244-1253.

20. Mikkonen, K., et al., Determination of physical emulsion stabilization mechanisms of wood hemicelluloses via rheological and interfacial characterization. Vol. 12. 2016. 8690-8700.

21. Risica, D., et al., Rheological properties of guar and its methyl, hydroxypropyl and hydroxypropyl-methyl derivatives in semidilute and concentrated aqueous solutions. Vol. 51. 2010. 1972-1982.

22. Roger, S., et al., Structural and multi-scale rheophysical investigation of diphasic magneto-sensitive materials based on biopolymers. Vol. 38. 2015. 173.

23. Galleguillos, R., et al., COMPLEX INTERACTIONS OF A HYPER-HASE POL YMER WITH ANIONIC AND NONIONIC SURFACTANTS. 2011.

24. Riazi, K., et al., Polystyrene comb architectures as model systems for the optimized solution electrospinning of branched polymers. Polymer, 2016. 104: p. 240-250.

25. Philpott, D.R., Whatman-Anotec update. Membrane Technology, 1992. 1992(21): p. 6-7.

26. Ansaloni, L., et al., Effects of Thermal Treatment and Physical Aging on the Gas Transport Properties in Matrimid B. Vol. 70. 2014. 367-379.

27. Yavari, M., et al., Physical aging of glassy perfluoropolymers in thin film composite membranes. Part II. Glass transition temperature and the free volume model. Journal of Membrane Science, 2017. 525: p. 399-408.

28. Falbo, F., et al., Polyimide hollow fiber membranes for CO2 separation from wet gas mixtures. Brazilian Journal of Chemical Engineering, 2014. 31: p. 1023-1034. 
29. Shishatskiy, S., et al., Polyimide Asymmetric Membranes for Hydrogen Separation: Influence of Formation Conditions on Gas Transport Properties. Vol. 8. 2006. 390-397.

30. Choi, S.-H., et al., H2 Separation From H2/N2 and H2/CO Mixtures with CoPolyimide Hollow Fiber Module. Separation Science and Technology, 2011. 46(1): p. 1-13.

31. Barsema, J.N., et al., Preparation and characterization of highly selective dense and hollow fiber asymmetric membranes based on BTDA-TDI/MDI co-polyimide. Journal of Membrane Science, 2003. 216(1): p. 195-205.

32. Muradov, N., Hydrogen via methane decomposition: an application for decarbonization of fossil fuels. International Journal of Hydrogen Energy, 2001. 26(11): p. 1165-1175.

33. Chen, W.-H., et al., Reaction phenomena of high-temperature water gas shift reaction in a membrane reactor. Fuel, 2017. 199(Supplement C): $\mathrm{p}$. 358-371.

34. Lee, S.H., et al., Development of water gas shift/membrane hybrid system for precombustion CO2 capture in a coal gasification process. Energy Procedia, 2011. 4(Supplement C): p. 1139-1146.

35. Tena, A., S. Shishatskiy, and V. Filiz, Poly(ether-amide) vs. poly(etherimide) copolymers for post-combustion membrane separation processes. RSC Advances, 2015. 5(29): p. 22310-22318.

36. Yampolskii, Y., et al., Correlations with and prediction of activation energies of gas permeation and diffusion in glassy polymers. Journal of Membrane Science, 1998. 148(1): p. 59-69. 
Chapter 6

Polymer membranes for high temperature applications 



\section{Polymer membranes for high temperature applications}

\subsection{Introduction}

In the previous chapter, the influence of the polymer solution used in the dipcoating process and its effect in the separation properties was studied for a selective ceramic-supported thin polymer. Moreover, composite ceramic-polymer membranes were tested at temperatures from $25 \stackrel{\circ}{ } \mathrm{C}$ to $90 \stackrel{\circ}{ } \mathrm{C}$, in order to analyze their permeation properties and selectivity values for different gas pair gases. In this chapter, thin film composite membranes (TFCMs) of 6FDA-6FpDA, Matrimid ${ }^{\circledR}$ and P84 ${ }^{\circledR}$ polyimides are tested at higher temperatures for the sake of investigating their chemical and mechanical stability, as well as their suitability for in-situ gas separation in catalytic membrane reactors. As it was previously mentioned, polyimides have been thoroughly investigated for the last 40 years [1, 2]. Polyimides exhibits considerably higher gas separation properties, permeability and selectivity, than other glassy polymers. A broad variety of publications and works related with polyimides, as well as several reports regarding outstanding polyimide properties have been published [3]. Unfortunately, only few publications where the maximum tested temperature reaches $100 \stackrel{\circ}{ } \mathrm{C}$ are available. In fact, the highest temperatures checked are between 60 and $90 \stackrel{\circ}{\mathrm{C}}$ [4-8]. In this chapter, novel single gas and mixed gas measurements performed at temperatures up to $280{ }^{\circ} \mathrm{C}$ are presented.

In chapter 5 , the gas pair target was $\mathrm{H}_{2} / \mathrm{CO}_{2}$ for in-situ gas separation for steam methane reforming and water gas shift reaction, among others. As far as our knowledge, there are not so many works related with polymer membranes for $\mathrm{H}_{2}$ separation at high temperatures $[9,10]$. Due to the reason that a thinner polymer layer is always preferred since permeance values will be higher than for thicker polymer layers, membranes were coated on ceramic support (previous chapter) and also on polymer support, in order to obtain thinner membrane layers.

In the first part of this chapter, water separation is firmly investigated since several processes which may require in-situ water separation exist. Hence, $\mathrm{H}_{2} \mathrm{O} / \mathrm{N}_{2}$ gas pair was selected as target for composite ceramic-polymer membranes. Secondly, $\mathrm{H}_{2} / \mathrm{CO}_{2}$ separation is investigated at high temperatures up to $280{ }^{\circ} \mathrm{C}$ by using polymer membrane deposited on polymer porous support. 
Mixed gas measurements have been reported for $\mathrm{H}_{2} \mathrm{O} / \mathrm{N}_{2}$ gas pair in the case of composite ceramic-polymer membranes, as well as single gas measurements for $\mathrm{H}_{2}$ and $\mathrm{CO}_{2}$ in the case of composite polymer-polymer membranes. Additionally, microscopy analysis was also carried out for both cases in order to ensure the proper coating of the supports, as well as evaluate the thickness of the selective layers. Regarding the ceramic support, ceramic discs from Atech Company were selected, which are formed by different layers of $\mathrm{Al}_{2} \mathrm{O}_{3} / \mathrm{ZrO}_{2}$.

Regarding polymer support, it was selected polybenzimidazole (PBI). This polyimide is a thermoplastic that exhibits an exceptionally high heat-resistance. PBI and its derivatives present outstanding properties, but they are quite expensive and difficult to manufacture, in comparison with other kind of polymers that do not offer such good gas properties. Actually, $\mathrm{PBI}$ is one of the highest performing engineering plastics on the industry and offers one of the highest heat resistance and service temperature of any unfilled thermoplastic [11]. Nevertheless, this polymer, apart from being uneconomical and difficult to assemble, it is also very problematic to do sufficiently thin selective layers out of it [12]. Accordingly, it was selected for developing an asymmetric porous support composed by $\mathrm{PBI}$ and polyphenylene sulfide fiber (PPS).

\subsection{Results and discussion}

\subsubsection{Composite Ceramic-Polymer Membranes}

\subsubsection{Support material}

Regarding the support material, ceramic discs from Atech Company were used in order to ensure desirable thermal and mechanical stability. Atech ceramic discs are asymmetric membranes consisting on a pure support of $\mathrm{Al}_{2} \mathrm{O}_{3}$, a microfiltration membrane of $\mathrm{Al}_{2} \mathrm{O}_{3} / \mathrm{ZrO}_{2}$ and a final ultrafiltration membrane of $\mathrm{ZrO}_{2}$. The diameter of the ceramic disc is around $15 \mathrm{~mm}$ and the pore size of the UF $\mathrm{ZrO}_{2}$ layer is approximately $0.03 \mu \mathrm{m}$ [13]. More information about the ceramic support can be found in Chapter 4 - Methodology. 


\subsubsection{Membrane formation}

Similar process as the explained for anodisc ceramic supports (Chapter 5 ) was performed for Atech ceramic supports. Polymer solutions were prepared using THF as a solvent for Matrimid ${ }^{\circledR}$ and 6FDA-6FpDA polymers, and NMP in the case of $P 84^{\circledR}$. The minimum viscosity needed for a defect free and continuous selective layer on top of a ceramic support was studied in Chapter 5 . Hence, the already studied concentrations and viscosities were used as starting point.

Firstly, it was coated an Atech ceramic membrane with a 5 wt. \% concentration solution of 6 FDA-6FpDA, in order to evaluate the behavior and the compatibility between the organic and the inorganic materials. In Figure 6.1, it can be seen a cross section of a trial of 6FDA-6FpDA composite ceramic-polymer membrane 5 wt. \% solution concentration. Support layers of Atech ceramic disc can be clearly differentiated: a first pure layer of $\mathrm{Al}_{2} \mathrm{O}_{3}$, a microfiltration membrane of $\mathrm{Al}_{2} \mathrm{O}_{3} / \mathrm{ZrO}_{2}$ and a final ultrafiltration membrane of $\mathrm{ZrO}_{2}$. On top, the polymer selective layer, which do not penetrate in the ceramic support, is placed. Unfortunately, although the polymer solution was viscous enough to not go through the ceramic support, it does not cover completely the surface. Hence, the membrane is not form correctly, and some blanks can be seen on top.

This effect is more visible in Figure 6.2, which shows different images of the top layer. It is appreciable that the top surface of the ceramic Atech discs is quite rough, and so, polymer solution should be more viscous in order to cover completely the zirconia layer, and do not leave any space without coating, as it happened in the first trial with 5 wt. \% solution concentration.

Consequently with the previous results, it was decided to increase the concentration, i.e. the viscosity for the three different polyimides. After several trials, the minimum viscosity needed for the manufacture of TFCM on Atech ceramic membranes was obtained for each polymer. In Figure 6.1, final concentrations and viscosities are detailed. 


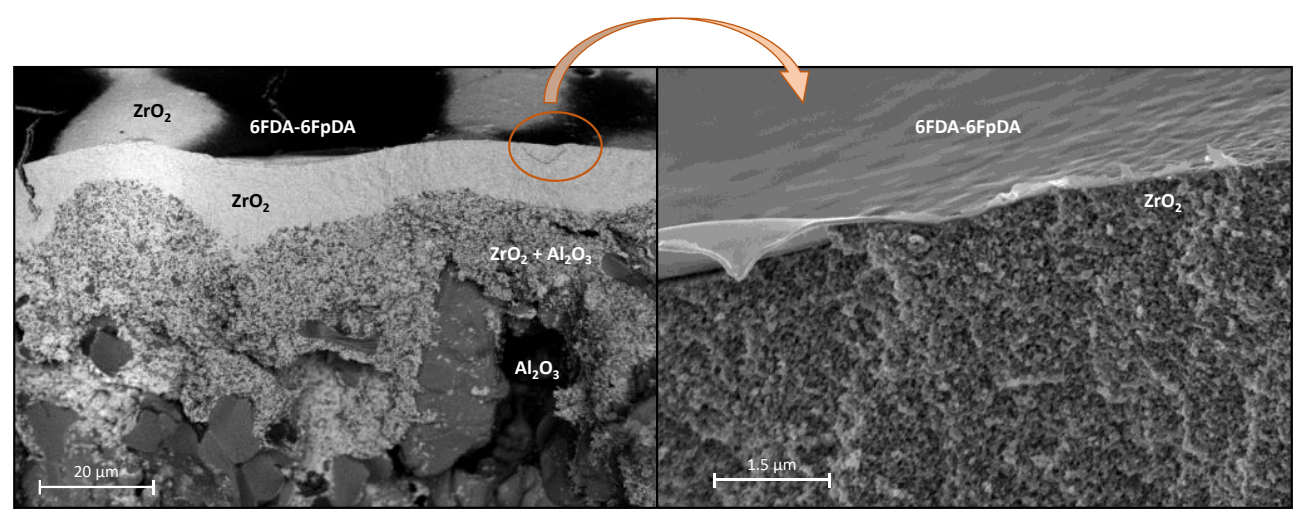

Figure 6.1. Cross-sections SEM micrographs of 6FDA-6FpDA 5 wt. \% composite ceramic-polymer membrane

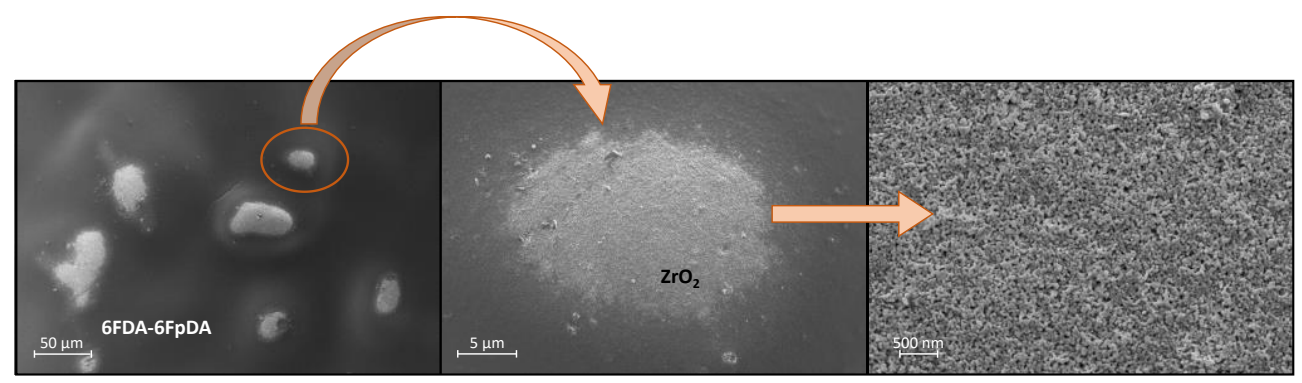

Figure 6.2. Top surface SEM micrographs of 6FDA-6FpDA 5 wt. \% composite-polymer membrane

Table 6.1. Solution specification of the three different polymers used in this work

Polymer Concentration (wt. \%) Viscosity (mPa.s)

\begin{tabular}{l|cc}
\hline 6FDA-6FpDA & 9 & 28 \\
Matrimid $^{\circledR}$ & 8.6 & 31 \\
P84 $^{\circledR}$ & 8.2 & 41 \\
\hline
\end{tabular}


All the membranes were fabricated by a single coating step, dismissing the possibility to dip-coat more than once (multiple steps) [14], in order to obtain better reproducibility and homogeneity, and also to prevent the chance of massive polymer penetration into pores of the porous support.

For this type of membranes, and after the coating process and solvent evaporation at ambient conditions, they were treated under vacuum at $250 \stackrel{\circ}{\circ}$ for 1 hour. The temperature of $250^{\circ} \mathrm{C}$ was selected in order to ensure that all the solvent used during the dip-coating process is fully evaporated, as well as to accelerate the initial aging process in the polymer, which leads to experimental results that are reproducible in time (samples can be measured at different times after membrane preparation).

Microscopy analysis was performed for the three membranes listed in Table 6.1 and different images of the top layer and the cross-section of the three different polymer membranes were analyzed based on Focused Ion Beam (FIB).

Figure 6.3 shows microscopy images from the cross section and the top surface image from composite ceramic-polymer membrane of 6FDA-6FpDA, Matrimid ${ }^{\circledast}$ and $\mathrm{P} 84^{\circledR}$. On the left side of the figure, it can be seen that, for all the polymers, the thickness of the selective layer is similar, due to the similar concentration of the coating solutions. Additionally, it observed no penetration of the polymer solution into the porous support because of their high viscosity, ensuring a proper coating of the layer.

Regarding the top surface images, on the right side of Figure 6.3, in the case of 6FDA-6FpDA, an image where the different support layers can be observed is shown. This part of the composite membrane corresponds to the edge of itself, where a small crack was produced after the testing of the permeation properties. In the rest of the sample, the polymer layer is continuous, as well as the other two polymer selective layers, Matrimid ${ }^{\circledR}$ and $\mathrm{P} 84^{\circledR}$. 


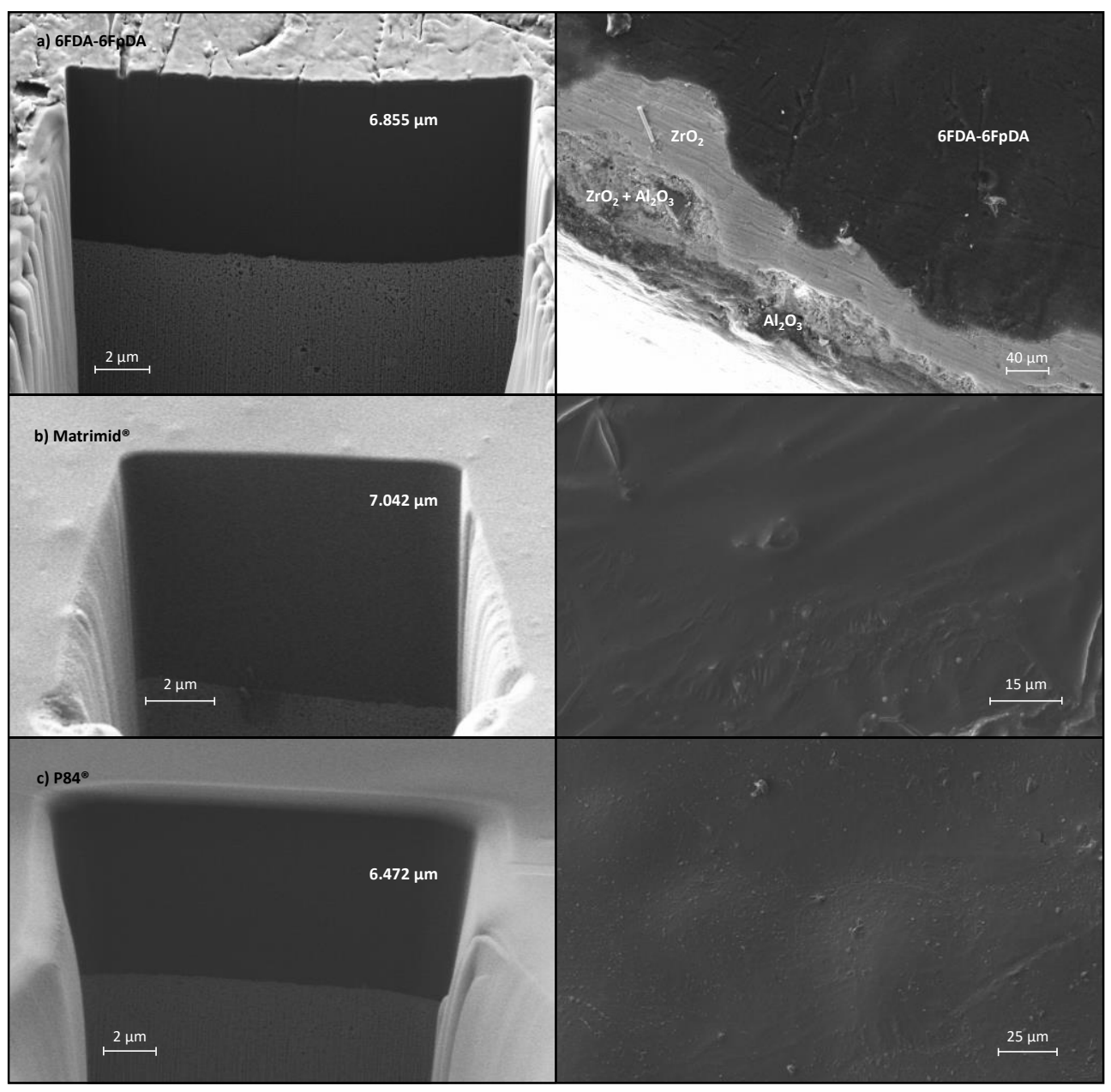

Figure 6.3. On the left side, cross section images from FIB micrographs of a) 6FDA-6FpDA with $1.439 \mu \mathrm{m}, b)$ Matrimid $^{\otimes}$ with $1.360 \mu \mathrm{m}$ and c) $P 84^{\circledR}$ with $3.617 \mu \mathrm{m}$. On the right side, top surface images from FE-SEM micrographs of a) 6FDA-6FpDA, b) Matrimid $^{\circledR}$ and c) $P 84^{\circledR}$ 


\subsubsection{Gas transport properties}

Permeance values and selectivities for the ceramic-polymers were characterized by using the polymeric membrane set-up explained in Chapter 4 Methodology. Water permeation was measured using a hygrometer, whereas permeation of the other gases was obtained by using a micro GC. $\mathrm{N}_{2}$ and $\mathrm{H}_{2} \mathrm{O}$ permeance, as well as $\mathrm{H}_{2} \mathrm{O} / \mathrm{N}_{2}$ selectivity were studied. $\mathrm{N}_{2}$ flow was kept constant at $50 \mathrm{~mL} / \mathrm{min}$, and before introduce it in the reactor, it went through a water gas bubbler. Depending on the temperature of the gas bubbler, and accordingly with the Antoine equation [15], the partial pressure of water, and so the amount of water which is introduced together with the $\mathrm{N}_{2}$ flow varies.

Table 6.2 summarizes the concentration of water in the feed as a function of the gas bubbler temperature, as well as the amount of water flow that is introduced with the inlet flow of $50 \mathrm{~mL} / \mathrm{min}$ of $\mathrm{N}_{2}$.

Table 6.2. Water partial pressure and inlet water flow as a function of temperature

\begin{tabular}{c|cc}
$\begin{array}{c}\text { Gas bubbler } \\
\text { temperature }\left(^{\circ} \mathrm{C}\right)\end{array}$ & $\begin{array}{c}\text { Water partial } \\
\text { pressure }(\mathbf{a t m})\end{array}$ & $\begin{array}{c}\text { Inlet water flow } \\
(\mathbf{m L} / \mathbf{m i n})\end{array}$ \\
\hline 50 & 0.1214 & 6.9118 \\
60 & 0.1961 & 12.1970 \\
70 & 0.3068 & 22.1300 \\
80 & 0.4665 & 43.7189 \\
85 & 0.5696 & 66.1620 \\
\hline
\end{tabular}


As a sweep gas, $50 \mathrm{~mL} / \mathrm{min}$ of $\mathrm{Ar}$ were used for the permeation test. In Figure 6.4 , it can be seen the permeance of $\mathrm{H}_{2} \mathrm{O}$ and $\mathrm{N}_{2}$ on the left-y-axes, while in the selectivity is depicted in the right-y-axes, as a function of the reactor temperature. Matrimid ${ }^{\circledR}$ and $\mathrm{P} 84^{\circledR}$ were measured at five different reactor temperatures: $75{ }^{\circ} \mathrm{C}-$ $100{ }^{\circ} \mathrm{C}-150 \stackrel{\circ}{\circ} \mathrm{C}-200{ }^{\circ} \mathrm{C}-240 \stackrel{\circ}{\circ} \mathrm{C}$. P84 ${ }^{\circledR}$ was only measured for the three first temperatures when the saturator was at $50^{\circ} \mathrm{C}$, due to the fact that the selectivity was below 1 once $200{ }^{\circ} \mathrm{C}$ was reached. On the other hand, due to technical problems, 6 FDA-6FpDA was measured from $150 \stackrel{\circ}{ } \mathrm{C}$ to $240 \stackrel{\circ}{\circ}$. In all the cases, water permeance constantly decreases with the reactor temperature, while $\mathrm{N}_{2}$ permeance slightly increase as a function of temperature, which is translated into a continuously decrease of the selectivity. Water vapor behaves differently to other gases such as $\mathrm{H}_{2}$ and $\mathrm{N}_{2}$ as a function of temperature due to its solubility coefficient, it decreases with temperature. Permeation tests for ceramic composite membranes were developed as mixed gas measurements, which can lead to a different behavior of gases as a function of temperature as compared with single gases measurements. Figure 6.4 shows how the permeance of $\mathrm{H}_{2} \mathrm{O}$ and $\mathrm{N}_{2}$ is similar for the three different polymers. This fact might be related with the thickness of the membranes, above 6 $\mu \mathrm{m}$, that makes complicated to observe significant differences between the permeances.

Ultrafiltration ceramic membranes are commonly used in the water treatment industry for water purification [16-18]. So as to assure that the ceramic support is not interfering the water permeance, a blank permeation test only with the ceramic support was carried out at $150 \stackrel{\circ}{\circ}$ (reactor temperature) and for the five different cases regarding water feed concentration. Figure 6.5 depicts the comparison between the permeance of $\mathrm{H}_{2} \mathrm{O}$ and $\mathrm{N}_{2}$ at $150{ }^{\circ} \mathrm{C}$ of the pure ceramic support and the composite ceramic-polymer membranes. Permeation of ceramic support exhibit identical $\mathrm{H}_{2} \mathrm{O}$ and $\mathrm{N}_{2}$ permeance, showing no selectivity. In contrast, for the three different polymers, $\mathrm{H}_{2} \mathrm{O}$ and $\mathrm{N}_{2}$ permeance differs from each other one order of magnitude.

It can be foreseen that the selectivity increases with the amount of water feed content, which is understandable since the selectivity depends directly on the feed amount of the tested gases. Additionally, it is more evident in Figure 6.5 than in Figure 6.4 that, the most permeable polymer is 6 FDA-6FpDA, followed by Matrimid ${ }^{\circledR}$ and ending on $\mathrm{P} 84^{\circledR}$. Still, it is not as indisputable as in Chapter 5 , where the polymer selective layers are thinner. 


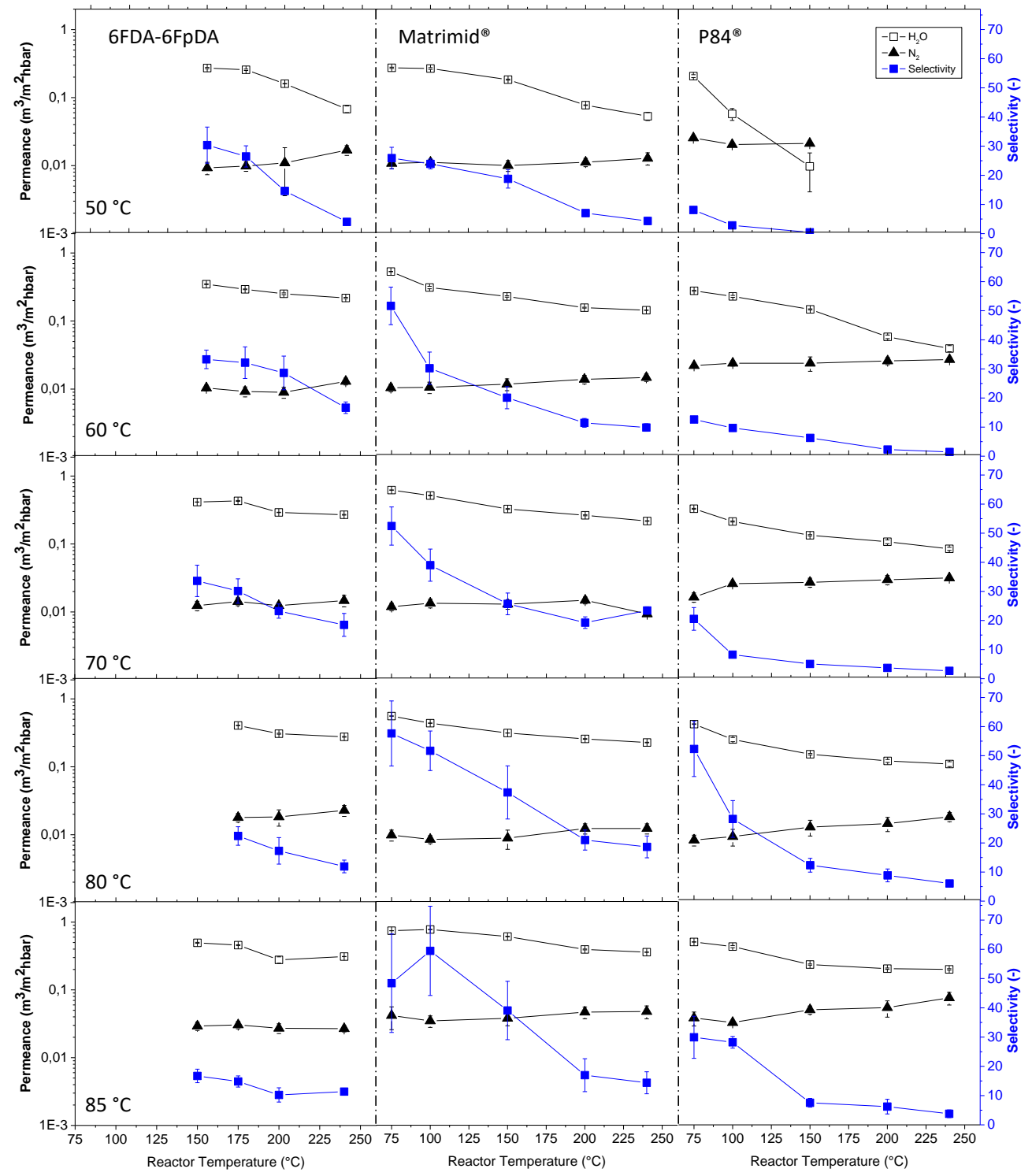

Figure 6.4. Separation properties of the ceramic-supported thin film polymers for $\mathrm{H}_{2} \mathrm{O} / \mathrm{N}_{2}$ separation as a function of the reactor temperature. Square unfilled symbols and triangle filled symbols represent the permeance of $\mathrm{H}_{2} \mathrm{O}$ and $\mathrm{N}_{2}$, respectively (in the left-y-axes), whereas square blue symbols represent selectivity (in the right-y-axes) 


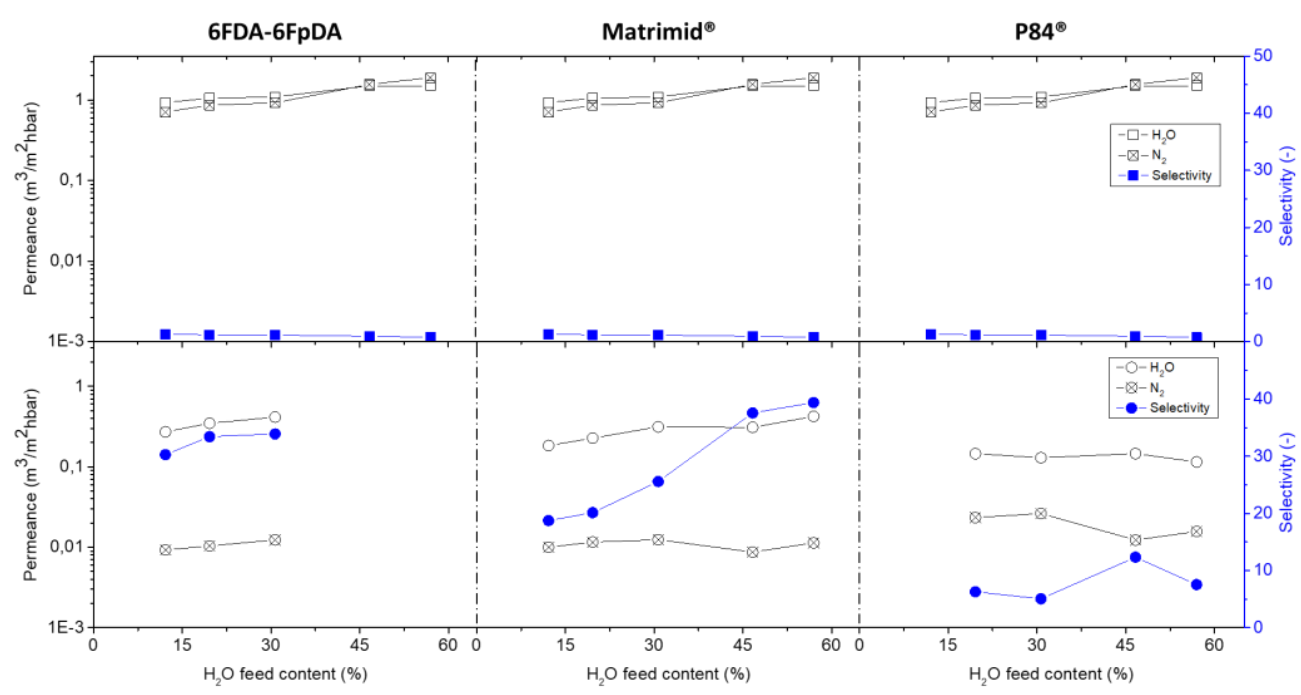

Figure 6.5. Gas properties comparison between pure ceramic support (square symbols, upper graphics) and composite membranes of 6FDA-6FpDA, Matrimid ${ }^{\otimes}$ and $P 84^{\oplus}$ (circle symbols, lower graphics), at $150^{\circ} \mathrm{C}$. Unfilled symbols and cross-filled symbols represent the permeance of $\mathrm{H}_{2} \mathrm{O}$ and $\mathrm{N}_{2}$, respectively (in the left-y-axes), whereas blue symbols represent selectivity (in the right-y-axes)

The change of the $\mathrm{H}_{2} \mathrm{O}$ and $\mathrm{N}_{2}$ permeances as a function of temperature can be expressed in terms of an Arrhenius-type relationship. Activation energies can be calculated out of the Arrhenius representation, obtaining in this case a negative values for water vapor, which indicates, as it was observed in Figure 6.4, that permeance decreases as a function of temperature. It also indicates that the solubility coefficient changes more meaningful than the diffusivity coefficient. On the other hand, activation energies for $\mathrm{N}_{2}$ in all the cases are positive, so permeances increase with temperature.

Table 6.3 shows all the activation energies, obtained in the range from $75^{\circ} \mathrm{C}$ to $240 \stackrel{\circ}{ } \mathrm{C}$, for the three different composite ceramic-polymer membranes, with different water feed content. In all the cases, $\mathrm{E}_{\mathrm{A}}$ value for $\mathrm{H}_{2} \mathrm{O}$ are significantly lower than that of $\mathrm{N}_{2}$. Thus, the selectivity $\mathrm{H}_{2} \mathrm{O} / \mathrm{N}_{2}$ decreases as a function of temperature. To conclude, it was possible to obtain a continuous and dense selective polymer layer on top of Atech ceramic support, but the thickness were not as thin as desired, hence the permeance of the membranes was low. For this reason, in the next section, another type of support was studied in order to acquire a thinner selective layer. 
Table 6.3. $\mathrm{H}_{2} \mathrm{O}$ and $\mathrm{N}_{2}$ activation energies of permeance for composite ceramic-polymer membranes

Activation energy $\left(E_{A}\right)\left(\mathrm{kJ} \cdot \mathrm{mol}^{-1}\right)$

\begin{tabular}{l|c|c|c|c|c|c}
\hline & \multicolumn{2}{|c|}{6 6FDA-6FpDA } & \multicolumn{2}{c|}{ Matrimid $^{\circledR}$} & \multicolumn{2}{c}{ P84 $^{\circledR}$} \\
\hline $\begin{array}{l}\text { Saturator } \\
\text { temperature }\left({ }^{\circ} \mathrm{C}\right)\end{array}$ & $\mathrm{H}_{2} \mathrm{O}$ & $\mathrm{N}_{2}$ & $\mathrm{H}_{2} \mathrm{O}$ & $\mathrm{N}_{2}$ & $\mathrm{H}_{2} \mathrm{O}$ & $\mathrm{N}_{2}$ \\
\hline $\mathbf{5 0}$ & -28.78 & 11.96 & -15.49 & 1.07 & -49.61 & 1.02 \\
$\mathbf{6 0}$ & -9.41 & 4.33 & -11.37 & 3.33 & -19.65 & 2.08 \\
$\mathbf{7 0}$ & -10.12 & 2.50 & -9.59 & 1.91 & -11.72 & 4.88 \\
$\mathbf{8 0}$ & -10.94 & 7.33 & -8.06 & 2.84 & -12.00 & 7.22 \\
\hline $\mathbf{8 5}$ & -11.13 & 2.45 & -9.64 & 2.62 & -11.94 & 8.79 \\
\hline
\end{tabular}

\subsubsection{Composite Polymer-Polymer Membranes/TFCMs}

\subsubsection{Support material}

An asymmetric support of polyphenylene sulfide fiber (PPS) and polybenzimidazole (PBI), is used for the thin film composite membrane production. This support possesses good chemical and mechanical stability properties, as well as high thermal resistance up to $300^{\circ} \mathrm{C}$. More information about the polymer support can be found in Chapter 4 - Methodology.

Microscopy analysis was performed and different images of the top layer and the cross-section of the three different polymer membranes were analyzed by using Focused lon Beam (FIB). Figure 6.6 presents a cross-section of the porous support. In the lower part, the fibers of the non-woven PPS are observed, and the continuous porous PBI layer is located on top, with a thickness of $30 \mu \mathrm{m}$ approximately. Figure 6.7 shows a detailed FIB image of the porous support $\mathrm{PBI}$, in the shape of a sponge. 


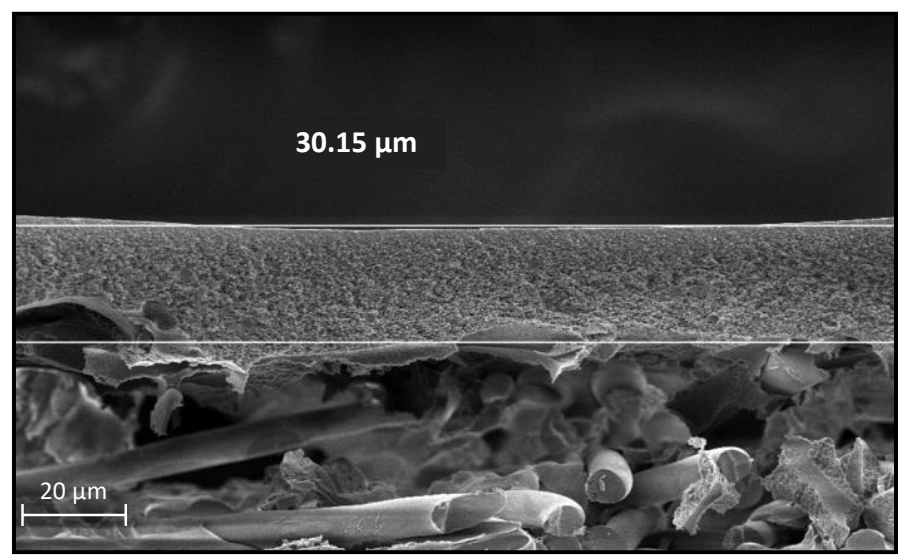

Figure 6.6. SEM image of the support of non-woven PPS and porous PBI structure

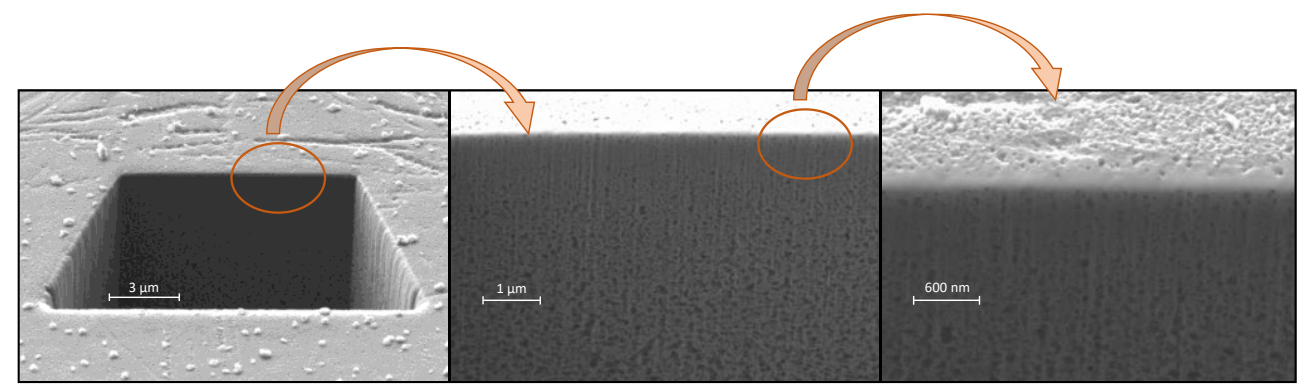

Figure 6.7. FIB image of PIB porous support

\subsubsection{Membrane formation}

Once the polymer support was developed, polymer layers were deposited on top. In Chapter 5, the effect and the relation between the polymer concentration and the viscosity ( $\eta$ ) was studied. This evaluation was performed due to the low compatibility between inorganic and organic materials. In the case of a polymer support, the need of study the compatibility is not essential, and the coating process, as well as the possibility to develop thin films present less difficulties. Asymmetric polymer supports were introduced perpendicular in the polymer solution. Thin film composite membranes (TFCMs) of 6FDA-6FpDA, Matrimid ${ }^{\circledR}$ and $\mathrm{P} 84^{\circledR}$, with a concentration of $3.5 \mathrm{wt}$. \%, with a protective layer of Teflon were produced. As with the other membranes, temperature and relative humidity were controlled and kept constant in order to avoid defects during the coating, such as pin-holes or non- 
continuous layer formation. More information about the manual coating of this membranes can be found in Chapter 4 - Methodology.

Once the membranes were dip-coating, following the process explained in Figure 4.6, they were treated under vacuum at $260^{\circ} \mathrm{C}$ for 2 hours. The temperature of $260{ }^{\circ} \mathrm{C}$ was selected in order to ensure that all the solvent used during the dipcoating process is completely evaporated, as well to accelerate the initial aging process in the polymer, which leads to experimental results reproducible both in time (samples can be measured at different times after membrane preparation) and for different samples.

Regarding the cross-section of the membranes, FIB micrographs are able to give information on thickness of the polymer layers. In Figure 6.8, the cross sections of 6FDA-6FpDA, Matrimid ${ }^{\circledR}$ and P84 ${ }^{\circledR}$, with a concentration of 3.5 wt. \% are shown. In the case of 6FDA-6FpDA and Matrimid ${ }^{\circledR}$, the thickness of the selective layer is $1.439 \mu \mathrm{m}$ and $1.360 \mu \mathrm{m}$ respectively, whereas $\mathrm{P} 84^{\circledR}$ is 2.51 and 2.66 times thicker. Additionally, it is difficult to check where the PBI layer is starting in the case of $\mathrm{P} 84^{\circledR}$. The reason could be ascribed to two different facts: (i) penetration of $\mathrm{P} 84^{\circledR}$ inside the support, blocking partially all the porous and creating a dense structure and (ii) solvent used for the P84 ${ }^{\circledR}$ membranes.

It should be noted that 6FDA-6FpDA and Matrimid ${ }^{\circledR}$ selective layers were coated with a protective layer of Teflon. With regards to $\mathrm{P} 84^{\circledR}$, due to manufacturing problems, it was not possible to add that final protective layer of Teflon. Usually, this protective layer is coated in order to cover any possible pin-hole that could exist on the selective layer. This Teflon layer is observed in the images a) and b), with a thickness of approximately $150 \mathrm{~nm}$. All the samples were analyzed after permeation measurements, so it is possible that the Teflon layers peel-off somehow after the treatment and manipulation of the sample. Teflon layer is not affecting the permeance of the selective layers, because its permeability is sufficiently high to not disturb permeance values of 6FDA-6FpDA and Matrimid ${ }^{\circledR}$. 


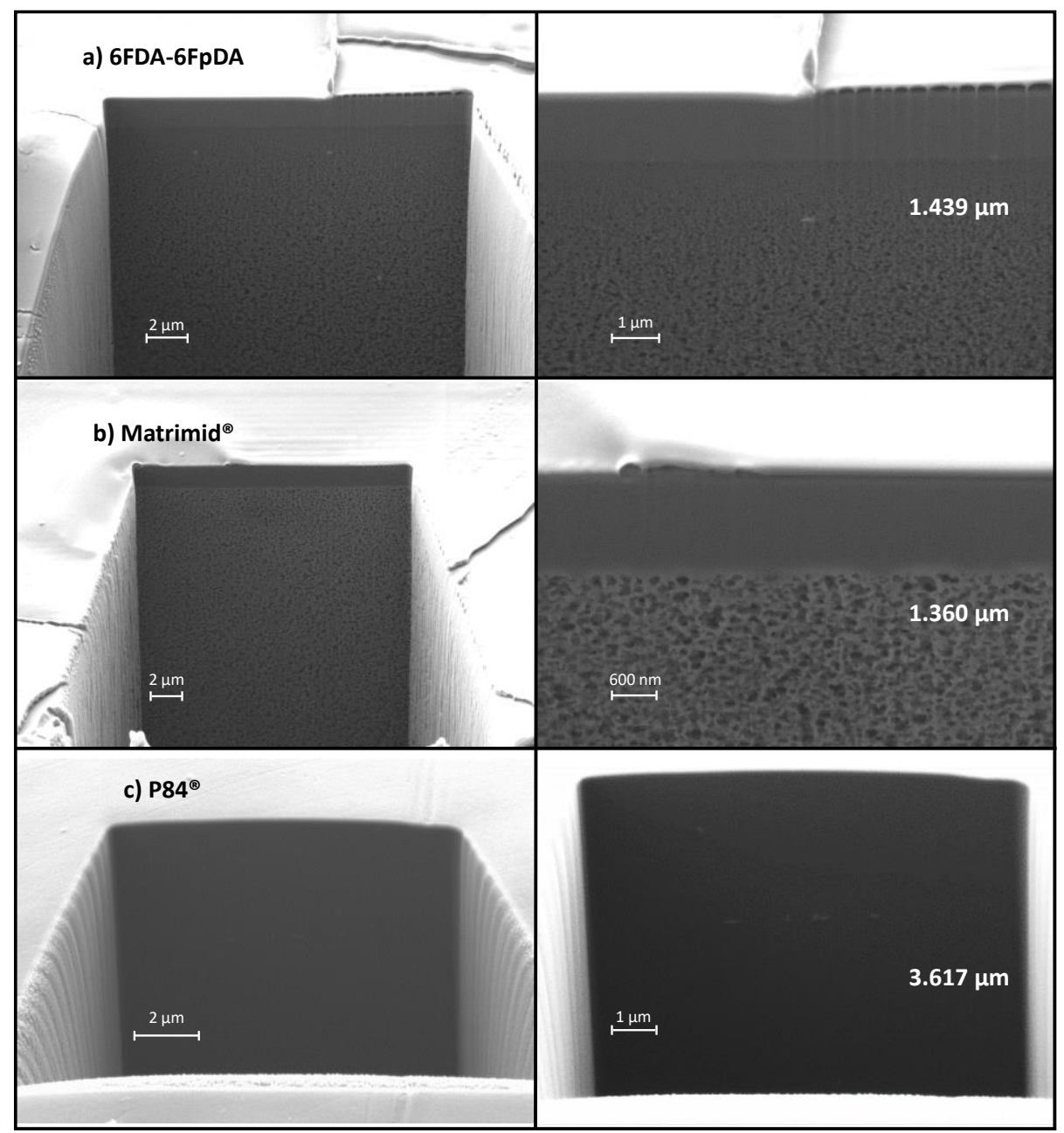

Figure 6.8. Cross section images from FIB micrographs of a) 6FDA-6FpDA with $1.439 \mu \mathrm{m}, b)$ Matrimid $^{\circledR}$ with $1.360 \mu \mathrm{m}$ and c) $P 84^{\circledR}$ with $3.617 \mu \mathrm{m}$ 


\subsubsection{Gas transport properties}

Permeance values and ideal selectivities for the thin film polymer layers were characterized by using the polymeric membrane module described on the Chapter 4 - Methodology. Single gas measurements of $\mathrm{H}_{2}$ and $\mathrm{CO}_{2}$ were performed from 30 ${ }^{\circ} \mathrm{C}$ to $270^{\circ} \mathrm{C}$ at 1 bar. Up to $180^{\circ} \mathrm{C}$, each $50^{\circ} \mathrm{C}$, afterwards each $25^{\circ} \mathrm{C}$ approximately, in order to have a better representation of the gas properties. The reason to select $270{ }^{\circ} \mathrm{C}$ as the maximum operational temperature was because TFCM were stable up to $275^{\circ} \mathrm{C}$, after this point the non-woven PPS starts to meld and the membrane breaks.

Additionally, in order to compare the selective layer in other configurations, and ensure its corrected formation, thick films were formed and measured in the time-lag equipment, the TFCM were also measured in the pressure increase equipment. Thick film and TFCM measurements can be seen in Figure 6.9 represent as circles and triangles respectively. In the case of 6FDA-6FpDA and Matrimid ${ }^{\circledR}$, both measurements are in perfect agreement with the polymeric membrane module used in this chapter. On the other hand, $\mathrm{P} 84^{\circledR}$ does not suit perfectly with the values obtained. The reason could be the manufacturing problems that were presented during the formation of the TFCM of $\mathrm{P} 84^{\circledR}$. In addition, the high thickness could affect the selectivity, resulting in an increase of it, as it is observed when the selectivity values are compared.

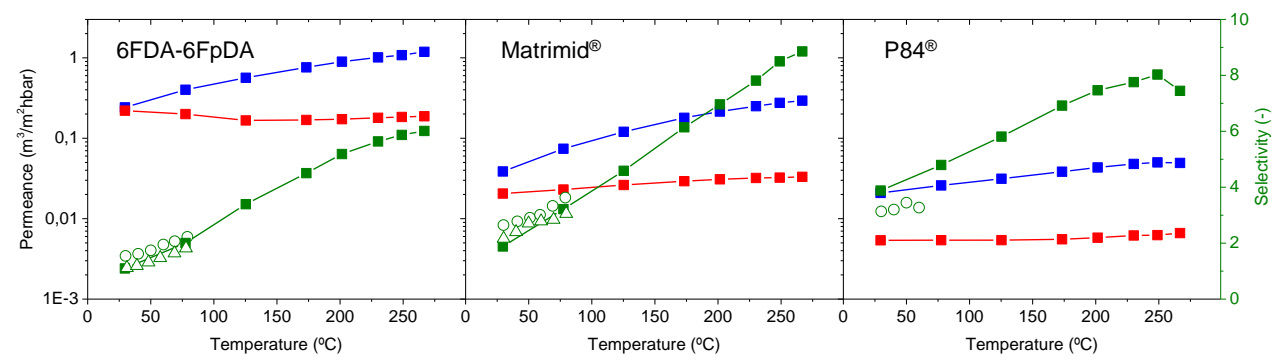

Figure 6.9. Separation properties of the polymers as a function of temperature. Permeances are represented in blue and red for $\mathrm{H}_{2}$ and $\mathrm{CO}_{2}$ respectively (logarithmic scale), whereas selectivity $\mathrm{H}_{2} / \mathrm{CO}_{2}$ is represented in green. Circles represent thick films of the studied polymers measured at time-lag equipment, whereas triangles are TFCM of the studied polymers measured at pressure increase equipment

Figure 6.9 plots the permeance values for $\mathrm{H}_{2}$ and $\mathrm{CO}_{2}$ and selectivities as a function of temperature. $\mathrm{H}_{2}$ permeances increase faster than $\mathrm{CO}_{2}$ permeance for the three polymers, and subsequently the selectivity for $\mathrm{H}_{2} / \mathrm{CO}_{2}$ increases as a function 
of temperature in all the cases. Accordingly with the images from microscopy (Figure 6.8), 6FDA-6FpDA and Matrimid ${ }^{\circledR}$ can be compared due to their similar thickness. The effect of the FFV mentioned in Chapter 5 can be seen again. The permeability of the polymer and the permeance of membranes with the same selective layer thickness is related with the polymer FFV: 0.19 for 6FDA-6FpDA [19], 0.17 for Matrimid $^{\circledR}$ [20] and 0.14 for $P 84^{\circledR}$ [21]. If the gas properties of 6FDA-6FpDA and Matrimid $^{\otimes}$ of Figure 6.9 are compared, it can be seen that the most permeable polymer is the 6FDA-6FpDA. In contrast, the selectivity of Matrimid ${ }^{\circledR}$ is higher than selectivity of 6FDA-6FpDA due to the same principle of fractional free volume, which was already explained in Table 5.1. Another significant remark is the tendency of the permeance. It can be appreciated in $\mathrm{H}_{2}$ permeance and in $\mathrm{H}_{2} / \mathrm{CO}_{2}$ selectivity, for the three polymers, how the slope exhibit a slight decrease at high temperatures (6FDA6FpDA and Matrimid ${ }^{\circledR}$ ), or the slope change from positive to negative (P84 ${ }^{\circledR}$ ). One plausible explanation could be that the diffusivity coefficient do not increase anymore beyond a certain temperature. As it was advanced in the Introduction, in glassy polymers, the mobility coefficient, or the diffusivity coefficient, dominates the transport mechanism. Hence, permeability decreases with increasing permeant molecular size and so, small molecules (e.g. $\mathrm{H}_{2}$ ) permeate preferentially to large molecules. However, TFCMs tested at temperatures above $100 \stackrel{\circ}{\mathrm{C}}$ was not found in literature, and so the behavior of diffusivity coefficients, i.e. permeance values, was not reported before.

Thickness of $\mathrm{P} 84^{\circledR}$ is higher than thickness of $6 \mathrm{FDA}-6 \mathrm{FpDA}$ and Matrimid ${ }^{\circledR}$. Hence, comparison between the polymers is not straight forward. Nevertheless, it is possible to extract some hypothesis. If $\mathrm{P} 84^{\circledR}$ would have the same thickness as the other two polymers, it should exhibit lower permeances for $\mathrm{H}_{2}$ and $\mathrm{CO}_{2}$ and higher $\mathrm{H}_{2} / \mathrm{CO}_{2}$ selectivity. On the contrary, permeances are indeed the lowest of the three cases, but because of the thickness, and the selectivity is not as high as it was expected. Another plausible explanation for the decrease of $\mathrm{H}_{2}$ permeance in the case of $\mathrm{P} 84^{\circledR}$ could be the lack of protective Teflon layer. The selective layer may be undergoing certain changes at these high temperatures, so without a Teflon protective layer, the permeability was affected. As conclusion, the gas properties for the three composite polymer-polymer membranes can be explained.

The evolution of the $\mathrm{H}_{2}$ and $\mathrm{CO}_{2}$ permeances as a function of temperature can be expressed in terms of an Arrhenius-type relationship. It considers the transport of the gas molecules through a membrane as a thermally activated process [22]. Figure 
6.10 shows the Arrhenius representation for the three different polymers. The activation energy for $\mathrm{P} 84^{\circledR}$ changes with the temperature for both, $\mathrm{CO}_{2}$ and $\mathrm{H}_{2}$ permeances, whereas for $6 \mathrm{FDA}-6 \mathrm{FpDA}$, it only occurs for $\mathrm{CO}_{2}$ permeance. It can be also appreciated in the Arrhenius representation how 6FDA-6FpDA is the most permeable polymer for both gases, $\mathrm{H}_{2}$ and $\mathrm{CO}_{2}$, followed by Matrimid ${ }^{\circledR}$ and ending by $\mathrm{P} 84^{\circledR}$, which perfectly correlates with the polymer FFV and the thickness of the selective layers, as previously explained.

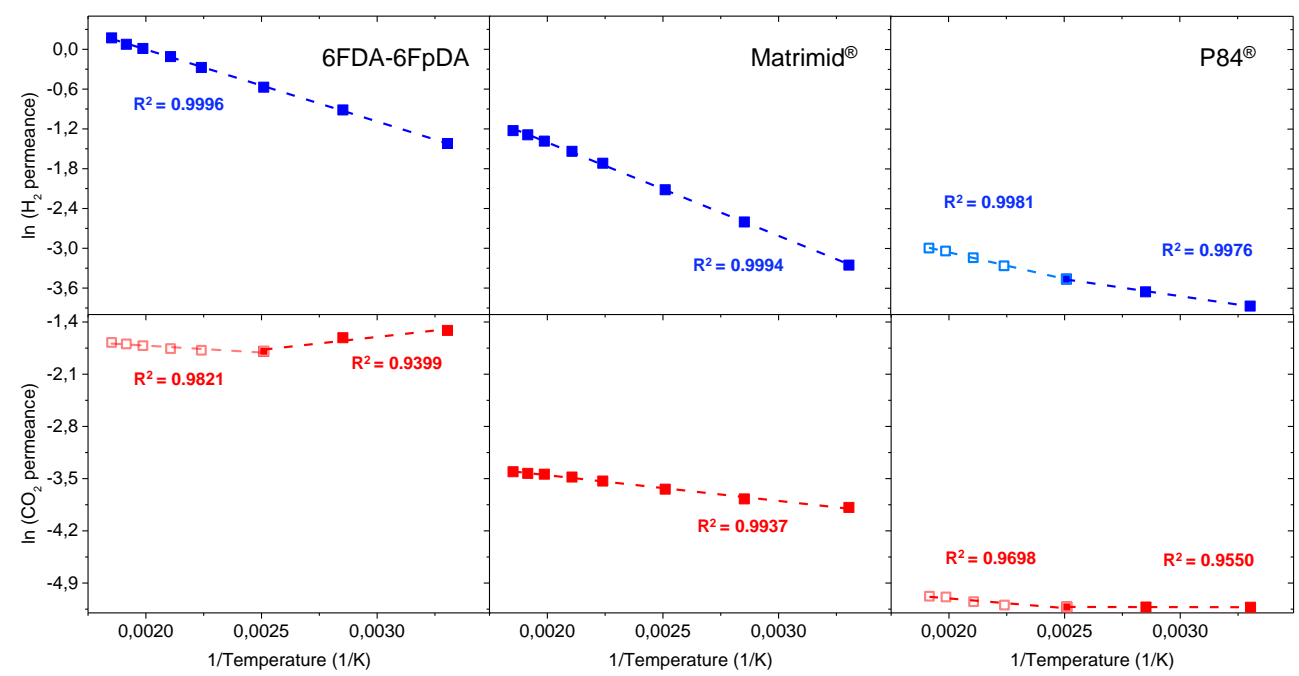

Figure 6.10. Arrhenius-type relationship for $\mathrm{H}_{2}$ (upper graphs) and for $\mathrm{CO}_{2}$ (bottom graphs) permeances for the three studied polymers: 6FDA-6FpDA, Matrimid ${ }^{\circledR}$ and $P 84^{\boxplus}$, with polymeric support

Calculated activation energies $\mathrm{E}_{\mathrm{A}}$ are listed in Table 6.4, obtained in the range from $30 \stackrel{\circ}{\circ}$ to $270 \stackrel{\circ}{\circ}$. Activation energy values depend on the polymer nature and the differences between the $E_{A}$ values for different gases indicate how the selectivity will develop with changing temperature. As it can be seen in Figure 6.10, there is a change in the slope for two of the three studied polymers. This situation gives two different activation energies for $6 \mathrm{FDA}-6 \mathrm{FpDA}$, only for $\mathrm{CO}_{2}$ ) and $\mathrm{P} 84^{\circledR}$. As with the Anodisc support, $E_{A}$ values are positive, which means that the diffusion coefficient change more significantly with temperature than the solubility coefficient, including $\mathrm{CO}_{2}$. Only one of the $\mathrm{E}_{\mathrm{A}}$ values are negative, the second value for $\mathrm{CO}_{2}$ in $6 \mathrm{FDA}$ $6 \mathrm{FpDA}$. This means that at low temperatures, the solubility coefficient change more significantly than the diffusion coefficient. Again, the $\mathrm{E}_{\mathrm{A}}$ value for $\mathrm{CO}_{2}$ is significantly 
lower than that of $\mathrm{H}_{2}$. Thus, the selectivity $\mathrm{H}_{2} / \mathrm{CO}_{2}$ increases as a function of temperature.

Table 6.4. Activation energies of permeance for the different gases for asymmetric polymer membranes, prepared using 3.5 wt. \% polymer solutions

\begin{tabular}{|c|c|c|c|c|}
\hline & \multicolumn{4}{|c|}{ Activation energy $\left(E_{A}\right)\left(\mathrm{kJ} \cdot \mathrm{mol}^{-1}\right)$} \\
\hline & \multicolumn{2}{|c|}{$\mathrm{H}_{2}$} & \multicolumn{2}{|c|}{$\mathrm{CO}_{2}$} \\
\hline 6FDA-6FpDA & \multicolumn{2}{|c|}{9.02} & 1.54 & -2.91 \\
\hline Matrimid $^{\circledR}$ & \multicolumn{2}{|c|}{11.76} & \multicolumn{2}{|c|}{2.87} \\
\hline$P 84^{\circledR}$ & 4.23 & 6.72 & 0.04 & 3.63 \\
\hline
\end{tabular}




\subsection{Conclusions}

Thin film composite membranes (TFCMs) with an inorganic support (porous ceramic membranes) and with an organic support (PPS + PBI porous polymer) were successfully obtained.

Composite ceramic-polymer membranes were tested at high temperatures. Mixed gas measurements were performed for $\mathrm{H}_{2} \mathrm{O}$ and $\mathrm{N}_{2}$. TFCMs were subjected to different water partial pressure in the feed, in order to analyze the effect of water. Additionally, temperature range was between $75 \stackrel{\circ}{\circ}$ to $240 \stackrel{\circ}{ } \mathrm{C}$ in order to proof the stability at high temperatures, and to observe the selectivity behavior. Unfortunately, due to the lack of compatibility between inorganic support and organic selective layer, thickness of the membranes were above $6 \mu \mathrm{m}$, and so the permeance was not as high as expected, with little difference between the different feeds and temperatures.

Considering the different incompatibilities between ceramic support and selective polymer solutions, new TFCMs were developed using a different support, this time polymeric support composed by PPS and PBI. Formation of thin selective layer around $1.5 \mu \mathrm{m}$ was successfully performed for 6 FDA-6FpDA and Matrimid ${ }^{\circledR}$, whereas for $\mathrm{P} 84^{\circledR}$, the selective layer was 2 times thicker. Single gas measurements were performed for $\mathrm{H}_{2}$ and $\mathrm{CO}_{2}$, at a wide range of temperatures between $30 \stackrel{\circ}{\mathrm{C}}$ and $270 \stackrel{\circ}{\circ}$. Permeances increases with temperature and for values close to $250 \stackrel{\circ}{\circ}$, a change of slope in selectivity was observed, which may indicate that the diffusivity coefficient was no longer controlling transport properties.

Activation energies were calculated for both types of supported membranes. Regarding ceramic support, in all the cases, $\mathrm{E}_{\mathrm{A}}$ value for $\mathrm{H}_{2} \mathrm{O}$ are negative, which means that the solubility coefficient change more significantly with temperature than the diffusion coefficient, and also, they are significantly lower than that of $\mathrm{N}_{2}$. Thus, the selectivity $\mathrm{H}_{2} \mathrm{O} / \mathrm{N}_{2}$ decreases as a function of temperature.

With regard to polymer support, and following a similar trend as with the Anodisc support, $E_{A}$ values for $\mathrm{H}_{2}$ and $\mathrm{CO}_{2}$ are positive, which means that the diffusion coefficient change more significantly with temperature than the solubility coefficient, including $\mathrm{CO}_{2}$. Once more, the $\mathrm{E}_{\mathrm{A}}$ value for $\mathrm{CO}_{2}$ is significantly lower than that of $\mathrm{H}_{2}$. Thus, the selectivity $\mathrm{H}_{2} / \mathrm{CO}_{2}$ increases as a function of temperature. 
To conclude, different polymer membranes with two types of support were manufactured and tested at elevated temperatures in order to study their gas transport properties for processes that require in-situ water removal, purification of $\mathrm{H}_{2}$, or $\mathrm{CO}_{2}$ capture. 


\subsection{References}

1. Pye, D.G., H.H. Hoehn, and M. Panar, Measurement of gas permeability of polymers. II. Apparatus for determination of permeabilities of mixed gases and vapors. Journal of Applied Polymer Science, 1976. 20(2): p. 287-301.

2. Hoehn, H.H., Aromatic Polyamide Membranes, in Materials Science of Synthetic Membranes. 1985, American Chemical Society. p. 81-98.

3. Alexander Stern, S., Polymers for gas separations: the next decade. Journal of Membrane Science, 1994. 94(1): p. 1-65.

4. Poley, L.H., et al., Water and Vapor Permeability at Different Temperatures of Poly (3-Hydroxybutyrate) Dense Membranes. Polímeros: Ciência e Tecnologia, 2005. 15(1): p. 22-26.

5. Gülmüs, S.A. and L. Yilmaz, Effect of temperature and membrane preparation parameters on gas permeation properties of polymethacrylates. Journal of Polymer Science Part B: Polymer Physics, 2007. 45(22): p. 30253033.

6. Komatsuka, T. and K. Nagai, Temperature Dependence on Gas Permeability and Permselectivity of Poly(lactic acid) Blend Membranes. Polymer Journal, 2009. 41: p. 455.

7. Zhukova, E.K., et al., Gas separation properties of new thermoplastic polyimides with phenylamide groups in diamine moiety: Effect of polymer structure. Petroleum Chemistry, 2014. 54(7): p. 544-550.

8. Guzmán-Lucero, D., et al., Gas Permeation Properties of Soluble Aromatic Polyimides Based on 4-Fluoro-4,4'-Diaminotriphenylmethane. Materials, 2015. 8(4): p. 1951.

9. Myers, C., et al., High temperature separation of carbon dioxide/hydrogen mixtures using facilitated supported ionic liquid membranes. Journal of Membrane Science, 2008. 322(1): p. 28-31.

10. Scholes, C.A., et al., CO2 capture from pre-combustion processesStrategies for membrane gas separation. International Journal of Greenhouse Gas Control, 2010. 4(5): p. 739-755.

11. (CROW), C.R.o.t.W. Polymer Properties Database. 2015; Available from: http://polymerdatabase.com/polymer\%20classes/Polybenzimidazole\%20ty pe.html.

12. Pesiri, D.R., B. Jorgensen, and R.C. Dye, Thermal optimization of polybenzimidazole meniscus membranes for the separation of hydrogen, methane, and carbon dioxide. Journal of Membrane Science, 2003. 218(1): p. 11-18.

13. gmbh, A.-i. 2018; Available from: http://www.atechinnovations.com/home.html. 
14. Yoon, T.S., et al., Single and Multiple-Step Dip-Coating of Colloidal Maghemite ( $y$-Fe2O3) Nanoparticles onto Si, Si3N4, and SiO2 Substrates. Advanced Functional Materials, 2004. 14(11): p. 1062-1068.

15. Thomson, G.W., The Antoine Equation for Vapor-pressure Data. Chemical Reviews, 1946. 38(1): p. 1-39.

16. Lobo, A., et al., Ultrafiltration of oil-in-water emulsions with ceramic membranes: Influence of $\mathrm{pH}$ and crossflow velocity. Journal of Membrane Science, 2006. 278(1): p. 328-334.

17. Ebrahimi, M., et al., Investigations on the use of different ceramic membranes for efficient oil-field produced water treatment. Desalination, 2010. 250(3): p. 991-996.

18. Alpatova, A., et al., Treatment of oil sands process-affected water with ceramic ultrafiltration membrane: Effects of operating conditions on membrane performance. Separation and Purification Technology, 2014. 122: p. $170-182$.

19. Wang, X.-Y., et al., A molecular simulation study of cavity size distributions and diffusion in para and meta isomers. Polymer, 2005. 46(21): p. 91559161.

20. Wiegand, J.R., et al., Synthesis and characterization of triptycene-based polyimides with tunable high fractional free volume for gas separation membranes. Journal of Materials Chemistry A, 2014. 2(33): p. 13309-13320.

21. Tin, P.S., et al., Separation of $\mathrm{CO} 2 / \mathrm{CH} 4$ through carbon molecular sieve membranes derived from P84 polyimide. Carbon, 2004. 42(15): p. 31233131.

22. Tena, A., S. Shishatskiy, and V. Filiz, Poly(ether-amide) vs. poly(etherimide) copolymers for post-combustion membrane separation processes. RSC Advances, 2015. 5(29): p. 22310-22318. 
Chapter 7

Mixed Matrix Membranes for high temperature applications 



\section{Mixed Matrix Membranes for high temperature applications}

\subsection{Introduction}

In the previous chapter, 6FDA-6FpDA, Matrimid ${ }^{\circledR}$ and $\mathrm{P} 84^{\circledR}$ polyimides membranes were tested at higher temperatures for the sake of investigating their chemical and mechanical stability, as well as their suitability for in-situ gas separation in catalytic membrane reactors, with two different supports: an asymmetric porous support composed by polyphenylene sulfide fiber (PPS) and polybenzimidazole $(\mathrm{PBI})$, and asymmetric ceramic membranes consisting on a pure support of $\mathrm{Al}_{2} \mathrm{O}_{3}$, a microfiltration membrane of $\mathrm{Al}_{2} \mathrm{O}_{3} / \mathrm{ZrO}_{2}$ and a final ultrafiltration membrane of $\mathrm{ZrO}_{2}$.

In order to improve gas transport properties, different inorganic particles were investigated. In this chapter, firstly, the three polyimides already used in this thesis and six new inorganic fillers in a form of nanometer-sized particles are studied as thick film solution cast mixed matrix membranes (MMMs) for single gas transport of $\mathrm{CO}_{2}, \mathrm{CH}_{4}$ and $\mathrm{H}_{2} \mathrm{O}$. Mixed matrix membranes (MMMs) are known as a very promising route to overcome limitations of the Robeson upper bound of the permeability/selectivity relationship [1, 2]. Secondly, the already mentioned fillers and the most permeable polyimide, 6FDA-6FpDA are used in thin film composite membranes (TFCMs) for mix gas transport of $\mathrm{H}_{2}, \mathrm{CO}_{2}$ and $\mathrm{H}_{2} \mathrm{O}$. Schematic difference between this two types of MMMs can be appreciated in Figure 4.7. MMMs exhibit the advantage to merge good mechanical but unsatisfying gas transport properties of polymers with excellent diffusion and sorption properties of inorganic porous media but very poor mechanical properties [3].

Gas separation membranes have been successfully on the market for the last 40 years $[4,5]$. Actually, since the end of the $20^{\text {th }}$ century, not too many new membranes reached practical application and surpass the existing membranes, due to the fact that they allow to combine membrane separation stages with other unit operations at industrial processes, achieving goals of the separation process [6]. Consequently, there is a necessity to introduce new membranes with a better gas transport performance in order to overtake those already commercially available. At this point, the combination of properties of polymers and inorganic fillers that are able to selectively transport gas or vapor molecules becomes very appealing [7]. 
The conditions for polymers to be used in membranes are: adequate gas transport properties (balance between permeability and selectivity), able to process as a thin film and high reproducible manufacturing from batch to batch. Regarding formation of MMMs, good adhesion between the polymer matrix and the inorganic filler is imperative, especially in case of polymers with high $T_{g}$ [8], good mechanical properties and stability of properties as a function of time.

The inorganic fillers to be used in MMMs should exhibit (i) particles as small as possible since thickness of selective layers of current polymer membranes evidence less than $100 \mathrm{~nm}$; (ii) good affinity to the polymer; and (iii) gas transport properties matching for the target gas in the separation process [9]. In the first part of this chapter, three different cases were studied: 6FDA-6FpDA with 10 wt. \% of the 6 different particles, 6FDA-6FpDA with different percentage of the $\mathrm{BaCe}_{0.2} \mathrm{Zr}_{0.7} \mathrm{Y}_{0.1} \mathrm{O}_{3}$ (BCZY) particles, and 6FDA-6FpDA, Matrimid ${ }^{\circledR}$ and P84 $4^{\circledR}$ with 10 wt. \% of BCZY. Additionally, the transport of water vapor in MMMs was studied for the three cases. Regarding the second part, TFCMs of $3.5 \mathrm{wt}$. \% of 6FDA-6FpDA with $10 \mathrm{wt}$. $\%$ of 5 out of 6 different particles were studied. In this section, $\mathrm{La}_{2} \mathrm{O}_{3}$ was not longer studied because its hydrophobic properties did not allow to perfectly introduce the filler into the polymer matrix.

\subsection{Results and discussion}

\subsubsection{MMMs as Thick Films}

\subsubsection{Membrane formation}

For this thesis, six different inorganic fillers were employed: $8 \mathrm{~mol} \%$ Yttria

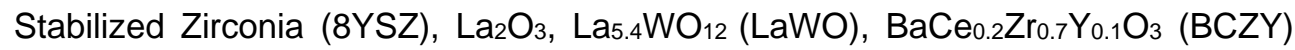
and two zeolites (ITQ-2 and Beta). 8YSZ powder was provided by Tosoh Corporation (Japan). $\mathrm{La}_{2} \mathrm{O}_{3}$ was synthesized by co-precipitation from lanthanum nitrate $\left(\mathrm{La}\left(\mathrm{NO}_{3}\right)_{3}\right)$ and subsequent calcination at $800{ }^{\circ} \mathrm{C}$ for $5 \mathrm{~h}$. LaWO, provided by CerPoTech (Norway) in powder form was calcined at $800^{\circ} \mathrm{C}$ for $6 \mathrm{~h}$. BCZY powder, also provided by CerPoTech, was calcined at $950^{\circ} \mathrm{C}$ for $6 \mathrm{~h}$. Nanocrystalline Beta zeolite (BEA material) and ITQ-2 (delaminated MCM-22 zeolite material) [10] were synthesized by the ITQ (Instituto de Tecnología Química) and are here used after calcination (organics removal) in its acidic form. All the fillers were ball-milled 
previously for 24 hours. In Chapter 4 - Methodology, Table 4.1 shows a summary of the fillers properties.

Mix matrix membranes (MMMs) were made with $0.25 \mathrm{~g}$ of polymer and inorganic fillers and $2.25 \mathrm{~g}$ of solvent. Firstly, the inorganic fillers were dried at $120^{\circ} \mathrm{C}$ for $24 \mathrm{~h}$ before the membrane preparation. Secondly, the fillers were dispersed in $1 \mathrm{~g}$ of NMP solvent by using an ultrasound device. Simultaneously, the polymer was dissolved with the rest of the solvent. The particle suspension was finally added to the polymer solution, obtaining a homogeneous solution of polymer and fillers. Afterwards, solvent evaporation method was used to prepare the membranes. The mixed matrix solutions were poured into metal rings placed on a heating plate at $70{ }^{\circ} \mathrm{C}$ for $12 \mathrm{~h}$, allowing a slow evaporation of the solvent. Then, the membranes were heat treated under vacuum in three steps: (a) $100^{\circ} \mathrm{C}$ for $1.5 \mathrm{~h}$, (b) $200^{\circ} \mathrm{C}$ for $2 \mathrm{~h}$ and (c) cooling to room temperature.

The compatibility between the inorganic filler and the polymer matrix can result in four different possibilities (Figure 7.1). These four cases give different effects on the separation properties [11-15]. As ideal situation, case 1 appears, where the filler is perfectly incorporated into the polymer matrix. This situation can result in an improvement of the separation properties of the mixed matrix material. In Case 2, a rigidification of the polymer matrix in the area around the filler occurs, resulting in an increase of the selectivity, but consequently, in a decrease of the permeability. Usually, case 2 is also confirmed by an increase on the $T_{g}$ of the MMMs. Case 3 exhibits a creation of an interphase due to the incompatibility between the particle and the polymer matrix. In this case, permeability increase whereas selectivity decrease due to the bigger fractional free volume. In Case 4, the polymer matrix penetrates the pore or free volume of the filler, and consequently both permeability and selectivity decrease. 


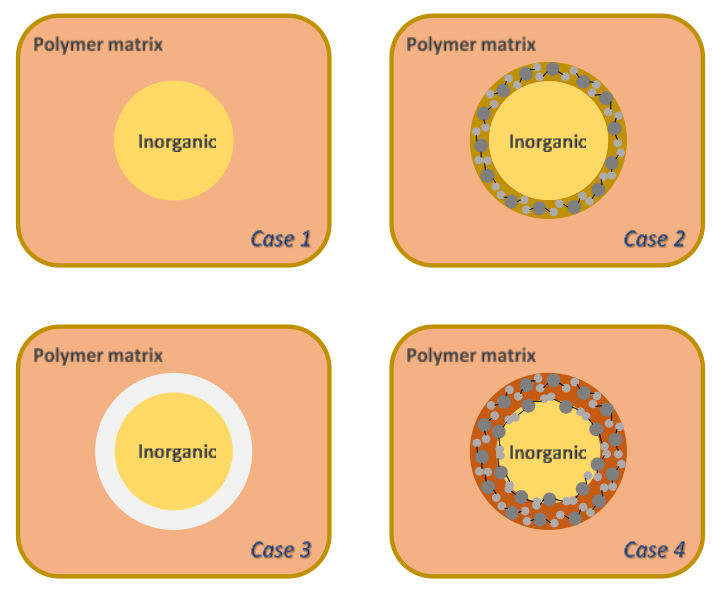

Figure 7.1. Schematic diagram of various structures for MMMs [16, 17]

\subsubsection{Thermal properties}

Thermogravimetric analysis experiments (TGA) were performed in order to assess the thermal stability of the MMMs and to additionally define the real amount of particles in the final sample [18]. Residual mass $\left(R_{M}\right)$ was the parameter used to evaluate the concentration of particles in the membranes. In Table 7.1, the TGA results for different cases addressed in this chapter are represented: 6FDA-6FpDA with 10 wt. \% of the 6 different particles, 6FDA-6FpDA with different percentage of the BCZY particles, and 6FDA-6FpDA, Matrimid ${ }^{\circledR}$ and $P 84^{\circledR}$ with 10 wt. \% of BCZY. It can be appreciated that the temperature of the maximum weight loss ( $T_{\max }$ loss $)$ is an intrinsic property of the polymer matrix, i.e. $550^{\circ} \mathrm{C}$ for $6 \mathrm{FDA}-6 \mathrm{FpDA}, 560{ }^{\circ} \mathrm{C}$ for Matrimid $^{\circledR}$ and, finally, $580{ }^{\circ} \mathrm{C}$ for $\mathrm{P} 84^{\circledR}$. After exposure of the sample to synthetic air at $800{ }^{\circ} \mathrm{C}$, the value of the residual mass $\left(\mathrm{R}_{\mathrm{M}}\right)$ was obtained, which theoretically indicates the quantity of inorganic particles within the sample. The low deviation from the theoretical values observed for 10 wt. \% 8YSZ, $\mathrm{La}_{2} \mathrm{O}_{3}, \mathrm{LaWO}$ and $\mathrm{BCZY}$ in 6FDA-6FpDA indicates a good dispersion and adhesion of these particles in the polymer matrix $[19,20]$.

Nevertheless, regarding the zeolites (ITQ-2 and Beta), it does not behave as expected since the nanometer size of the particles may cause loss of part of the constituting elements of these particles. On the contrary, for the samples 6FDA6FpDA $20 \%$ wt. BCZY, and for Matrimid ${ }^{\circledR} 10$ wt. \% BCZY, RM is higher than the initial percentage of particles which may indicates an irregular distribution of the polymer chains around the particles. In addition, Figure 7.2 shows an identical temperature 
of the maximum weight loss $T_{\max }$ loss for $6 \mathrm{FDA}-6 \mathrm{FpDA}$ with different percentages of the BCZY particle. From these results, it can be concluded that the incorporation of inorganic fillers to the polymer matrix does not influence to the thermal stability of the polymer.

Differential scanning calorimetry (DSC) was used to calculate the glass transition temperature $\left(\mathrm{T}_{\mathrm{g}}\right)$ of these three polymers. It could be appreciated an evolution of the $T_{g}$ with the rigidity of the polymer chains following the rigidity order 6FDA-6FpDA $<$ Matrimid $^{\circledR}<$ P84 $4^{\circledR}$. For all the 6FDA-6FpDA-based MMMs the $T_{g}$ reduces in comparison to the reference, except for the BCZY membrane that presents a similar $T_{g}$ to the pure polyimide. This decrease of the $T_{g}$ might indicate a plasticization effect introduced by the filler particles. Regarding MMMs with different BCZY contents in 6FDA-6FpDA, the behavior of the $T_{g}$ exhibits only small irregular changes, i.e. an increase of $T_{g}$ for low BCZY percentages between 1 and $5 \mathrm{wt}$ \% and a similar value for $10 \mathrm{wt}$. \%, which may indicate an small macromolecular chain rigidification [21] (see Table 7.1). This behavior could have an effect on the gas transport properties, expecting an increase in selectivity but a decrease of the permeability coefficients.

Table 7.1. TGA and DSC results for the three different cases studied in this chapter

\begin{tabular}{|c|c|c|c|c|}
\hline & $T \max$ loss $\left({ }^{\circ} \mathrm{C}\right)$ & Theoretical (wt. \%) & $\boldsymbol{R}_{M}(w t . \%)$ & $\operatorname{Tg}\left({ }^{\circ} \mathrm{C}\right)$ \\
\hline 6FDA-6FpDA & 550 & 0 & 0 & 311.1 \\
\hline + 10 wt. \% 8YSZ & 550 & 10 & 9.8 & 300.2 \\
\hline$+10 w t . \% \mathrm{La}_{2} \mathrm{O}_{3}$ & 550 & 10 & 8.1 & 302.4 \\
\hline + 10 wt. \% LaWO & 550 & 10 & 8.1 & 290.6 \\
\hline$+10 w t . \% B C Z Y$ & 550 & 10 & 10.0 & 311.2 \\
\hline+10 wt. \% ITQ-2 & 550 & 10 & 0 & 294.7 \\
\hline+10 wt. \% Beta & 550 & 10 & 0 & 294.5 \\
\hline 6FDA-6FpDA & 550 & 0 & 0 & 311.1 \\
\hline+1 wt. \% BCZY & 550 & 1 & 0 & 314.2 \\
\hline+5 wt. \% BCZY & 550 & 5 & 4.9 & 312.5 \\
\hline$+10 w t . \% B C Z Y$ & 550 & 10 & 10.0 & 311.2 \\
\hline$+15 w t . \% B C Z Y$ & 550 & 15 & 16.8 & 307.9 \\
\hline+20 wt. \% BCZY & 550 & 20 & 27.2 & 306.3 \\
\hline 6FDA-6FpDA & 550 & 0 & 0 & 311.1 \\
\hline+10 wt. \% BCZY & 550 & 10 & 10.0 & 311.2 \\
\hline Matrimid $^{\circledR}$ & 560 & 0 & 0 & 320.2 \\
\hline+10 wt. \% BCZY & 560 & 10 & 13.3 & 315.7 \\
\hline$P 84^{\circledR}$ & 580 & 0 & 0 & 322.4 \\
\hline$+10 w t . \% B C Z Y$ & 580 & 10 & 7.2 & 318.2 \\
\hline
\end{tabular}




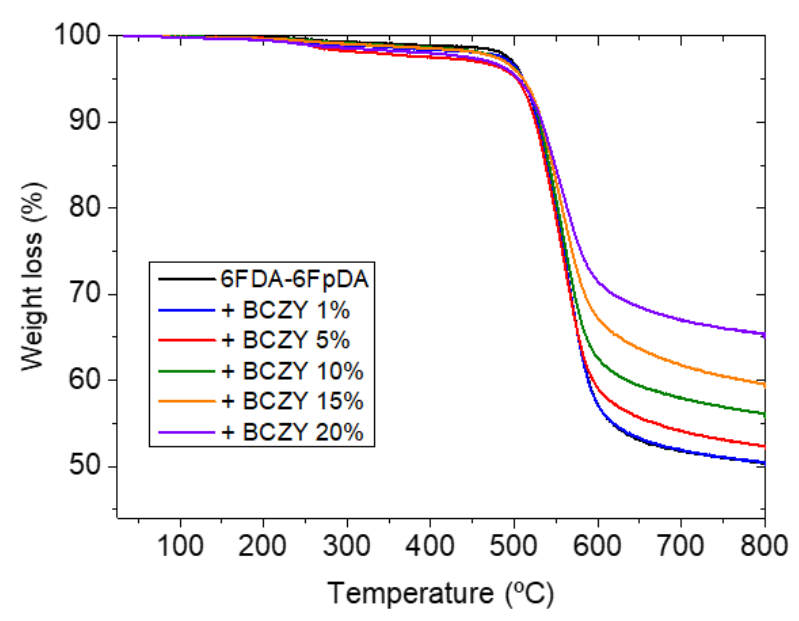

Figure 7.2. TGA graphs for the results of $6 F D A-6 F p D A$ with different percentage of the BCZY particle

\subsubsection{Microstructural characterization}

The X-ray diffraction (XRD) technique is employed to assess how the particles used in this work interact with the polymer matrix. Figure 7.3 displays the $\mathrm{X}$-ray diffraction pattern of MMMs made of 6FDA-6FpDA, Matrimid ${ }^{\circledR}$ and $\mathrm{P} 84^{\circledR}$ combined with BCZY 10 wt. \% and shows how the intersegmental distance $(d)$ (see Equation (4.1)) between polymer backbones are clearly related to the FFV of the polyimides $\left(6 F D A-6 F p D A>\right.$ Matrimid $\left.^{\circledR}>\mathrm{P} 84^{\circledR}\right)$, because FFV is directly related to $d$, or in other words, FFV is inversely related to $2 \theta[22,23]$. Figure 7.4 shows the $\mathrm{X}$-ray diffraction spectra of the MMMs with $10 \mathrm{wt}$. \% of all the particles. In addition, reference patterns of the inorganic fillers: $8 Y S Z, \mathrm{La}_{2} \mathrm{O}_{3}, \mathrm{LaWO}$ and $\mathrm{BCZY}$ crystals are shown. Regarding $\mathrm{La}_{2} \mathrm{O}_{3}$, its crystalline structure may be affected since this inorganic filler is highly hygroscopic. In fact, this was the case in this thesis, and, as exposed in Figure 7.4, the pattern of $\mathrm{La}_{2} \mathrm{O}_{3}$ changed to $\mathrm{La}(\mathrm{OH})_{3}$. Nonetheless, it has been demonstrated that the particles are well integrated in the polymer matrix, showing the combination of the diffraction pattern of the polymer and particles. Nevertheless, in the case of $8 \mathrm{YSZ}, \mathrm{La}_{2} \mathrm{O}_{3}$ and Beta zeolite, the main peak of the polymer matrix shifted to higher values of $2 \Theta$ and, therefore, the polymer intersegmental distance decreases [24-26]. This may indicate that part of the fraction free volume (FFV) of the polymer can be altered in the vicinity to the embedded particle. 


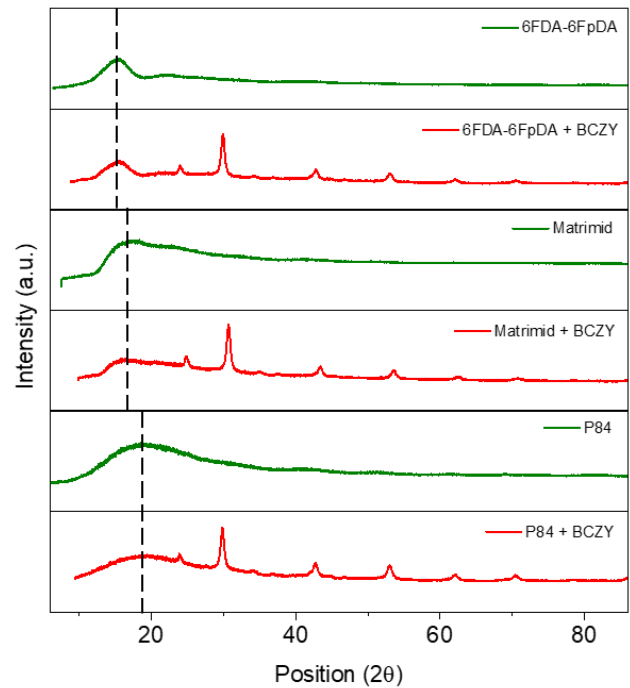

Figure 7.3. X-ray patterns for different polymer matrix: pure - blue lines, and with $10 \mathrm{wt}$ \% BCZYred lines

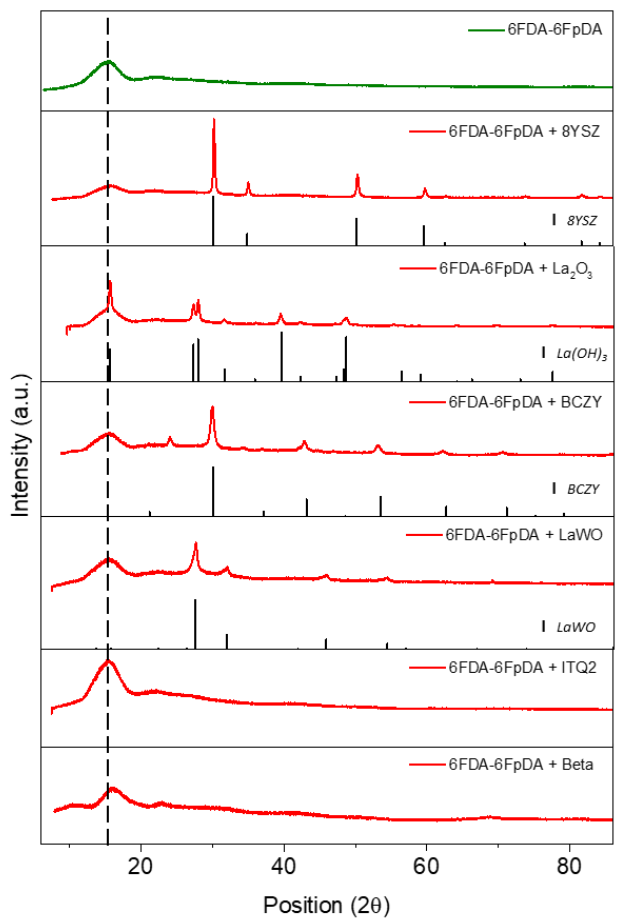

Figure 7.4. X-ray diffraction patterns for 6FDA-6FpDA with $10 \mathrm{wt}$ \% fillers (red lines) and reference patterns corresponding to $8 Y S Z, \mathrm{La}(\mathrm{OH})_{3}$, LaWO and BCZY crystals (black peaks) 
The fillers distribution, agglomeration, and sedimentation in the polymeric membranes were analyzed based on scanning electron microscopy (SEM) crosssectional images.

The cross-section of micrographs of 6FDA-6FpDA MMMs with $10 \%$ wt. fillers, are shown in Figure 7.5, where two effects can be appreciated. First, agglomerates from the inorganic fillers are observed. In theory, the size of particles should be in the nanometer range, but the most of the fillers occurs as agglomerates of embedded single nanoparticles. Secondly, sedimentation of particles can also be assured for most fillers. These two phenomena may be associated with the dynamics of the membrane formation process. In general, the slow process for solvent evaporation gives sufficient time for particles for sedimentation to the bottom, something very common in thick films MMMs. Two facts are related: the solvent used, NMP, which exhibits a high boiling point and the high density of most of the studied filler particles.

When all the inorganic fillers are compared, it is ascertained that $\mathrm{La}_{2} \mathrm{O}_{3}$ showed the largest amount of agglomerates and, in general, a poor distribution. In contrast, $B C Z Y$ is the filler with the best particle distribution throughout the membrane thickness, the least agglomeration and sedimentation. 


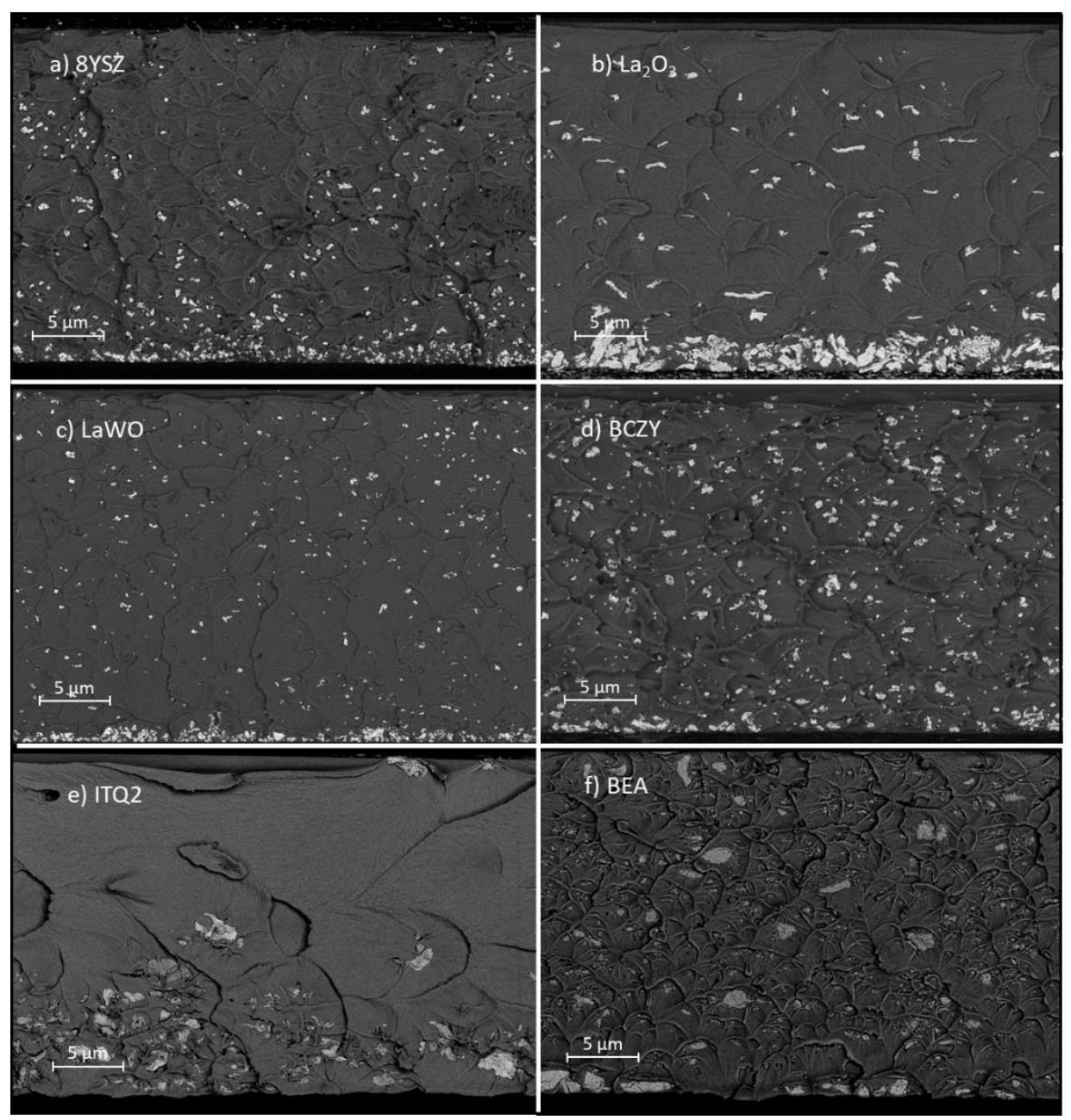

Figure 7.5. SEM images (fracture cross-sections) for 6FDA-6FpDA MMMs and 10 wt. \% fillers

\subsubsection{Gas transport properties}

The gas transport properties for the three different cases (i.e. particle type, particle content and polymer type) are evaluated. For the study of permeability, selectivity, solubility and diffusivity coefficient of gases and water vapor in MMMs as a function of temperature, time lag equipment was used. 


\section{Influence of the particle type in MMMs}

Mixed Matrix Membranes composed by 90 wt. \% of 6FDA-6FpDA as polymer matrix and 10 wt. \% of different fillers are characterized. Table 7.2 shows the influence of the particles in the polymer matrix reference (6FDA-6FpDA) in terms of permeability and selectivity at room temperature. As it can be seen, $\mathrm{CO}_{2}$ permeability decreases for all the fillers compare with the reference, giving negative variations values. On the other hand, $\mathrm{CO}_{2} / \mathrm{CH}_{4}$ selectivity values increase in all the cases. The decrease in permeability with the addition of inorganic fillers can be related to the formation of a densified layer (rigidification, see Figure 7.1) of polymer on the polymer/particle interphase (case 2 in Figure 7.1), although a reduction of the $T_{g}$ was not observed (Table 7.2). Polymer densification leads to a decrease in the fractional free volume, decrease of permeability and, as a consequence, to higher selectivity for the gas pair with significantly different kinetic diameters of gas molecules (our current studied case, see Table 3.6). Interestingly, there is a reverse-proportional relation between the decrease of $\mathrm{CO}_{2}$ permeability and the increase of the activation energy of $\mathrm{CO}_{2}$ permeability [27]. One plausible conclusion is the good contact between polymer and inorganic particle, i.e. presence of no gaps in this interface $[11,28]$.

Table 7.2. $\mathrm{CO}_{2}$ permeability, $\mathrm{CO}_{2} / \mathrm{CH}_{4}$ selectivity, percentage variations of permeability and selectivity (6FDA-6FpDA with 10 wt. \% fillers at $30{ }^{\circ} \mathrm{C}$ ). Additionally, the activation energy for $\mathrm{CO}_{2}$ permeability derived from the data shown in Figure 7.6 is listed

\begin{tabular}{|c|c|c|c|c|c|}
\hline $\begin{array}{l}\text { Membrane } \\
\text { sample } \\
\text { description }\end{array}$ & $\begin{array}{c}\mathrm{CO}_{2} \\
\text { Permeability } \\
\text { (Barrer) }\end{array}$ & $\begin{array}{c}\mathrm{CO}_{2} / \mathrm{CH}_{4} \\
\text { Selectivity } \\
(-)\end{array}$ & $\begin{array}{l}\mathrm{CO}_{2} \\
\text { Permeability } \\
\text { variation (\%) }\end{array}$ & $\begin{array}{c}\mathrm{CO}_{2} / \mathrm{CH}_{4} \\
\text { Selectivity } \\
\text { variation } \\
(\%)\end{array}$ & $\begin{array}{c}\text { Activation } \\
\text { energy } \\
\text { (kJ/mol) }\end{array}$ \\
\hline 6FDA-6FpDA & 77.4 & 48.0 & - & - & 0.69 \\
\hline$+10 w t . \% 8 Y S Z$ & 25.8 & 53.9 & -67 & +12 & 3.73 \\
\hline+10 wt. \% $\mathrm{La}_{2} \mathrm{O}_{3}$ & 34.1 & 51.9 & -56 & +8 & 2.69 \\
\hline +10 wt. \% LaWO & 11.9 & 77.3 & -85 & +61 & 5.51 \\
\hline+10 wt. \% BCZY & 63.8 & 54.6 & -18 & +14 & 1.22 \\
\hline$+10 w t . \%$ ITQ-2 & 28.9 & 55.1 & -63 & +15 & 2.63 \\
\hline+10 wt. \% Beta & 22.7 & 64.9 & -71 & +35 & 4.98 \\
\hline
\end{tabular}

$\mathrm{CO}_{2}$ permeability and $\mathrm{CO}_{2} / \mathrm{CH}_{4}$ selectivity was also measured as a function of temperature, from 30 to $80^{\circ} \mathrm{C}$. The permeability of $\mathrm{CO}_{2}$ increases with temperature for all tested MMMs. However, any MMMs exhibit higher permeability values than the pure polyimide membrane, see Figure 7.6 (left-hand). On the other hand, selectivity of $\mathrm{CO}_{2} / \mathrm{CH}_{4}$ decreases as a function of temperature and the effect of the fillers is more relevant (in terms of selectivity) at lower temperatures. Additionally, 
Table 7.2 shows the activation energy for the different fillers and the reference. The activation energy of the MMMs is higher than the activation energy of the polymeric membrane 6FDA-6FpDA. Hence, one can confirmed the formation of a rigid layer around the particles.
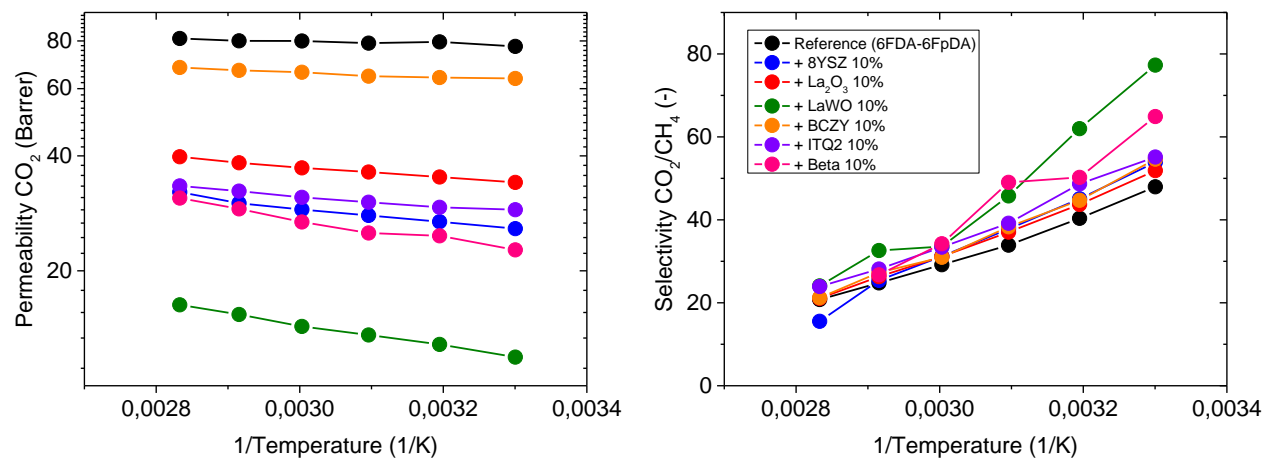

Figure 7.6. Permeability of $\mathrm{CO}_{2}$ and $\mathrm{CO}_{2} / \mathrm{CH}_{4}$ selectivity for the MMMs composed by 90 wt. \% of $6 \mathrm{FDA}$ 6FpDA and 10 wt. \% of different fillers as a function of temperature
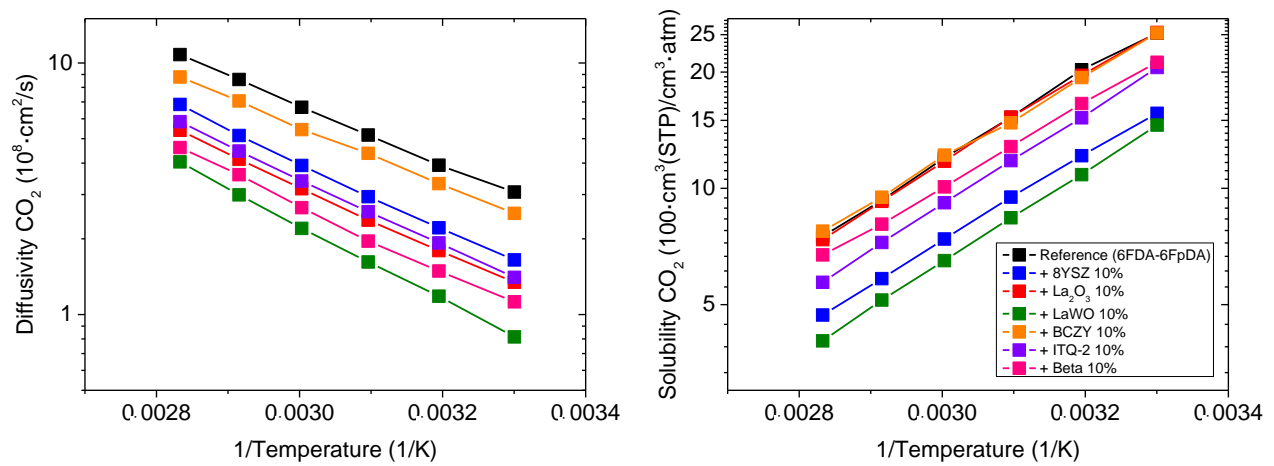

Figure 7.7. Diffusivity and solubility coefficient of MMMs composed by 90 wt. \% of $6 F D A-6 F p D A$ and 10 $w t . \%$ of different fillers, as a function of temperature

With regard to all the MMMs exposed in this subsection, BCZY sample exhibits the highest permeability value, as well as an acceptable increase in $\mathrm{CO}_{2} / \mathrm{CH}_{4}$ selectivity. In general, all MMMs exhibit worse permeability than the pure polyimide 6FDA-6FpDA (reference) while a visible improvement in selectivity can be observed. Gas permeability through a membrane depends on two parameters, diffusivity coefficient and solubility coefficient, and these two parameters were measured as a function of temperature (Figure 7.7). All the inorganic fillers causes a decrease in $\mathrm{CO}_{2}$ diffusivity coefficient, which is mainly determined by the FFV, and all of them decrease as a function of temperature. Regarding the solubility coefficient, similar 
behavior is exhibit, but, in particular, the membranes containing $\mathrm{BCZY}$ and $\mathrm{La}_{2} \mathrm{O}_{3}$ particles have practically the same $\mathrm{CO}_{2}$ solubility coefficient as the reference.

After all the data addressed, it is assumed that particles are blocking part of the FFV of the polymer matrix, and therefore, the final permeability decreases. Observing the evolution of the diffusivity coefficient as a function of temperature, this statement can be confirmed, since the reference diffusivity coefficient is higher than the rest at room temperature, and this difference becomes bigger at higher temperatures. To conclude, among all the studied fillers, BCZY was the most promising particle for MMMs, due to the fact that it is the particle that exhibits the highest permeability value, as well as a notable increase in $\mathrm{CO} 2 / \mathrm{CH} 4$ selectivity, and hence, it was decided to use this nano-sized filler for further studies, i.e. assessment of the influence of the nanoparticles amount on the separation performance.

\section{Influence of the particle contents in MMMs}

Five membranes were prepared with different BCZY content: 1-5-10-15-20 wt. $\%$ in the same polymer matrix, i.e. reference (6FDA-6FpDA), in order to understand the influence of the inorganic filler concentration on MMMs transport properties. A summary with permeability and ideal selectivity data obtained for the aforementioned membranes at $30^{\circ} \mathrm{C}$ is shown in Table 7.3.

Table 7.3. $\mathrm{CO}_{2}$ permeability, $\mathrm{CO}_{2} / \mathrm{CH}_{4}$ selectivity, percentage variations of permeability and selectivity (6FDA-6FpDA with different content of $\mathrm{BCZY}$ at $30^{\circ} \mathrm{C}$ ). Additionally, activation energy for $\mathrm{CO}_{2}$ permeability derived from the data shown in Figure 7.8 is listed

\begin{tabular}{|c|c|c|c|c|c}
$\begin{array}{c}\text { Membrane } \\
\text { sample } \\
\text { description }\end{array}$ & $\begin{array}{c}\mathrm{CO}_{2} \\
\text { Permeability } \\
\text { (Barrer) }\end{array}$ & $\begin{array}{c}\mathrm{CO}_{2} / \mathrm{CH}_{4} \\
\text { Selectivity } \\
(-)\end{array}$ & $\begin{array}{c}\mathrm{CO}_{2} \\
\text { Permeability } \\
\text { variation (\%) }\end{array}$ & $\begin{array}{c}\mathrm{CO}_{2} / \mathrm{CH}_{4} \\
\text { Selectivity } \\
\text { variation } \\
\text { (\%) }\end{array}$ & $\begin{array}{c}\text { Activation } \\
\text { energy } \\
\text { (kJ/mol) }\end{array}$ \\
\hline 6FDA-6FpDA & 77.4 & 48.0 & - & - & 0.69 \\
+1 wt. $\%$ BCZY & 61.4 & 49.7 & -21 & +3.6 & 2.56 \\
+5 wt. \% BCZY & 45.5 & 49.6 & -41 & +3.3 & 1.89 \\
+10 wt. \% BCZY & 63.8 & 54.6 & -18 & +14 & 1.22 \\
+15 wt. \% BCZY & 66.0 & 47.8 & -15 & -0.3 & 0.57 \\
+20 wt. \% BCZY & 59.7 & 45.1 & -23 & -6.0 & 1.46 \\
\hline
\end{tabular}

Similar to the section 5.2.4.1, the permeability values for the different filler concentration are lower than the permeability of the reference membrane (6FDA$6 \mathrm{FpDA})$. With regard to the selectivity variation, the MMMs with the highest content of BCZY (20 wt. \%) has a negative effect on selectivity. This suggests that aggregates influence the selectivity negatively, as well as blocking the FFV, i.e. decreasing the permeability. 

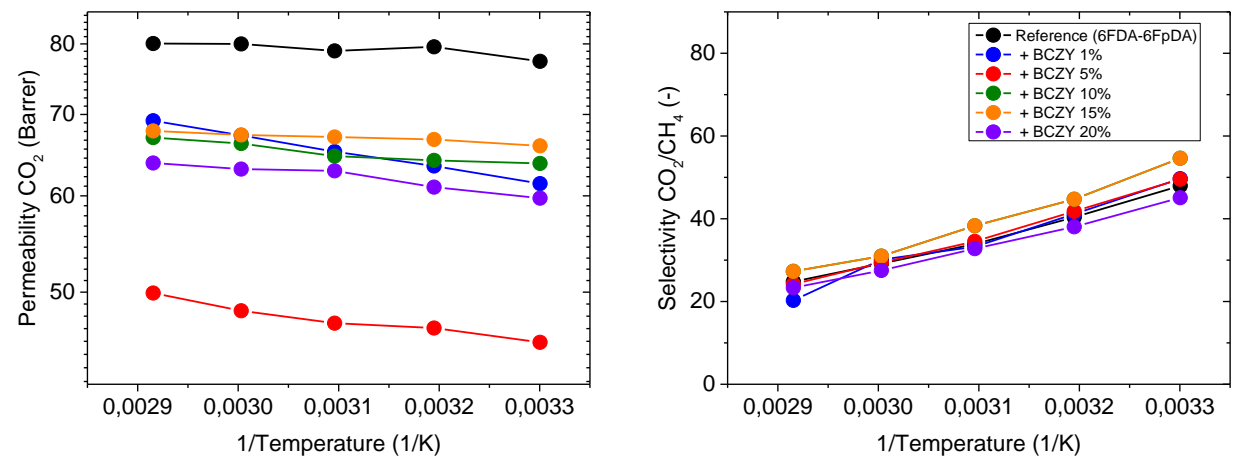

Figure 7.8. Permeability of $\mathrm{CO}_{2}$ and $\mathrm{CO}_{2} / \mathrm{CH}_{4}$ selectivity for the MMMs composed by 6FDA-6FpDA and different concentration of $B C Z Y$ filler as a function of temperature

$\mathrm{CO}_{2}$ permeability and $\mathrm{CO}_{2} / \mathrm{CH}_{4}$ selectivity was also measured as a function of temperature, from 30 to $70 \stackrel{\circ}{\circ}$ (see Figure 7.8). Activation energies for the MMMs of 6FDA-6FpDA with different $\%$ of BCZY filler are presented in Table 7.3. In addition, permeability of $\mathrm{CO}_{2}$ increases with temperature but decreases with the content of BCZY fillers. Nevertheless, MMMs with BCZY exhibit higher permeability values than with the other fillers studied in the previous section (see Figure 7.6).
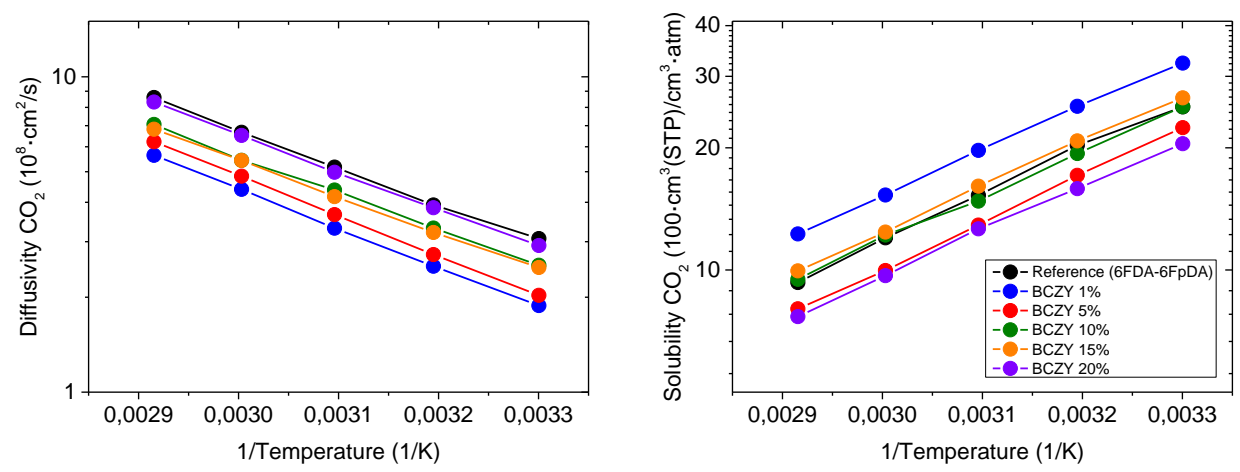

Figure 7.9. Diffusivity and solubility coefficient of MMMs composed by $90 \mathrm{wt}$ \% of 6FDA-6FpDA and different concentration of $B C Z Y$ filler as a function of temperature

This fact concludes that BCZY is the most promising particle. With regards to $\mathrm{CO}_{2} / \mathrm{CH}_{4}$ selectivity, it decreases as a function of temperature, and there is not a wide difference between the reference polymer and MMMs, leading to the statement that no clear dependence between BCZY content and activation energy can be observed. As it was explained in the previous subsection, gas permeability through 
a membrane depends on diffusivity coefficient and solubility coefficient. Hence, these two parameters were measured as a function of temperature (see Figure 7.9). Nevertheless, no remarkable difference were observed when it is compared the reference polyimide with the MMMs. It was supposed that this filler requires a polymer matrix which exhibits lower permeability values, so the effect of the particles would be appreciated. Therefore, in the next sub-section, the filler BCZY at $10 \mathrm{wt}$. \% is tested for two other polymers that present lower FFV, i.e. lower permeability, in order to check if the addition of particles enables to improve their separation performance.

\section{Influence of the polymer matrix in the MMMs}

In this section, the influence of three polymeric matrixes with different FFV (6FDA-6FpDA, Matrimid ${ }^{\circledR}$ and $\mathrm{P} 84^{\circledR}$ ) on the separation properties is addressed. The filler and the amount of filler used is selected considering the results of the previous sections: BCZY as the most suitable filler, and $10 \mathrm{wt}$. \% as the most suitable proportion [29]. Table 7.4 shows the polymer matrix influence (6FDA-6FpDA, Matrimid $^{\circledR}$ and $P 84^{\circledR}$ ) in terms of permeability and selectivity at $30{ }^{\circ} \mathrm{C}$. We hypothesized that, for lower permeable polymers, the particles may affect positively the gas separation properties of the mixed matrix membranes [30-32]. As it is shown in the table below, the Matrimid ${ }^{\circledR}$ mixed matrix membrane exhibits higher permeability, as well as selectivity (case 1 in Figure 7.1), compared to its reference, while the $\mathrm{P} 84^{\circledR}$ mixed matrix membrane behaves similar to the 6 FDA-6FpDA mixed matrix membrane, with a decrease in permeability and an increase in selectivity (case 2 in Figure 7.1) [28].

Table 7.4. $\mathrm{CO}_{2}$ permeability, $\mathrm{CO}_{2} / \mathrm{CH}_{4}$ selectivity, percentage variations of permeability and selectivity (membranes with different polymeric matrix at $30^{\circ} \mathrm{C}$ ). Additionally, activation energy for $\mathrm{CO}_{2}$ permeability derived from the data shown in Figure 7.10 is listed

\begin{tabular}{|c|c|c|c|c|c|}
$\begin{array}{c}\text { Membrane } \\
\text { sample } \\
\text { description }\end{array}$ & $\begin{array}{c}\mathrm{CO}_{2} \\
\text { Permeability } \\
\text { (Barrer) }\end{array}$ & $\begin{array}{c}\mathrm{CO}_{2} / \mathrm{CH}_{4} \\
\text { Selectivity } \\
(-)\end{array}$ & $\begin{array}{c}\mathrm{CO}_{2} \\
\text { Permeability } \\
\text { variation (\%) }\end{array}$ & $\begin{array}{c}\mathrm{CO}_{2} / \mathrm{CH}_{4} \\
\text { Selectivity } \\
\text { variation (\%) }\end{array}$ & $\begin{array}{c}\text { Activation } \\
\text { energy } \\
\text { (kJ/mol) }\end{array}$ \\
\hline 6FDA-6FpDA & 77.4 & 48.0 & - & - & 0.69 \\
+10 wt. \% BCZY & 63.8 & 54.6 & -18 & +14 & 1.22 \\
Matrimid & 5.1 & 40.5 & - & - & 9.30 \\
+10 wt. \% BCZY & 6.7 & 47.5 & +31 & +17 & 7.42 \\
P84 & 1.4 & 47.0 & - & - & 11.64 \\
+10 wt. \% BCZY & 1.0 & 64.6 & -32 & +38 & 18.33 \\
\hline
\end{tabular}


$\mathrm{CO}_{2}$ permeability and $\mathrm{CO}_{2} / \mathrm{CH}_{4}$ selectivity was also measured as a function of temperature, from 30 to $60^{\circ} \mathrm{C}$. All polymers show good compatibility with BCZY particles, but exhibit different behavior as MMMs. P84 ${ }^{\circledR}$ behaves similar to 6FDA$6 F p D A$, they show lower permeability values of $\mathrm{CO}_{2}$, whereas $\mathrm{MMMs}$ of Matrimid ${ }^{\circledR}$ with 10 wt. \% of $\mathrm{BCZY}$ presents an improvement in both $\mathrm{CO}_{2}$ permeability and $\mathrm{CO}_{2} / \mathrm{CH}_{4}$ selectivity. As it can be expected for the $\mathrm{CO}_{2} / \mathrm{CH}_{4}$ gas pair, the ideal selectivity decreases with temperature not only for pure polymer, but also for MMMs (see Figure 7.10).
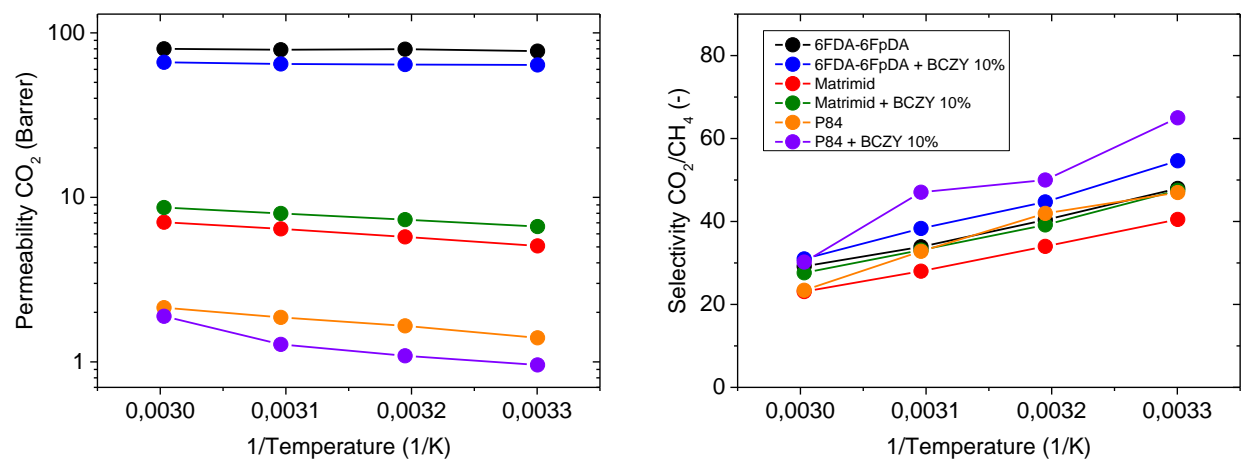

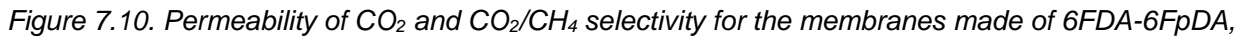
Matrimid ${ }^{\circledR}$ and $P 84^{\circledR}$ with and without 10 wt. $\%$ BCZY as a function of temperature
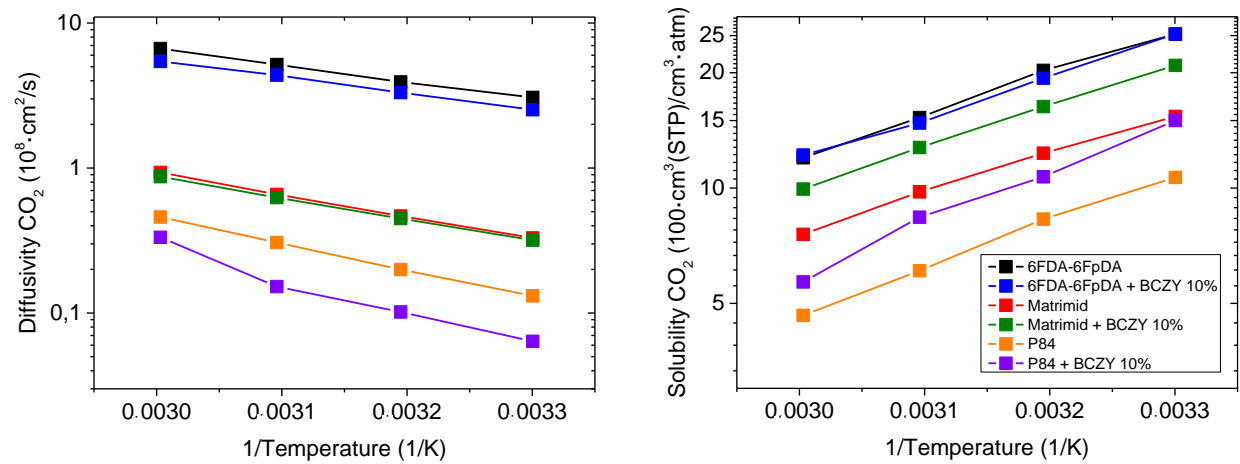

Figure 7.11. Diffusivity and solubility coefficient of $\mathrm{CO}_{2}$ of membranes made of 6FDA-6FpDA, Matrimid ${ }^{\circledR}$ and $P 84^{\circledR}$ with and without 10 wt. $\% B C Z Y$ as a function of temperature 
With reference to diffusion and solubility coefficients of $\mathrm{CO}_{2}$ as a function of temperature, Figure 7.11 is displayed. It can be observed that, the permeability of Matrimid ${ }^{\circledR}$ with BCZY filler is higher than the pure polymer Matrimid ${ }^{\circledR}$. The reason is because solubility coefficients improve, and diffusivity coefficients remains constant with respect to its reference. In general, the activation energy of $\mathrm{CO} 2$ diffusivity (Figure 7.11) of the polymer membrane is not influenced by the incorporation of BCZY particles suggesting that the diffusion mechanism may not be affected.

\section{Transport of water vapor in MMMs}

Among other properties already explained, fillers were selected because they exhibit a high affinity towards water. These fillers used in this thesis can be future candidate materials for membranes able to remove water from $\mathrm{CO}_{2}$-rich gas streams as combustion tail-gas or catalytic converters products. Moreover, all the MMMs tested until now present high $\mathrm{CO}_{2}$ solubility coefficients, which may be related to the water vapor transport properties. As a consequence, it was decided to test them for water vapor transport using the "time-lag" setup.

A summary of water vapor permeabilities and the activation energies for all the MMMs can be seen in Table 7.5. The accomplished water vapor permeability values are outstandingly high, although permeability decreases with the temperature. The negative values of the activation energy are related to the exothermic nature of the water solubility and its effect dominates in the overall separation process. In all cases, water permeability decreased in MMMs compared to pure polymers except the case of Matrimid ${ }^{\circledR}$ with 10 wt. \% of BCZY (see Figure 7.12). 
Table 7.5. $\mathrm{H}_{2} \mathrm{O}$ permeability, $\mathrm{H}_{2} \mathrm{O} / \mathrm{CO}_{2}$ selectivity, percentage variations of permeability and selectivity at $30{ }^{\circ} \mathrm{C}$. Additionally, activation energy for $\mathrm{H}_{2} \mathrm{O}$ permeability derived from permeability vs. temperature data is listed

\begin{tabular}{|c|c|c|c|c|c|}
\hline $\begin{array}{l}\text { Membrane } \\
\text { sample } \\
\text { description }\end{array}$ & $\begin{array}{c}\mathrm{H}_{2} \mathrm{O} \\
\text { Permeability } \\
\text { (Barrer) }\end{array}$ & $\begin{array}{c}\mathrm{H}_{2} \mathrm{O} / \mathrm{CO}_{2} \\
\text { Selectivity } \\
(-)\end{array}$ & $\begin{array}{c}\mathrm{H}_{2} \mathrm{O} \\
\text { Permeability } \\
\text { variation (\%) }\end{array}$ & $\begin{array}{c}\mathrm{H}_{2} \mathrm{O} / \mathrm{CO}_{2} \\
\text { Selectivity } \\
\text { variation (\%) }\end{array}$ & $\begin{array}{c}\text { Activation } \\
\text { energy } \\
\text { (kJ/mol) }\end{array}$ \\
\hline 6FDA-6FpDA & 3875 & 60.06 & - & (1) & -3.34 \\
\hline$+10 w t . \% 8 Y S Z$ & 1998 & 77.48 & -48 & +55 & -2.22 \\
\hline+10 wt. $\% \mathrm{La}_{2} \mathrm{O}_{3}$ & 2381 & 69.85 & -39 & +40 & -2.79 \\
\hline+10 wt. \% LaWO & 1287 & 108.30 & -67 & +116 & -1.35 \\
\hline+10 wt. \% BCZY & 3319 & 52.02 & -14 & +4 & -3.31 \\
\hline$+10 w t . \%$ ITQ-2 & 2015 & 69.70 & -48 & +39 & -1.31 \\
\hline+10 wt. \% Beta & 1914 & 84.35 & -51 & +69 & 0.69 \\
\hline 6FDA-6FpDA & 3875 & 60.06 & - & - & -3.34 \\
\hline+1 wt. $\%$ BCZY & 3144 & 51.20 & -19 & +2 & -2.30 \\
\hline+5 wt. \% BCZY & 2766 & 60.83 & -29 & +22 & -2.23 \\
\hline+10 wt. \% BCZY & 3319 & 52.02 & -14 & +4 & -3.31 \\
\hline+15 wt. \% BCZY & 3276 & 49.67 & -15 & -1 & -2.13 \\
\hline+20 wt. \% BCZY & 3108 & 52.03 & -20 & +4 & -2.28 \\
\hline 6FDA-6FpDA & 3875 & 60.06 & - & - & -3.34 \\
\hline+10 wt. \% BCZY & 3319 & 52.02 & -14 & +4 & -3.31 \\
\hline Matrimid $^{\Theta}$ & 1524 & 300.6 & 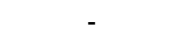 & 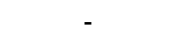 & 0.87 \\
\hline+10 wt. \% BCZY & 1835 & 276.02 & +20 & -8 & -1.16 \\
\hline$P 84^{\circledR}$ & 1226 & 875.71 & - & - & 2.36 \\
\hline$+10 w t . \% B C Z Y$ & 821 & 856.40 & -33 & -2 & 1.73 \\
\hline
\end{tabular}

This filler showed the highest permeability coefficient of MMMs when compared to other fillers mixed with 6FDA-6FpDA. Looking at activation energies of water permeability in $10 \mathrm{wt}$ \% MMMs based on three polymers, one may conclude that the "slower" polymers Matrimid ${ }^{\circledR}$ and $\mathrm{P} 84^{\circledR}$ are more benefitting by the incorporation of BCZY. Namely, $P 84^{\circledR}$-based MMMs shows slightly positive $E_{a}(P)$ for water vapor and Matrimid ${ }^{\circledR}$ MMMs exhibits a higher water permeability coefficient than for the pure polymer and a lower corresponding activation energy. Regarding diffusivity and solubility coefficients, it can be observed that a similar behavior to Figure 7.11 is happened. $\mathrm{H}_{2} \mathrm{O}$ permeability of Matrimid ${ }^{\circledR}$ with $\mathrm{BCZY}$ filler is higher than the pure polymer Matrimid ${ }^{\circledR}$, because mainly solubility coefficient is improving with respect to its reference, see Figure 7.13. Generally, the activation energy of $\mathrm{H}_{2} \mathrm{O}$ diffusivity is not influenced by the incorporation of BCZY particles suggesting that the diffusion mechanism may not be affected, as it occurred with $\mathrm{CO}_{2}$ diffusivity coefficients. 

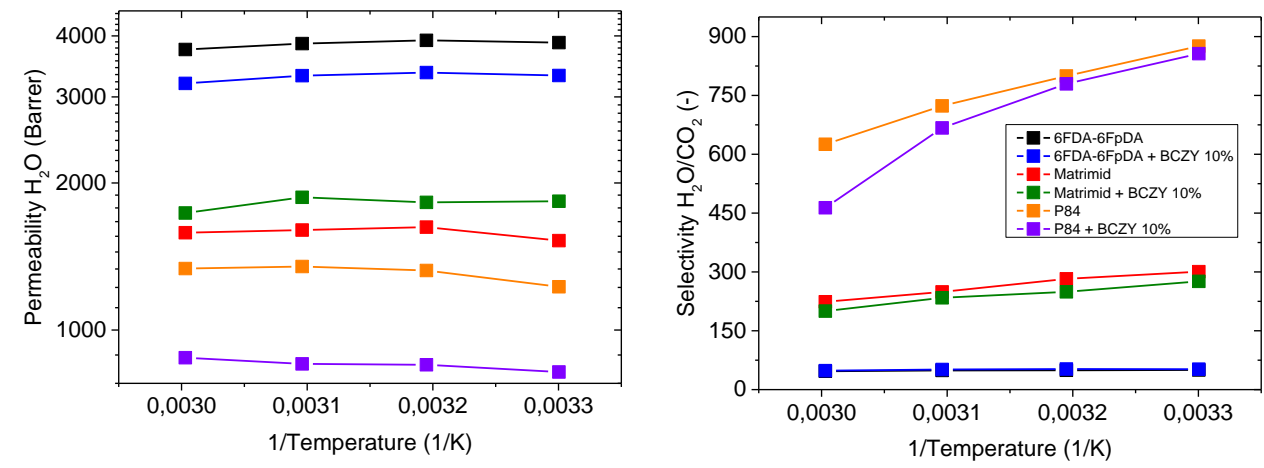

Figure 7.12. Permeability of $\mathrm{H}_{2} \mathrm{O}$ and $\mathrm{H}_{2} \mathrm{O} / \mathrm{CO}_{2}$ selectivity for the membranes made of $6 F D A-6 F p D A$, Matrimid ${ }^{\circledR}$ and $P 84^{\circledR}$ with and without 10 wt. $\% B C Z Y$ as a function of temperature
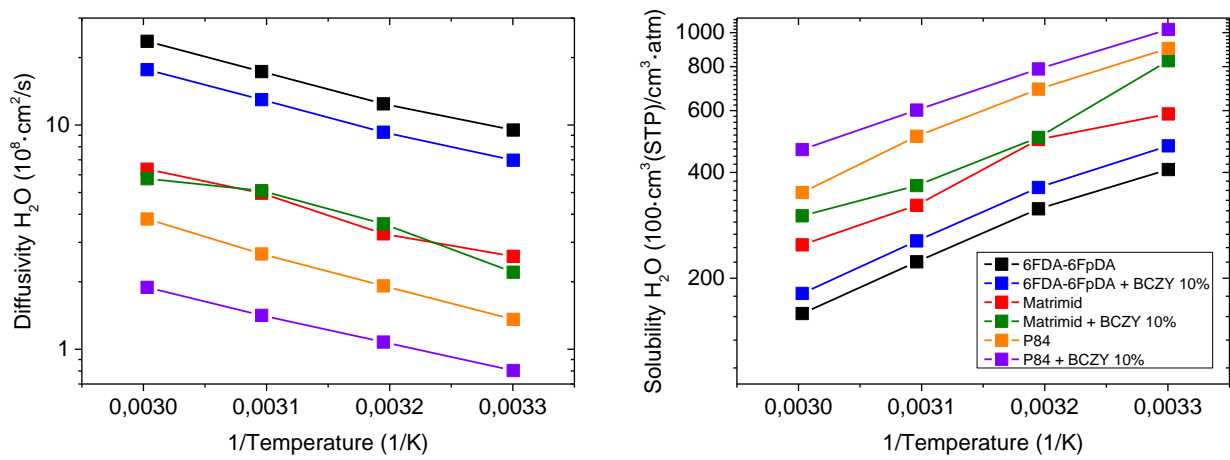

Figure 7.13. Diffusivity and solubility coefficient of $\mathrm{H}_{2} \mathrm{O}$ of membranes made of $6 F D A-6 F p D A$, Matrimid ${ }^{\circledR}$ and $P 84^{\circledR}$ with and without 10 wt. $\% B C Z Y$ as a function of temperature

These two materials, Matrimid ${ }^{\circledR}$ and $\mathrm{P} 84^{\circledR}$, are appealing materials for further application in membrane-assisted water vapor removal from combustion streams or in catalytic reactors in order to shift chemical equilibrium in $\mathrm{CO}_{2}$-hydrogenation reactions. 


\subsubsection{MMMs as TFCMs}

\subsubsection{Support material}

Regarding the TFMCs, an asymmetric support of polyphenylene sulfide fiber (PPS) and polybenzimidazole (PBI), is used for the thin film composite membrane production. This support possesses good chemical and mechanical stability properties, as well as high thermal resistance up to $300^{\circ} \mathrm{C}$. More information about the polymer support can be found in Chapter 4 - Methodology. This support material is the same as in Chapter 6, section 6.2.1

\subsubsection{Membrane formation}

Regarding membrane formation, mixed-matrix solution was prepared to obtain a $10 \mathrm{wt}$. \% of particles in comparison to the polymer (6FDA-6FpDA). Firstly, the particles were mixed with a small amount in THF and dispersed in an ultrasonic device for $30 \mathrm{~min}$. The 6FDA-6FpDA was also dissolved with a small amount of THF and then mixed together with the solution of particles. Afterwards the polymer/particles solution was diluted with THF to get a $3.5 \mathrm{wt}$. \% of total mass (polymer + particles) compared to the solvent. Dip coating process was followed as in Chapter 6, section 6.2.2

\subsubsection{Microstructural characterization}

The cross-section of micrographs of 6FDA-6FpDA MMMs with $10 \%$ wt. fillers, are shown in Figure 7.14. 6FDA-6FpDA selective layer with a protective layer of Teflon can be seen in a), which was firstly presented in Chapter 6 . It was already explained that the peel of the Teflon layer which is appreciated in Figure 7.14 a) could be due to the fact that the membranes were already tested at this point. Nevertheless, thickness of the TFCM can be ascertained. The rest of the images in Figure 7.14 are related to the different fillers already testes for thick films MMMs in the previous section. Zeolites ITQ-2 and Beta exhibit the lower thickness, around $200 \mathrm{~nm}$, whereas 8YSZ, LaWO and BCZY present higher thicknesses. Inorganic fillers were not correctly and homogeneously distributed in the polymer matrix, as it is appreciable in Figure 7.14. Particles are agglomerated, and in some cases such as LaWO and BCZY, fillers seem to have a higher diameter than the selective layer thickness. 


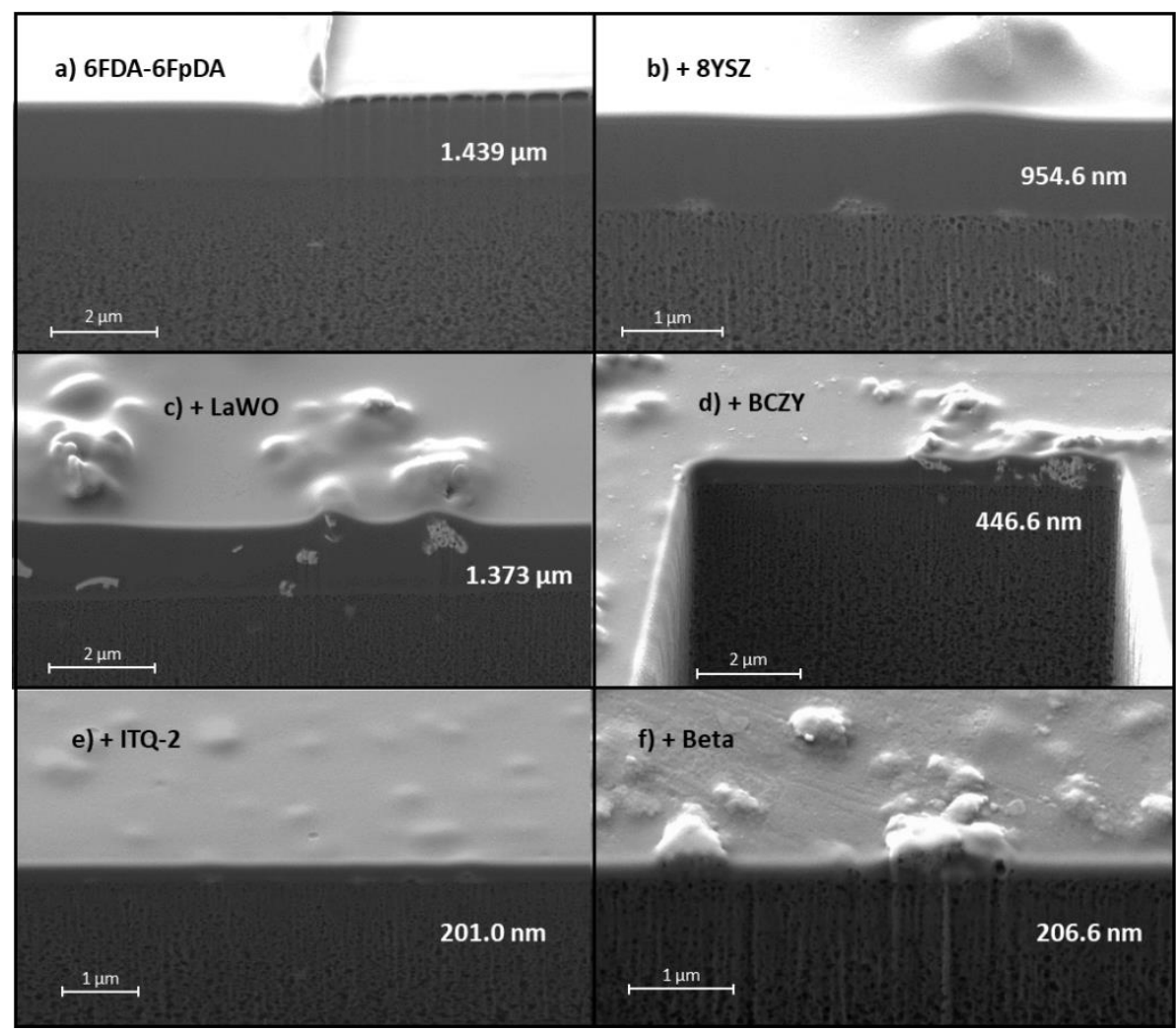

Figure 7.14. Cross section images from FIB micrographs of 6FDA-6FpDA (a)) with different fillers $b$ ) 8YSZ c) LaWO, d) BCZY, e) ITQ-2 and f) Beta

As it was observed in the section before, 5.2.1. MMMs as thick films, $\mathrm{La}_{2} \mathrm{O}_{3}$ happened to show the largest amount of agglomerates and, in general, a poor distribution. Additionally, it was observed in Figure 7.4 (the pattern changed to $\left.\mathrm{La}(\mathrm{OH})_{3}\right)$, that its crystalline structure is affected since $\mathrm{La}_{2} \mathrm{O}_{3}$ is highly hygroscopic. Hence, although it has been demonstrated that the particles are well integrated in the polymer matrix, it was decided not to include this inorganic filler for the MMMs as thin films.

\subsubsection{Gas transport properties}

The gas transport properties for the five different MMMs and the pure TFCM of 6FDA-6FpDA are evaluated. For the study of permeance and selectivity, of gases and water vapor in MMMs as a function of temperature, polymeric membrane module described on the Chapter 4 - Methodology was used. Mixed gas measurements of $\mathrm{H}_{2} / \mathrm{CO}_{2} / \mathrm{H}_{2} \mathrm{O}$ were performed from $240{ }^{\circ} \mathrm{C}$ to $260^{\circ} \mathrm{C}$ and 1 bar. As in the Chapter 6 , 
section 4.2.1., the maximum selected operational temperature was $260^{\circ} \mathrm{C}$ because TFCM were stable up to $275^{\circ} \mathrm{C}$, after this point the non-woven PPS starts to meld and the membrane collapse.
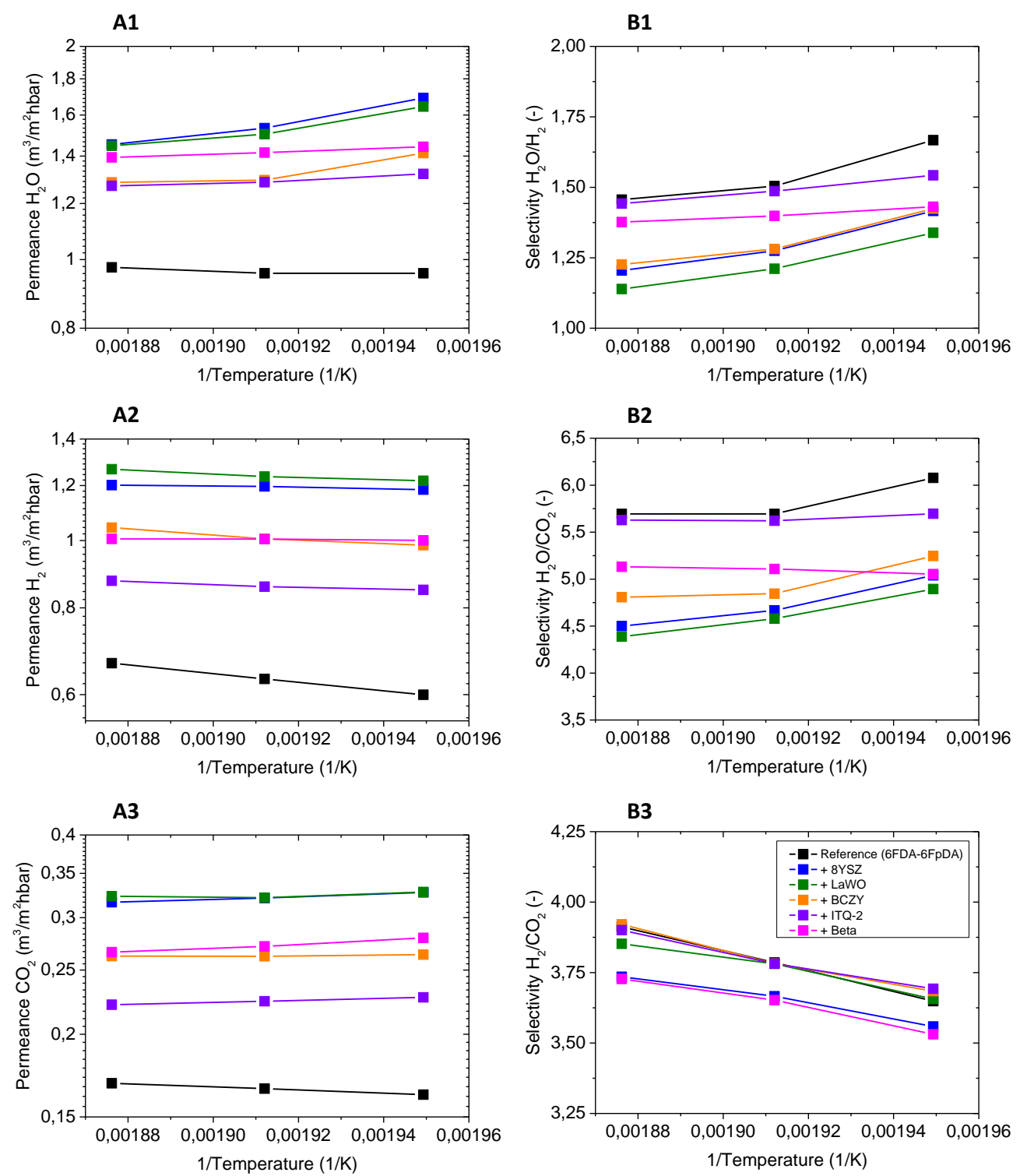

Figure 7.15. Gas separation properties of the MMMs as thin films, as a function of temperature. A1, A2 and $A 3$ represents water vapor, $\mathrm{H}_{2}$ and $\mathrm{CO}_{2}$ permeances respectively, whereas $B 1, B 2$ and $B 3$ exhibits selectivity of $\mathrm{H}_{2} \mathrm{O} / \mathrm{H}_{2}, \mathrm{H}_{2} \mathrm{O} / \mathrm{CO}_{2}$ and $\mathrm{H}_{2} / \mathrm{CO}_{2}$ respectively 
Water permeation was calculated using a hygrometer, whereas gas permeation was obtained by using a micro GC. $\mathrm{H}_{2}, \mathrm{CO}_{2}$ and $\mathrm{H}_{2} \mathrm{O}$ permeance, as well as $\mathrm{H}_{2} \mathrm{O} / \mathrm{H}_{2}$, $\mathrm{H}_{2} \mathrm{O} / \mathrm{CO}_{2}$ and $\mathrm{H}_{2} / \mathrm{CO}_{2}$ selectivity were studied. Mixed gas flow were kept constant in order to obtain the following concentration on the feed: $62 \% \mathrm{H}_{2}, 16 \% \mathrm{CO}_{2}$ and 22 $\% \mathrm{H}_{2} \mathrm{O}$. This composition was selected due to its similarities to several process where water is a by-product, such as methanation. Additionally, hydrocarbons were not selected in the feed gas because their permeability through polymer membranes is not as high as $\mathrm{H}_{2}$ or $\mathrm{CO}_{2} . \mathrm{H}_{2}$ usually exhibits the highest diffusivity coefficient whereas $\mathrm{CO}_{2}$ normally exhibits the higher solubility coefficients. Hence, with this composition as feed gas, a concrete idea of the gas separation properties of MMMs as TFCMs can be obtained.

As it can be seen in Figure 7.15 left-side, permeances of the pure polymer matrix, 6FDA-6FpDA, are lower than the permeances of the MMMs, while selectivity of 6FDA-6FpDA are equal or higher than selectivities of MMMs, see Figure 7.15 right-side. Regarding the compatibility between the inorganic filler and the polymer matrix (Figure 7.1), the current work can be related to Case 3, where a creation of an interphase due to the incompatibility between the particle and the polymer matrix is observed, because permeability increase whereas selectivity decrease due to the bigger fractional free volume.

$\mathrm{H}_{2} \mathrm{O}$ permeances stand higher than $\mathrm{H}_{2}$ or $\mathrm{CO}_{2}$ permeances, and while for pure 6FDA-6FpDA, it remains constant with temperature (or even slightly increase), when fillers are included in the polymer matrix, $\mathrm{H}_{2} \mathrm{O}$ permeance decrease as a function of temperature, especially for $8 Y S Z$, LaWO and BCZY, whereas zeolites, although they also decrease with temperature, the slope is not as steep as others. $\mathrm{H}_{2}$ permeance increase with temperature in all the cases, for the pure polymer matrix, as well as MMMs. Higher permeances are obtained for fillers 8YSZ and LaWO, followed by $\mathrm{BCZY}$ and Beta, and finally ITQ-2. Finally, $\mathrm{CO}_{2}$ permeances exhibit the lowest permeances of all the gases tested. Higher permeances are obtained for $8 Y S Z$ and LaWO; whereas the lowest permeance is observed for pure 6FDA-6FpDA. Dependence with temperature is similar to water vapor. Pure 6FDA-6FpDA increase slightly with temperature, whereas MMMs show contrary effect, they barely decrease as a function of temperature.

With regard to selectivity, $\mathrm{H}_{2} \mathrm{O} / \mathrm{H}_{2}, \mathrm{H}_{2} \mathrm{O} / \mathrm{CO}_{2}$ and $\mathrm{H}_{2} / \mathrm{CO}_{2}$ was calculated, which are shown in Figure 7.15 on the right-side. Water vapor over hydrogen or carbon 
dioxide decrease with temperature, due to the fact that $\mathrm{E}_{\mathrm{A}}$ value for $\mathrm{H}_{2} \mathrm{O}$ are negative (except pure 6FDA-6FpDA), which means that the solubility coefficient change more significantly with temperature than the diffusion coefficient, and also, they are significantly lower than $\mathrm{H}_{2}$ and also $\mathrm{CO}_{2}$ although it also exhibit negative $E_{A}$. Activation energies can be found in Table 7.6. H2/CO2 selectivity was also studied as a function of temperature, and it can be appreciated that it increases with temperature. As in the previous chapters, where this gas pair was already studied, $E_{A}$ values of $\mathrm{H}_{2}$ are positive, which means that the diffusion coefficient change more significantly with temperature than its solubility coefficient. $\mathrm{E}_{\mathrm{A}}$ value for $\mathrm{CO}_{2}$ is significantly lower than that of $\mathrm{H}_{2}$. Thus, the selectivity $\mathrm{H}_{2} / \mathrm{CO}_{2}$ increases as a function of temperature.

Table 7.6. Activation energies of permeance for the different gases for asymmetric polymer membranes, prepared using $3.5 \mathrm{wt}$. \% polymer solutions and $10 \mathrm{wt}$. \% of fillers

\begin{tabular}{l|c|c|c}
\multicolumn{4}{|c}{ Activation energy $\left(E_{A}\right)\left(\mathbf{k J} \cdot \mathbf{m o l}^{-1}\right)$} \\
\hline \multirow{2}{*}{ 6FDA-6FpDA } & $\mathbf{H}_{2} \mathbf{O}$ & $\mathrm{H}_{2}$ & $\mathbf{C O}_{2}$ \\
\cline { 2 - 4 }$+\mathbf{+ 1 0}$ wt. \% 8YSZ & 2.15 & 11.89 & 4.51 \\
$\mathbf{+ 1 0}$ wt. \% LaWO & -17.20 & 1.72 & -3.87 \\
$\mathbf{+ 1 0}$ wt. \% BCZYZ & -14.51 & 4.36 & -1.69 \\
$\mathbf{+ 1 0}$ wt. \% ITQ-2 & -10.86 & 6.60 & -0.60 \\
$\mathbf{+ 1 0}$ wt. \% Beta & -4.42 & 3.39 & -2.89 \\
\hline
\end{tabular}




\subsection{Conclusions}

In this chapter, it was presented and developed a complete study of the influence of inorganic fillers on the gas transport properties of different polyimides, typically applied in gas separation processes, i.e. purification of biogas and natural gas. These inorganic nanoparticles materials were selected because the expected good affinity for gas molecules as $\mathrm{CO}_{2}$ and water vapor. The particles were successfully dispersed and incorporated into the polymer matrix. As a consequence, 15 different MMMs were successfully produced as a thick film. In order to characterize the materials used for the MMMs, different techniques including TGA, XRD, DSC or SEM were employed. Gas transport properties were evaluated for $\mathrm{CH}_{4}$, $\mathrm{CO}_{2}$ and $\mathrm{H}_{2} \mathrm{O}$ at temperatures from 30 to $80^{\circ} \mathrm{C}$, in a time lag equipment.

Although MMMs do not exhibit higher $\mathrm{T}_{\mathrm{g}}$, it was observed that the inorganic fillers could produce a small rigidification in the polymer matrix. Hence, developed MMMs allowed to improve selectivity but with a negative impact on permeability. On plausible explanation is related to particle aggregation (see Figure 7.5 for SEM images), blocking part of the FFV but increasing tortuosity of the gases trough the membrane. With regard to the influence of the particle type and/or content, no clear effect of the particles in terms of pore size or particle size was distinguished. A small decrease in interspacing of the polymer chains with no modification of the particles pattern was shown by XRD analysis, which means that the particle do not interact with polymer.

Among all the different tested inorganic particles, BCZY exhibits the best improvement of selectivity with a small and acceptable decrease in permeability. In addition, it also shows the best distribution and, as a consequence, it was selected for the next two experiments (different percentages and different polymer matrix). It was also observed that, for polymer matrixes with lower FFV, i.e. Matrimid ${ }^{\circledR}$ and $\mathrm{P} 84^{\circledR}$, there is a result in improvement of the properties by adding particles, possible due to the creation of interface between particle and polymer chain.

Accordingly, MMMs with particles can be used to create interface resulting in an increase separation properties of slow polymers. In terms of temperature dependence, some changes were observed on activation energy of the process. Nevertheless, the incorporation of inorganic fillers does not significantly affect the permeation mechanism determined by the polymer transport properties. 
Finally, water permeability was firstly reported for several polyimides and MMMs of inorganic particles with polyimides, reaching relatively high values. On the other hand, the effect of the filler incorporation on the water permeation was not relevant for the polymers except for the case of Matrimid ${ }^{\circledR}$. 


\subsection{References}

1. Santi Kulprathipanja, R.W.N., Norman N. Li Separation of fluids by means of mixed matrix membranes. 1988, Honeywell International Inc.

2. Kulprathipanja, S., Mixed Matrix Membrane Development. Annals of the New York Academy of Sciences, 2003. 984(1): p. 361-369.

3. Robeson, L.M., The upper bound revisited. Journal of Membrane Science, 2008. 320(1): p. 390-400.

4. Paul, D.R. and U.P. Âmpol'skij, Polymeric gas separation membranes. 1994, Boca Raton: CRC.

5. Baker, R.W., Research needs in the membrane separation industry: Looking back, looking forward. Journal of Membrane Science, 2010. 362(1): p. 134136.

6. Stünkel, S., et al., Carbon dioxide capture for the oxidative coupling of methane process - A case study in mini-plant scale. Chemical Engineering Research and Design, 2011. 89(8): p. 1261-1270.

7. Cheng, Y., Z. Wang, and D. Zhao, Mixed Matrix Membranes for Natural Gas Upgrading: Current Status and Opportunities. Vol. 57. 2018.

8. J. Koros, W. and C. Zhang, Materials for next-generation molecularly selective synthetic membranes. Vol. 16. 2017.

9. $\mathrm{Li}, \mathrm{Y}$., et al., Recent advances in the fabrication of advanced composite membranes. Vol. 1. 2013.

10. Corma, A., et al., Preparation, characterisation and catalytic activity of ITQ2, a delaminated zeolite. Microporous and Mesoporous Materials, 2000. 38(2): p. 301-309.

11. Bastani, D., N. Esmaeili, and M. Asadollahi, Polymeric mixed matrix membranes containing zeolites as a filler for gas separation applications: $A$ review. Journal of Industrial and Engineering Chemistry, 2013. 19(2): p. 375393.

12. Carreon, M.A., Membranes for gas separations. Colorado School of Mines, USA ed. 2018. 376.

13. Liu, C., D.W. Greer, and B.W. O'Leary, Advanced Materials and Membranes for Gas Separations: The UOP Approach, in Nanotechnology: Delivering on the Promise Volume 2. 2016, American Chemical Society. p. 119-135.

14. Dechnik, J., et al., Mixed-Matrix Membranes. Angewandte Chemie International Edition, 2017. 56(32): p. 9292-9310.

15. Yang, Y., et al., Enhancing the mechanical strength and $\mathrm{CO} / \mathrm{CH} 4$ separation performance of polymeric membranes by incorporating amineappended porous polymers. Journal of Membrane Science, 2019. 569: $\mathrm{p}$. 149-156. 
16. Maghami, M. and A. Abdelrasoul, Zeolite Mixed Matrix Membranes (ZeoliteMMMs) for Sustainable Engineering. 2018.

17. Ansaloni, L. and L. Deng, 7 - Advances in polymer-inorganic hybrids as membrane materials, in Recent Developments in Polymer Macro, Micro and Nano Blends, P.M. Visakh, G. Markovic, and D. Pasquini, Editors. 2017, Woodhead Publishing. p. 163-206.

18. Zhang, C., et al., High performance ZIF-8/6FDA-DAM mixed matrix membrane for propylene/propane separations. Journal of Membrane Science, 2012. 389: p. 34-42.

19. Fernández-Barquín, A., et al., LTA/Poly(1-trimethylsilyl-1-propyne) MixedMatrix Membranes for High-Temperature CO2/N2 Separatio. Vol. 38. 2015. 658-666.

20. Fernández-Barquín, A., et al., Permselectivity improvement in membranes for CO2/N2 separation. Vol. 157. 2016. 102-111.

21. Sabetghadam, A., et al., Metal Organic Framework Crystals in Mixed-Matrix Membranes: Impact of the Filler Morphology on the Gas Separation Performance. Advanced Functional Materials, 2016. 26(18): p. 3154-3163.

22. Calle, M., et al., Design of gas separation membranes derived of rigid aromatic polyimides. 1. Polymers from diamines containing di-tert-butyl side groups. Journal of Membrane Science, 2010. 365(1): p. 145-153.

23. Liu, Y., et al., Barrier and thermal properties of polyimide derived from a diamine monomer containing a rigid planar moiety. Polymer International, 2017. 66(8): p. 1214-1222.

24. Khayet, M. and M.C. García-Payo, X-Ray diffraction study of polyethersulfone polymer, flat-sheet and hollow fibers prepared from the same under different gas-gaps. Desalination, 2009. 245(1): p. 494-500.

25. Recio, R., et al., Gas separation of 6FDA-6FpDA membranes: Effect of the solvent on polymer surfaces and permselectivity. Journal of Membrane Science, 2007. 293(1): p. 22-28.

26. Tylkowski, N.A.G.B.a.B., Chemical Synergies: From the Lab to In Sllico Modelling. 2018: De Gruyter.

27. Yampolskii, Y., et al., Correlations with and prediction of activation energies of gas permeation and diffusion in glassy polymers. Journal of Membrane Science, 1998. 148(1): p. 59-69.

28. Jamil, A., P.C. Oh, and A. B. M. Shariff, Current Status and Future Prospect of Polymer-Layered Silicate Mixed-Matrix Membranes for $\mathrm{CO} 2 / \mathrm{CH} 4$ Separation. Vol. 39. 2016.

29. Bae, T.-H. and J.R. Long, CO2/N2 separations with mixed-matrix membranes containing Mg2(dobdc) nanocrystals. Energy \& Environmental Science, 2013. 6(12): p. 3565-3569. 
30. Castarlenas, S., C. Téllez, and J. Coronas, Gas separation with mixed matrix membranes obtained from MOF UiO-66-graphite oxide hybrids. Journal of Membrane Science, 2017. 526: p. 205-211.

31. Galve, A., et al., Copolyimide mixed matrix membranes with oriented microporous titanosilicate JDF-L1 sheet particles. Vol. 370. 2011. 131-140.

32. Vinoba, M., et al., Recent progress of fillers in mixed matrix membranes for CO2 separation: A review. Separation and Purification Technology, 2017. 188: p. 431-450. 
Chapter 8

Catalytic Membrane Reactor for $\mathrm{CO}_{2}$ Methanation 



\section{Catalytic Membrane Reactor for $\mathrm{CO}_{2}$ Methanation}

\subsection{Introduction}

In previous chapters, several membranes for gas separation were developed and tested at temperatures above $200^{\circ} \mathrm{C}$, and they were characterized in terms of their selective thickness, single and mixed gas measurements and water vapor transportation. In this chapter, a novel micro reactor is used in order to test the outstanding characteristics of the TFCMs recently developed in the $\mathrm{CO}_{2}$ methanation reaction.

Nowadays, methane stands as an essential energy carrier for different worldwide sectors such as industry, energy and transportation. Due to its already existing delivery infrastructure in various countries, methane is a well-established component in current economies. Although methane is mostly derived from fossil fuels, i.e. natural gas resources, methane production from carbon oxide-rich gases (methanation) have gained remarkable importance over the last years [1]. Methanation processes were firstly discovered by Sabatier and Senderens in 1902 and they have been investigated and developed since then [2]. $\mathrm{CO}_{2}$ methanation (Equation (8.1)) is an exothermic process that use carbon dioxide and hydrogen as a starting materials to produce methane and water. $\mathrm{CO}_{2}$ methanation can be also explained as a linear combination of $\mathrm{CO}$ methanation and water-gas shift reaction (Equation (8.2) and (8.3), respectively).

$$
\begin{array}{cc}
\mathrm{CO}_{2}+4 \mathrm{H}_{2} \leftrightarrow \mathrm{CH}_{4}+2 \mathrm{H}_{2} \mathrm{O}(\mathrm{g}) & -164 \mathrm{~kJ} / \mathrm{mol} \\
\mathrm{CO}+3 \mathrm{H}_{2} \leftrightarrow \mathrm{CH}_{4}+\mathrm{H}_{2} \mathrm{O}(\mathrm{g}) & -206 \mathrm{~kJ} / \mathrm{mol} \\
\mathrm{CO}_{2}+\mathrm{H}_{2} \leftrightarrow \mathrm{CO}+\mathrm{H}_{2} \mathrm{O}(\mathrm{g}) & 41 \mathrm{~kJ} / \mathrm{mol}
\end{array}
$$

Many heterogeneous catalyst have been used to produce such precious chemical, such as zeolites, metal-organic frameworks, etc. [1, 3, 4]. It has been observed that one way to enhance methane production is doping the catalyst with 
different metals. Therefore, a wide range of metals have been tested for the $\mathrm{CO}_{2}$ methanation [5-7]. Activity of the tested metals was arranged by Graf et al. as follows: $\mathrm{Ru}>\mathrm{Fe}>\mathrm{Ni}>\mathrm{Co}>\mathrm{Rh}>\mathrm{Pd}>\mathrm{Pt}>\mathrm{Ir}$ [8]. Among all, nickel (Ni) is the most common metal used for the $\mathrm{CO}_{2}$ methanation, due to its high activity, high $\mathrm{CH}_{4}$ selectivity, and its low price. Unfortunately, the main drawback is its high tendency to oxidize in oxidizing atmospheres [9]. In addition, $\mathrm{CO}_{2}$ methanation exhibit other challenges such as temperature control in the reactor due to the reaction is highly exothermic, deactivation of methanation catalyst, thermodynamic limitations or desired product purification [10-12].

This chapter aims at improving the process and solve the issues commented above by placing TFCMs in a microreactor for the selectively removal of water vapor during the $\mathrm{CO} 2$ methanation. Due to its interesting features, TFCMs composed by a polymer support (PBI) and a selective polyimide layer of 6FDA-6FpDA, already introduced in Chapter 6, section 6.2.2., has been selected as the material to perform the reaction. In-situ separation techniques by selective membranes provide (i) purification of the desired product, as well as (ii) removal of possible by-products that could deactivate or poison the catalyst.

\subsection{Results and discussion}

\subsubsection{Methanation catalyst}

A catalyst of Ni-Todorokite was firstly used for $\mathrm{CO}_{2}$ methanation. Ni-Todorokite catalyst was synthesized according to the procedure described in other works [13]. Synthesis of the catalyst was explained In Chapter 4 - Methodology. Todorokite belong to the group type of octahedral molecular sieve (OMS), and it is known as OMS-1. OMS are composed by octahedral $\mathrm{MnO}_{6} \mathrm{x}$ - ions, offering different pore sizes which depend on the number of octahedral that contains the structure. In particular for the Todorokite, tunnels of $6.9 \times 6.9 \times 9.76 \AA$ with three manganese oxide octahedrons on each side are characteristic [14]. This catalyst was selected for $\mathrm{CO}_{2}$ methanation because the presence of $\mathrm{Mn}$ (i) improved the $\mathrm{Ni}$ dispersion, (ii) increased the number of $\mathrm{CO}_{2}$ adsorption sites, (iii) increased the number of mediumstrength basic sites and (iv) inhibited Ni particle agglomeration [15].

In order to evaluate the crystalline structure of the synthesized catalyst, X-Ray diffraction (XRD) was performed. The XRD pattern of the synthesized catalyst $\mathrm{Ni}$ - 
Todorokite is shown in Figure 8.1 in green. In the present diffractogram, the main reflection peaks are characteristic of Todorokite structure. After reduction at $450 \stackrel{\circ}{\circ}$, Todorokite structure is entirely transformed, as it can be seen in Figure 8.1 in pink. It is clearly observed that, after the reduction step at $450{ }^{\circ} \mathrm{C}, \mathrm{MnO}$ is the main phase detected. On the other hand, nickel $(\mathrm{Ni})$ in both states, either reduced or oxidized, cannot be distinctly observed by XRD. Hence, it can be concluded that a good dispersion of $\mathrm{Ni}$ with small crystallite size might be obtained as no diffraction peaks are perceptible in the XRD pattern of Ni-Todorokite.

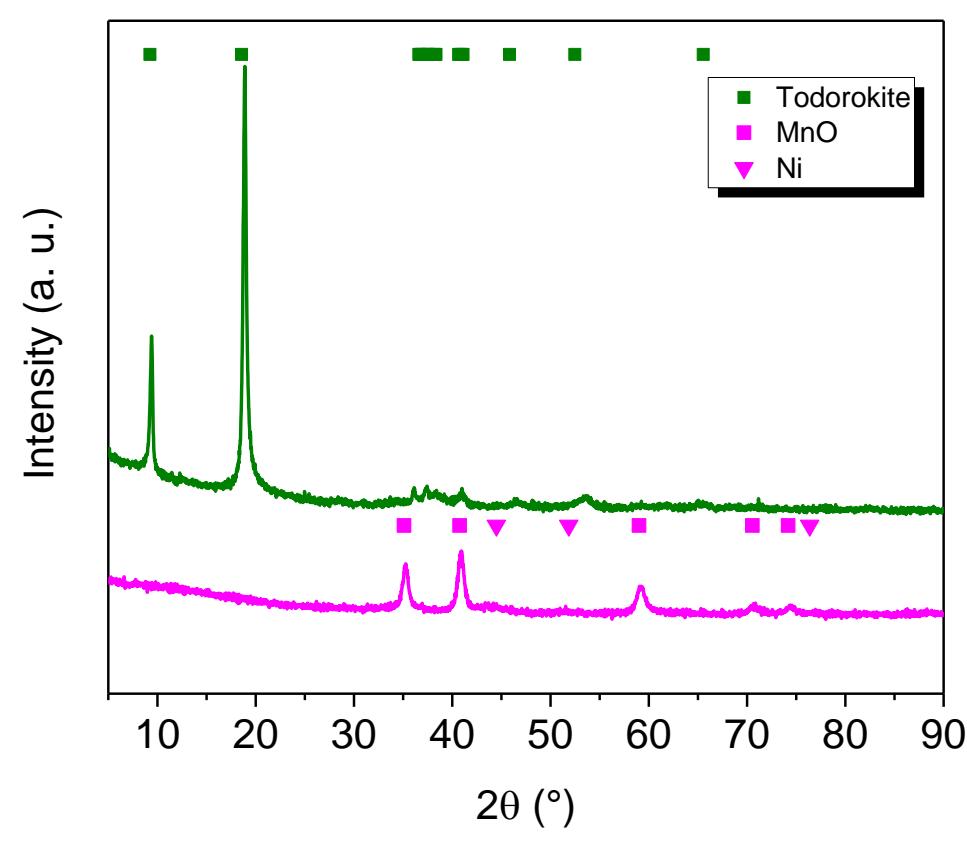

Figure 8.1. X-Ray diffraction of synthesized Ni-Todorokite (green) and reduced Ni-Todorokite (pink)

Ni-Todorokite catalyst contains 50.70 wt. \% of $\mathrm{Mn}$ and 15.00 wt. \% of $\mathrm{Ni}$ and it exhibits a quite low surface area of $13.00 \mathrm{~m}^{2} / \mathrm{g}$, as it can be seen in Table 8.1. These results are consistent with the values given by Onda et al. for this kind of materials [13]. 
Table 8.1. Chemical composition and textural properties of Ni-Todorokite

$\begin{array}{cccc}\text { Ni concent. } & \text { Mn concent. } & \text { Molar ratio } & \begin{array}{c}S_{B E T} \\ \text { (wt. \%) }\end{array} \\ \text { (wt. \%) } & \text { Ni:Mn (-) } & \left(m^{2} / g\right)\end{array}$

Ni-Todorokite

15.00

50.70

0.28

13.00

With regards to TPR measurements, Figure 8.2 in green shows the reducibility of manganese and nickel species of $\mathrm{Ni}$-Todorokite. Three different peaks can be clearly distinguished in the TPR profile: peak I at $250{ }^{\circ} \mathrm{C}$, peak II at $290{ }^{\circ} \mathrm{C}$ approximately and finally, peak III at higher temperature, around $440{ }^{\circ} \mathrm{C}$.

As the Mn content of the sample is much higher (around fivefold more) than $\mathrm{Ni}$ content (Table 8.1), the influence of $\mathrm{Mn}$ in TPR signal will be more meaningful. According to literature, the reduction of manganese oxides follows two routes: (i) $\mathrm{MnO}_{2} \rightarrow \mathrm{Mn}_{2} \mathrm{O}_{3} \rightarrow \mathrm{Mn}_{3} \mathrm{O}_{4} \rightarrow \mathrm{MnO}[16,17]$ and (ii) $\mathrm{MnO}_{2} \rightarrow \mathrm{Mn}_{3} \mathrm{O}_{4} \rightarrow \mathrm{MnO}$ [18]. The reduction through $\mathrm{Mn}_{2} \mathrm{O}_{3}$ intermediate could be recognized by the presence of overlapping reduction peaks with 1:1 ratio of the lower temperature peak to the higher temperature peak. Otherwise, the reduction path with $\mathrm{Mn}_{3} \mathrm{O}_{4}$ as intermediate is related with the presence of a sharp peak at low temperature and a broad peak at higher temperature with a 2:1 ratio of areas of the lower temperature peak to the higher temperature peak [18].

Taking into account that manganese average oxidation state in Todorokite materials is between 3.0 and 4.0 [14], both reduction routes may be presented in the reduction of Ni-Todorokite. One plausible assignation of peaks for TPR profile is as follows: peak I is most probably related to the reduction of $\mathrm{MnO}_{2}$ to $\mathrm{Mn}_{2} \mathrm{O}_{3} / \mathrm{Mn}_{3} \mathrm{O}_{4}$, peak II corresponds to the reduction of $\mathrm{Mn}_{2} \mathrm{O}_{3}$ to $\mathrm{Mn}_{3} \mathrm{O}_{4} / \mathrm{MnO}$ and finally, peak III is associated to the reduction of $\mathrm{Mn}_{3} \mathrm{O}_{4}$ to $\mathrm{MnO}[18,19]$. Following any of these routes, it is clear that manganese oxides of $\mathrm{Ni}$-Todorokite are reduced to $\mathrm{MnO}$ after the reduction step at $450^{\circ} \mathrm{C}$, as it is confirmed by XRD (Figure 8.1).

Moreover no peaks were detected in TPR at higher temperatures, therefore it is assumed that Ni reduction has taken place. Its contribution to TPR profile cannot be definitely stated, mostly because it may be hidden by the reduction of $\mathrm{Mn}_{3} \mathrm{O}_{4}$ to $\mathrm{MnO}$ 
(peak III) as reduction of $\mathrm{Ni}$ usually takes place in this range of temperatures [20]. Additionally, the TPR profile of the catalyst after reduction at $450{ }^{\circ} \mathrm{C}$ is shown it Figure 8.2 in pink. It can be ascertained that this first reduction step improves the reducibility of the catalyst. In this way, in-situ reduction can be performed at lower temperature in order to assure that the properties of the materials used in the microreactor are preserved. This is known as passivation process, which will be explained in the following sections.

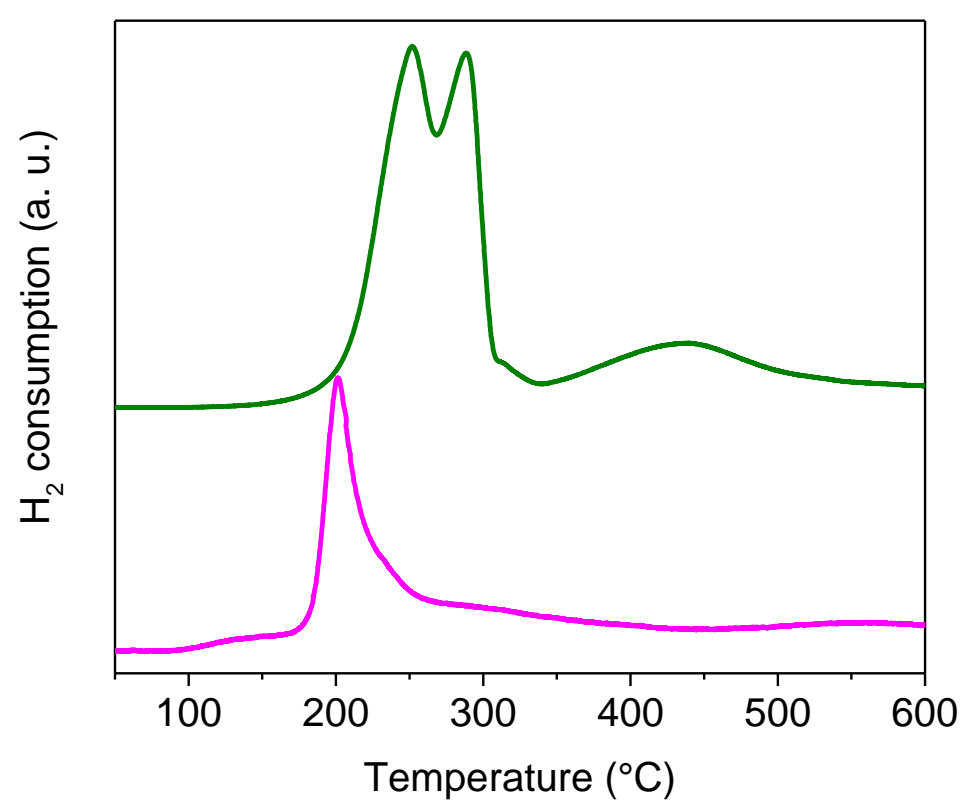

Figure 8.2. TPR of synthesized Ni-Todorokite (green) and reduced Ni-Todorokite (pink)

\subsubsection{Membrane characterization}

Regarding membrane characterization, as already mentioned, a thin film composite membrane (TFCM) of 6FDA-6FpDA supported on PBI/PPS polymer support was selected. These membranes were analyzed and subjected to permeation tests, which were already reported in this thesis, in Chapter 7 - Mixed Matrix Membranes for high temperature applications. In this subchapter, characterization of the membranes as well as gas transport properties are presented. 
Figure 8.3 shows FIB micrographs of the cross sections of 6FDA-6FpDA with a concentration of $3.5 \mathrm{wt}$. \%. Teflon protective layer can also be seen on the right image. As the FIB micrographs were performed once the membranes were tested, possible defects may be appreciated, such as the peel-off of the Teflon.

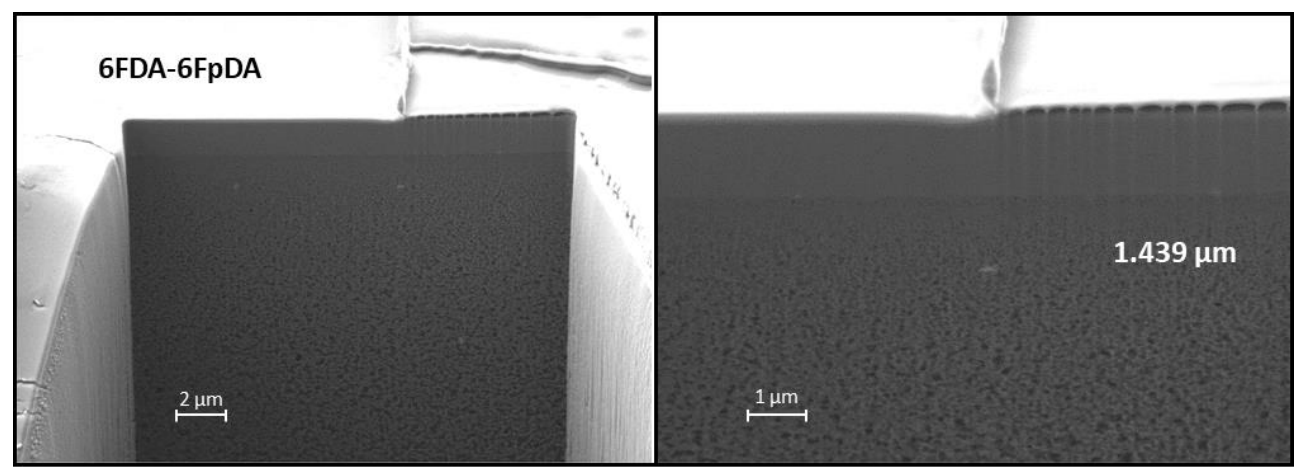

Figure 8.3. Cross section images from FIB micrographs of $6 F D A-6 F p D A$ with $1.439 \mu \mathrm{m}$

Regarding gas transport properties of 6FDA-6FpDA TFCMs, permeance values and ideal selectivities for the thin film polymer layers were characterized. Mixed gas measurements of $\mathrm{H}_{2} / \mathrm{CO}_{2} / \mathrm{H}_{2} \mathrm{O}$ were performed from $240{ }^{\circ} \mathrm{C}$ to $260{ }^{\circ} \mathrm{C}$ and 1 bar. The reason to select $270{ }^{\circ} \mathrm{C}$ as the maximum operational temperature was because TFCM are stable up to $275^{\circ} \mathrm{C}$, after this point the non-woven PPS starts to meld and the membrane breaks. This was detailed explained in Chapter 6 and 7, were this polymer support was introduced.
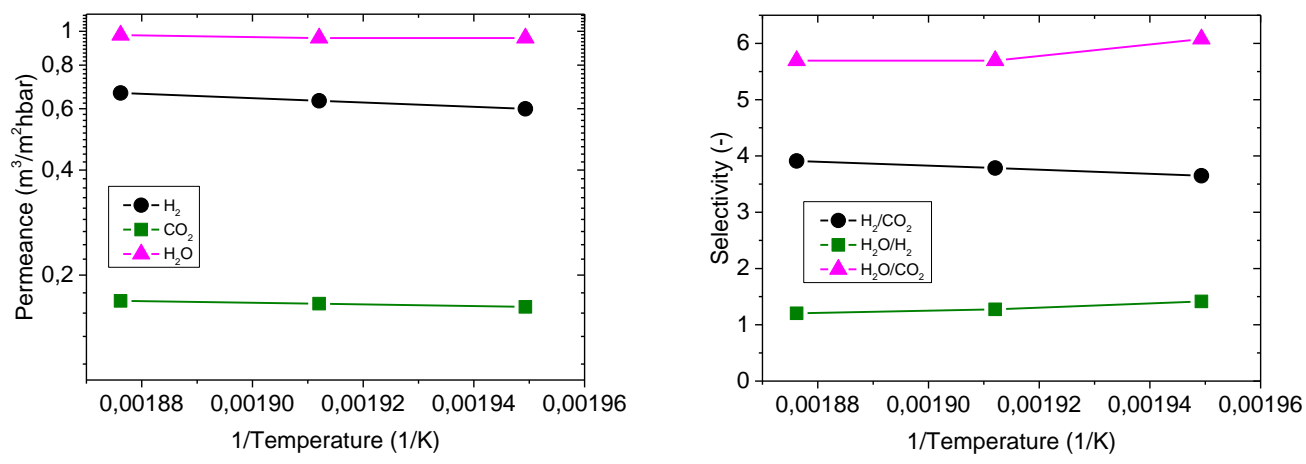

Figure 8.4. Gas transport properties of TFCM of 6FDA-6FpDA 
Water permeation was analyzed using a hygrometer, whereas gas permeation results were obtained by means of a micro $\mathrm{GC} . \mathrm{H}_{2}, \mathrm{CO}_{2}$ and $\mathrm{H}_{2} \mathrm{O}$ permeance, as well as $\mathrm{H}_{2} \mathrm{O} / \mathrm{H}_{2}, \mathrm{H}_{2} \mathrm{O} / \mathrm{CO}_{2}$ and $\mathrm{H}_{2} / \mathrm{CO}_{2}$ selectivity were studied. Mixed gas flow was kept constant in order to obtain the following concentration on the feed: $62 \% \mathrm{H}_{2}, 16$ $\% \mathrm{CO}_{2}$ and $22 \% \mathrm{H}_{2} \mathrm{O}$. This composition was selected due to its similarities to methanation process. Additionally, hydrocarbons were not selected in the feed gas because their permeability through polymer membranes is not as high as $\mathrm{H}_{2}$ or $\mathrm{CO}_{2}$. $\mathrm{H} 2$ usually exhibits the highest diffusivity coefficient whereas $\mathrm{CO}_{2}$ normally exhibits the higher solubility coefficients. Hence, using this composition as feed gas can give a more realistic idea of the gas separation properties.

Figure 8.4 shows the permeance of $\mathrm{H}_{2}, \mathrm{CO}_{2}$ and $\mathrm{H}_{2} \mathrm{O}$ on the left side, whereas in the right side, selectivity of $\mathrm{H}_{2} / \mathrm{CO}_{2}, \mathrm{H}_{2} \mathrm{O} / \mathrm{H}_{2}$ and $\mathrm{H}_{2} \mathrm{O} / \mathrm{CO}_{2}$ is depicted. $\mathrm{H}_{2} \mathrm{O}$ permeance shows the highest values, followed by $\mathrm{H}_{2}$ and $\mathrm{CO}_{2}$. Hence, the highest selectivity values are for $\mathrm{H}_{2} \mathrm{O} / \mathrm{CO}_{2}$ gas pair, whereas $\mathrm{H}_{2} \mathrm{O} / \mathrm{H}_{2}$ exhibit the lowest. Permeance values slightly increase as a function of temperature in the case of $\mathrm{H}_{2}$ and $\mathrm{CO}_{2}$, while $\mathrm{H}_{2} \mathrm{O}$ permeance remains stable with temperature. On the other hand, selectivity do not exhibit great changes with temperature. $\mathrm{H}_{2} / \mathrm{CO}_{2}$ increase as a function of temperature, whereas $\mathrm{H}_{2} \mathrm{O} / \mathrm{H}_{2}$ and $\mathrm{H}_{2} \mathrm{O} / \mathrm{CO}_{2}$ decrease, due to the fact that $\mathrm{H}_{2} \mathrm{O}$ permeances keep constant.

\subsubsection{Catalytic membrane reactor}

\subsubsection{1. $\quad$ Reactor manufacture}

Catalytic membrane reactor (CMR) was designed for the purpose of the thesis. CMR is divided in two chambers, the catalyst is placed on the micro-channels in the upper chamber. Additionally, the catalyst is placed in constant contact with the membranes and is where the reaction takes place, whereas in the lower chamber a sweep flow of $\mathrm{Ar}$ is injected, in order to favor the gas transport of water through the membranes, which is separating both chambers. A detailed explanation of the setup operation is described in Chapter 4 - Methodology, section 4.4.6. 
On a first attempt, the upper part of the reactor was conceived as a complete sealing chamber made of silicone rubber with the help of different molds made by a $3 \mathrm{D}$ printer. Maximum operating temperature of the silicone is $350^{\circ} \mathrm{C}$ [21]. Although the membrane was perfectly sealed and no leaks were observed, the silicone rubber was interfering somehow with the reaction, and, as a consequence, carbon mass was not fitted and the damaged silicone was producing leaks in the system. In this specific situation, reaction was stopped as soon as the leaks and the corresponding unbalanced carbon mass was detected. When the silicone part was extracted from the reactor module, a blackening of the material was observed. In addition, the silicon part became much more fragile. These consequences can be observed in Figure 8.5 , where the preparation of the catalyst bed can be seen in a), before the reaction. The silicone at this step was visually red and sufficiently flexible to seal but also allowing mechanical stability for the microchannels. In contrast, after the reaction process, the silicone mold was completely blackened, not only in the micro-channels area (b), but also in the inner part (c), where apparently, gases should not penetrate.

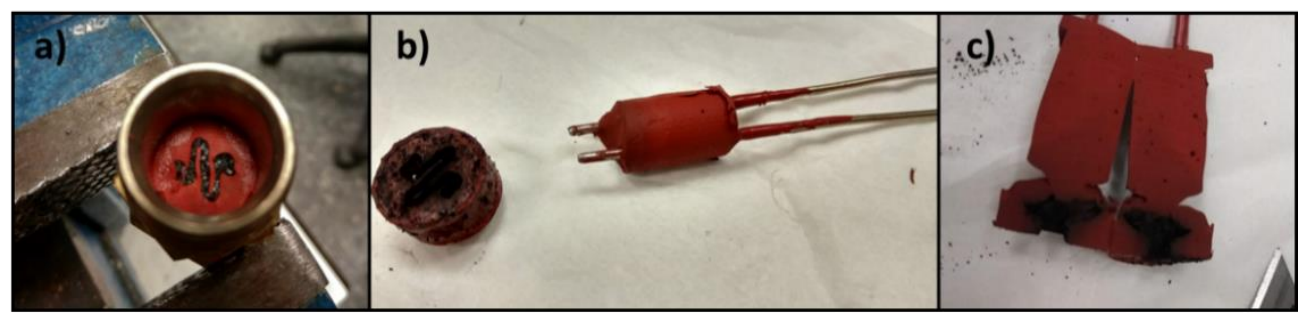

Figure 8.5. Different images of the silicone mold before reaction a) and after reaction b) and c).

In order to clarify if the reported problem related to the silicone mold resistance was associated to the temperature or to the products, a blank reaction without catalyst was performed. Hence, only $\mathrm{H}_{2}$ and $\mathrm{CO}_{2}$ were introduced as a feed, with $\mathrm{Ar}$ in the sweep, but with no catalyst. In this case, $\mathrm{CH}_{4}$ and water vapor were not produced. No effect on the silicone mold due to the temperature or to the $\mathrm{H}_{2}$ or $\mathrm{CO}_{2}$ interaction was observed. Concentration of $\mathrm{H}_{2}$ and $\mathrm{CO}_{2}$ in the feed was equal to the analyzed one in the sweep. It could then be concluded that the noticed interferences were the result of methane or water pollution.

Consequently, a solution for the silicone mold was studied. On a second design, silicone mold was replaced for an aluminium piece that possess only one straight channel, with a volume of approximately $100 \mathrm{~mm}^{3}$. Only a small piece of sealing was placed around the channels, this step was necessary in order not to break the 
membrane against the aluminum side when closing the reactor module. In Figure 8.6, a) a small house-made sealing ring is shown, this substitutes the whole piece of silicone. Once the catalyst together with silicon carbide $(\mathrm{SiC})$ were placed in the micro-channel, the sealing ring was placed (Figure $8.6 \mathrm{~b}$ )), afterwards the membrane, and finally the system was closed. Unfortunately, similar problems were faced during this second attempt in terms of the silicon sealing ring. $\mathrm{CH}_{4}$ productions and $\mathrm{CO}_{2}$ conversions were not as high as expected, and, as it can be appreciated in Figure $8.6 \mathrm{c}$ ) and d), the post-reaction appearance of the sealing ring was pretty similar to the first attempt.

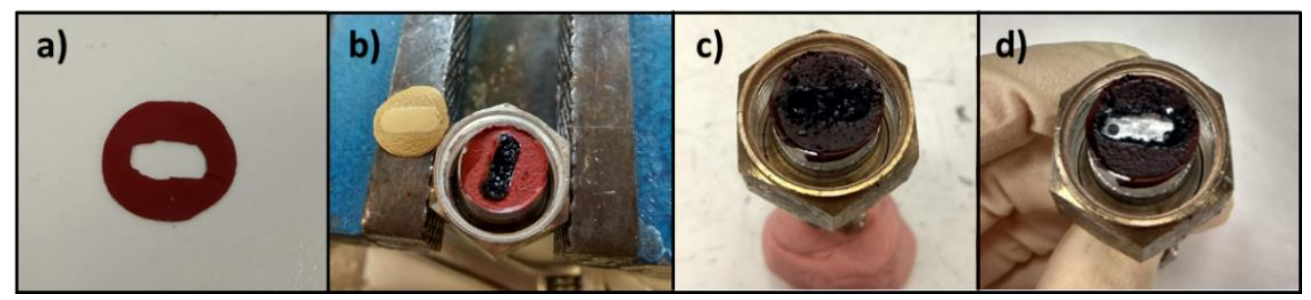

Figure 8.6. Parts of the aluminum piece: a) sealing ring, b) before reaction, c) and d) after reaction

Considering the above mentioned issues, a third set-up was designed. Silicone ring was substituted for a special Teflon sealing tape (see Figure 8.7), that resist a maximum operating temperature of $300^{\circ} \mathrm{C}$. Favorably, Teflon did not interact with the catalyst or with the reaction products. Hence, this last attempt was the definitive and the subsequent reactions were carried out following this configuration.

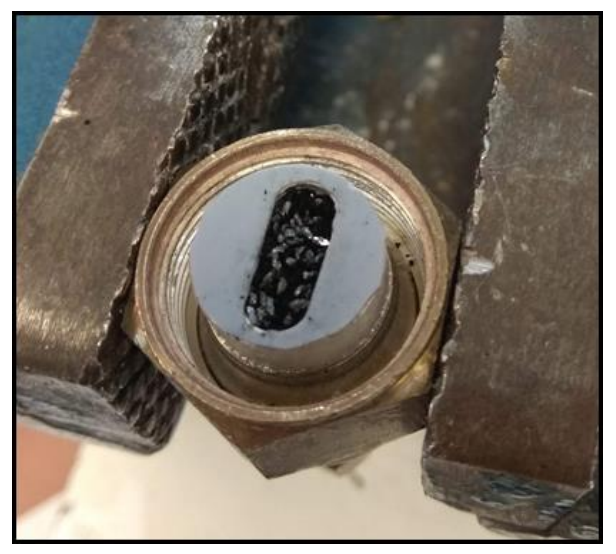

Figure 8.7. Teflon sealing tape and catalyst in the methanation micro reactor. 


\subsubsection{Catalytic performance and water extraction}

Once the set-up of the $\mathrm{CMR}$ was perfectly prepared, $\mathrm{CO}_{2}$ methanation reaction was performed. $5 \mathrm{~mL} /$ min of a composition of $\mathrm{H}_{2}, \mathrm{CO}_{2}$ and $\mathrm{N}_{2}$ was used as feed. Bottle composition was $72 \%$ of $\mathrm{H}_{2}, 18 \%$ of $\mathrm{CO}_{2}$ and $10 \%$ of $\mathrm{N}_{2}$. Nitrogen was used as internal standard, in order to check any possible leak or problem related with the reactor set-up. $30 \mathrm{ml} / \mathrm{min}$ extra of $\mathrm{Ar}$ was injected after the catalyst bed to ensure that all the reaction products, as well as the internal standard, reach correctly the gas chromatograph for analysis. Regarding sweep gas, an Ar flow of $35 \mathrm{ml} / \mathrm{min}$ was added in the lower (sweep) chamber. This option was only available when the membrane was placed between the two chambers. When a blank reaction was performed, instead of a gas separation membrane, an aluminium disc was placed to separate both chambers, and no sweep gas was needed.

Figure 4.19 offers a broader view of the different flow meters and pipes that allow a proper system operation. The experimental protocol was divided in 2 parts: (i) blank reaction, which consist of just the methanation reaction without the membrane and (ii) membrane reaction, which include the gas separation membrane for in-situ water removal.

i. Blank reaction. The aim of this first part is to evaluate the behavior of the catalyst without the selective membrane, in order to compare and normalize the advantages and improvements when the TFCM is placed in the CMR. Catalyst was firstly reduced with pure $\mathrm{H}_{2}$ at $450{ }^{\circ} \mathrm{C}$ for $2 \mathrm{~h}$ in an external oven. When the reduction oven was at room temperature, the catalyst was subjected to a passivation process with air and inert gas. Passivation is a protection method to retain the reduced state of metal catalysts during the transfer to the methanation chamber. It consists on a surface passivation of reduced metal particles by controlled re-oxidation to create a thin and protective oxide layer [22, 23].

Secondly, the catalyst was shaped in granules between 0.25 to 0.42 $\mathrm{mm}$ for catalytic evaluation. A detailed explanation of synthesis and shape process is explained in Methodology - Chapter 4. Afterwards, catalyst was mixed with silicon carbide $(\mathrm{SiC})$ in 1:1 ratio and placed homogenously in the microchannel. Once the reactor module was perfectly closed and located in the methanation module, a second 
reduction was performed, at $250 \stackrel{\circ}{\circ}$ for $2 \mathrm{~h}$, due to the previous passivation.

Subsequently, gas feed was analyzed through a bypass pipe in order to obtain the exact amount of the feed concentrations. Then, temperature in the reactor was set at $260 \stackrel{\circ}{ } \mathrm{C}$ and feed gases were introduced into the catalyst bed and the reaction started to take place. Reaction was left for 48 hours at $260 \stackrel{\circ}{ } \mathrm{C}$ to record a stabilizing test.

Reaction products were measured in the GC, the selectivity of methane, the conversion of carbon dioxide and the yield of $\mathrm{CH}_{4}$ can be calculated following Equations (8.4), (8.5) and (8.6), respectively:

$$
\begin{gathered}
S_{\mathrm{CH}_{4}}=\frac{\chi_{\mathrm{CH}_{4}}}{\chi_{\mathrm{CO}_{2} \mathrm{O}}-\chi_{\mathrm{CO}_{2}}} \cdot 100 \\
X_{\mathrm{CO}_{2}}=\frac{\chi_{\mathrm{CO}_{2 \_}-}-\chi_{\mathrm{CO}_{2}}}{\chi_{\mathrm{CO}_{2} \mathrm{o}}} \cdot 100 \\
Y_{\mathrm{CH}_{4}}=\frac{S_{\mathrm{CH}_{4}}}{X_{\mathrm{CO}_{2}}} \cdot 100
\end{gathered}
$$

where $S_{\mathrm{CH}_{4}}$ is the selectivity of $\mathrm{CH}_{4}(\%), \chi_{i}$ are the molar fractions of the other gases, $\chi_{\mathrm{CO}_{2} \mathrm{O}}$ is initial molar fraction of $\mathrm{CO}_{2}, \mathrm{X}_{\mathrm{CO}_{2}}$ is the conversion of $\mathrm{CO}_{2}(\%)$ and $Y_{\mathrm{CH}_{4}}$ is the yield of $\mathrm{CH}_{4}(\%)$.

$\mathrm{CO}_{2}$ conversion, and $\mathrm{CH}_{4}$ and $\mathrm{H}_{2} \mathrm{O}$ yield are represented as a function of time in Figure 8.9. Selectivity of $\mathrm{CH}_{4}$ was close to $99.99 \%$. A slight decrease of the conversion and yield can be appreciated during the 2 days that the experiment was performed. $\mathrm{CO}_{2}$ conversion decreased from $72 \%$ to $61 \%$, as well as $\mathrm{CH}_{4}$ yield and $\mathrm{H}_{2} \mathrm{O}$ yield from $35 \%$ to 29 $\%$. Overall reaction works properly, but there are some improvements that are hoped to be achieved with the implementation of TFCM. 
Figure 8.8 shows a brief scheme of the protocol followed for the blank reaction, as well as for the methanation reaction.

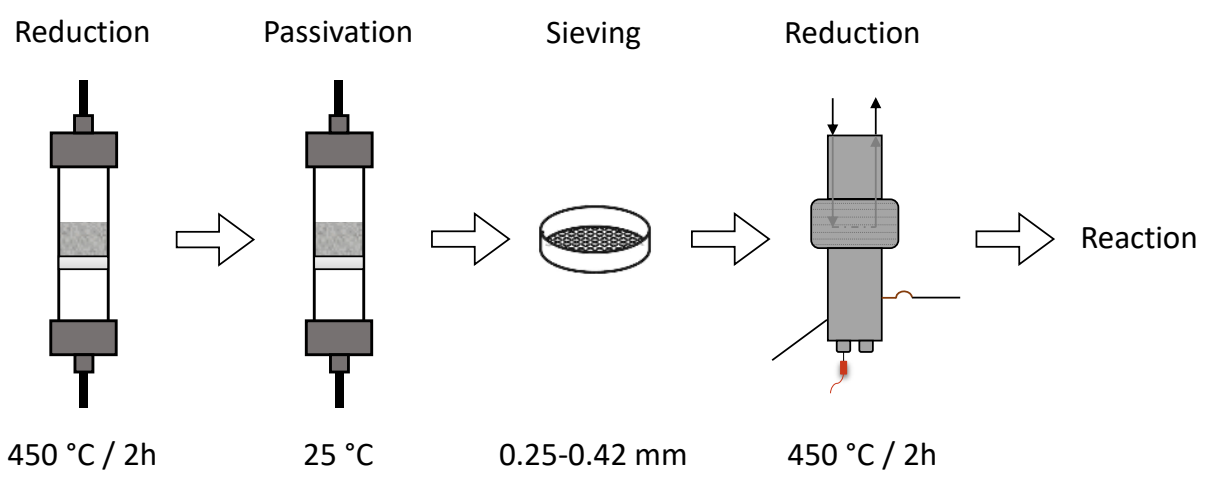

Figure 8.8. Brief scheme of the $\mathrm{CO}_{2}$ methanation reaction protocol

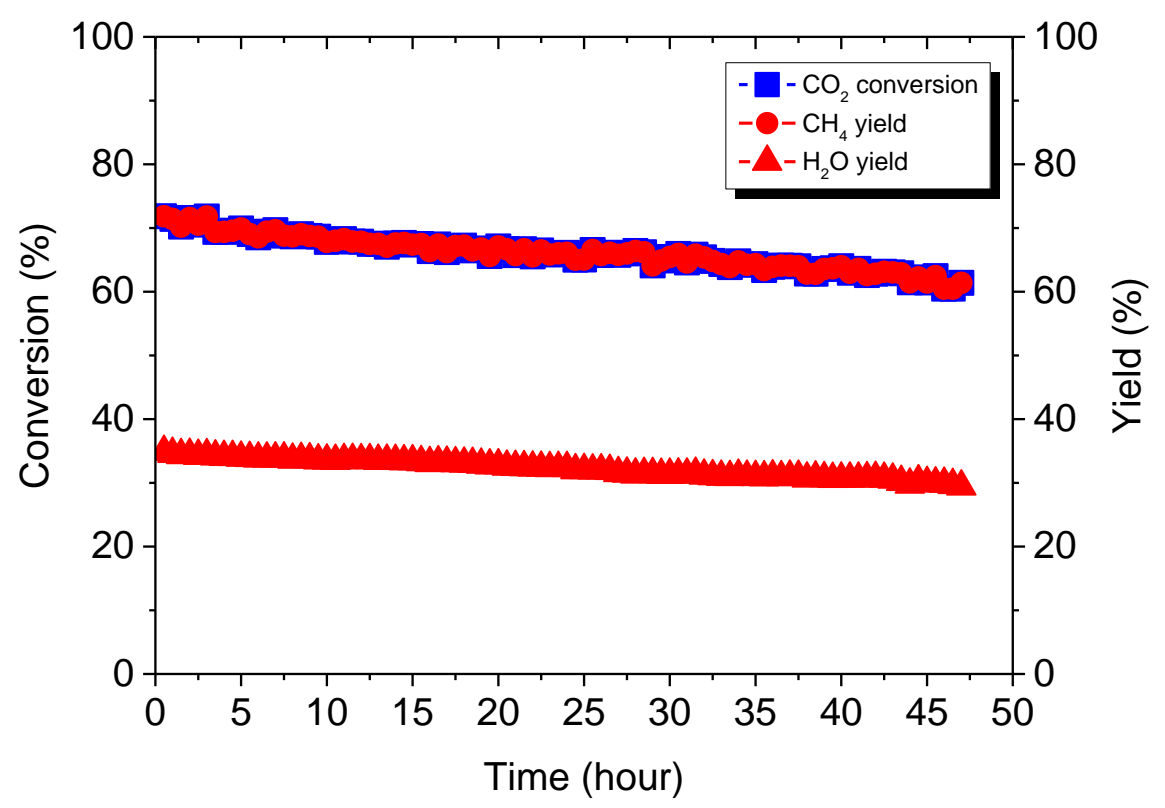

Figure 8.9. $\mathrm{CO}_{2}$ conversion, $\mathrm{CH}_{4}$ and $\mathrm{H}_{2} \mathrm{O}$ yield (in \%) for the stabilizing test at $260{ }^{\circ} \mathrm{C}$ without membrane. 
ii. Methane reaction. Once the behavior of the catalyst without the selective membrane was evaluated, another reaction was performed, following the same steps as in the blank reaction, but this time with a TFCM separating both chambers. First reduction in an external reduction oven $\left(450^{\circ} \mathrm{C}\right)$ was performed, followed by the passivation process $\left(250^{\circ} \mathrm{C}\right)$. Firstly, gas feed was introduced in a bypass pipe in order to obtain the exact amount of the feed concentrations, and afterwards, the gas feed was introduced into the reaction bed. As a selective membrane is placed to separate both chambers, an Ar flow of $30 \mathrm{ml} / \mathrm{min}$ was introduced in the lower chamber to sweep the gases (majority of $\mathrm{H}_{2} \mathrm{O}$ ) that permeate through the TFCM.

To record the relative humidity, water content was uninterruptedly measured by means of a hygrometer placed at the exit of this chamber. Other gases that could permeate though the membrane, such as $\mathrm{H}_{2}$, were analyzed with the GC. Reaction started at $260{ }^{\circ} \mathrm{C}$ and it was left for 24 hours. During this time, it was observed that $\mathrm{H}_{2}$ was also permeating through the membrane. In order to block the $\mathrm{H}_{2}$ flux and to equilibrate the partial pressures, $\mathrm{H}_{2}$ was injected to the lower chamber. In addition, Ar flow was decreased in order to keep constant the amount of sweep gas. As it can be observed in Figure 8.10, where $\mathrm{CO}_{2}$ conversion and $\mathrm{CH}_{4}$ and $\mathrm{H}_{2} \mathrm{O}$ yield are plotted as a function of time, an increase of $\mathrm{CO}_{2}$ conversion and $\mathrm{CH}_{4}$ yield was observed.

$\mathrm{H}_{2} \mathrm{O}$ yield remains constant with a slight decrease. Avoiding the loss of $\mathrm{H}_{2}$ as reactant in the upper chamber, results in an increase of $\mathrm{CO}_{2}$ conversion. Regarding $\mathrm{CH}_{4}$ yield increase, this improvement was expected because it is related to the conversion of $\mathrm{CO}_{2}$. After 48 hours approximately, $\mathrm{H}_{2}$ from the sweep gas was removed to observe if the studied parameters decreased again, and the premise was right. Finally, reaction was left for another 24 hours, and so in total, reaction was stable over 3 days. The amount of water extracted is also possible to calculate, since the hygrometer records the relative humidity. Therefore, the molar flux of water was calculated, as well as the extraction in percentage. 


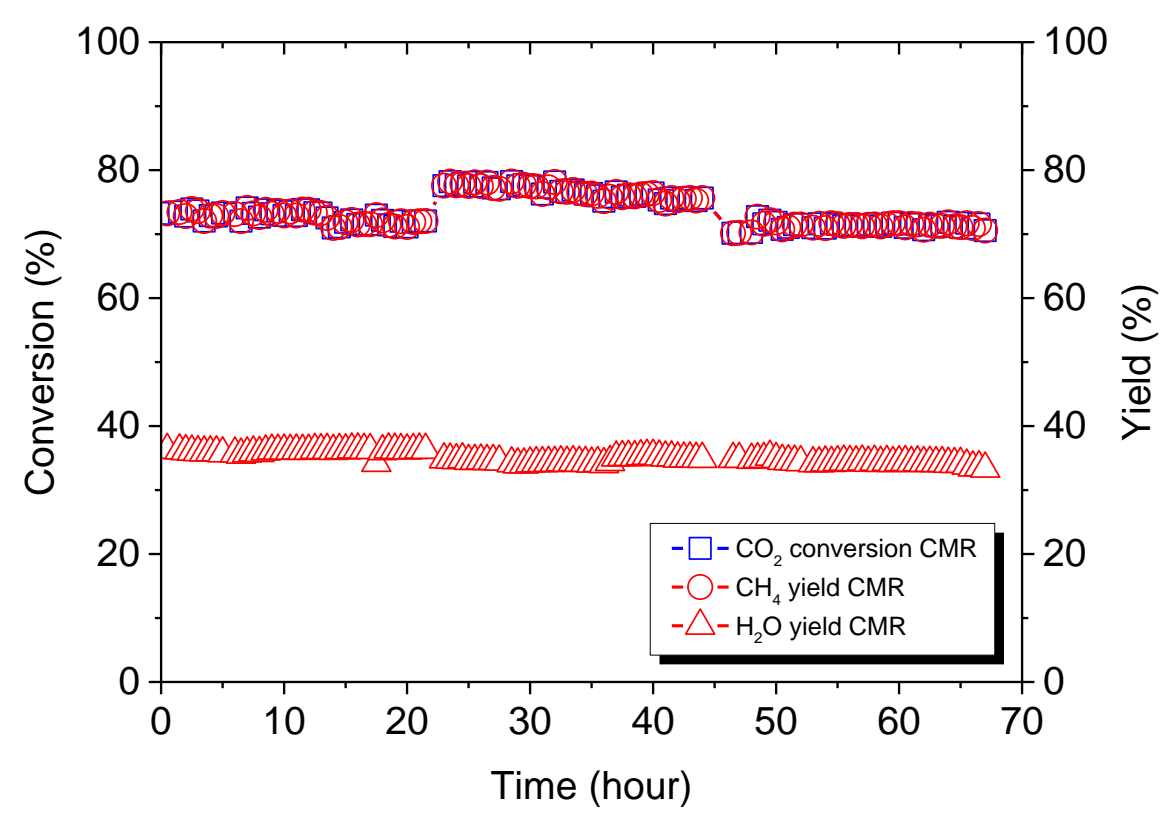

Figure 8.10. $\mathrm{CO}_{2}$ conversion, $\mathrm{CH}_{4}$ and $\mathrm{H}_{2} \mathrm{O}$ yield (in \%) for the stabilizing test at $260{ }^{\circ} \mathrm{C}$ with membrane

Figure 8.11 shows the molar flux of water produced in the reaction chamber, molar flux of water permeated through the TFCM and finally the water extraction in percentage. It can be appreciated how the extracted water increases when $\mathrm{H}_{2}$ is added in the sweep chamber. As membrane was not permeating $\mathrm{H}_{2}$ any more, selectivity towards water was higher, increasing the permeated water through the membrane, hence its extraction.

One plausible explanation for an increase in water production on the reaction chamber could be due to the fact that $\mathrm{H}_{2}$ partial pressure in the sweep chamber might be a little bit higher than $\mathrm{H}_{2}$ partial pressure on the reaction chamber. Hence, an extra amount of hydrogen could had been introduced as feed gas in the catalyst bed. 


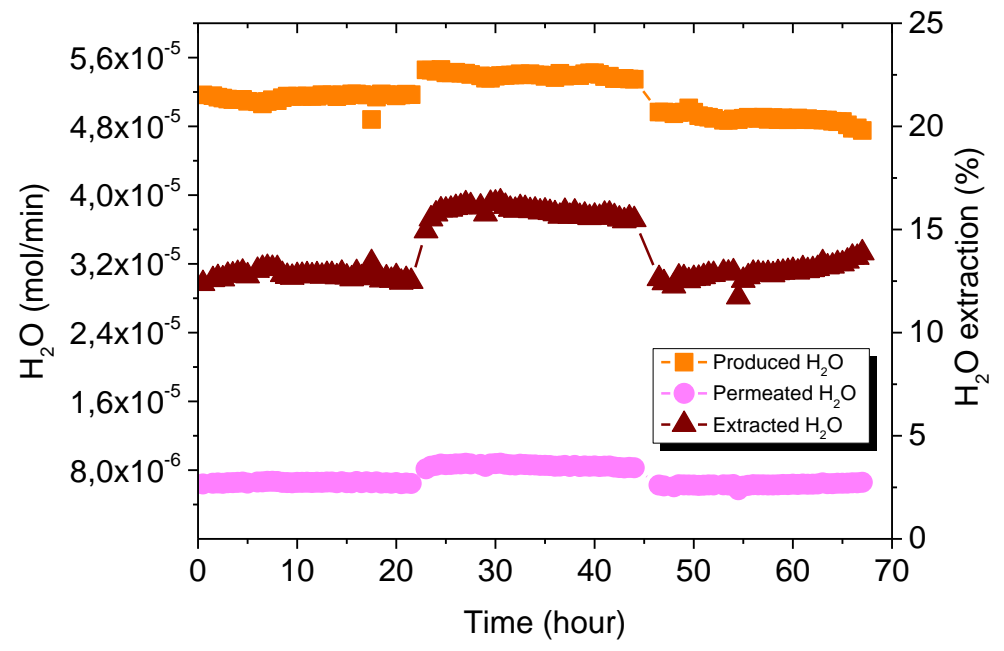

Figure 8.11. Molar flux of water production and water permeation (left-y axis) and percentage of water extraction (right-y axes) as a function of time

As a conclusion, $\mathrm{CO}_{2}$ methanation was remarkably improved with a stable value of $\mathrm{CO}_{2}$ conversion after 3 days of reaction. Assuming a continuous decay of the blank reaction, it can be stated an improvement of 15 points. Hence, the aim of the chapter was fulfilled avoiding catalyst deactivation (see Figure 8.12).

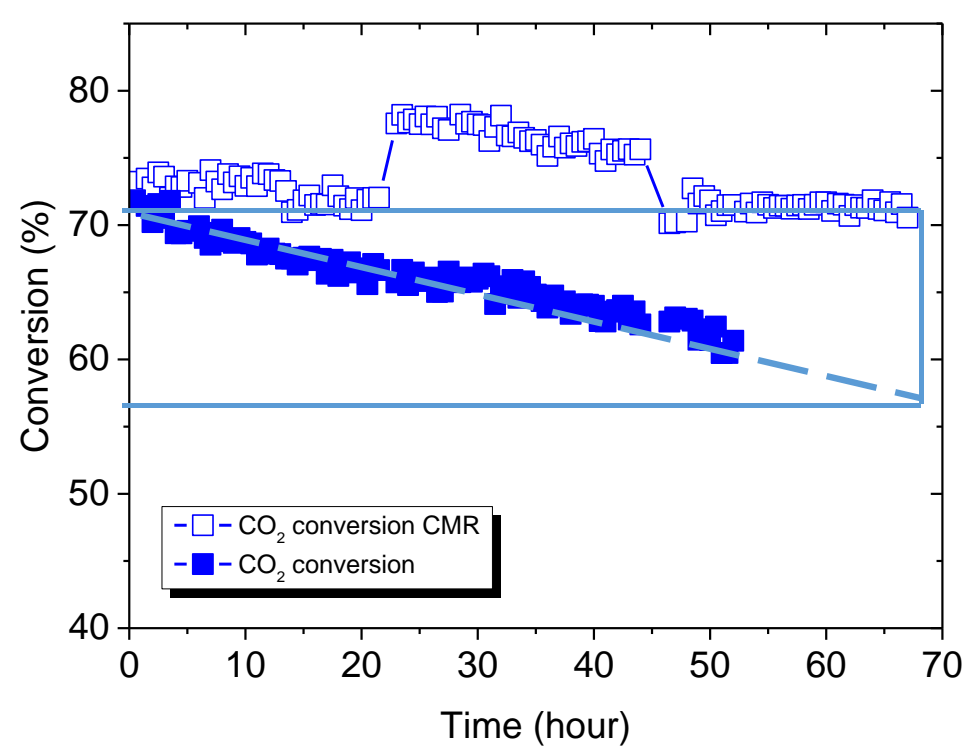

Figure 8.12. $\mathrm{CO}_{2}$ conversion with and without membrane 


\subsection{Conclusions}

A novel micro reactor which combine the outstanding characteristics of the TFCMs recently developed and $\mathrm{CO}_{2}$ methanation reaction was successfully developed.

A catalytic membrane reactor (CMR) composed by (i) microchannel reactor, which offers an excellent control of mass and heat transfer rates than other types of reactor, and (ii) a selective water separation membrane were developed. Several preliminary tests were needed for the upper part design of the CMR, i.e. a complete module made of silicone rubber, combination of aluminium and silicone, and finally, module with an aluminium body and the sealing ring material of Teflon, which stands up to $300 \stackrel{\circ}{\circ}$.

$\mathrm{CO}_{2}$ methanation reaction was successfully performed using an in-house developed microreactor. Selectivity of $\mathrm{CH}_{4}$ was almost $100 \%$ and hence, $\mathrm{CH}_{4}$ yield and $\mathrm{CO}_{2}$ conversion were similar. $\mathrm{CO}_{2}$ conversion is found as a quite high value although it decreases as a function of time. A stability test was performed during 48 hours and conversion decreased from $72 \%$ to $61 \%$.

In order to improve the stability of $\mathrm{CO}_{2}$ conversion and $\mathrm{CH}_{4}$ yield, a selective membrane was placed for water extraction during methanation reaction. Over three days, $\mathrm{CO}_{2}$ conversion and $\mathrm{CH}_{4}$ yield were stable with a water removal of $12.5 \%$. Additionally, due to the fact that $\mathrm{H}_{2}$ was also permeating through the membrane, it was included in the sweep gas in order to avoid $\mathrm{H}_{2}$ diffusion. Consequently, water extraction was increase from $12.5 \%$ to $16 \%$, increasing $\mathrm{CO}_{2}$ conversion and $\mathrm{CH}_{4}$ yield. As a conclusion, one of the main objectives of this thesis was fulfilled: implementation of a novel gas-separation membrane for in-situ water removal and improvement of catalytic deactivation, as well as reaction conversion, since $\mathrm{CO}_{2}$ conversion remained stable during the experiment. 


\subsection{References}

1. Rönsch, S., et al., Review on methanation - From fundamentals to current projects. Fuel, 2016. 166: p. 276-296.

2. Sabatier P, S.J.-B., Comptes Rendus Des Séances De L'Académie DesSciences, Section VI-Chimie. Paris: Imprimerie Gauthier-Villars, 1902.

3. Frontera, P., et al., Supported Catalysts for CO2 Methanation: A Review. Catalysts, 2017. 7(2): p. 59.

4. Stangeland, K., et al., CO2 Methanation: The Effect of Catalysts and Reaction Conditions. Energy Procedia, 2017. 105: p. 2022-2027.

5. da Silva, D.C.D., et al., The Ni/ZrO2 catalyst and the methanation of $\mathrm{CO}$ and CO2. International Journal of Hydrogen Energy, 2012. 37(11): p. 8923-8928.

6. Karelovic, A. and P. Ruiz, Mechanistic study of low temperature CO2 methanation over Rh/TiO2 catalysts. Journal of Catalysis, 2013. 301: p. 141153.

7. Hwang, S., et al., Methanation of carbon dioxide over mesoporous Ni-FeAl2O3 catalysts prepared by a coprecipitation method: Effect of precipitation agent. Journal of Industrial and Engineering Chemistry, 2013. 19(6): p. 2016-2021.

8. F. Graf, M.G.t., M. Henel, T. Schaaf, R. Tichler, Technoo"konomische Studie von Power-to-Gas-Konzepten. Final report. 2014, Deutscher Verein des Gas- und Wasserfaches (DVGW), Bonn.

9. Ghaib, K., K. Nitz, and F.-Z. Ben-Fares, Chemical Methanation of CO2: A Review. ChemBioEng Reviews, 2016. 3(6): p. 266-275.

10. Götz, M., State of the Art and Perspectives of CO2 Methanation Process Concepts for Power-to-Gas Applications (Vortrag). 2014, Vortrag gehalten auf International Gas Union Research Conference (IGRC), Copenhagen, 17. - 19.09.2014.

11. Li, W., et al., A short review of recent advances in $\mathrm{CO} 2$ hydrogenation to hydrocarbons over heterogeneous catalysts. RSC Advances, 2018. 8(14): p. 7651-7669.

12. Project, H. Methanation process. [January 2019]; Available from: http://www.helmeth.eu/index.php/technologies/methanation-process.

13. Onda, A., et al., Synthesis of manganese oxide octahedral molecular sieves containing cobalt, nickel, or magnesium, and the catalytic properties for hydration of acrylonitrile. Applied Catalysis A: General, 2007. 321(1): p. 7178.

14. Suib, S.L., Structure, porosity, and redox in porous manganese oxide octahedral layer and molecular sieve materials. Journal of Materials Chemistry, 2008. 18(14): p. 1623-1631. 
15. Zhao, K., Z. Li, and L. Bian, CO2 methanation and co-methanation of CO and $\mathrm{CO} 2$ over Mn-promoted Ni/Al2O3 catalysts. Frontiers of Chemical Science and Engineering, 2016. 10(2): p. 273-280.

16. Kapteijn, F., et al., Activity and selectivity of pure manganese oxides in the selective catalytic reduction of nitric oxide with ammonia. Applied Catalysis B: Environmental, 1994. 3(2): p. 173-189.

17. Christel, L., A. Pierre, and D.A.-M.R. Abel, Temperature programmed reduction studies of nickel manganite spinels. Thermochimica Acta, 1997. 306(1): p. 51-59.

18. Zhang, J., et al., Catalytic oxidation of formaldehyde over manganese oxides with different crystal structures. Catalysis Science \& Technology, 2015. 5(4): p. 2305-2313.

19. Hernández, W.Y., et al., Modified cryptomelane-type manganese dioxide nanomaterials for preferential oxidation of $\mathrm{CO}$ in the presence of hydrogen. Catalysis Today, 2010. 157(1): p. 160-165.

20. Wan, Y., et al., Ni-Mn bi-metal oxide catalysts for the low temperature SCR removal of NO with NH3. Applied Catalysis B: Environmental, 2014. 148149: p. 114-122.

21. Composites, R.G. Silicona para moldes SILRED. 2018; Available from: https://tienda.resineco.com/.

22. Gil, A., A. Diaz, and M. Montes, Passivation and reactivation of nickel catalysts. Journal of the Chemical Society, Faraday Transactions, 1991. 87(5): p. 791-795.

23. Huber, F., et al., Remarks on the passivation of reduced $\mathrm{Cu}$-, $\mathrm{Ni}-$, $\mathrm{Fe}-$, $\mathrm{Co}-$ based catalysts. Catalysis Letters, 2006. 110(3): p. 211-220. 
Chapter 9

Use of Pd-based membrane under Fischer-Tropsch reaction conditions 



\section{Use of Pd-based membrane under Fischer- Tropsch reaction conditions}

\subsection{Introduction}

Several polymeric membranes and their application as catalytic membrane reactors have been studied in the past chapters. In this chapter, another type of membranes, metallic membranes, will be addressed. In particular, the use of palladium-based membranes for selective hydrogen addition.

Hydrogen separation membranes can be integrated in catalytic membrane reactors (CMR) for different industrial processes [1]. Among the different hydrogen separation membranes, palladium membranes offer high purity hydrogen current up to $99.99 \%$ [2]. For this reason, they have been investigated for the selective addition of hydrogen to a Fischer-Tropsch synthesis reactor. In this chapter, a Pd-based membrane, which exhibits a tubular shape with a length of $90 \mathrm{~mm}$, and a thickness of $100 \mu \mathrm{m}$ approximately (self-supported membrane) is used. Different experiments were performed at $250{ }^{\circ} \mathrm{C}$, in a wide range of pressures, in order to assess the permeance of the membrane at the operational conditions.

The aim of the present chapter is the implementation of the tested Pd-based membrane in a Fischer-Tropsch synthesis (FTS) reactor for the selective production of liquid hydrocarbons $\left(\mathrm{C}_{5}-\mathrm{C}_{20}\right)$ in a single stage using bi-functional catalysts. With this novel system, the goal is to enhance the selectivity to the target products as well as improving the catalyst stability. It has been reported that membranes as reactant distributor along the FTS reactor axis and the catalytic bed, are able to control the activity and product selectivity, as they depend significantly on the $\mathrm{H}_{2} / \mathrm{CO}$ ratio $[3,4]$. The bi-functional catalyst used in this thesis is composed of a FTS catalyst named as CoBase and a Beta zeolite. CoBase catalyst is in charge of producing hydrocarbons, whereas Beta zeolite is responsible for hydrocracking and hydroisomerization of the olefins and paraffins assisted by the presence of an elevated partial pressure of hydrogen $[5,6]$.

Three different permeation tests under similar operation conditions were performed, in order to assess the capability of Pd-based membranes to be used in catalytic membrane reactor for FTS for the selective addition of hydrogen. As $\mathrm{CO}$ is 
part of the feed for FTS, a poisoning of Pd active sites occurred. Hence, a protective layer of other metal that avoid the membrane damage was required. Cu was studied as a plausible candidate, since, from an electronic point of view, $\mathrm{Pd}-\mathrm{CO}$ bonding interactions are reduced due to alloying with $\mathrm{Cu}$ [7].

Finally, Pd-based membrane with a protective layer of $\mathrm{Cu}$ was integrated inside a FTS reactor and used for the selective addition of $\mathrm{H}_{2}$ to the catalyst bed. Unfortunately, no difference was found between using or not a Pd-based membrane for introducing part of the $\mathrm{H}_{2}$ from the syngas feed. Nevertheless, the membrane was able to stand stable during the entire experiment and introducing a constant flow of $\mathrm{H}_{2}$ without being poisoned.

\subsection{Results and discussion}

\subsubsection{Gas transport properties}

Fischer-Tropsch reaction module was designed specifically for the purpose of this thesis. The inner chamber is the membrane itself, where a stream of $\mathrm{H}_{2}$ will be pressurized and it will be added controllably to the catalytic bed. This part of the module can work up to 55 bar. The outer chamber is a stainless steel reactor where the catalytic bed is placed and the reactants of Fischer-Tropsch synthesis, syngas $\left(\mathrm{CO}+\mathrm{H}_{2}\right)$ will be fed. The standard work pressure is 20 bar. A detailed explanation of the set-up operation is described in Chapter 4-Methodology, section 4.4.5. Three different scenarios have been studied for better understanding of the in-situ addition of $\mathrm{H}_{2}$ to FTS reactor: (i) Pd-based membrane and $\mathrm{N}_{2}$ as sweep gas, (ii) Pd-based membrane and syngas as sweep gas, and (iii) Pd-based membrane with a $\mathrm{Cu}$ protective layer and syngas as sweep gas

\subsubsection{1. $\quad$ Pd-based membrane and $\mathrm{N}_{2}$ as sweep gas}

Firstly, in order to assess $\mathrm{H}_{2}$ permeation through the membrane, different permeation tests at different pressures were performed. Nitrogen was introduced as sweep gas in the outer chamber (reaction chamber). Conditions of this first experiment are detailed in Table 9.1. After setting the feed pressure at the desired value, $\mathrm{H}_{2}$ flow was observed from the mass flow sensor after 20 min of stabilization. 
Table 9.1. Experimental conditions for test number 1: Pd-based membrane and $N_{2}$ as sweep gas

\section{$11^{\circ}$ Experiment}

Reactor temperature

Sweep gas $\left(N_{2}\right)$

Sweep pressure

Feed pressure
$250 \stackrel{\circ}{ } \mathrm{C}$

$190 \mathrm{~mL} / \mathrm{min}$

Atmospheric

From 10 to 55 bar

As it can be seen in Table 9.2, $\mathrm{H}_{2}$ flow increases as a function of the feed pressure, recording values from $35 \mathrm{~mL} / \mathrm{min}$ up to $105 \mathrm{~mL} / \mathrm{min}$. Once $\mathrm{H}_{2}$ flow is known, $\mathrm{H}_{2}$ flux ( $\mathrm{mol} / \mathrm{m}^{2} \mathrm{~s}$ ) can be calculated and consequently, it can be plotted as a function of $\mathrm{pH}_{2}$ feed $^{\mathrm{n}}-\mathrm{pH}_{2}$ sweep $^{\mathrm{n}}$, where the value $\mathrm{n}$ may vary from 0.5 to 1 , as it is explained in Chapter 3 - Introduction, section 3.5.3. The variation of this value depends on the rate-determining step. Ideally, when the rate controlling step is the diffusion of $\mathrm{H}^{+}$ and $\mathrm{e}^{-}$into the membrane bulk, $\mathrm{n}$ is equal to 0.5 , because the diffusion rate is proportional to the concentration of $\mathrm{H}_{2}$ atoms on opposite sides of the metal surface and this $\mathrm{H}_{2}$ concentration is proportional to the square root of the $\mathrm{H}_{2}$ pressure. This is known as Sievert's law [8].

Table 9.2. Hydrogen flow as a function of feed pressure for experiment 1: Pd-based membrane and $\mathrm{N}_{2}$ as sweep gas

$\Delta P($ bar $)$

10
20
30
40
50
55

$\mathrm{H}_{2}$ flow (mL/min)

35.3

56.5

73.1

86.4

99.4

105.2 
Figure 9.1 depicts $\mathrm{H}_{2}$ flux as a function of $\mathrm{pH}_{2}$ feed $^{0,5}-\mathrm{pH}_{2}$ sweep $^{0,5}$, presenting a linear dependence on the square-root of pressure, which agrees with the Sievert's law perfectly.

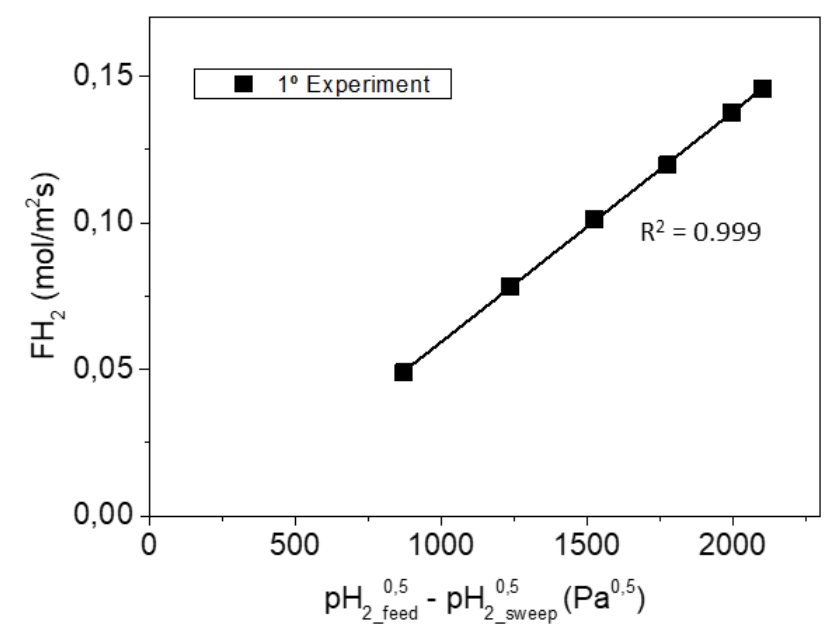

Figure 9.1. $1^{\circ}$ Experiment. $\mathrm{H}_{2}$ flux through palladium membrane with $\mathrm{N}_{2}$ as sweep gas at $250{ }^{\circ} \mathrm{C}$

\subsubsection{Pd-based membrane and syngas as sweep gas}

Once the $\mathrm{H}_{2}$ flux was assessed through the Pd membrane, FTS conditions were studied. $\mathrm{H}_{2} / \mathrm{CO}$ ratio used in FTS is commonly 2 . The idea of this work was to introduce part of the $\mathrm{H}_{2}$ through the membrane, this is, reducing $\mathrm{H}_{2} / \mathrm{CO}$ ratio of the feed to 1 , and controllably adding the extra needed $\mathrm{H}_{2}$ through the $\mathrm{Pd}$ membrane. According to the goal of this chapter, a second experiment was performed, introducing $\mathrm{H}_{2}$ and $\mathrm{CO}$ as sweep gas in the outer chamber (reaction chamber). Conditions of this second experiment are detailed in Table 9.3. After setting the feed pressure at the desired value, $\mathrm{H}_{2}$ flow was observed from the mass flow sensor after 20 min of stabilization. 
Table 9.3. Experimental conditions for test number 2: Pd-based membrane and syngas as sweep gas

\section{$2^{\circ}$ Experiment}

\begin{tabular}{l|c} 
Reactor temperature & $250 \stackrel{\circ}{ }{ }^{\circ}$ \\
Sweep gas $\left(\mathrm{H}_{2} / \mathrm{CO}=2\right)$ & $190 \mathrm{~mL} / \mathrm{min}$ \\
Sweep pressure & Atmospheric \\
Feed pressure & From 10 to 55 bar
\end{tabular}

Similar to the first experiment, $\mathrm{H}_{2}$ flow increase as a function of the feed pressure, as it can be seen in Table 9.4. Lower values were expected since the difference of $\mathrm{H}_{2}$ partial pressure had decreased in comparison with the first experiment. However, the values were extremely low, from $3 \mathrm{~mL} / \mathrm{min}$ up to 10 $\mathrm{mL} / \mathrm{min}, 10$ times lower than first experiment.

$\mathrm{H}_{2}$ flux is plotted as a function of $\mathrm{pH}_{2}$ feed $^{0.5}-\mathrm{pH}_{2 \_ \text {sweep }} 0.5$ in Figure 9.2, in agreement with the Sievert's law. On the previous experiment, the maximum $\mathrm{H}_{2}$ flux was around $0.15 \mathrm{~mol} / \mathrm{m}^{2} \mathrm{~s}$, whereas in this case, maximum reached flux is not higher than $0.015 \mathrm{~mol} / \mathrm{m}^{2} \mathrm{~s}$. The reason for this detriment is the adsorption of $\mathrm{CO}$ on the membrane surface, inhibiting $\mathrm{H}_{2}$ transport across the Pd layer. Additionally, it has been also demonstrated that other mechanisms may affect $\mathrm{H}_{2}$ transport due to $\mathrm{CO}$, such as carbon deposition and formation of bulk $\mathrm{Pd}_{1-x} \mathrm{C}_{x}$ phases.

Table 9.4. Hydrogen flow as a function of feed pressure for experiment 2: Pd-based membrane and syngas as sweep gas

\begin{tabular}{|c|c|}
\hline$\Delta P$ (bar) & $H_{2}$ flow $(\mathrm{mL} / \mathrm{min})$ \\
\hline 10 & 3.3 \\
\hline 20 & 5.6 \\
\hline 30 & 7.5 \\
\hline 40 & 9.0 \\
\hline 50 & 10.2 \\
\hline 55 & 10.8 \\
\hline
\end{tabular}


Several studies have reported on $\mathrm{CO}$ retarding effects on the $\mathrm{H}_{2}$ permeation through Pd-based membranes [7, 9-14]. It was found that the reduction in the hydrogen permeation flux became more significant at lower temperature and/or higher $\mathrm{CO}$ concentration. In the current work, the content of $\mathrm{CO}$ in the syngas is up to $30 \%$ and the reaction temperature is $250 \stackrel{\circ}{ } \mathrm{C}$. Hence, our scenario is set in the most unfavorable situation described by previous works. If the Pd-based membrane is exposed to contaminants such as $\mathrm{CO}, \mathrm{H}_{2}$ flux may decrease by over $70 \%$ in comparison with pure hydrogen permeation [15]. When experiment number 1 and experiment number 2 are compared, a decrease of $90 \%$ can be observed.

The effects of $\mathrm{CO}$ on hydrogen permeation through $\mathrm{Pd}$ membranes have been explained as co-adsorption/competition of $\mathrm{CO}$ on $\mathrm{Pd}$ or its alloy surface. In other words, $\mathrm{CO}$ is adsorbed and displaces the adsorbed $\mathrm{H}_{2}$, which leads to a block of the $\mathrm{H}_{2}$ adsorption sites in the $\mathrm{Pd}$ membrane. Consequently, the rate of $\mathrm{H}_{2}$ penetration into the metal bulk is reduced by the presence of the absorbed $\mathrm{CO}[14,16,17]$.

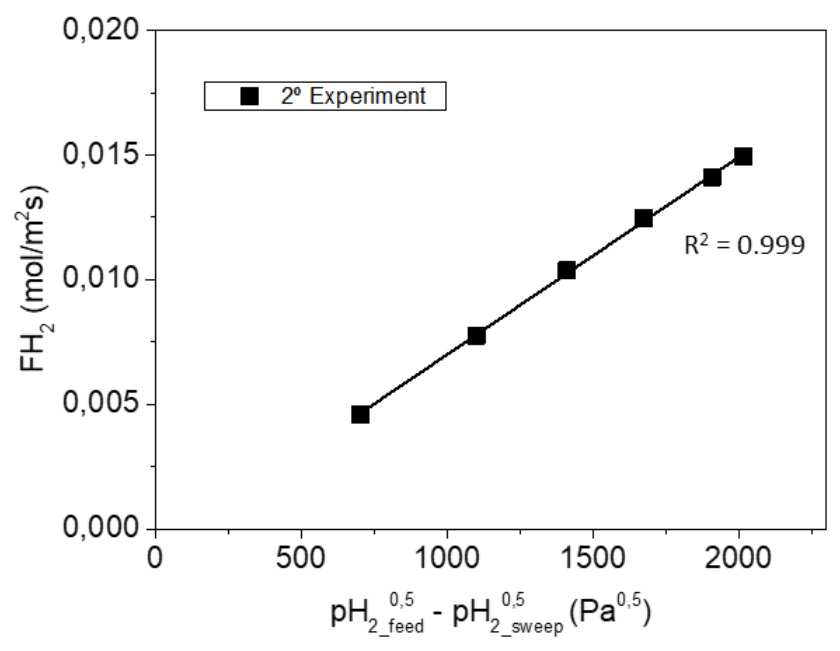

Figure 9.2. $2^{\circ}$ Experiment. $\mathrm{H}_{2}$ flux through palladium membrane with syngas as sweep gas at $250 \stackrel{\circ}{ } \mathrm{C}$ 


\subsubsection{3. $\quad$ Pd-based membrane with a Cu protective layer and syngas as sweep gas}

Once the effect of $\mathrm{CO}$ on the membrane is known, it is necessary to look for a solution to avoid the detriment of $\mathrm{H}_{2}$ permeation. On one hand, a possible solution reported was $\mathrm{H}_{2}$ reduction at elevated temperatures, around $600 \stackrel{\circ}{\circ}$. This technique was found to be effective to remove carbon formation on the membrane surface, obtaining values closer to the $80 \%$ of the initial $\mathrm{H}_{2}$ permeation $[13,18]$. On the other hand, another effective strategy to improve the stability against $\mathrm{CO}$ or carboncontaining species poisoning is by doping $\mathrm{Pd}$ with other metals. The adsorption of $\mathrm{CO}$ on the surface of alloy membranes is different from that on pure Pd membranes.

Although the current Pd-based membrane used in this thesis is an alloy of Pd$\mathrm{Ag}$, there is a clear necessity of doping with another metal the surface of the membrane, in order to improve the chemical stability against CO. According to previous works, $\mathrm{Pd}-\mathrm{CO}$ bonding interactions are reduced due to alloying with $\mathrm{Cu}$ from an electronic point of view [14, 17, 19]. As a consequence, a protective layer of Cu was placed by sputtering technique on top of the Pd membrane, which will avoid $\mathrm{CO}$ poisoning on the $\mathrm{Pd}$ sites. Sputtering technique was precisely explained in Chapter 4 - Methodology, section 4.2.2. Conditions of this third and last experiment are detailed in Table 9.5. As it can be appreciated, the $\mathrm{H}_{2} / \mathrm{CO}$ ratio in the syngas flow was reduced this time to a ratio of 1 , so the $\mathrm{H}_{2}$ from the syngas and the $\mathrm{H}_{2}$ from the membrane were exactly the amount of $\mathrm{H}_{2}$ needed. After setting the feed pressure at the desired value, $\mathrm{H}_{2}$ flow was observed from the mass flow sensor after 20 min of stabilization.

Table 9.5. Experimental conditions for test number 3: Pd-based membrane with a Cu protective layer and syngas as sweep gas

\section{3ํㅡㄹ Experiment}

Reactor temperature
Sweep gas $\left(\mathrm{H}_{2} / \mathrm{CO}=1\right)$

Sweep pressure

Feed pressure

\section{$250 \stackrel{\circ}{ } \mathrm{C}$}

$127 \mathrm{~mL} / \mathrm{min}$

Atmospheric

From 10 to 50 bar 
Similar to previous experiments, $\mathrm{H}_{2}$ flow increases as a function of the feed pressure, as it can be seen in Table 9.6. As for the second experiment, lower values were expected since the difference of $\mathrm{H}_{2}$ partial pressure had decreased in comparison with the first experiment. Nevertheless, the values were higher than the values from the second experiment, increasing approximately by $85 \%$. Still, a decrease between $22 \%$ and $37 \%$ was experienced from the first values. These data conclude that $\mathrm{Cu}$ is protecting the $\mathrm{Pd}$ active sites, and thus, $\mathrm{H}_{2}$ is permeating although $\mathrm{CO}$ is in the feed gas.

Table 9.6. Hydrogen flow as a function of feed pressure for experiment 3: Pd-based membrane with a $\mathrm{Cu}$ protective layer and syngas as sweep gas

\begin{tabular}{c|c}
$\Delta \boldsymbol{P}($ bar $)$ & $\boldsymbol{H}_{2}$ flow $(\mathbf{m L} / \mathbf{m i n})$ \\
\hline 10 & 22.2 \\
20 & 37.3 \\
30 & 49.0 \\
40 & 58.0 \\
50 & 66.5
\end{tabular}

$\mathrm{H}_{2}$ flux is plotted as a function of $\mathrm{pH}_{2}$ feed $^{0.5}-\mathrm{pH}_{2 \_ \text {sweep }} 0.5$ in Figure 9.3, in agreement with the Sievert's law, together with the two previous experiments. In this last experiment, the maximum $\mathrm{H}_{2}$ flux is around $0.09 \mathrm{~mol} / \mathrm{m}^{2} \mathrm{~s}$. On previous experiments, maximum reached flux was around $0.15 \mathrm{~mol} / \mathrm{m}^{2} \mathrm{~s}\left(\left(1^{\text {st }}\right.\right.$ experiment $)$ and $0.015 \mathrm{~mol} / \mathrm{m}^{2} \mathrm{~s}$ ( $2^{\text {nd }}$ experiment). Hence, the solution proposed was checked and proved as optimal, since the amount of $\mathrm{H}_{2}$ that was introduced through the membrane was still significant with regard to the amount of $\mathrm{H}_{2}$ introduced as syngas (feed gas). 


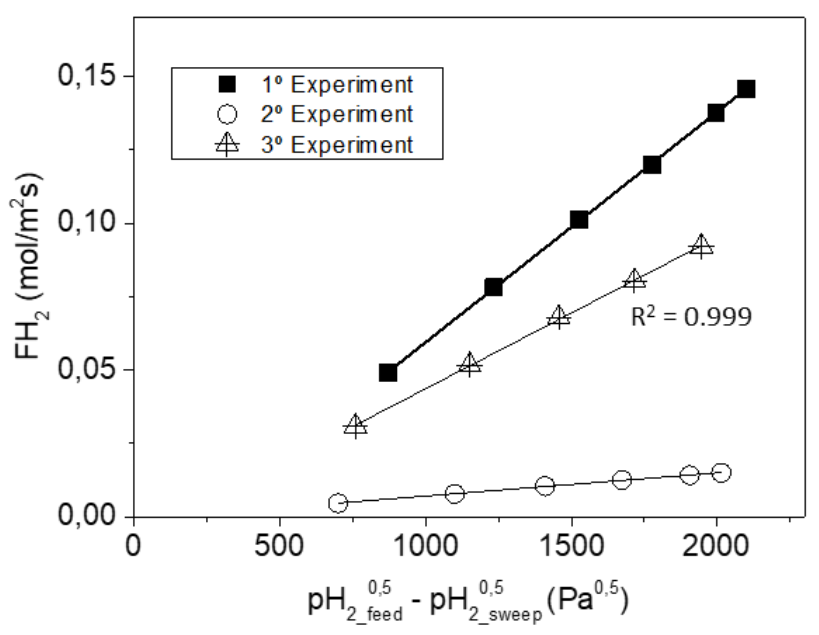

Figure 9.3. $3^{\circ}$ Experiment. $\mathrm{H}_{2}$ flux through palladium membrane with a $\mathrm{Cu}$ protective layer with syngas as sweep gas at $250^{\circ} \mathrm{C}$

In addition to the experiments checking the $\mathrm{H}_{2}$ flux as a function of pressure, a stabilization test of $\mathrm{H}_{2}$ flux as a function of time was performed in order to assure that the membrane was able to permeate a constant $\mathrm{H}_{2}$ flow during the FTS reaction. In order to reproduce the reaction conditions as accurate as possible, syngas was diluted with $50 \%$ of $\mathrm{N}_{2}$ as feed gas, so a $\mathrm{CO}$ conversion of $50 \%$ was assumed. Conditions of the stabilization experiment are detailed in Table 9.5. Stabilization test was performed during 8 hours. 
Table 9.7. Experimental conditions for stabilization test.

Stabilization Experiment

Reactor temperature

Sweep gas

$\mathrm{H}_{2} / \mathrm{CO}=1$

$\mathrm{N}_{2}$

Sweep pressure

Feed pressure
$250 \stackrel{\circ}{-C}$

$63.4 \mathrm{~mL} / \mathrm{min}$

$91.9 \mathrm{~mL} / \mathrm{min}$

Atmospheric

35 bar

Figure 9.4 shows $\mathrm{H}_{2}$ flow ( $\mathrm{mL} / \mathrm{min}$ ) as a function of time on stream (h). As it can be seen, $\mathrm{H}_{2}$ flow not only stays stable over time, but also increases from $25 \mathrm{~mL} / \mathrm{min}$ to $32 \mathrm{~mL} / \mathrm{min}$ at the end of the experiment. It can be concluded that Pd membrane with a $\mathrm{Cu}$ protective layer can stand reaction conditions and avoid poisoning during at least 8 hours.

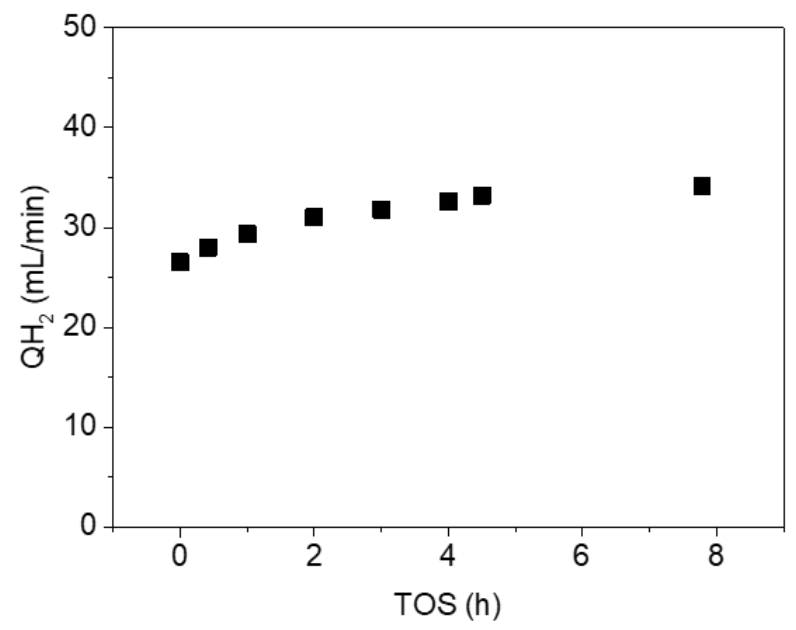

Figure 9.4. Stabilization test at reaction conditions with a $50 \%$ of CO conversion 


\subsubsection{Microstructural characterization}

The Cu protective layers formation in the Pd-based membranes were analyzed based on scanning electron microscopy (SEM) cross-sectional images. In a first attempt, a small tube of $50 \mathrm{~mm}$ length was used to test $\mathrm{Cu}$ deposition using sputtering technique. One planar magnetron sputtering was used during approximately two hours. Afterwards, this preliminary tube was treated under $\mathrm{H}_{2}$ flow for $12 \mathrm{~h}$ at $400 \stackrel{\circ}{ } \mathrm{C}$. This treatment step was performed due to the fact that $\mathrm{FT}$ catalyst needs to be reduced at that temperature. Hence, the membrane will also be reduced during the reaction. Figure 9.5 shows cross section images from FIB micrographs and top surface images of the preliminary tube before and after the reduction treatment.

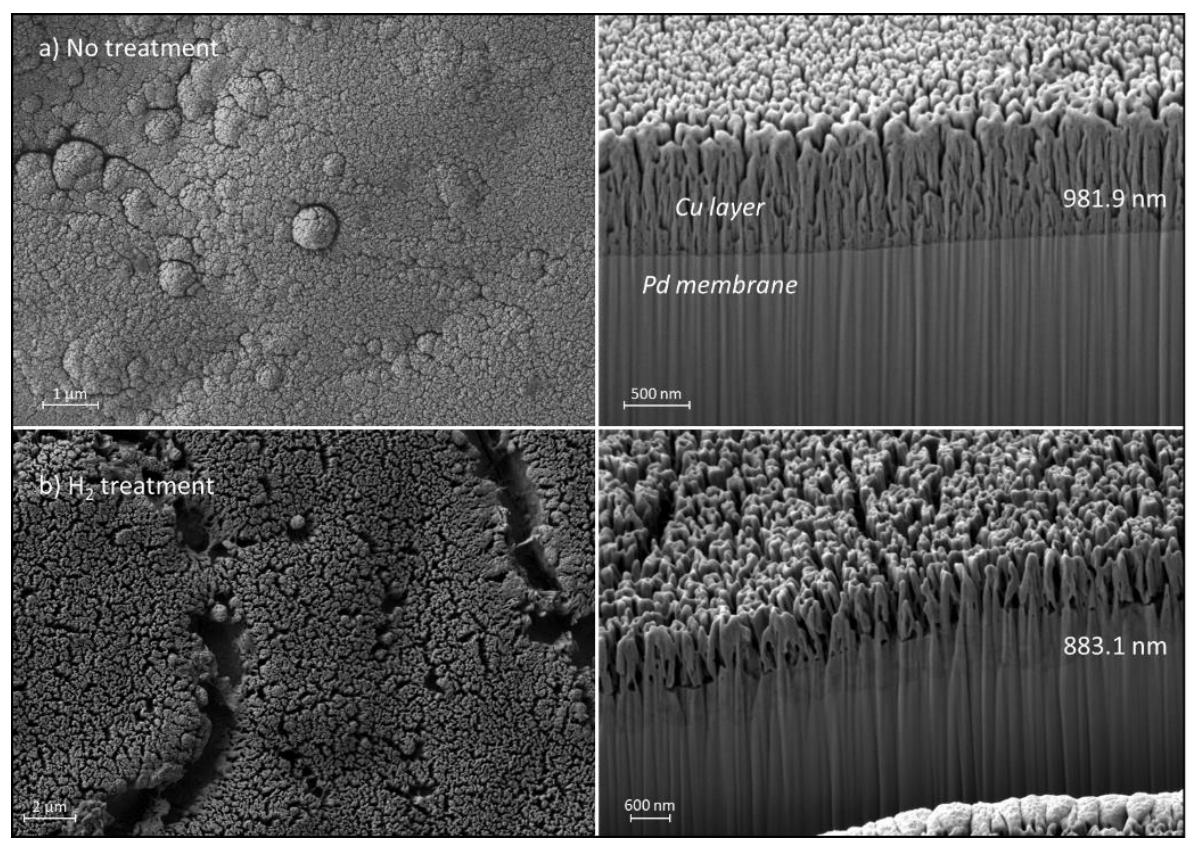

Figure 9.5. Cross section images from FIB micrographs and top surface images of (a) the preliminary tube before $\mathrm{H}_{2}$ treatment and (b) after the reduction treatment at $400{ }^{\circ} \mathrm{C}$ during $12 \mathrm{~h}$

As it is observed, on one hand, before reduction treatment the layer of $\mathrm{Cu}$ was perfectly defined on top of the Pd-based membrane with a thickness of approximately $1 \mu \mathrm{m}$. The top surface was completely covered by Cu layer, and a 
shape of sponge was noted. On the other hand, after the $\mathrm{H}_{2}$ treatment, an interlayer was observed between Pd and Cu layers. An interphase was formed most likely from the alloy of $\mathrm{Pd}$ and $\mathrm{Cu}$ at high temperature. Still the defined layer of $\mathrm{Cu}$ had a thickness of less than a micron, and this time, the texture was less homogeneous and the grains were defined and with more space between them.

Once the thickness of the layer and the proper deposition was assessed, it was decided to sputter another tube with less exposure time (30min) and two magnetrons. The reason for this modification was to compare better with the working tube, which needs two magnetrons to cover completely the surface. Additionally, this second trial tube was subjected to a second treatment at temperature and atmosphere similar to FTS conditions: $5 \% \mathrm{H}_{2}$ and $1 \% \mathrm{CO}$. Figure 9.6 shows cross section images from FIB micrographs and top surface images of the preliminary tube after the reduction treatment and after FTS conditions treatment.

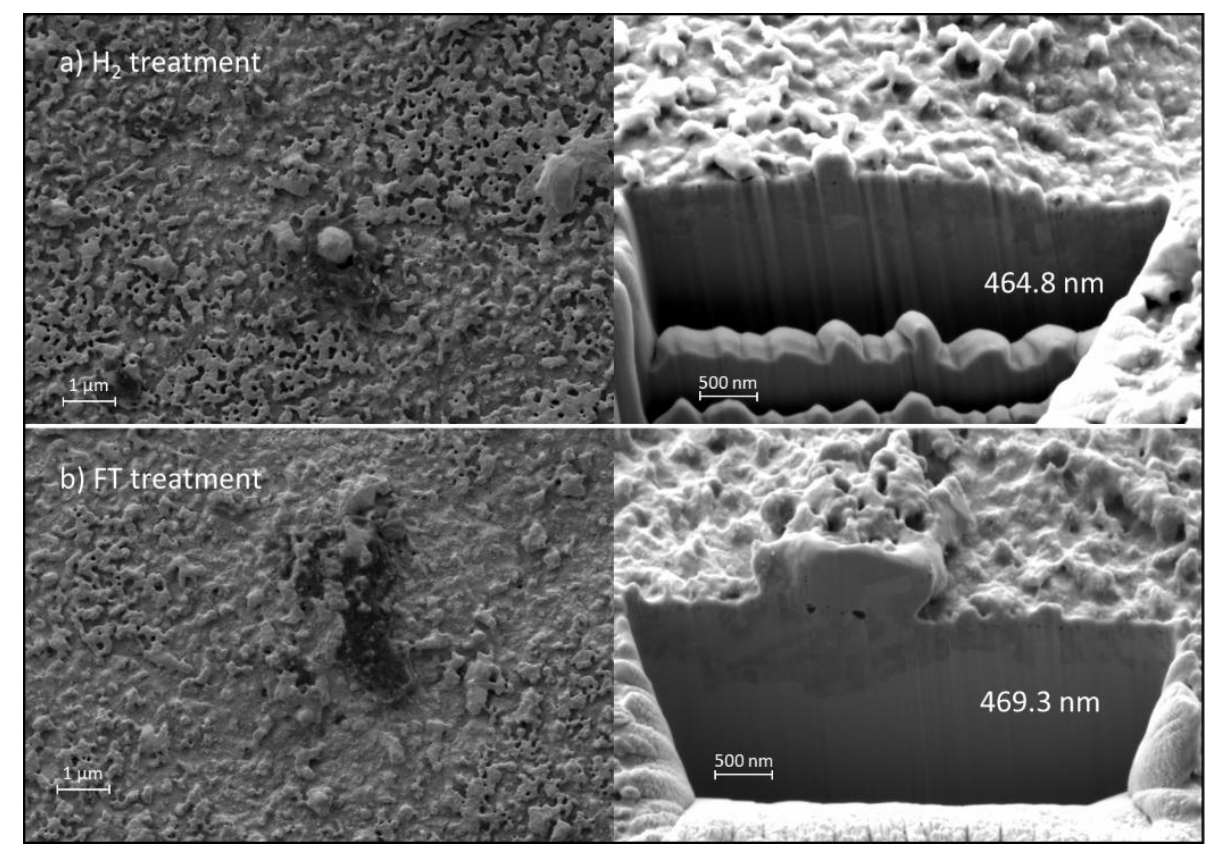

Figure 9.6. Cross section images from FIB micrographs and top surface images of (a) the second preliminary tube after $\mathrm{H}_{2}$ treatment at $400^{\circ} \mathrm{C}$ during $12 \mathrm{~h}$ and (b) after the FT condition treatment at $250{ }^{\circ} \mathrm{C}$ during $15 \mathrm{~h}$ 
With two magnetron and an exposure time of $30 \mathrm{~min}$, thickness layer was reduced to half. Not only that, but also it was not possible to differentiate between the $\mathrm{Cu}$ layer itself and the interlayer $\mathrm{Pd}-\mathrm{Cu}$. Once the membrane was treated with $\mathrm{H}_{2}$ at $400{ }^{\circ} \mathrm{C}$ during $12 \mathrm{~h}$, a second treatment in $\mathrm{H}_{2} / \mathrm{CO}$ was performed at $250 \stackrel{\circ}{\circ}$ during $15 \mathrm{~h}$, simulating the real conditions. As it can be seen, no clear difference can be seen between the two images of the cross section images from FIB. Nevertheless, it can be appreciated from top a slight change in the shape of the grains towards a smoother surface. This might be a consequence of $\mathrm{CO}$ interaction with the Cu protective layer.

Still, the layer was not destroyed after the FT conditions treatment, and so a membrane for in-situ $\mathrm{H}_{2}$ addition during FTS was sputtered.

\subsubsection{Fischer-Tropsch reaction}

After all the preliminary tests, Pd-based membrane with a $\mathrm{Cu}$ protective layer was introduced in a FTS reactor for the controlled addition of $\mathrm{H}_{2}$.

Catalyst was explained in detail in Chapter 4 - Methodology, section 4.1.3. The catalyst was obtained by physically mixing $0.35 \mathrm{~g}$ of each component, both previously pressed, crushed, and sieved to a particle size of $0.25-0.42 \mathrm{~mm}$. Catalyst was placed around the Pd-based membrane together with $\mathrm{SiC}$, filling the bed catalyst reactor and coinciding with the isothermal section of equipment. A detailed explanation of the set-up operation is described in Chapter 4 - Methodology, section 4.4.5.

Firstly, a reduction treatment was performed at $400{ }^{\circ} \mathrm{C}$ during $10 \mathrm{~h}$ in order to reduce $\mathrm{CO}$ oxides in the CoBase catalyst precursor to active metallic $\mathrm{Co}$, and GSHV was equal to $200 \mathrm{~mL} /(\mathrm{min} \cdot \mathrm{gcoBase})$. Feed content was composed by $45 \% \mathrm{CO}, 45 \% \mathrm{H}_{2}$ and $10 \%$ Ar. Additionally, in order to obtain a $\mathrm{H}_{2} / \mathrm{CO}$ ratio of 2 together with the syngas and the $\mathrm{H}_{2}$ permeating through the Pd-based membrane, an extra flow of $\mathrm{H}_{2}$ was added. Reaction conditions were as follows: pressure of the outside chamber (reaction chamber) was set at 20 bar, whereas pressure inside the Pd-based membrane was 55 bar. Temperature of the reactor was set at $250^{\circ} \mathrm{C}$, and the initial GSHV was equal to $29.3 \mathrm{~L}_{\text {syngas }} /(\mathrm{h} \cdot \mathrm{g}$ coBase $)$. 
The experiment was running over 15 hours and the percentage that was permeating through the membrane was around $40 \%$ over the total $\mathrm{H}_{2}$. In order to compare not only the reaction with and without membrane, three different experiments were performed modifying as well the catalyst: (i) FTS reaction with catalyst CoBase, (ii) FTS reaction with catalyst CoBase and the zeolite Beta, and (iii) FTS reaction with catalyst CoBase and the zeolite Beta, and additionally with the Pdbased membrane and the Cu protective layer. Figure 9.7 shows the $\mathrm{CO}$ conversion for the three different cases studied in this thesis.

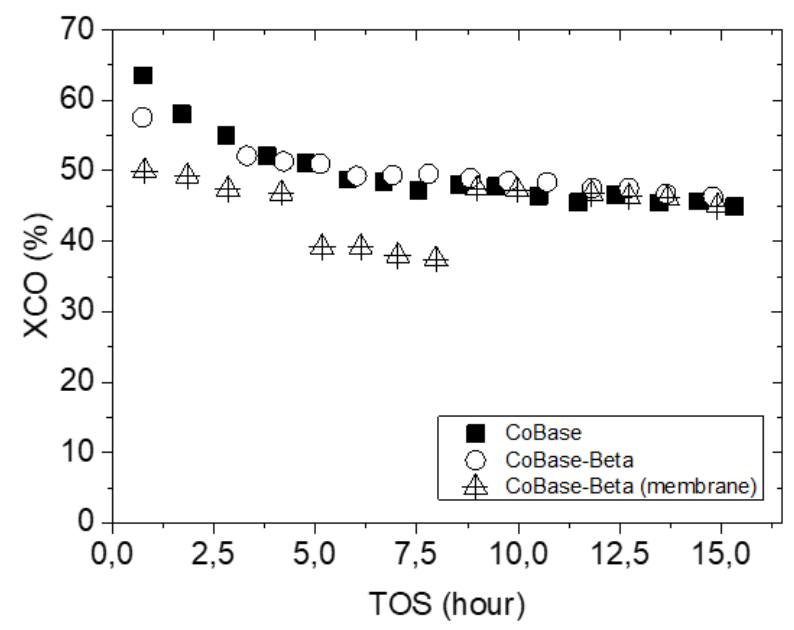

Figure 9.7. CO conversion for FTS reaction for the cases: (i) catalyst CoBase, (ii) catalyst CoBase and zeolite Beta, and (iii) catalyst CoBase and zeolite Beta with the Pd-based membrane

As it can be observed, $\mathrm{CO}$ conversion between the two different catalysts exhibit similar values, an expected behavior as the conversion of $\mathrm{CO}$ exclusively occurs on the metal sites of the CoBase FT component. Regarding the experiment with Pdbased membrane, during the first 8 hours, CO conversion was approximately 10 points lower than previous experiments. In order to obtain the same conversion for proper comparison, and taking into consideration that the aim is to enhance the selectivity to the target products as well as to improve the catalyst stability, GSHV

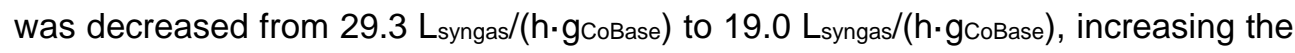
contact time and hence, working under isoconversion. So, once the GSHV is decreased, the conversion increase for the last 8 hours. 


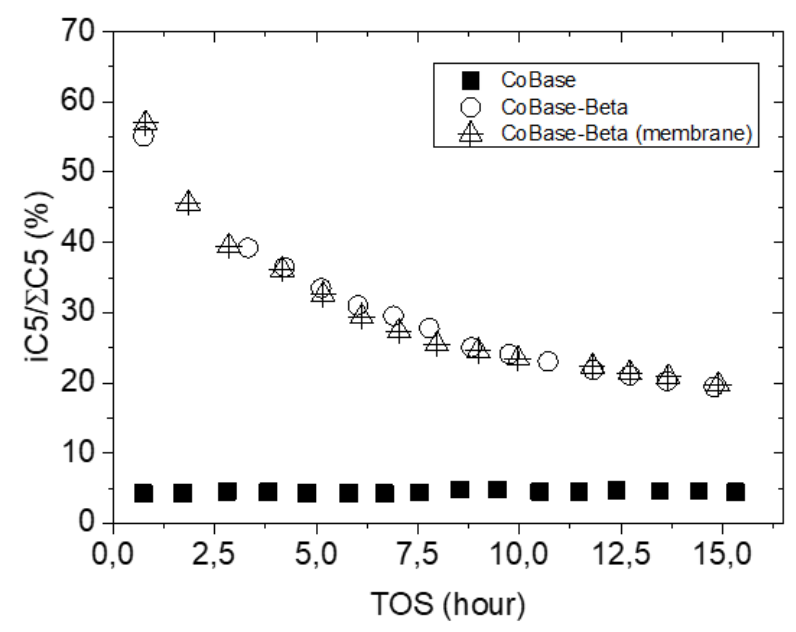

Figure 9.8. iC5/ $\Sigma C 5$ mass percentage for FTS reaction for the cases: (i) catalyst CoBase, (ii) catalyst CoBase and zeolite Beta, and (iii) catalyst CoBase and zeolite Beta with the Pd-based membrane

Regarding selectivity to the target products and the catalyst stability, Figure 9.8 shows the mass ratio between the sum of all isoparaffins-isolefins with 5 carbons divided by all compounds with 5 carbons, this is branched products (formed through acid-catalyzed reactions on the Beta zeolite) over branched and linear products. In this way, the deactivation of zeolite as a function of the branched products evolution can be observed. One first conclusion is that the change in space velocity does not affect the trend in Figure 9.8 as it was affecting $\mathrm{CO}$ conversion. It can be seen the low production if only the CoBase is used as catalyst, but no difference is observed when CoBase-Beta with and without selective addition of hydrogen through the membrane is performed. 


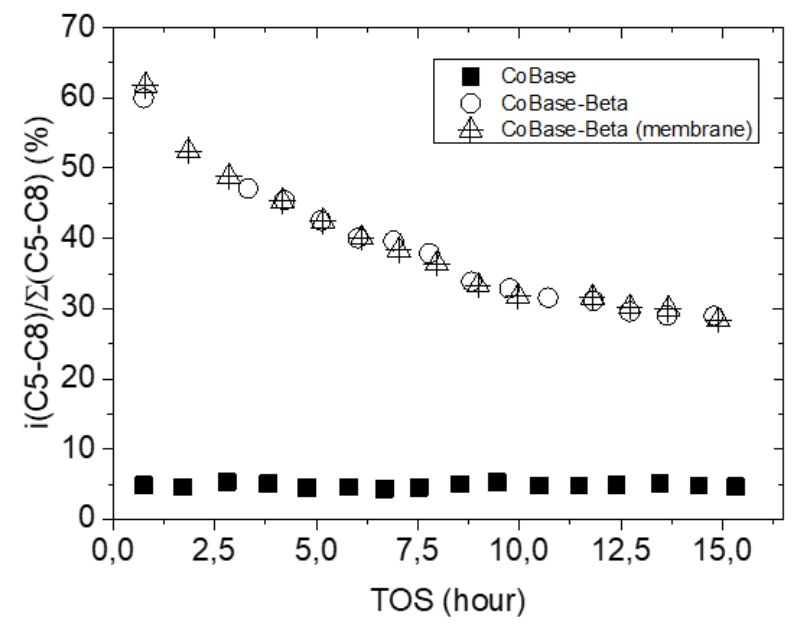

Figure 9.9. i(C5-C8)/ $\Sigma(C 5-C 8)$ mass percentage for FTS reaction for the cases: (i) catalyst CoBase, (ii) catalyst CoBase and zeolite Beta, and (iii) catalyst CoBase and zeolite Beta with the Pd-based membrane

Regarding products from 5 to 8 carbons, Figure 9.9 shows the mass ratio as in the Figure 9.8 , but for $\mathrm{C} 5$ to $\mathrm{C} 8$ (gasoline range hydrocarbons). As for the previous experiment, the change in space velocity does not affect the trend, and no difference is observed when CoBase-Beta with and without Pd-based membrane is used. CoBase catalyst also produced much lower target products.

As conclusions, the membrane was able to stand stable during the entire experiment and introducing a constant flow of $\mathrm{H}_{2}$ without being poisoned. Hence, further investigation on the Pd-based membrane used in-situ for FTS reactor will be continued. The research on different set-ups with other configurations will also be studied, as well as other possible catalysts. 


\subsection{Conclusions}

A novel set-up for Fischer-Tropsch synthesis reaction with an in-situ Pd-based membrane for selective addition of $\mathrm{H}_{2}$ was successfully developed for this thesis.

Gas transport properties were analyzed under different gas feed conditions, as well as different pressures. It was observed that the $\mathrm{H}_{2}$ permeation was reduced due to the presence of $\mathrm{CO}$. Different studies have reported that the presence of $\mathrm{CO}$ reduces $\mathrm{H}_{2}$ permeation through $\mathrm{Pd}$-based membranes. The reduction in the $\mathrm{H}_{2}$ permeation flux became more significant at lower temperature and/or higher $\mathrm{CO}$ concentration, which is exactly our case with a $\mathrm{CO}$ content in the syngas up to $30 \%$ and a reaction temperature of $250^{\circ} \mathrm{C}$.

As one plausible solution, Pd-based membrane was functionalized in order to avoid the poisoning effect of $\mathrm{CO}$ in the $\mathrm{Pd}$-active sites. Pd-based membrane surface was doped with another metal, in order to improve the chemical stability against $\mathrm{CO}$. According to previous works, $\mathrm{Pd}-\mathrm{CO}$ bonding interactions are reduced due to alloying with $\mathrm{Cu}$ from an electronic point of view [14, 17, 19]. As a consequence, a protective layer of $\mathrm{Cu}$ was placed by sputtering technique on top of the $\mathrm{Pd}$ membrane, in order to avoid CO poisoning on the Pd sites.

After functionalizing the $\mathrm{Pd}$-based membrane with $\mathrm{Cu}$ deposition, $\mathrm{H}_{2}$ permeation was recovered and a stabilization test was performed in order to assure the membrane was able to permeate a constant $\mathrm{H}_{2}$ flow during the FTS reaction. Afterwards, $\mathrm{Pd}$-based membrane with a Cu protective layer was introduced in a FTS reactor for the controlled addition of $\mathrm{H}_{2}$.

The Cu protective layers formation in the Pd-based membranes were analyzed based on scanning electron microscopy (SEM) cross-sectional images in order to evaluate the thickness and quality. In addition, trial samples were treated under FTS and assessed afterwards by SEM.

In order to compare not only the reaction with and without membrane, three different experiments were performed modifying as well the catalyst type: (i) FTS reaction with catalyst CoBase, (ii) FTS reaction with catalyst CoBase and the zeolite Beta, and (iii) FTS reaction with catalyst CoBase and the zeolite Beta, and additionally with the $\mathrm{Pd}$-based membrane and the $\mathrm{Cu}$ protective layer.Regarding 
selectivity to the target products, no difference was observed when CoBase-Beta with and without selective addition of hydrogen through the membrane was performed, both for C5 or C5-C8.

It can be concluded that the membrane was introducing a constant flow of $\mathrm{H}_{2}$ without being poisoned during the entire experiment. Hence, the further study of the Pd-based membrane used in-situ for FTS reactor should be implemented. The investigation of different set-ups with other configurations, as well as other possible catalysts will be studied. 


\subsection{References}

1. Membrane Reactors for Hydrogen Production Processes. 2011: SpringerVerlag London.

2. Adhikari, S. and S. Fernando, Hydrogen Membrane Separation Techniques. Industrial \& Engineering Chemistry Research, 2006. 45(3): p. 875-881.

3. Rohde, M.P., D. Unruh, and G. Schaub, Membrane application in FischerTropsch synthesis reactors-Overview of concepts. Catalysis Today, 2005. 106(1): p. 143-148.

4. Liuzzi, D., et al., Catalytic membrane reactor for the production of biofuels. Catalysis Today, 2016. 268: p. 37-45.

5. Viswanathan, B., Chapter 2 - Petroleum, in Energy Sources, B. Viswanathan, Editor. 2017, Elsevier: Amsterdam. p. 29-57.

6. Corma, A. and A. Martínez, Zeolites in refining and petrochemistry, in Studies in Surface Science and Catalysis, J. Cejka and H. van Bekkum, Editors. 2005, Elsevier. p. 337-366.

7. Li, H., A. Caravella, and H.Y. Xu, Recent progress in Pd-based composite membranes. Journal of Materials Chemistry A, 2016. 4(37): p. 14069-14094.

8. Yun, S. and S. Ted Oyama, Correlations in palladium membranes for hydrogen separation: A review. Journal of Membrane Science, 2011. 375(1): p. 28-45.

9. Amano, M., C. Nishimura, and M. Komaki, Effects of High Concentration CO and CO2 on Hydrogen Permeation through the Palladium Membrane. Vol. 31. 1990. 404-408.

10. Li, A., W. Liang, and R. Hughes, The effect of carbon monoxide and steam on the hydrogen permeability of a Pd/stainless steel membrane. Journal of Membrane Science, 2000. 165(1): p. 135-141.

11. Hou, K. and R. Hughes, The effect of external mass transfer, competitive adsorption and coking on hydrogen permeation through thin $\mathrm{Pd} / \mathrm{Ag}$ membranes. Journal of Membrane Science, 2002. 206(1): p. 119-130.

12. O'Brien, C.P. and I.C. Lee, CO Poisoning and CO Hydrogenation on the Surface of Pd Hydrogen Separation Membranes. The Journal of Physical Chemistry C, 2017. 121(31): p. 16864-16871.

13. Li, H., et al., PdC formation in ultra-thin Pd membranes during separation of H2/CO mixtures. Journal of Membrane Science, 2007. 299(1): p. 130-137.

14. Gao, H., et al., Chemical Stability and Its Improvement of Palladium-Based Metallic Membranes. Industrial \& Engineering Chemistry Research, 2004. 43(22): p. 6920-6930.

15. Wieland, I.S., I.T. Melin, and I.A. Lamm, Membrane reactors for hydrogen production. Chemical Engineering Science, 2002. 57(9): p. 1571-1576. 
16. Van Hieu, N. and J.H. Craig, Effect of CO on hydrogen adsorption on palladium. Surface Science, 1985. 160(1): p. L483-L487.

17. Noordermeer, A., G.A. Kok, and B.E. Nieuwenhuys, Comparison between the adsorption properties of $\mathrm{Pd}(111)$ and $\mathrm{PdCu}(111)$ surfaces for carbon monoxide and hydrogen. Surface Science, 1986. 172(2): p. 349-362.

18. Jung, S.H., et al., Effects of co-existing hydrocarbons on hydrogen permeation through a palladium membrane. Journal of Membrane Science, 2000. 170(1): p. 53-60.

19. Padama, A.A.B., et al., CO-induced Pd segregation and the effect of subsurface $\mathrm{Pd}$ on $\mathrm{CO}$ adsorption on CuPd surfaces. Journal of Physics: Condensed Matter, 2017. 29(2): p. 025005. 
Chapter 10

General remarks and Conclusions 



\section{General remarks and Conclusions}

Different materials for membrane manufacture and reaction catalysts as well as several reactor configurations were considered and studied throughout this thesis in order to develop novel gas-separation membranes and their subsequent in-situ use in catalytic membrane reactors for process intensification. The results presented in this thesis have led to the following conclusions:

\section{1) Development of composite ceramic-polymer membrane}

- Different polymer solutions were prepared with different concentrations for P84 ${ }^{\circledast}$, Matrimid ${ }^{\circledR}$, and 6FDA-6FpDA: 0.5 - 1 - 2.5 - 3 - 4 -5 - 7.5 - 8 and 10 wt. \%. By adjustment of the conditions, defect-free thin films of less than $1 \mu \mathrm{m}$ thickness were successfully deposited on porous alumina supports for all the studied polymers.

- The entanglement concentration $\left(C^{*}\right)$ for the three polymers were obtained from the solution viscosity study. The order for intrinsic viscosity values in $\mathrm{mL} \cdot \mathrm{g}^{-1}$ were 6 FDA-6FpDA $(52.544)>$ Matrimid $^{\circledR}(34.754)>\mathrm{P}^{\circledR} 4^{\circledR}$ (27.249), which defines the border between the dilute and semi-dilute regions.

- The influence of the polymer solution employed in the dip-coating process and its effect in the separation properties was studied for a selective ceramic-supported thin polymer for three gas pair: $\mathrm{H}_{2} / \mathrm{CO}_{2}, \mathrm{O}_{2} / \mathrm{N}_{2}$ and $\mathrm{CO}_{2} / \mathrm{CH}_{4}$.

- The effect of the temperature on the separation properties was studied. The permeance for all the gases tested increased with the temperature, but the increase of the $\mathrm{H}_{2}$ permeance was higher than for the rest of the gases, included $\mathrm{CO}_{2}$. Hence, $\mathrm{H}_{2} / \mathrm{CO}_{2}$ selectivity increases with temperature

- The prediction of the properties at elevated temperatures was foreseen. This study shows the potential of this approach in order to apply polymeric membranes for processes at elevated temperatures. 


\section{2) Polymer membranes for high temperature applications}

- Thin film composite membranes (TFCMs) of 6FDA-6FpDA, Matrimid ${ }^{\circledR}$ and P84 ${ }^{\circledR}$ polyimides with an inorganic support (porous ceramic membranes) and with an organic support (PPS + PBI porous polymer) are tested at higher temperatures in favor of investigating their mechanical and chemical stability, and their suitability for in-situ gas separation in catalytic membrane reactors.

- Composite ceramic-polymer membranes were tested between $75 \stackrel{\circ}{\mathrm{C}}$ to $240 \stackrel{\circ}{ } \mathrm{C}$ for $\mathrm{H}_{2} \mathrm{O} / \mathrm{N}_{2}$ mixed gas. These membranes were subjected to different water partial pressure in the feed. Membranes thickness were around $6 \mu \mathrm{m}$.

- Activation energies for $\mathrm{H}_{2} \mathrm{O}$ are negative (whereas activation energies of $\mathrm{N}_{2}$ are positives), which means that the solubility coefficient change more significantly with temperature than the diffusion coefficient. $\mathrm{H}_{2} \mathrm{O} / \mathrm{N}_{2}$ selectivity decreases as a function of temperature.

- Composite polymer-polymer membranes were tested between $30 \stackrel{\circ}{\mathrm{C}}$ to $270 \stackrel{\circ}{\circ}$ for $\mathrm{H}_{2} \mathrm{O} / \mathrm{CO}_{2}$ single gas. Permeance increases as a function of temperature and for values close to $250^{\circ} \mathrm{C}$, a change of slope in selectivity was observed, which may indicate that the diffusivity coefficient was no longer controlling transport properties. Membranes thickness were between $1.5 \mu \mathrm{m}$ to $3 \mu \mathrm{m}$.

- Activation energy values for $\mathrm{H}_{2}$ and $\mathrm{CO}_{2}$ are positive $\left(\mathrm{H}_{2}\right.$ value higher than $\mathrm{CO}_{2}$ value), which means that the diffusion coefficient change more significantly with temperature than the solubility coefficient. $\mathrm{H}_{2} / \mathrm{CO}_{2}$ selectivity increases as a function of temperature.

\section{3) Mixed matrix membranes for high temperature applications}

- A complete study of the influence of inorganic fillers, which exhibit good affinity for gas molecules as $\mathrm{CO}_{2}$ and water vapor, on the gas transport properties of 6 FDA-6FpDA, Matrimid ${ }^{\circledR}$ and $P 84^{\circledR}$ polyimides was developed.

- The particles were successfully dispersed and incorporated into the polymer matrix. As a consequence, 15 different MMMs were successfully produced as a thick film. Three different studies were performed and gas 
transport properties were evaluated for $\mathrm{CH}_{4}, \mathrm{CO}_{2}$ and $\mathrm{H}_{2} \mathrm{O}$ at temperatures from 30 to $80^{\circ} \mathrm{C}$, in a time lag equipment.

- With regard to the influence of the particle type, no clear effect of the particles in terms of pore size or particle size was distinguished. Among all the different tested inorganic particles, BCZY exhibits the best improvement of selectivity with a small and acceptable decrease in permeability, and the best particle distribution.

- With regard to the influence of the particle content (BCZY), there is not a wide difference between the reference polymer and MMMs, meaning that no clear dependence between BCZY content and activation energy can be observed.

- With regard to the influence of the polymer matrix, it was observed an improvement of the properties of Matrimid ${ }^{\circledR}$ and $\mathrm{P} 84^{\circledR}$, polyimides with low FFV, possibly due to the creation of interface between particle and polymer chain. Nevertheless, the incorporation of inorganic fillers does not significantly affect the permeation mechanism determined by the polymer transport properties.

- In addition, water permeability was firstly reported for several polyimides and MMMs of inorganic particles with polyimides, reaching relatively high values. The effect of the filler incorporation on the water permeation was only relevant for the case of Matrimid ${ }^{\circledR}$.

\section{4) Catalytic Membrane Reactor for $\mathrm{CO}_{2}$ Methanation}

- A novel micro reactor which combines the outstanding characteristics of the TFCMs recently developed in the previous chapter and $\mathrm{CO}_{2}$ methanation reaction was successfully developed.

- A catalytic membrane reactor (CMR) composed by microchannel reactor, which offers an excellent control of mass and heat transfer rates than other types of reactor, was developed. Configuration of the microchannel upper part required several preliminary tests until obtain the final module composed by an aluminium body and the sealing ring material of Teflon, which stands up to $300{ }^{\circ} \mathrm{C}$.

- $\mathrm{CO}_{2}$ methanation reaction was successfully performed using the CMR developed for the thesis. Selectivity of $\mathrm{CH}_{4}$ was almost $100 \%$ and $\mathrm{CO}_{2}$ conversion is found as a quite high value although it decreases as a function of time from $72 \%$ to $61 \%$. 
- A selective membrane was placed for water extraction during methanation reaction in order to improve the stability of $\mathrm{CO}_{2}$ conversion and $\mathrm{CH}_{4}$ yield. Over three days, $\mathrm{CO}_{2}$ conversion and $\mathrm{CH}_{4}$ yield were stable with a water removal of $12.5 \%$.

- For avoiding $\mathrm{H}_{2}$ permeation through the membrane, a similar amount of $\mathrm{H}_{2}$ was included in the sweep gas for equalizing partial pressures of $\mathrm{H}_{2}$. Consequently, water extraction was increase from $12.5 \%$ to $16 \%$, increasing $\mathrm{CO}_{2}$ conversion and $\mathrm{CH}_{4}$ yield.

\section{5) Use of Pd-based membrane under Fischer-Tropsch reaction conditions}

- A novel set-up for Fischer-Tropsch synthesis reaction with an in-situ Pdbased membrane for selective addition of $\mathrm{H}_{2}$ was successfully developed.

- Gas transport properties were analyzed under different gas feed conditions, as well as different pressures, observing that $\mathrm{H}_{2}$ permeation was reduced due to the presence of $\mathrm{CO}$. $\mathrm{CO}$ is adsorbed and displaces the adsorbed $\mathrm{H}_{2}$, which leads to a block of the $\mathrm{H}_{2}$ adsorption sites in the Pd membrane.

- Pd-based membrane was functionalized through $\mathrm{Cu}$ deposition, recovering $\mathrm{H}_{2}$ permeation. Flux of $\mathrm{H} 2$ was kept stable during FTS reaction.

- Three different experiments were performed: (i) FTS reaction with catalyst CoBase, (ii) FTS reaction with catalyst CoBase and the zeolite Beta, and (iii) FTS reaction with catalyst CoBase and the zeolite Beta, and additionally with the Pd-based membrane and the Cu protective layer.

- Although no difference was observed when CoBase-Beta with and without selective addition of hydrogen through the membrane was performed, both for $\mathrm{C} 5$ or $\mathrm{C} 5-\mathrm{C} 8$, it can be concluded that the membrane enabled to inject a constant flow of $\mathrm{H}_{2}$ along the packed-bed length without being poisoned during the entire experiment.

After exposing the final conclusions and remarks, it can be stated that the two main objectives of the thesis were successfully addressed: (i) novel materials for gas-separation membranes were researched and developed, and (ii) one of those novel gas-separation membranes was implemented for in-situ water removal and improvement of catalytic deactivation. Additionally, a gas-separation membrane was functionalized for the improvement of its properties, and was used in-situ for FTS. 




\section{Acronyms, abbreviations and symbols}

\begin{tabular}{|c|c|}
\hline$(x+y)$ & Number of tetrahedral per crystallographic unit cell at a zeolite \\
\hline$p_{H_{2} O_{\text {s sweep }}}^{*}$ & Saturation pressure of water at the sweep side \\
\hline$K^{\prime}$ & Coefficient in Darcy's law, reflecting the medium nature \\
\hline$Q_{H_{2} O_{-} o u t l e t \_s w e e p}$ & Outlet water flow at the sweep side \\
\hline$Q_{\text {inlet_sweep }}$ & Inlet total flow at the sweep side \\
\hline$Q_{\text {outlet_sweep }}$ & Outlet total flow at the sweep side \\
\hline$V_{p}$ & Constant permeate volume \\
\hline$X^{n}$ & Exponential pressure value for metallic membranes \\
\hline$d_{p}$ & Pore diameter \\
\hline$p_{H_{2 \_} \text {sweep }}$ & Partial pressure of hydrogen at the sweep side \\
\hline$p_{H_{2} O_{-} \text {sweep }}$ & Partial pressure of water at the sweep side \\
\hline$p_{0}$ & Feed pressure \\
\hline$p_{l}$ & Permeate pressure \\
\hline$p_{\text {sat }}$ & Saturation vapor pressure \\
\hline$r_{p}$ & Pore radius \\
\hline$v_{T}$ & Mean thermal molecular speed \\
\hline$\mu^{0}$ & Pure chemical potential \\
\hline$\rho^{0}$ & Permeance \\
\hline$\rho_{V}$ & Permeability to viscous flow \\
\hline 6FDA & 4,4'-(hexafluoroisopropylidene) diphthalic anhydride \\
\hline 6FpDA & 2,2-bis(4-aminophenyl) hexafluoropropane \\
\hline $\mathrm{ABO}_{3}$ & Perovskite \\
\hline $\mathrm{Ac}_{2} \mathrm{O}$ & Acetic anhydride \\
\hline Al & Aluminum \\
\hline $\mathrm{Al}_{2} \mathrm{O}_{3}$ & Alumina \\
\hline BCC & Body centered cubic \\
\hline BSE & Back scattered electrons \\
\hline Btu & British thermal units \\
\hline CMR & Catalytic membrane reactor \\
\hline CTMS & Chlorotrimethylsilane \\
\hline DI & Dialysis \\
\hline
\end{tabular}




\begin{tabular}{|c|c|}
\hline DMAC & Dimethyl acetamide \\
\hline DMAP & N,N-dimethylaminopyridine \\
\hline DMSO & Dimethyl sulfoxide \\
\hline DSC & Differential Scanning Calorimetry \\
\hline DTA & Differential thermal analysis \\
\hline Ea & Activation energy \\
\hline ED & Electrodialysis \\
\hline EDS & Energy dispersive $x$-ray spectroscopy \\
\hline EPA & Environmental Protection Agency \\
\hline FCC & Face centered cubic \\
\hline FESEM & Field emission scanning electron microscopy \\
\hline FFV & Fractional free volume \\
\hline FIB & Focused lo Beam \\
\hline F-T & Fischer-Tropsch. \\
\hline GC & Gas chromatography \\
\hline GNP & Gross National Product \\
\hline GPC & Gel permeation Chromatography \\
\hline GS & Gas separation \\
\hline GWP & Global warming potential \\
\hline HiGee & High-gravity technology \\
\hline HZG & Helmholtz Zentrum Geesthacht \\
\hline IEA & International Energy Agency \\
\hline IEO2026 & International Energy Outlook 2016 \\
\hline IMR & Inert membrane reactor \\
\hline IUPAC & International Union of Pure and Applied Chemistry \\
\hline MDR & Methane dry reforming \\
\hline MF & Microfiltration \\
\hline MR & Membrane reactor \\
\hline $\mathbf{M}_{\mathbf{w}}$ & Molecular weight \\
\hline NF & Nanofiltration \\
\hline NMP & Anhydrous N-methyl-2-pyrrolidone \\
\hline OECD & Organization for Economic Cooperation and Development \\
\hline P2G & Power-to-gas \\
\hline PI & Process Intensification \\
\hline
\end{tabular}




\begin{tabular}{|c|c|}
\hline POM & Methane partial oxidation \\
\hline PPO & Polyphenylene oxide \\
\hline PSA & Pressure swing adsorption \\
\hline PV & Pervaporation \\
\hline Py & Pyridine \\
\hline$R$ & Gas constant \\
\hline RO & Reverse Osmosis \\
\hline RWGS & Reversed water-gas shift \\
\hline SE & Secondary electrons \\
\hline SEC & Size exclusion chromatography \\
\hline SEM & Scanning Electron Microscopy \\
\hline Si & Silicon \\
\hline $\mathrm{SiO}_{2}$ & Silica \\
\hline SMR & Steam methane reforming \\
\hline $\mathbf{T}$ & Absolute temperature \\
\hline TCD & Thermal conductivity detector \\
\hline TFCMs & Thin film composite membranes \\
\hline $\mathbf{T}_{\mathrm{g}}$ & Glass transition temperature \\
\hline TGA & Thermogravimetric analysis \\
\hline THF & Tetrahydrofuran \\
\hline $\mathrm{TIO}_{2}$ & Titania \\
\hline TPR & Temperature programmed reduction \\
\hline UF & Ultrafiltration \\
\hline $\mathbf{v}$ & Specific volume \\
\hline$v_{0}$ & Occupied volume \\
\hline $\mathbf{v}_{\mathrm{f}}$ & Volumen refer to FFV \\
\hline WGSR & Water-gas shift reaction \\
\hline XRD & X-Ray diffraction \\
\hline $\mathrm{ZrO}_{2}$ & Zirconia \\
\hline$\alpha$ & Hydrogen absorption phase at low $\mathrm{H} / \mathrm{Pd}$ atomic ratios \\
\hline $\boldsymbol{\beta}$ & Hydrogen absorption phase at high $\mathrm{H} / \mathrm{Pd}$ atomic ratios \\
\hline $\boldsymbol{A}$ & Cation \\
\hline $\boldsymbol{A}$ & Effective area membrane \\
\hline$D$ & Diffusion coefficient \\
\hline
\end{tabular}




\begin{tabular}{|l|l|}
\hline $\boldsymbol{F}$ & Molar flux \\
\hline $\boldsymbol{H R}(\%)$ & Relative humidity \\
\hline $\boldsymbol{J}$ & Mass flux \\
\hline $\boldsymbol{L}$ & Proportional coefficient for linking flux and chemical potential \\
\hline $\boldsymbol{R}$ & Internal pore radius \\
\hline $\boldsymbol{S}$ & Solution coefficient \\
\hline $\boldsymbol{c}$ & Concentration \\
\hline $\boldsymbol{d}$ & Spacing between atoms \\
\hline $\boldsymbol{d} \boldsymbol{c} / \boldsymbol{d} \boldsymbol{x}$ & Concentration gradient \\
\hline $\boldsymbol{d} \boldsymbol{p} / \boldsymbol{d} \boldsymbol{x}$ & Pressure gradient \\
\hline $\boldsymbol{d} \boldsymbol{\mu} / \boldsymbol{d} \boldsymbol{x}$ & Chemical potential gradient \\
\hline $\boldsymbol{l}$ & Thickness \\
\hline $\boldsymbol{m}$ & Element charge \\
\hline $\boldsymbol{n}$ & Mol fraction \\
\hline $\boldsymbol{p}$ & Pressure \\
\hline $\boldsymbol{w}$ & Geometry parameter for Knudsen diffusion regime \\
\hline $\boldsymbol{x} / \boldsymbol{y}$ & Framework silicon/aluminum ratio \\
\hline $\boldsymbol{y}$ & Molar concentration \\
\hline $\boldsymbol{T}$ & Time-lag \\
\hline $\boldsymbol{\alpha}$ & Selectivity coefficient \\
\hline $\boldsymbol{\gamma}$ & Activity coefficient \\
\hline $\boldsymbol{\varepsilon}$ & Membrane porosity \\
\hline $\boldsymbol{\eta}$ & Viscosity (polymer) \\
\hline $\boldsymbol{\theta}$ & Angle from the electron beam and the sample material (XRD) \\
\hline $\boldsymbol{\lambda}$ & Wavelength \\
\hline $\boldsymbol{\mu}$ & Chemical potential \\
\hline $\boldsymbol{\rho}$ & Permeability \\
\hline $\boldsymbol{\tau}$ & Membrane tortuosity \\
\hline $\boldsymbol{v}$ & Molar volume \\
\hline $\boldsymbol{D}$ & Density \\
\hline $\boldsymbol{v}$ & Gas viscosity \\
\hline & \\
\hline
\end{tabular}






\section{Figures list}

Figure 3.1. World energy consumption by energy source (quadrillion Btu). Note that dotted line for coal and renewables show projected effects of the U.S. Clean Power Plan [2]. 22

Figure 3.2. Energy-intensive industry shares of total OECD industrial sector energy consumption (left) and non-OECD industrial sector energy consumption (right), for

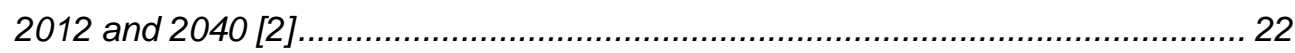

Figure 3.3. Process intensification and its components [10] .............................. 26 Figure 3.4. Indirect natural gas route conversions to produce fuels and value-added

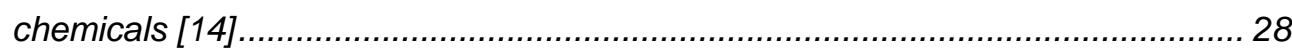

Figure 3.5. World hydrogen production (left graph) and use (right graph) [25]..... 32

Figure 3.6. Scheme of Power-to-gas technology ........................................... 35

Figure 3.7. Tubular catalytic membrane scheme ............................................. 39

Figure 3.8. Driving force gradients acting on a single component solution permeating (a) pore flow and (b) solution-diffusion membrane [43]..... 45

Figure 3.9. Pressure (a) and concentration (b) gradients through a dense gas permeation membrane, in agreement with solution-diffusion model [43].............. 48

Figure 3.10. Theoretical relation between pore size and membrane type [43] ...... 51

Figure 3.11. Pore diameter of zeolite and some kinetic diameter for small gases [69] 54

Figure 3.12. Ceramic composite membranes structure 55

Figure 3.13. Knudsen diffusion mechanism 57

Figure 3.14. Hydrogen permeability (left graph) and hydrogen solubility at $1 \mathrm{~atm}$ pressure (right graph) as a function of temperature for different metals [43]........ 58

Figure 3.15. Palladium-hydrogen phase diagram .......................................... 59

Figure 3.16. Transport mechanism in metallic membranes .............................. 62

Figure 3.17. Diffusion and solubility coefficient for different polyimides [43, 94]... 66 Figure 3.18. Behavior of a general specific volume polymer as a function of

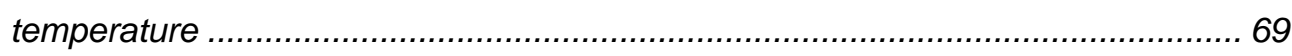

Figure 3.19. Effect of long-term aging on PPO thin film membrane...................... 70 Figure 3.20. a) Robeson prior Upper Bound for $\mathrm{O}_{2} / \mathrm{N}_{2}$ (1991) and present Upper Bound for $\mathrm{O}_{2} / \mathrm{N}_{2}$ (2008) [101] and b) Robeson's upper bound selectivity/permeability lines for a number of commercially important gas separations [102] .................... 71

Figure 4.1. Structures and properties of the polyimides used in this thesis.......... 84

Figure 4.2. Co-precipitation route for pure solid oxide phase formation ............... 85 
Figure 4.3. Whatman ${ }^{\circledR}$ Anodisc inorganic filter, a) front face and b) side face, Atech ceramic membranes, $c$ ) front face and d) side face and polymer support, e) front face and f) side face 88

Figure 4.4. Polymers support structure 90

Figure 4.5. Schematics of the dip coating configuration and process for composite ceramic-polymer membranes. 91

Figure 4.6. Schematics of the dip coating configuration and process for composite polymer-polymer membranes. 91

Figure 4.7. Schematic representation of the different polymeric membrane structures

Figure 4.8. SAES Pd membrane 94

Figure 4.9. Scheme of sputtering deposition. 94

Figure 4.10. Schematic figure of Bragg's law, diffraction of $X$-rays on a crystalline material [21]. 96

Figure 4.11. The fourteen Bravais lattices [22]. 97

Figure 4.12. Schematic SEM column description [27]..... .99

Figure 4.13. Schematic representation of the GC equipment. 103

Figure 4.14. Pressure Increase equipment scheme.. 104

Figure 4.15. Set-up for polymeric membranes. 107

Figure 4.16. Set-up for palladium membranes 109

Figure 4.17. Set-up for Fischer-Tropsch reaction module. 111

Figure 4.18. Set-up for methanation reaction..... 112

Figure 4.19. Different types for resin molds (bottom parts).. 113

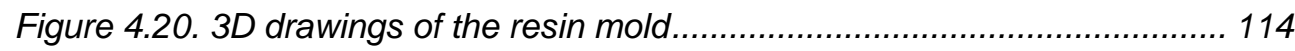

Figure 4.21. Final silicone mold after curing process ...................................... 114

Figure 4.22. Visual description of the microchannel reactor parts ..................... 115

Figure 5.1. TGA of the three polyimide: $6 F D A-6 F p D A$, Matrimid ${ }^{\boxplus}$ and $P 84^{\circledR} \ldots . . .123$ Figure 5.2. DSC of the three polyimides: $6 F D A-6 F p D A$, Matrimid $^{\circledR}$ and $P 84^{\circledR} \ldots . .123$ Figure 5.3. Evolution of the viscosity as a function of the polymer concentration (dotted lines are eye guides only). 125

Figure 5.4. Huggins representation for intrinsic viscosity determination 127

Figure 5.5. Overlap concentration $\left(C^{*}\right)$ for the polymers solutions studied obtained from the representation of $\log \eta s p$ as a function of $\log (\mathrm{C} \eta)$ (left side) and as function of $\log (C)$ (right side) 128

Figure 5.6. Relative $\mathrm{H}_{2}$ permeance at room temperature stabilization test. For untreated and thermally treated 6FDA-6FpDA membrane (5 wt. \% polymer solution) supported on alumina Anodisc 130 
Figure 5.7. SEM micrographs of 6FDA-6FpDA dip-coated in alumina support with different solution concentrations: $C<C^{*}(\boldsymbol{a}), C \sim C^{*}(\boldsymbol{b})$, and $C>C^{*}(\boldsymbol{c}, \boldsymbol{d})$. Inset image in (a) corresponds to a magnification where the porous support is observed to be below the polymer layer. 132

Figure 5.8. Cross-sections SEM micrographs for the polymers deposited with two different solution concentrations: $C<C^{*}\left(2.5\right.$ wt. \%) and $C>C^{*}(5$ wt. \% for the 6FDA-6FpDA and 7.5 wt. \% for $P 84^{\circledR}$ and Matrimid $\left.{ }^{\circledR}\right)$. 133

Figure 5.9. Cross-section micrograph and EDX analysis of 6FDA-6FpDA 2.5 wt. \% (upper part) and 6FDA-6FpDA 5 wt. \% (lower part). 134

Figure 5.10. Separation properties of the polymers as a function of the solution concentration at $30^{\circ} \mathrm{C}$. Dashed lines refer to the ideal selectivity for each polymer and gas pair. Permeance values (left-y axis) are plotted in logarithmic scale .... 135 Figure 5.11. Evolution of the separation properties for the ceramic-supported thin film polymers obtained from $5,7.5$ and $10 \mathrm{wt}$. \% solution for the gas pairs $\mathrm{CO}_{2} / \mathrm{CH}_{4}$, $\mathrm{O}_{2} / \mathrm{N}_{2}$ and $\mathrm{H}_{2} / \mathrm{CO}_{2}$. Permeances (left-y axis) are plotted in logarithmic scale at room temperature 138

Figure 5.12. Separation properties of the ceramic-supported thin film polymers for the $\mathrm{H}_{2} / \mathrm{CO}_{2}$ separation as a function of the temperature and concentration of the polymer solution. Unfilled symbols represent the permeance (in the left-y axis) and filled symbols represent selectivity (in the right-y-axis). Squares represent $5 \%$ solution, triangles $7.5 \%$, circles $10 \%$ and crosses thick films. 140 Figure 5.13. Evolution and prediction of the permeance and selectivity as a function of the process temperature conditions for $10 \%$ concentration of polymer. Open symbols represent the permeance (on the left-y axis) and filled symbols represent selectivity (on the right-y-axis). Hexagon represent $P 84^{\circledR}$, diamond Matrimid ${ }^{\circledR}$ and triangle 6FDA-6FpDA...... 142

Figure 6.1. Cross-sections SEM micrographs of 6FDA-6FpDA 5 wt. \% composite ceramic-polymer membrane...... 152 Figure 6.2. Top surface SEM micrographs of 6FDA-6FpDA 5 wt. \% compositepolymer membrane. 152

Figure 6.3. On the left side, cross section images from FIB micrographs of a) 6FDA6FpDA with $1.439 \mu \mathrm{m}$, b) Matrimid ${ }^{\circledR}$ with $1.360 \mu \mathrm{m}$ and c) $P 84^{\circledR}$ with $3.617 \mu \mathrm{m}$. On the right side, top surface images from FE-SEM micrographs of a) 6FDA-6FpDA, b) Matrimid $^{\circledR}$ and c) $P 84^{\circledR}$ 154

Figure 6.4. Separation properties of the ceramic-supported thin film polymers for $\mathrm{H}_{2} \mathrm{O} / \mathrm{N}_{2}$ separation as a function of the reactor temperature. Square unfilled symbols and triangle filled symbols represent the permeance of $\mathrm{H}_{2} \mathrm{O}$ and $\mathrm{N}_{2}$, respectively (in 
the left-y-axes), whereas square blue symbols represent selectivity (in the right-yaxes)

Figure 6.5. Gas properties comparison between pure ceramic support (square symbols, upper graphics) and composite membranes of 6FDA-6FpDA, Matrimid ${ }^{\circledR}$ and $P 84^{\circledR}$ (circle symbols, lower graphics), at $150^{\circ} \mathrm{C}$. Unfilled symbols and crossfilled symbols represent the permeance of $\mathrm{H}_{2} \mathrm{O}$ and $\mathrm{N}_{2}$, respectively (in the left-yaxes), whereas blue symbols represent selectivity (in the right-y-axes)...... 158 Figure 6.6. SEM image of the support of non-woven PPS and porous PBI structure 160

Figure 6.7. FIB image of PIB porous support 160

Figure 6.8. Cross section images from FIB micrographs of a) 6FDA-6FpDA with $1.439 \mu \mathrm{m}$, b) Matrimid ${ }^{\circledR}$ with $1.360 \mu \mathrm{m}$ and c) $P 84^{\circledR}$ with $3.617 \mu \mathrm{m}$. 162

Figure 6.9. Separation properties of the polymers as a function of temperature. Permeances are represented in blue and red for $\mathrm{H}_{2}$ and $\mathrm{CO}_{2}$ respectively (logarithmic scale), whereas selectivity $\mathrm{H}_{2} / \mathrm{CO}_{2}$ is represented in green. Circles represent thick films of the studied polymers measured at time-lag equipment, whereas triangles are TFCM of the studied polymers measured at pressure increase equipment 163

Figure 6.10. Arrhenius-type relationship for $\mathrm{H}_{2}$ (upper graphs) and for $\mathrm{CO}_{2}$ (bottom graphs) permeances for the three studied polymers: 6FDA-6FpDA, Matrimid ${ }^{\boxplus}$ and $P 84^{\circledR}$, with polymeric support. 165

Figure 7.1. Schematic diagram of various structures for MMMs [16, 17].... 176

Figure 7.2. TGA graphs for the results of 6FDA-6FpDA with different percentage of the BCZY particle. 178

Figure 7.3. $X$-ray patterns for different polymer matrix: pure - blue lines, and with 10 wt. \% BCZY - red lines... 179

Figure 7.4. X-ray diffraction patterns for 6FDA-6FpDA with $10 \mathrm{wt}$. \% fillers (red lines) and reference patterns corresponding to $8 Y S Z, \mathrm{La}(\mathrm{OH})_{3}$, LaWO and BCZY crystals (black peaks) 179

Figure 7.5. SEM images (fracture cross-sections) for 6FDA-6FpDA MMMs and 10 wt. \% fillers. 181

Figure 7.6. Permeability of $\mathrm{CO}_{2}$ and $\mathrm{CO}_{2} / \mathrm{CH}_{4}$ selectivity for the MMMs composed by $90 \mathrm{wt}$. \% of 6FDA-6FpDA and $10 \mathrm{wt}$. \% of different fillers as a function of temperature 183

Figure 7.7. Diffusivity and solubility coefficient of MMMs composed by $90 \mathrm{wt}$. $\%$ of 6FDA-6FpDA and $10 \mathrm{wt}$ \% of different fillers, as a function of temperature. 183 
Figure 7.8. Permeability of $\mathrm{CO}_{2}$ and $\mathrm{CO}_{2} / \mathrm{CH}_{4}$ selectivity for the MMMs composed by 6FDA-6FpDA and different concentration of $B C Z Y$ filler as a function of temperature 185

Figure 7.9. Diffusivity and solubility coefficient of MMMs composed by $90 \mathrm{wt}$. \% of 6FDA-6FpDA and different concentration of BCZY filler as a function of temperature 185

Figure 7.10. Permeability of $\mathrm{CO}_{2}$ and $\mathrm{CO}_{2} / \mathrm{CH}_{4}$ selectivity for the membranes made of 6 FDA-6FpDA, Matrimid ${ }^{\boxplus}$ and $P 84^{\circledR}$ with and without 10 wt. $\%$ BCZY as a function of temperature 187

Figure 7.11. Diffusivity and solubility coefficient of $\mathrm{CO}_{2}$ of membranes made of 6FDA-6FpDA, Matrimid ${ }^{\boxplus}$ and $P 84^{\circledR}$ with and without 10 wt. \% BCZY as a function of temperature 187

Figure 7.12. Permeability of $\mathrm{H}_{2} \mathrm{O}$ and $\mathrm{H}_{2} \mathrm{O} / \mathrm{CO}_{2}$ selectivity for the membranes made of $6 F D A-6 F p D A$, Matrimid ${ }^{\circledR}$ and $P 84^{\circledR}$ with and without 10 wt. $\% B C Z Y$ as a function of temperature 190

Figure 7.13. Diffusivity and solubility coefficient of $\mathrm{H}_{2} \mathrm{O}$ of membranes made of 6FDA-6FpDA, Matrimid ${ }^{\boxplus}$ and $P 84^{\circledR}$ with and without 10 wt. $\%$ BCZY as a function of temperature 190

Figure 7.14. Cross section images from FIB micrographs of 6FDA-6FpDA (a)) with different fillers b) 8YSZ c) LaWO, d) BCZY, e) ITQ-2 and f) Beta..... 192 Figure 7.15. Gas separation properties of the MMMs as thin films, as a function of temperature. $\mathrm{A} 1, \mathrm{~A} 2$ and $\mathrm{A} 3$ represents water vapor, $\mathrm{H}_{2}$ and $\mathrm{CO}_{2}$ permeances respectively, whereas $\mathrm{B1}, \mathrm{B} 2$ and $\mathrm{B} 3$ exhibits selectivity of $\mathrm{H}_{2} \mathrm{O} / \mathrm{H}_{2}, \mathrm{H}_{2} \mathrm{O} / \mathrm{CO}_{2}$ and $\mathrm{H}_{2} / \mathrm{CO}_{2}$ respectively..... 193

Figure 8.1. X-Ray diffraction of synthesized Ni-Todorokite (green) and reduced NiTodorokite (pink). 205

Figure 8.2. TPR of synthesized Ni-Todorokite (green) and reduced Ni-Todorokite (pink) 207

Figure 8.3. Cross section images from FIB micrographs of 6FDA-6FpDA with 1.439 $\mu m$. 208

Figure 8.4. Gas transport properties of TFCM of 6FDA-6FpDA 208 Figure 8.5. Different images of the silicone mold before reaction a) and after reaction b) and c)...... 210

Figure 8.6. Parts of the aluminum piece: a) sealing ring, b) before reaction, c) and d) after reaction. 211

Figure 8.7. Teflon sealing tape and catalyst in the methanation micro reactor.... 211 Figure 8.8. Brief scheme of the $\mathrm{CO}_{2}$ methanation reaction protocol..... 
Figure 8.9. $\mathrm{CO}_{2}$ conversion, $\mathrm{CH}_{4}$ and $\mathrm{H}_{2} \mathrm{O}$ yield (in \%) for the stabilizing test at 260 ${ }^{\circ} \mathrm{C}$ without membrane. 214

Figure 8.10. $\mathrm{CO}_{2}$ conversion, $\mathrm{CH}_{4}$ and $\mathrm{H}_{2} \mathrm{O}$ yield (in \%) for the stabilizing test at 260 ${ }^{\circ} \mathrm{C}$ with membrane. 216

Figure 8.11. Molar flux of water production and water permeation (left-y axis) and percentage of water extraction (right-y axes) as a function of time. 217

Figure 8.12. $\mathrm{CO}_{2}$ conversion with and without membrane 217

Figure 9.1. $1^{\circ}$ Experiment. $\mathrm{H}_{2}$ flux through palladium membrane with $\mathrm{N}_{2}$ as sweep gas at $250^{\circ} \mathrm{C}$ 226

Figure 9.2. $2^{\circ}$ Experiment. $\mathrm{H}_{2}$ flux through palladium membrane with syngas as sweep gas at $250^{\circ} \mathrm{C}$. 228

Figure 9.3. $3^{\circ}$ Experiment. $\mathrm{H}_{2}$ flux through palladium membrane with a Cu protective layer with syngas as sweep gas at $250^{\circ} \mathrm{C}$. 231

Figure 9.4. Stabilization test at reaction conditions with a $50 \%$ of CO conversion 232

Figure 9.5. Cross section images from FIB micrographs and top surface images of (a) the preliminary tube before $\mathrm{H}_{2}$ treatment and (b) after the reduction treatment at $400 \stackrel{\circ}{C}$ during $12 \mathrm{~h}$ 233

Figure 9.6. Cross section images from FIB micrographs and top surface images of (a) the second preliminary tube after $\mathrm{H}_{2}$ treatment at $400{ }^{\circ} \mathrm{C}$ during $12 \mathrm{~h}$ and (b) after the FT condition treatment at $250^{\circ} \mathrm{C}$ during $15 \mathrm{~h}$ 234 Figure 9.7. CO conversion for FTS reaction for the cases: (i) catalyst CoBase, (ii) catalyst CoBase and zeolite Beta, and (iii) catalyst CoBase and zeolite Beta with the $P d$-based membrane. 236

Figure 9.8. iC5/ऽC5 mass percentage for FTS reaction for the cases: (i) catalyst CoBase, (ii) catalyst CoBase and zeolite Beta, and (iii) catalyst CoBase and zeolite Beta with the Pd-based membrane 237

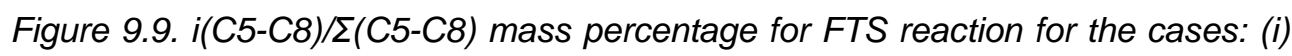
catalyst CoBase, (ii) catalyst CoBase and zeolite Beta, and (iii) catalyst CoBase and zeolite Beta with the Pd-based membrane. 238 




\section{Tables list}

Table 3.1. Classification of Hydrogen production [25].... 31

Table 3.2. Classification of membranes for their trans-membrane gradient [46] ... 37 Table 3.3. Advantages and disadvantages of organic and inorganic catalytic membranes [54]. 40

Table 3.4. Characteristic classification of $\mathrm{H}_{2}$ separation membranes [29] .42 Table 3.5. Advantages and disadvantages between organic and inorganic membranes for $\mathrm{H}_{2}$ separation [42] ............................................................. 42

Table 3.6. Kinetic diameter and other properties for different gas molecules........ 53

Table 3.7. Properties of metals, binary alloys and ternary alloys [83, 93]............. 61

Table 4.1. Properties of the used particles. 8YSZ [11], $\mathrm{La}_{2} \mathrm{O}_{3}$ [12], LaWO [13], BCZY [14, 15], ITQ-2 [10] and Beta [16]..... .93

Table 5.1. Ideal permeability and selectivity for the polymers studied as thick films at room temperature 124

Table 5.2. Viscosity nomenclature. 126

Table 5.3. Activation energies of permeance for the different gases for TFCMs prepared using $10 \mathrm{wt}$. \% polymer solutions. 141

Table 6.1. Solution specification of the three different polymers used in this work 152

Table 6.2. Water partial pressure and inlet water flow as a function of temperature 155

Table 6.3. $\mathrm{H}_{2} \mathrm{O}$ and $\mathrm{N}_{2}$ activation energies of permeance for composite ceramicpolymer membranes. 159

Table 6.4. Activation energies of permeance for the different gases for asymmetric polymer membranes, prepared using $3.5 \mathrm{wt}$. \% polymer solutions. 166 Table 7.1. TGA and DSC results for the three different cases studied in this chapter 177

Table 7.2. $\mathrm{CO}_{2}$ permeability, $\mathrm{CO}_{2} / \mathrm{CH}_{4}$ selectivity, percentage variations of permeability and selectivity (6FDA-6FpDA with $10 \mathrm{wt}$. \% fillers at $30^{\circ} \mathrm{C}$ ). Additionally, the activation energy for $\mathrm{CO}_{2}$ permeability derived from the data shown in Figure 7.6 is listed...... 182

Table 7.3. $\mathrm{CO}_{2}$ permeability, $\mathrm{CO}_{2} / \mathrm{CH}_{4}$ selectivity, percentage variations of permeability and selectivity (6FDA-6FpDA with different content of $B C Z Y$ at $30^{\circ} \mathrm{C}$ ). Additionally, activation energy for $\mathrm{CO}_{2}$ permeability derived from the data shown in Figure 7.8 is listed. 184 
Table 7.4. $\mathrm{CO}_{2}$ permeability, $\mathrm{CO}_{2} / \mathrm{CH}_{4}$ selectivity, percentage variations of permeability and selectivity (membranes with different polymeric matrix at $30^{\circ} \mathrm{C}$ ). Additionally, activation energy for $\mathrm{CO}_{2}$ permeability derived from the data shown in Figure 7.10 is listed.. 186

Table 7.5. $\mathrm{H}_{2} \mathrm{O}$ permeability, $\mathrm{H}_{2} \mathrm{O} / \mathrm{CO}_{2}$ selectivity, percentage variations of permeability and selectivity at $30{ }^{\circ} \mathrm{C}$. Additionally, activation energy for $\mathrm{H}_{2} \mathrm{O}$ permeability derived from permeability vs. temperature data is listed 189 Table 7.6. Activation energies of permeance for the different gases for asymmetric polymer membranes, prepared using $3.5 \mathrm{wt}$. \% polymer solutions and $10 \mathrm{wt}$. \% of fillers. 195

Table 8.1. Chemical composition and textural properties of Ni-Todorokite... 206 Table 9.1. Experimental conditions for test number 1: Pd-based membrane and $\mathrm{N}_{2}$ as sweep gas. 225

Table 9.2. Hydrogen flow as a function of feed pressure for experiment 1: Pd-based membrane and $\mathrm{N}_{2}$ as sweep gas.

225

Table 9.3. Experimental conditions for test number 2: Pd-based membrane and syngas as sweep gas 227

Table 9.4. Hydrogen flow as a function of feed pressure for experiment 2: Pd-based membrane and syngas as sweep gas. 227

Table 9.5. Experimental conditions for test number 3: Pd-based membrane with a Cu protective layer and syngas as sweep gas 229 Table 9.6. Hydrogen flow as a function of feed pressure for experiment 3: Pd-based membrane with a Cu protective layer and syngas as sweep gas 230

Table 9.7. Experimental conditions for stabilization test. 232 




\section{Scientific contribution}

\section{Publications}

1) S. Escorihuela, A. Tena, S. Shishatskiy, S. Escolástico, T. Brinkmann, J.M. Serra and V. Abetz. Gas Separation Properties of Polyimide Thin Films on Ceramic Supports for High Temperature Applications. Membranes, 2018. 8(1): p. 16.

2) S. Escorihuela, L. Valero, A. Tena, S. Shishatskiy, S. Escolástico, T. Brinkmann and J.M. Serra. Study of the Effect of Inorganic Particles on the Gas Transport Properties of Glassy Polyimides for Selective $\mathrm{CO}_{2}$ and $\mathrm{H}_{2} \mathrm{O}$ Separation. Membranes, 2018. 8(4): p. 128.

3) S. Escorihuela, F. Weigelt, C. Cerdá, S. Escolástico, A. Tena, S. Shishatskiy, T. Brinkmann, A. Chica and J.M. Serra. In-situ water removal from $\mathrm{CO}_{2}$ methanation process with a polymeric thin film composite membrane. Submitted for publication.

4) F. Weigelt, S. Escorihuela, A. Descalzo, A. Tena, S. Escolástico, S. Shishatskiy, J.M. Serra and T. Brinkmann. Novel polymeric Thin-Film Composite Membranes for high Temperature Gas Separations. Submitted for publication.

5) S. Escorihuela, S. Escolástico, R. Murciano, F. Toldrá-Reig, A. Martínez and J.M. Serra. Surface functionalized Pd-based membrane for operation in a Fischer-Tropsch synthesis reactor. Submitted for publication.

\section{Congress Participation}

\section{Oral presentations}

1) S. Escorihuela, S. Escolástico, R. Murciano, F. Toldra-Reig, A. Martínez and J.M. Serra. Selective addition of $\mathrm{H}_{2}$ through a palladium membrane in a Fischer-Tropsch synthesis reactor. 16th Network Young Membrains Conference. Valencia, Spain (2018).

2) S. Escorihuela, S. Escolástico, R. Murciano, A. Martínez and J.M. Serra. Catalytic palladium membrane for selective $\mathrm{H}_{2}$ addition in a 
Fischer-Tropsch synthesis reactor. III encuentro jóvenes investigadores de la SECAT. Valencia, Spain (2018).

3) S. Escorihuela, A. Tena, S. Shishatskiy, S. Escolástico, T. Brinkmann, J.M. Serra and V. Abetz. Gas separation properties of thin film polyimides on ceramic supports for high temperature applications. Euromembrane 18. Valencia, Spain (2018).

4) S. Escorihuela, A. Tena, S. Shishatskiy, S. Escolástico, T. Brinkmann, J.M. Serra and V. Abetz. Gas separation properties of thin film polyimides on ceramic supports for high temperature applications. I Edición del "ITQ Winter School". Valencia, Spain (2018).

\section{Poster presentations}

1) S. Escorihuela, A. Prieto, U. Díaz, A. Corma and J.M. Serra Hydrogen permeation through tubular palladium-silver membranes. Summer School: Ionic and protonic conducting ceramic membranes for Green energy applications. Valencia, Spain (2015).

2) S. Escorihuela, S. Escolástico, R. Murciano, F. Toldrá-Reig, A. Martínez and J.M. Serra. Selective $\mathrm{H}_{2}$ addition through palladium membrane in a Fischer-Tropsch synthesis reactor. 15th International Conference on Inorganic Membranes. Dresden, Germany (2018).

3) S. Escorihuela, S. Escolástico, R. Murciano, A. Martínez and J.M. Serra. Selective $\mathrm{H}_{2}$ addition through palladium membrane in a FischerTropsch synthesis reactor. III encuentro jóvenes investigadores de la SECAT. Valencia, Spain (2018).

4) S. Escorihuela, S. Escolástico, R. Murciano, A. Martínez and J.M. Serra. Selective $\mathrm{H}_{2}$ addition through palladium membrane in a FischerTropsch synthesis reactor. I Edición del "ITQ Winter School". Valencia, Spain (2018). 


\section{Acknowledgments}

This is it. I have to admit that I had pictured this moment in my mind many times before, and it feels even better than I imagined. Nevertheless, writing this last part of my thesis is taking more time than I thought, and not because of the English indeed.

First of all, I would like to express my gratitude to my supervisors. To Jose, for giving me the opportunity to apply to this $\mathrm{PhD}$ position in his research group at the ITQ, and for his valuable help and guidance for more than 4 years. To Sonia, who has been an extraordinary support since the very beginning, thanks for all your advices and supervision.

I would like to thank also all my colleagues from Pilas group, those who are no longer in the laboratory, the ones that are continuing and the new incorporations: Alfonso, Álvaro, Cecilia, Cyril, David, Julio, Jorge, Juan Borrás, Juan Escribano, Laura Almar, Laura Navarrete, María Balaguer, María Fabuel, María Siurana, María Valls, Marwan, Mateusz, Nahum, Raquel, Sebastián, Sonia Remiro, Vicente, and all the people who had visited our laboratory for short periods of time. Thanks a lot for all your kind support and for all the great moments we had lived inside and outside the lab. Thanks also to Alejandro, Cristina and Raúl, who had shown me that life exists outside Pilas lab. Special mention to my PhD friends, Fidel and Nuria, we started together this adventure and I feel really grateful to have shared it with you. There were difficult times during this race, and all of you had contributed somehow in making my $\mathrm{PhD}$ (and life) easier.

I want to thank as well the ITQ staff and the UPV microscopy department, for all their help during these years, being a key work factor on the development of my work. In addition, I would like to acknowledge the Spanish Government, for funding my research with the Severo Ochoa scholarship.

I want to express my gratitude to Volker Abetz and Torsten Brinkmann for accepting me to carry out my research stage at the Helmholtz-Zentrum Geesthacht. I would like also to mention Alberto, Crista, Fynn, Karabi, Lara, Mónica, Sergey, Xabi and all the people who had helped me during those 4 months, not only regarding professional and technical issues, but also with their friendship and support. 
My dearest gratitude to all my friends who have walked along the road with me, who have shared my frustrations and have been happy with my successes. Thanks for helping me to disconnect from work. The list would be endless, all of you know that you occupy a very important place in my heart.

To my parents and my sister. You are always there, with me, no matter what project I am involved in or what new adventure I begin. Thank you for your infinite patience, constant encouragement, for your words full of love and support, for never letting me fall. I would have never come this far without you. Thanks to all my family for always believing in me, and especially thanks to my grandfather, wherever you are, I am working to make this world a better place, as you used to tell me.

And last but not least, my warmest gratitude to Diego, for your unconditional love and patience. I believe a part of this work is yours. Thanks for supporting me and putting up with my bad temper every day I came home angry and frustrated, and for encouraging me to continue more motivated the next day. With you by my side, I am a better version of myself. 